\title{
DEMONSTRATION OF LEACHXS TM /ORCHESTRA CAPABILITIES BY SIMULATING CONSTITUENT RELEASE FROM A CEMENTITIOUS WASTE FORM IN A REINFORCED CONCRETE VAULT
}

Cementitious Barriers Partnership

March 2010

CBP-TR-2010-007-C1, Rev. 0 



\title{
DEMONSTRATION OF LEACHXS ${ }^{\text {TM }}$ /ORCHESTRA CAPABILITIES BY SIMULATING CONSTITUENT RELEASE FROM A CEMENTITIOUS WASTE FORM IN A REINFORCED CONCRETE VAULT
}

\author{
J. C. L. Meeussen \\ H. A. van der Sloot \\ Energy Research Centre of the Netherlands \\ Petten, The Netherlands \\ D. S. Kosson \\ S. Sarkar \\ Vanderbilt University, School of Engineering \\ Consortium for Risk Evaluation with Stakeholder Participation III \\ Nashville, TN 37235
}




\section{ACKNOWLEDGEMENTS}

This report was prepared for the United States Department of Energy in part under Contract No. DE-AC0908SR22470 and is an account of work performed in part under that contract. Reference herein to any specific commercial product, process, or service by trademark, name, manufacturer, or otherwise does not necessarily constitute or imply endorsement, recommendation, or favoring of same by Savannah River Nuclear Solutions or by the United States Government or any agency thereof. The views and opinions of the authors expressed herein do not necessarily state or reflect those of the United States Government or any agency thereof. The authors would like to acknowledge the contributions of Kevin Brown of Vanderbilt University and CRESP and Sarynna Lopez of the Great Lakes Bioenergy Research Center at Michigan State University for contributions to the document. They would also like to acknowledge the contributions of Media Services of Savannah River Nuclear Solutions for assistance with production of the document.

and

This report is based on work supported by the U. S. Department of Energy, under Cooperative Agreement Number DE-FC01-06EW07053 entitled 'The Consortium for Risk Evaluation with Stakeholder Participation III' awarded to Vanderbilt University. The opinions, findings, conclusions, or recommendations expressed herein are those of the author(s) and do not necessarily represent the views of the Department of Energy or Vanderbilt University.

\section{DISCLAIMER}

This work was prepared under an agreement with and funded by the U. S. Government. Neither the U.S. Government or its employees, nor any of its contractors, subcontractors or their employees, makes any express or implied: 1. warranty or assumes any legal liability for the accuracy, completeness, or for the use or results of such use of any information, product, or process disclosed; or 2. representation that such use or results of such use would not infringe privately owned rights; or 3. endorsement or recommendation of any specifically identified commercial product, process, or service. Any views and opinions of authors expressed in this work do not necessarily state or reflect those of the United States Government, or its contractors, or subcontractors, or subcontractors.

\section{Printed in the United States of America}

United State Department of Energy Office of Environmental Management Washington, DC

This document is available on the U.S. DOE Information Bridge and on the CBP website: http://cementbarriers.org/ An electronic copy of this document is also available through links on the following website: http://cementbarriers.org/ 


\section{FOREWORD}

The Cementitious Barriers Partnership (CBP) Project is a multi-disciplinary, multi-institutional collaboration supported by the United States Department of Energy (US DOE) Office of Waste Processing. The objective of the CBP project is to develop a set of tools to improve understanding and prediction of the long-term structural, hydraulic, and chemical performance of cementitious barriers used in nuclear applications.

A multi-disciplinary partnership of federal, academic, private sector, and international expertise has been formed to accomplish the project objective. In addition to the US DOE, the CBP partners are the Savannah River National Laboratory (SRNL), Vanderbilt University (VU) / Consortium for Risk Evaluation with Stakeholder Participation (CRESP), Energy Research Center of the Netherlands (ECN), and SIMCO Technologies, Inc. The Nuclear Regulatory Commission (NRC) is providing support under a Memorandum of Understanding. The National Institute of Standards and Technology (NIST) is providing research under an Interagency Agreement. Neither the NRC nor NIST are signatories to the CRADA.

The periods of cementitious performance being evaluated are $>100$ years for operating facilities and $>1000$ years for waste management. The set of simulation tools and data developed under this project will be used to evaluate and predict the behavior of cementitious barriers used in near-surface engineered waste disposal systems, e.g., waste forms, containment structures, entombments, and environmental remediation, including decontamination and decommissioning analysis of structural concrete components of nuclear facilities (spentfuel pools, dry spent-fuel storage units, and recycling facilities such as fuel fabrication, separations processes). Simulation parameters will be obtained from prior literature and will be experimentally measured under this project, as necessary, to demonstrate application of the simulation tools for three prototype applications (waste form in concrete vault, high-level waste tank grouting, and spent-fuel pool). Test methods and data needs to support use of the simulation tools for future applications will be defined.

The CBP project is a five-year effort focused on reducing the uncertainties of current methodologies for assessing cementitious barrier performance and increasing the consistency and transparency of the assessment process. The results of this project will enable improved risk-informed, performance-based decision-making and support several of the strategic initiatives in the DOE Office of Environmental Management Engineering \& Technology Roadmap. Those strategic initiatives include 1) enhanced tank closure processes; 2) enhanced stabilization technologies; 3) advanced predictive capabilities; 4) enhanced remediation methods; 5) adapted technologies for site-specific and complex-wide D\&D applications; 6) improved SNF storage, stabilization and disposal preparation; 7) enhanced storage, monitoring and stabilization systems; and 8) enhanced long-term performance evaluation and monitoring.

Christine A. Langton, PhD Savannah River National Laboratory

David S. Kosson, PhD Vanderbilt University / CRESP 


\section{EXECUTIVE SUMMARY}

This report provides an overview of the current capabilities of the LeachXSTM/ORCHESTRA database reactive transport model combination and how these relate to the objectives and development efforts of the Cementitious Barriers Partnership (CBP). LeachXS includes a database with an extended set of experimental data on different waste and building materials, including cementitious materials. Within LeachXS, ORCHESTRA is used as the geochemical speciation and reactive transport code for simulating experimental results and the chemical behavior of materials in specific application scenarios. ORCHESTRA can calculate chemical speciation in thermodynamic equilibrium systems in a similar way as other geochemical speciation programs (e.g., PHREEQC or MINTEQ) by using the same thermodynamic database format. ORCHESTRA contains state-of-the-art adsorption models for oxide and organic surfaces as well as solid solutions. The ORCHESTRA chemical speciation module can be used in combination with previously established transport algorithms (modules) that calculate single or multi-phase diffusion or convection in single or multi-regime porous media models. Within the CBP context, LeachXSTM/ORCHESTRA will be used to calculate transport rates of reactive substances through reactive porous media, including release of material constituents and ingress of external reacting substances (e.g., sulfate, oxygen, or carbon dioxide).

This report illustrates the use of LeachXSTM/ORCHESTRA for the following applications:

1. Comparing model and experimental results for leaching tests for a range of cementitious materials including cement mortars, grout, stabilized waste, and concrete. The leaching test data includes liquid-solid partitioning as a function of $\mathrm{pH}$ and release rates based on laboratory column, monolith, and field testing.

2. Modeling chemical speciation of constituents in cementitious materials, including liquid-solid partitioning and release rates.

3. Evaluating uncertainty in model predictions based on uncertainty in underlying composition, thermodynamic, and transport characteristics.

4. Generating predominance diagrams to evaluate predicted chemical changes as a result of material aging using the example of exposure to atmospheric conditions.

5. Modeling coupled geochemical speciation and diffusion in a three layer system consisting of a layer of Saltstone, a concrete barrier, and a layer of soil in contact with air. The simulations show developing concentration fronts over a time period of 1000 years.

6. Modeling sulfate attack and cracking due to ettringite formation. An example case is provided in a separate article by the authors.

Finally, based on the computed results, the sensitive input parameters for this type of modeling are identified and discussed. 


\section{TABLE OF CONTENTS}

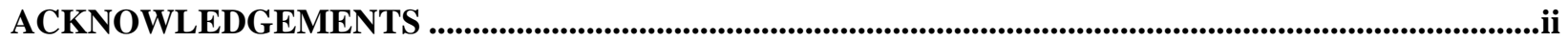

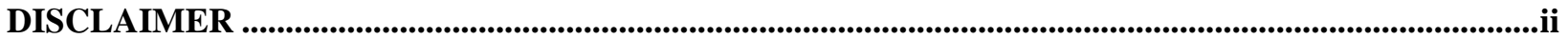

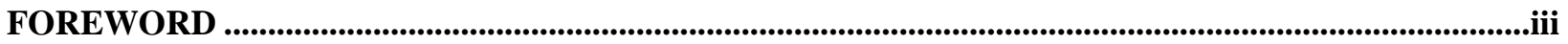

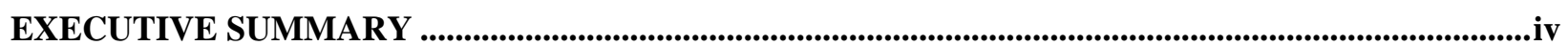

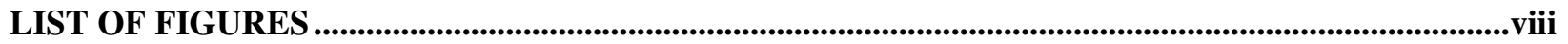

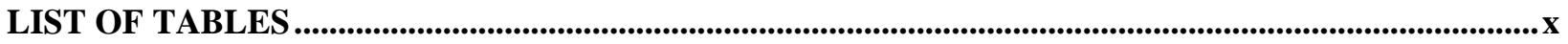

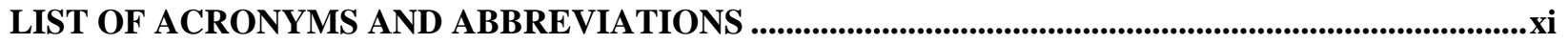

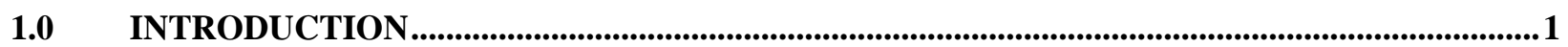

2.0 COMPARISON OF TEST DATA

2.1 Comparison of Leaching Test Data for Cement Mortars ..........................................................2

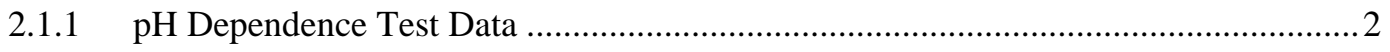

2.1.2 Monolith Leach Test Data ................................................................................. 4

2.2 Comparison of Leaching Test Data for Grout and Stabilized Waste........................................5

2.2.1 pH Dependence Test ...........................................................................................

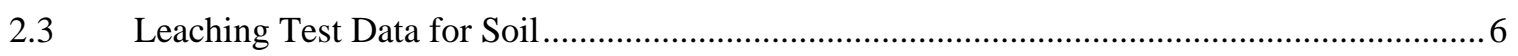

2.4 Comparison Between Cement Mortar and Stabilized Waste.................................................... 7

2.4.1 pH Dependence Test ................................................................................................

2.5 Comparison Between Cement Mortar and Concrete ..........................................................

2.6 Comparison Between Grout Column Data and Database Data ................................................ 10

2.7 Comparison Between Laboratory Test Data and Core Samples From a Field Site.................12

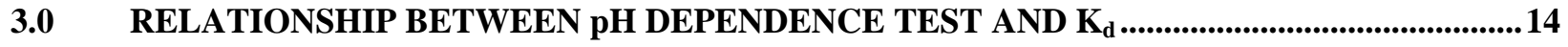

4.0 RELEASE BEHAVIOR OF SUBSTANCES .................................................................................14

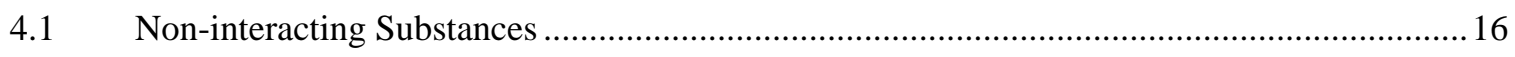

$4.2 \quad$ Solubility Controlled Substance ............................................................................................. 18

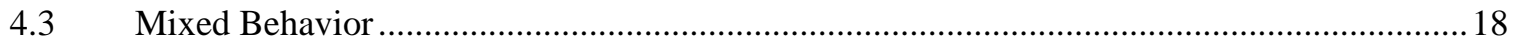

4.4 Simplified Solutions for Assessing Release ..................................................................21

5.0 MODELING THE CHEMICAL SPECIATION OF A MATERIAL ...............................................22

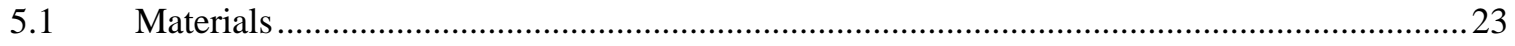

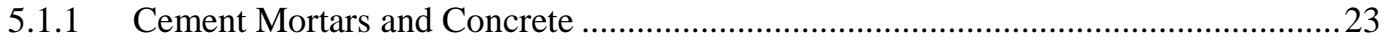

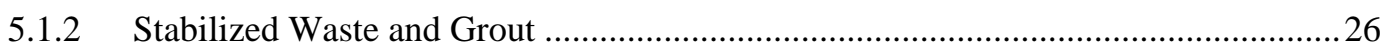

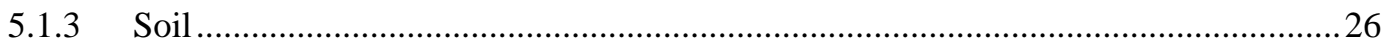

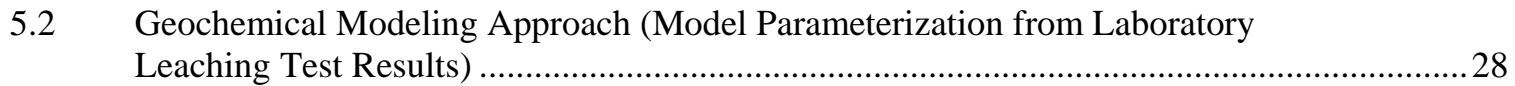

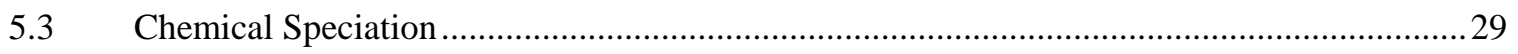

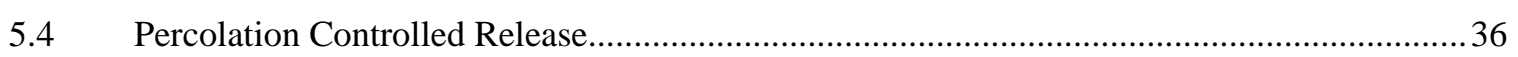

5.5 Mass Transfer Limited Release from Monolithic Products .......................................................38 
CONTENTS (Continued)

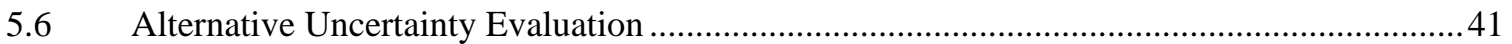

6.0 STABILIZED WASTE - CONCRETE BARRIER - SOIL SYSTEM ............................................44

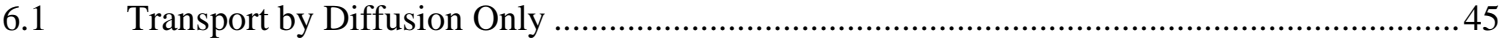

6.2 Transport by Percolation (Degradation Case) …....................................................................... 51

7.0 DEMONSTRATION OF THE EVALUATION OF UNCERTAINTY AND

ACCURACY IN CHEMICAL EQUILIBRIUM CALCULATIONS................................................56

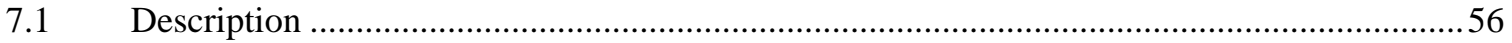

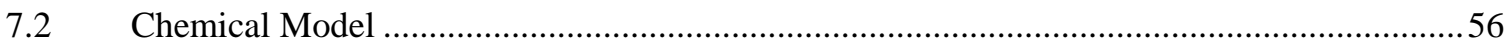

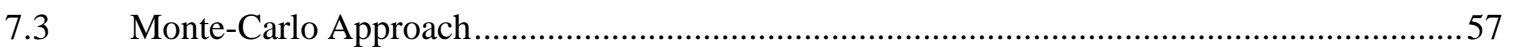

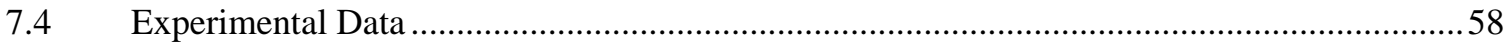

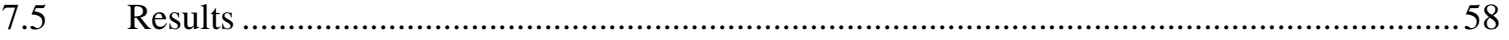

8.0 DEMONSTRATION OF THE USE OF PREDOMINANCE DIAGRAMS TO

EVALUATE CHEMICAL CHANGES AS A RESULT OF AGING..........................................62

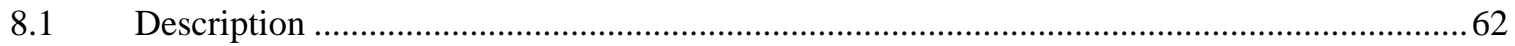

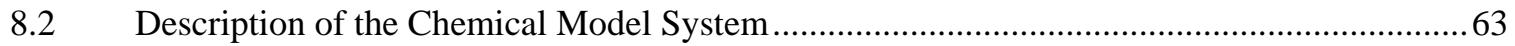

8.3 Predominance diagrams for Slected Elements..........................................................................63

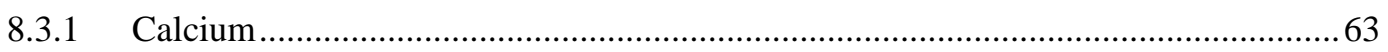

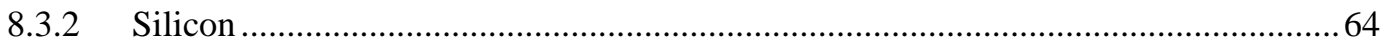

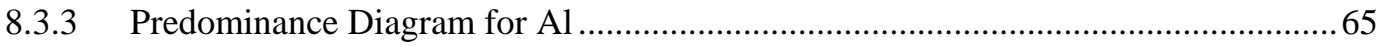

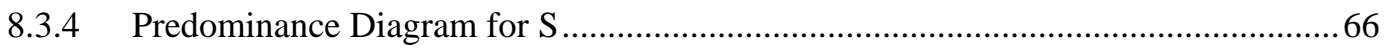

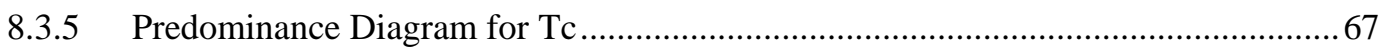

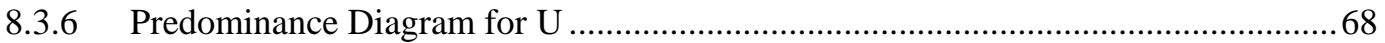

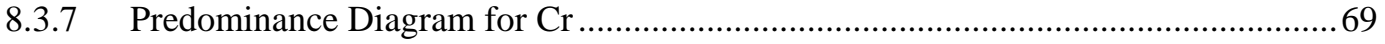

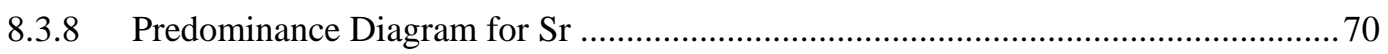

9.0 DEMONSTRATION OF REACTION - DIFFUSION CALCULATIONS ....................................71

$9.1 \quad$ Overall System Model Description …………....................................................................... 71

9.1.1 Chemical Composition of Materials Used ...................................................................... 72

9.1.2 Physical Parameters of Materials Used.......................................................................... 72

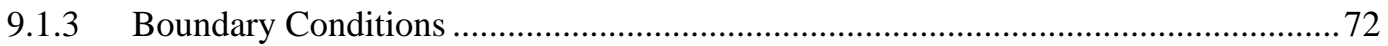

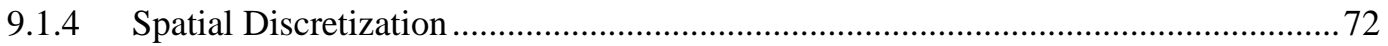

9.1.5 Oxygen and Carbonate Fluxes .................................................................................. 73

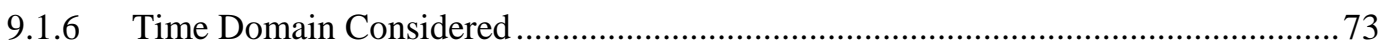

9.1.7 Constituents Considered …………………….......................................................... 73

9.1.8 Results...............................................................................................................

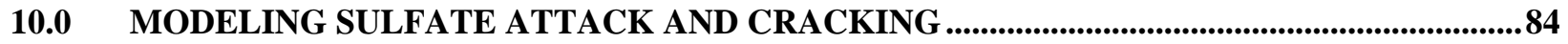

11.0 EVALUATION OF REFERENCE CASE SIMULATIONS........................................................84 
Demonstration of LeachXSTM/ORCHESTRA Capabilities by Simulating Constituent Release from a Cementitious Waste Form in a Reinforced Concrete Vault

CONTENTS (Continued)

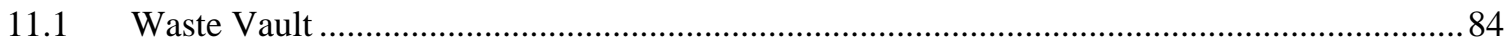

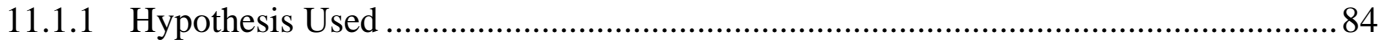

11.1.2 Alternative Hypotheses ............................................................................................ 84

11.1.3 Consequences for Predicted Release Rates.................................................................. 85

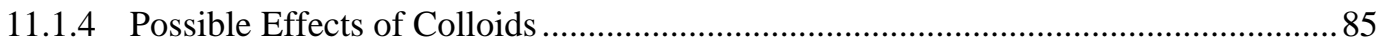

11.1.5 Retention Under Oxidized Conditions ....................................................................... 85

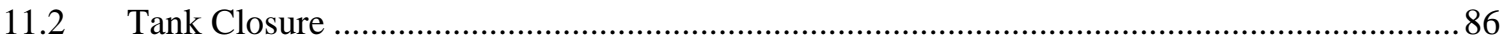

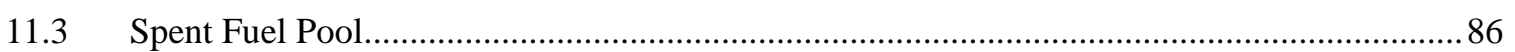

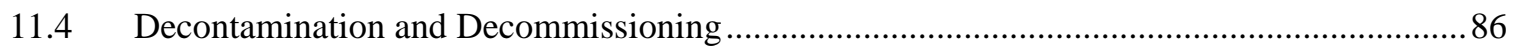

12.0 CONCLUSIONS AND RECOMMENDATIONS ............................................................................87

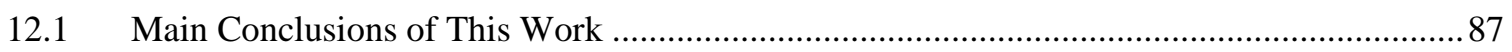

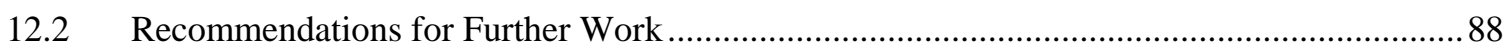

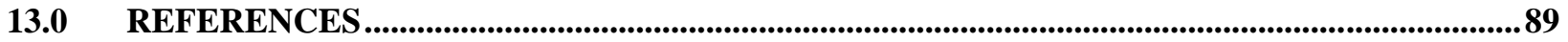

14.0 APPENDICES

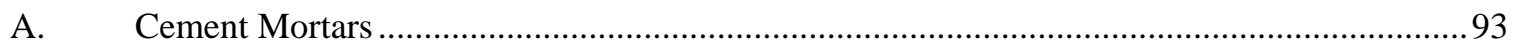

B. Partitioning of Substances Over Different Chemical Phases In A Blended Cement

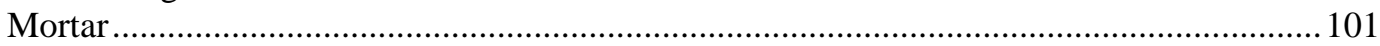

C. Different Cement Mortars - Same Chemistry And Sorption Properties ................................111 


\section{LIST OF FIGURES}

Figure 1. Release of $\mathrm{Al}, \mathrm{Ca}, \mathrm{SO}_{4}$ as $\mathrm{S}, \mathrm{Si}, \mathrm{V}$ and $\mathrm{Zn}$ from cement mortars of worldwide origin and ranging from regular Portland to different types of blended cements using the $\mathrm{pH}$ dependence test

Figure 2. Release of $\mathrm{Al}, \mathrm{SO}_{4}$ as $\mathrm{S}, \mathrm{Cr}, \mathrm{Mo}, \mathrm{V}$ and $\mathrm{Zn}$ from cement mortars from worldwide origin and ranging from regular Portland to different types of blended cements using the monolith leach test.

Figure 3. Comparison for grout simulation mixes with cement stabilized hazardous waste ........................... 6

Figure 4. Comparison of release behavior between cement mortar and stabilized waste .................................. 8

Figure 5. Comparison of concrete and cement mortar leachability................................................................ 9

Figure 6. $\mathrm{Al}$ and $\mathrm{K}$ leaching data from grout column and data from monolith leach test, percolation test, and $\mathrm{pH}$ dependence test for cement-based products.

Figure 7. $\mathrm{Ca}, \mathrm{SO}_{4}$ as $\mathrm{S}, \mathrm{Si}$ and $\mathrm{Fe}$ leaching data from grout column and data from monolith leach test, percolation test and $\mathrm{pH}$ dependence test for cement based products.

Figure 8. $\mathrm{Mg}, \mathrm{Na}, \mathrm{Cl}$, and $\mathrm{U}$ leaching data from grout column and data from monolith leach test, percolation test and $\mathrm{pH}$ dependence test for cement-based products.

Figure 9. Comparison of laboratory test data for fresh and aged stabilized waste (cores from the field) in comparison with field leachate.

Figure 10. Calculated $\mathrm{K}_{\mathrm{d}}$ for $\mathrm{V}, \mathrm{Zn}, \mathrm{Sr}$, and Mo in cement mortar calculated based on data from the $\mathrm{pH}$ dependence leaching test for HOL 12 - CEM V/A

Figure 11. Example of non interacting substance with typical diffusion controlled release......

Figure 12. Possible effect of change in tortuosity based on increased porosity by release of substantial amount of soluble salt

Figure 13. Example of a substance that is solubility controlled under all test conditions.

Figure 14. Example of a substance that is solubility controlled in a percolation test and largely diffusion controlled in a monolith leach test.

Figure 15. Relationship between monolith leach test data and release behavior as a function of $\mathrm{pH}$ on crushed mortar for standard test conditions and with different exposure to carbonation 22

Figure 16. Speciation modeling of cement mortar CEM V/A (HOL-12) ........................................................ 32

Figure 17. Model prediction of $\mathrm{pH}$ dependent leaching behavior of a simulated grout................................... 35

Figure 18. Modeled release of Ag, I, Sr, Th, and U from a simulated grout as a function of $\mathrm{pH}$ and the associated partitioning between mineral and sorptive phases.

Figure 19. Cumulative release as obtained from full mechanistic modeling in comparison with measurements according to a monolith leach test with leachant renewal.

Figure 20. Cumulative release from cement mortar NOR2 measured and modeled using LeachXS ${ }^{\mathrm{TM}} / \mathrm{ORCHESTRA.}$

Figure 21. Synthesized model outputs of $\mathrm{Al}$ and $\mathrm{Ca}$ for different cement mortars using the same mineral composition using only sample specific composition

Figure 22. Synthesized model outputs of sulfate and Si for different cement mortars using the same mineral composition using only sample specific composition 


\section{Demonstration of LeachXSTM/ORCHESTRA Capabilities by Simulating Constituent Release from a Cementitious Waste Form in a Reinforced Concrete Vault}

Figure 23. Aging processes and the conceptualization of the processes governing release from the waste vault through the cementitious barrier to the surrounding soil

Figure 24. Aging processes and the conceptualization of the processes governing release from grout used in tank closure through the cementitious barrier to the surrounding soil ................................. 45

Figure 25. Smoothing out of an initial gradient over a barrier with a specified porosity and tortuosity........... 46

Figure 26. Diffusion profiles for $\mathrm{U}$ and $\mathrm{Sr}$ for the stabilized waste - concrete - soil system .......................... 49

Figure 27. Diffusion profiles for $\mathrm{Pb}$ and $\mathrm{Mg}$ for the stabilized waste - concrete - soil system....................... 50

Figure 28. Transport by percolation from cracked stabilized waste through cementitious barrier into soil 55

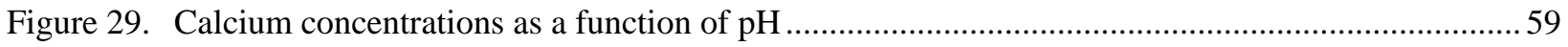

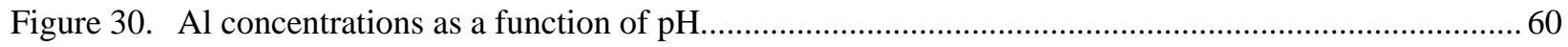

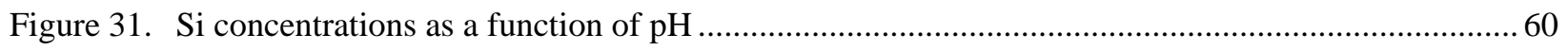

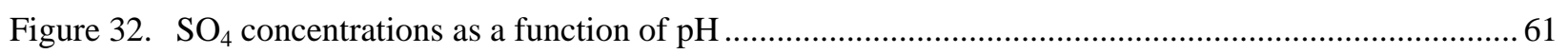

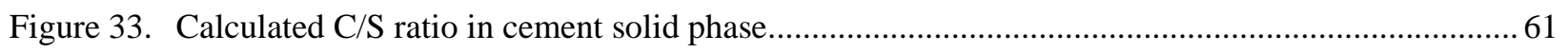

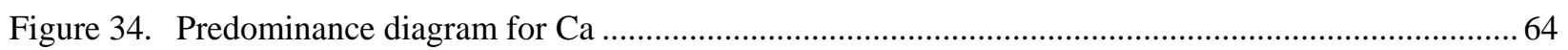

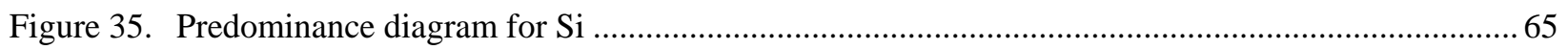

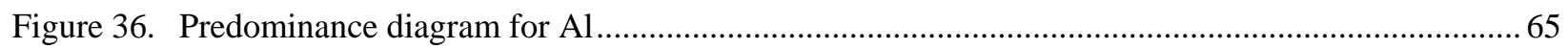

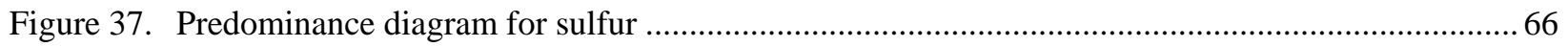

Figure 38. Predominance diagram for sulfur at reduced Na concentrations ...................................................67

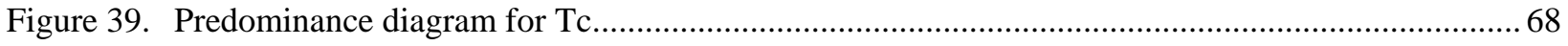

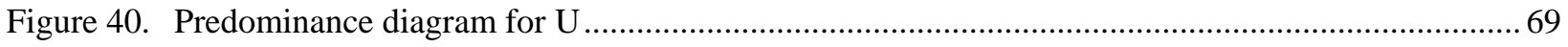

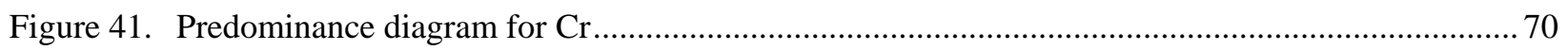

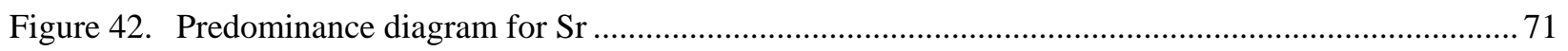

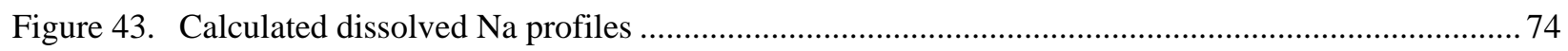

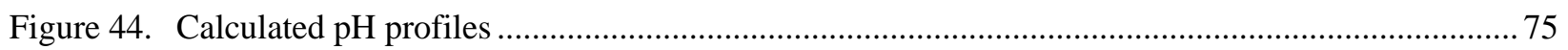

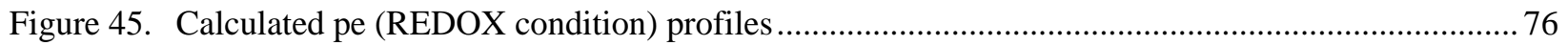

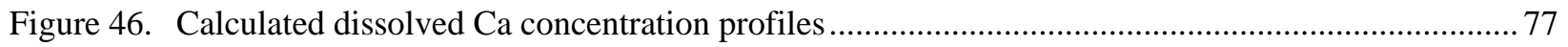

Figure 47. Calculated dissolved Al profiles ................................................................................................. 78

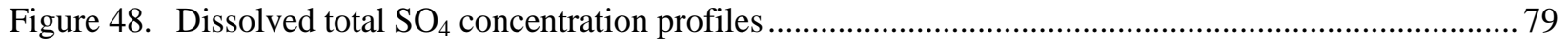

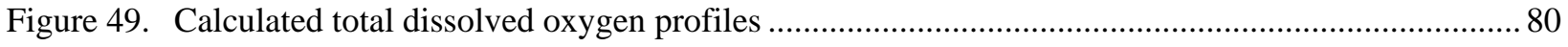

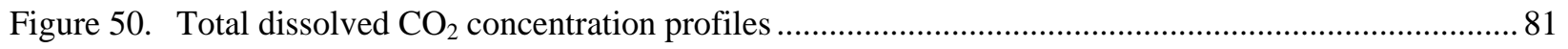

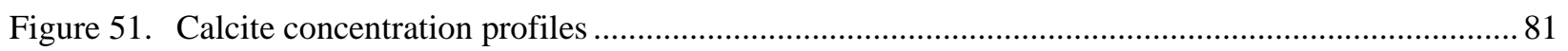

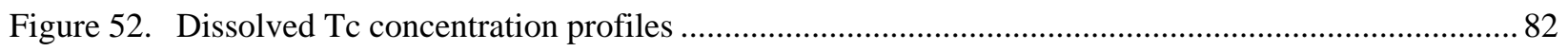

Figure 53. Calculated concentrations of Ettringite as a function of depth ....................................................... 83 


\section{LIST OF TABLES}

Table 1. Source of information, nature of information and relevant time scale covered .............................. 23

Table 2. Composition mortar and concrete CEM V/A (HOL-12) ................................................................ 24

Table 3. Composition mortar and concrete CEM V/A (HOL-12) - trace elements ....................................... 24

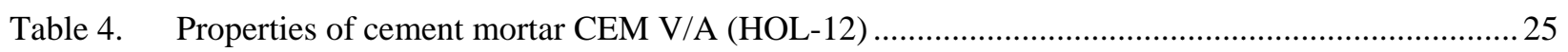

Table 5. Comparison CBP blends with available cement mortars in LeachXS ${ }^{\mathrm{TM}}$ database ........................... 26

Table 6. Composition of stabilized waste and simulation grouts................................................................2

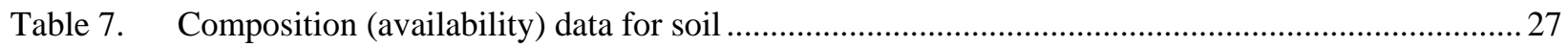

Table 8. Input specification for $\mathrm{pH}$ dependence test modeling of a cement mortar....................................... 30

Table 9. Input specification for $\mathrm{pH}$ dependence test modeling of a simulated grout..................................... 34

Table 10. Input parameters for percolation modeling of stabilized waste ....................................................... 37

Table 11. Input specification for the monolith leach test on cement mortar NOR2 ...................................... 39

Table 12. Input parameters for 3-layer diffusion model ................................................................................... 47

Table 13. Input parameters for the percolation in the 3-layer system (i.e., stabilized waste - concrete

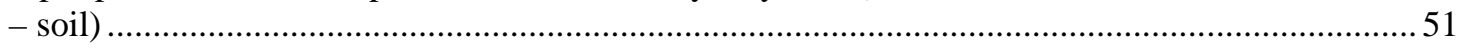

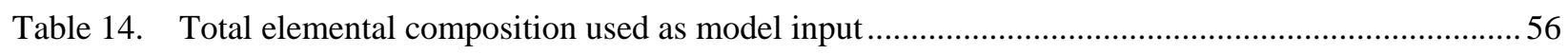

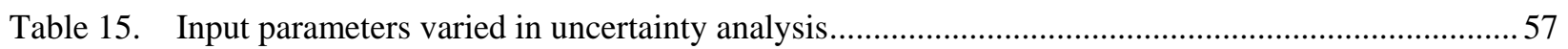

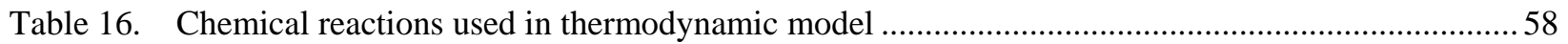

Table 17. Total elemental composition of Saltstone as used for predominance calculations ..........................63

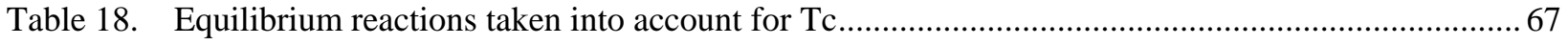


Demonstration of LeachXSTM/ORCHESTRA Capabilities by Simulating Constituent Release from a Cementitious Waste Form in a Reinforced Concrete Vault

\title{
LIST OF ACRONYMS AND ABBREVIATIONS
}

\author{
CBP Cementitious Barriers Partnership \\ CEN European Committee for Standardization \\ CRESP Consortium for Risk Evaluation with Stakeholder Participation \\ CS Compressive Strength \\ CSF Chemical Speciation Fingerprint \\ DHA Dissolved Humic Acid \\ DOC Dissolved Organic Carbon \\ D\&D Decontamination and Decommissioning \\ ECN Energy Research Center of the Netherlands \\ EPA U.S. Environmental Protection Agency \\ ECRICEM Environmental Criteria for Cement Based Products \\ FA [Coal] Fly Ash \\ GBFS Granulated Blast Furnace Slag \\ HFO Hydrous Ferric Oxide \\ LeachXS Leaching eXpert System \\ L/S Liquid to Solid Ratio \\ NEN Netherlands Standardization Institute \\ ORCHESTRA Objects Representing CHEmical Speciation and TRAnsport \\ REDOX REDuction/OXidation \\ RH Relative Humidity \\ SHA Solid Humic Acid \\ SI Saturation Index(ices)
}


Demonstration of LeachXSTM/ORCHESTRA Capabilities by Simulating Constituent Release from a Cementitious Waste Form in a Reinforced Concrete Vault 


\title{
Demonstration of LeachXS ${ }^{\mathrm{TM}}$ /ORCHESTRA Capabilities by Simulating Constituent Release from a Cementitious Waste Form in a Reinforced Concrete Vault
}

\author{
J. C. L. Meeussen and H. A. van der Sloot \\ Energy Research Centre of the Netherlands \\ Petten, The Netherlands \\ D. S. Kosson and S. Sarkar \\ Vanderbilt University, School of Engineering \\ Consortium for Risk Evaluation with Stakeholder Participation III \\ Nashville, TN 37235
}

\subsection{INTRODUCTION}

The objective of the work described in this report is to demonstrate the capabilities of the current version of LeachXSTM/ORCHESTRA for simulating chemical behavior and constituent release processes in a range of applications that are relevant to the CBP. This report illustrates the use of LeachXS ${ }^{\mathrm{TM}}$ /ORCHESTRA for the following applications:

1. Comparing model and experimental results for leaching tests for a range of cementitious materials including cement mortars, grout, stabilized waste, and concrete. The leaching test data includes liquid-solid partitioning as a function of $\mathrm{pH}$ and release rates based on laboratory column, monolith, and field testing.

2. Modeling chemical speciation of constituents in cementitious materials, including liquid-solid partitioning and release rates.

3. Evaluating uncertainty in model predictions based on uncertainty in underlying composition, thermodynamic, and transport characteristics.

4. Generating predominance diagrams to evaluate predicted chemical changes as a result of material aging using the example of exposure to atmospheric conditions.

5. Modeling coupled geochemical speciation and diffusion in a three layer system consisting of a layer of Saltstone, a concrete barrier, and a layer of soil in contact with air. The simulations show developing concentration fronts over a time period of 1000 years.

6. Modeling sulfate attack and cracking due to ettringite formation. A detailed example for this case is provided in a separate article by the authors (Sarkar et al. 2010).

Finally, based on the computed results, the sensitive input parameters for this type of modeling are identified and discussed.

The chemical speciation behavior of substances is calculated for a batch system and also in combination with transport and within a three layer system. This includes release from a barrier to the surrounding soil as a function of time. As input for the simulations, the physical and chemical properties of the materials are used. The test cases used in this demonstration are taken from Reference Cases for Use in the Cementitious Barriers Partnership (Langton et al. 2009). 


\section{Demonstration of LeachXS $\mathrm{TM} / O R C H E S T R A$ Capabilities by Simulating \\ Constituent Release from a Cementitious Waste Form in a Reinforced Concrete Vault}

Before it is possible to model the release of substances from stabilized waste or radioactive grout through a cement barrier into the engineered soil barrier or natural soil, the relevant characteristics of such materials must be known. Additional chemical characteristics are needed for mechanistic modeling to be undertaken, not just the physical properties relevant for modeling of transport. The minimum required properties for modeling are given in Section 5.0, "Modeling the chemical speciation of a material".

\subsection{COMPARISON OF TEST DATA}

The materials database function in LeachXS ${ }^{\mathrm{TM}}$ /ORCHESTRA has a number of features that are useful in meeting CBP needs; it allows retrieval and comparison of material characteristics for a range of relevant materials, such as concrete, grout, stabilized waste, Saltstone, fly ash, and blast furnace slag. Experience with a wide range of different materials has shown that similarities exist between release behavior of seemingly different materials (Grathwohl et al. 2003; Grathwohl \& van der Sloot 2007; van der Sloot 2002; van der Sloot \& Dijkstra 2004; van der Sloot, Heasman \& Quevauviller 1997), implying that the CBP can benefit from already existing information obtained in other areas. Relevant studies include those on leaching of cement mortars and concrete (van der Sloot et al. 2001; van der Sloot et al. 2008), stabilized waste (Dijkstra 2007; Tiruta-Barna, Barna \& Moszkowicz 2000; van der Sloot et al. 2007b) and related cement based waste forms (Garrabrants, Kosson \& DeLapp 2007). The data are structured in such a manner that cross comparisons can be made between several laboratory test data, pilot scale studies and field measurements (e.g., leachate [Kosson et al. 2002]). Functional comparison templates have been derived that allow conclusions on the chemical phases controlling constituent release as well as the controlling release mechanisms. This is particularly useful for long term assessment because several processes act simultaneously on the release of substances from monolithic materials.

\subsection{Comparison of Leaching Test Data for Cement Mortars}

From studies on cement mortars worldwide, information is available on the leachability of mortars that resemble to a large extent the composition of the concrete formulation recommended for the CBP work (Langton et al. 2009). Placing this information in context with the constituent release behavior from other cement types provides an alternative way of evaluating uncertainty in material release behavior because variations occur in cement mortar and concrete composition in spite of the specified formulation.

\subsection{1 pH Dependence Test Data}

The results of pH dependence test data (CEN/TS 14429 (2005); similar to EPA Draft Method 1313 (2009a) and ISO/TS 21268-4 (2007b)) on a variety of cement mortars (ECRICEM I (van der Sloot et al. 2001); Ecricem II (van der Sloot et al. 2008)) are presented in Figure 1 for a selection of major, minor and trace elements; Appendix A provides, for the full set of elements, the $\mathrm{pH}$ dependence data on a range of cement mortars. Cement mortar HOL 12, a composite cement with $32 \%$ granulated blast furnace slag and $20 \%$ fly ash, is very similar to the formulation specified for the Type I/II Ternary Blend and Type V Quaternary Blend (Langton et al. 2009). 

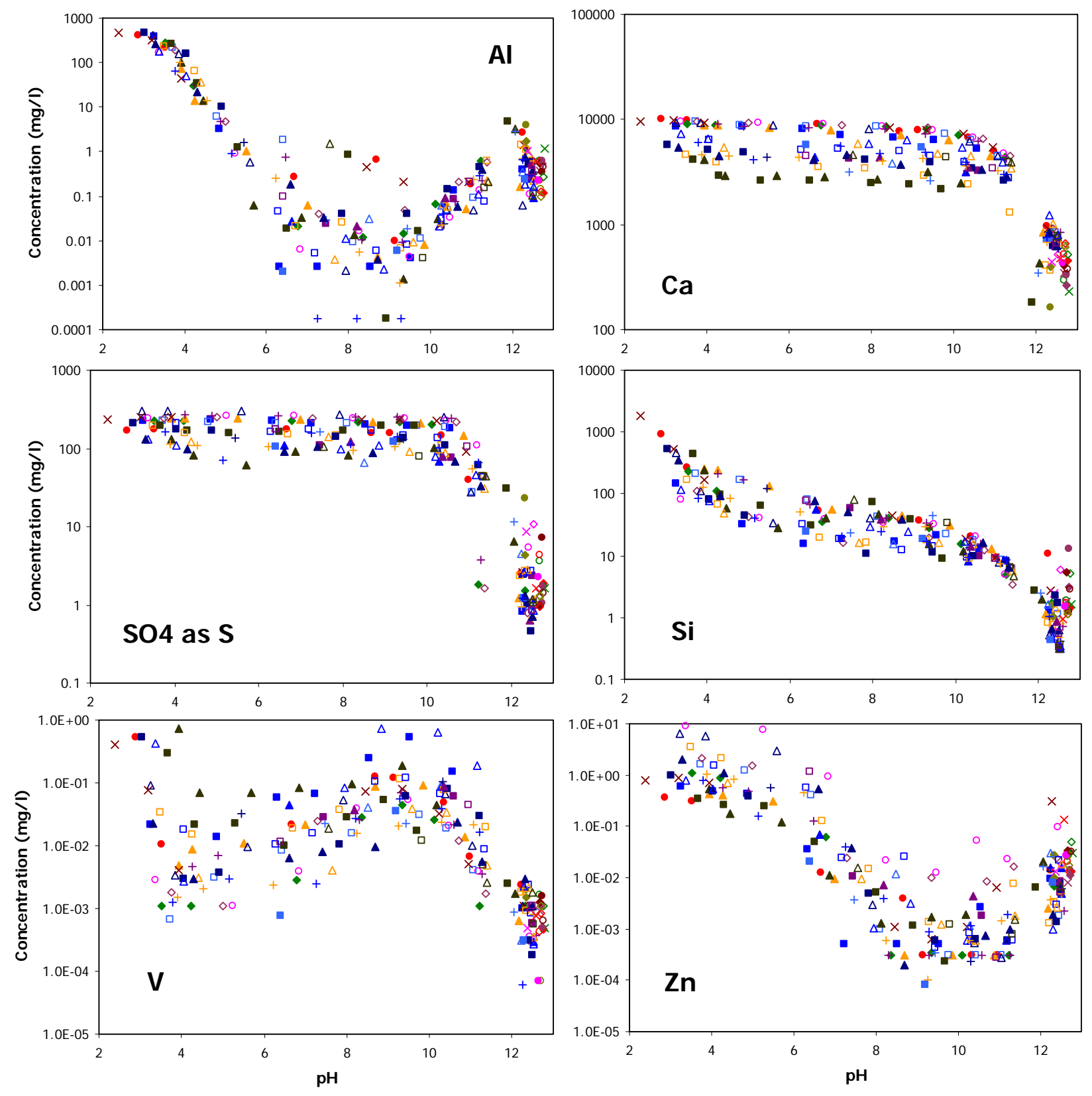

Figure 1. Release of $\mathrm{Al}, \mathrm{Ca}, \mathrm{SO}_{4}$ as $\mathrm{S}, \mathrm{Si}, \mathrm{V}$ and $\mathrm{Zn}$ from cement mortars of worldwide origin and ranging from regular Portland to different types of blended cements (including cements blended with granulated blast furnace slag - GBFS and coal fly ash - FA) using the pH dependence test (CEN/TS 14429, similar to EPA Draft Method 1313).

The conclusion from comparison of available data is that, despite the widely different origins and compositions, the release of substances by leaching is remarkably consistent for many substances. This implies that the chemistry controlling the systematic release is common for many types of mortar with the understanding that blended cements with reducing properties (due to inclusion of a reducing blast furnace slag) will deviate for a few substances affected by the lower Eh. 


\subsubsection{Monolith Leach Test Data}

A comparison of monolith leach test data according to NEN 7345 (1995), which is similar to CEN/TS 15863 (2009) and EPA Draft Method 1315 (2009c), is provided in Figure 2 for the same mortars as specified in the previous Section 2.1.1, " $p H$ Dependence Test Data”. A selection of major, minor, and trace elements is displayed for illustration. Appendix A provides the full set of data, constituents, and parameters.
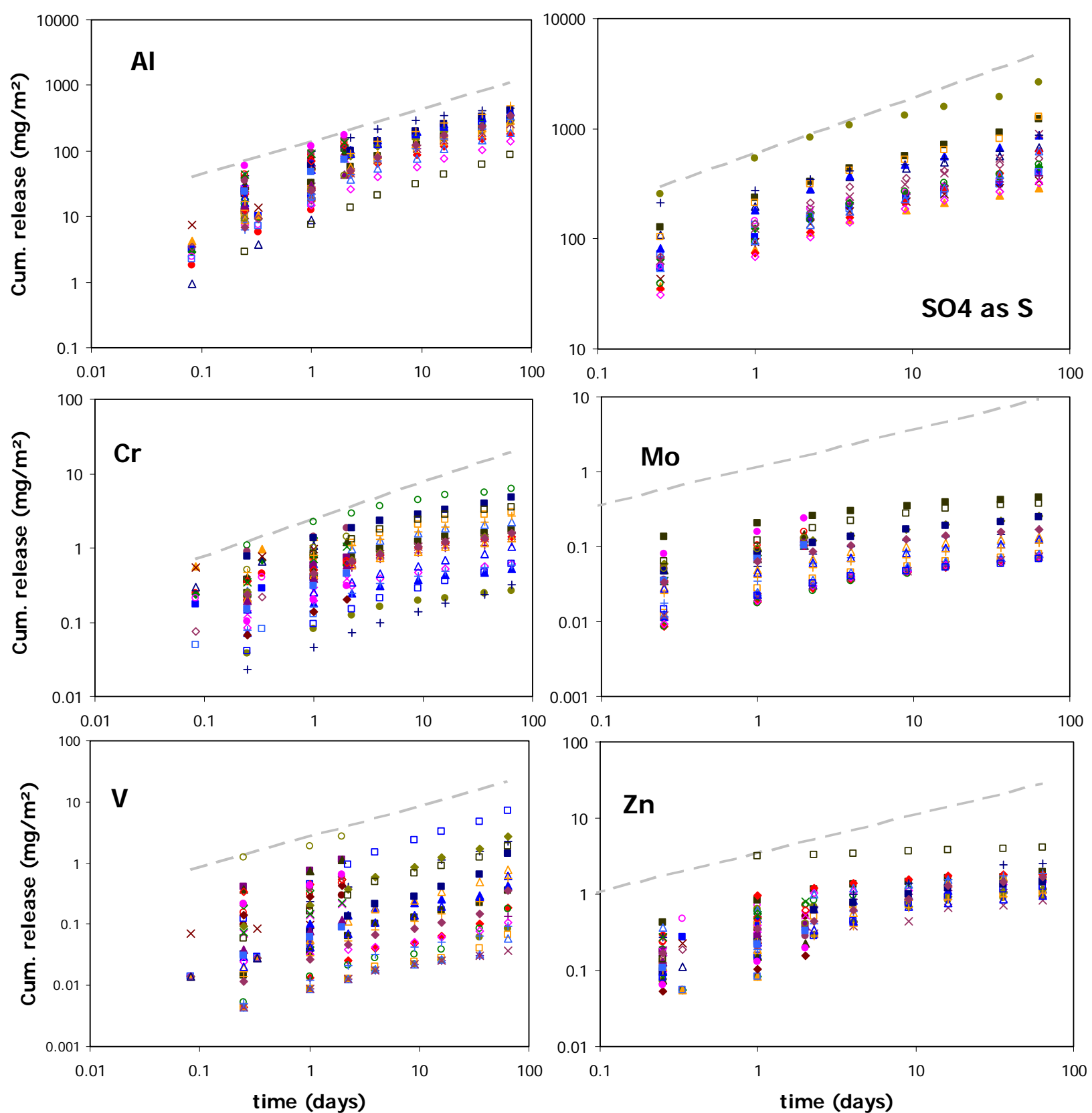

Figure 2. Release of $\mathrm{Al}, \mathrm{SO}_{4}$ as $\mathrm{S}, \mathrm{Cr}, \mathrm{Mo}, \mathrm{V}$ and $\mathrm{Zn}$ from cement mortars from worldwide origin and ranging from regular Portland to different types of blended cements (including cements blended with granulated blast furnace slag - GBFS and coal fly ash - FA) using the monolith leach test (CEN/TS 15863, similar to EPA Draft Method 1315). 
The release data from monolithic cement mortars indicates that the release behavior is very consistent and, except for $\mathrm{V}$ and $\mathrm{Cr}$, proceeds within relatively narrow bounds given the wide spread in mortar origin and types (about one order of magnitude or less). However, these data are limited to relatively fresh mortars (cured for a minimum of 28 days). The wide range in release data for $\mathrm{V}$ is linked to the very steep gradient in release as a function of $\mathrm{pH}$ whereby a relatively small shift in $\mathrm{pH}$ leads to a significant change in leachability. For Cr, the different levels of release are caused by the different REDOX status of the cement mortars due to the presence of reducing slag in several blends or the addition of $\mathrm{Cr}$ reducing agents (now required by regulation in Europe). Based on the consistency of these data and the level of understanding of release controlling factors, finding a common description for constituent release is most likely within reach.

\subsection{Comparison of Leaching Test Data for Grout and Stabilized Waste}

Although grouts simulating Saltstone and stabilized hazardous waste are different in purpose and design, a comparison of their leachability is interesting as leachability from alkaline cement based products has shown many similarities.

\subsection{1 pH Dependence Test}

When the results of the $\mathrm{pH}$ dependence test of the grout simulation mixes (AMD and SWD [Garrabrants, Kosson \& DeLapp 2007]) are compared with stabilized hazardous waste, the leachability of many elements show common characteristics. For illustration, Figure 3 presents the release behavior of $\mathrm{Cd}$ and Co for grout simulation mixes AMD and SWD compared to stabilized hazardous waste mixes. It appears as though the release behavior as a function of $\mathrm{pH}$ is largely controlled by the same solubility-controlling phases. The contaminant level is clearly a factor in the release behavior. For metals, this is reached at the lowest $\mathrm{pH}$ measured, while for oxyanions the highest level is mostly found at mild alkaline $\mathrm{pH}$. 

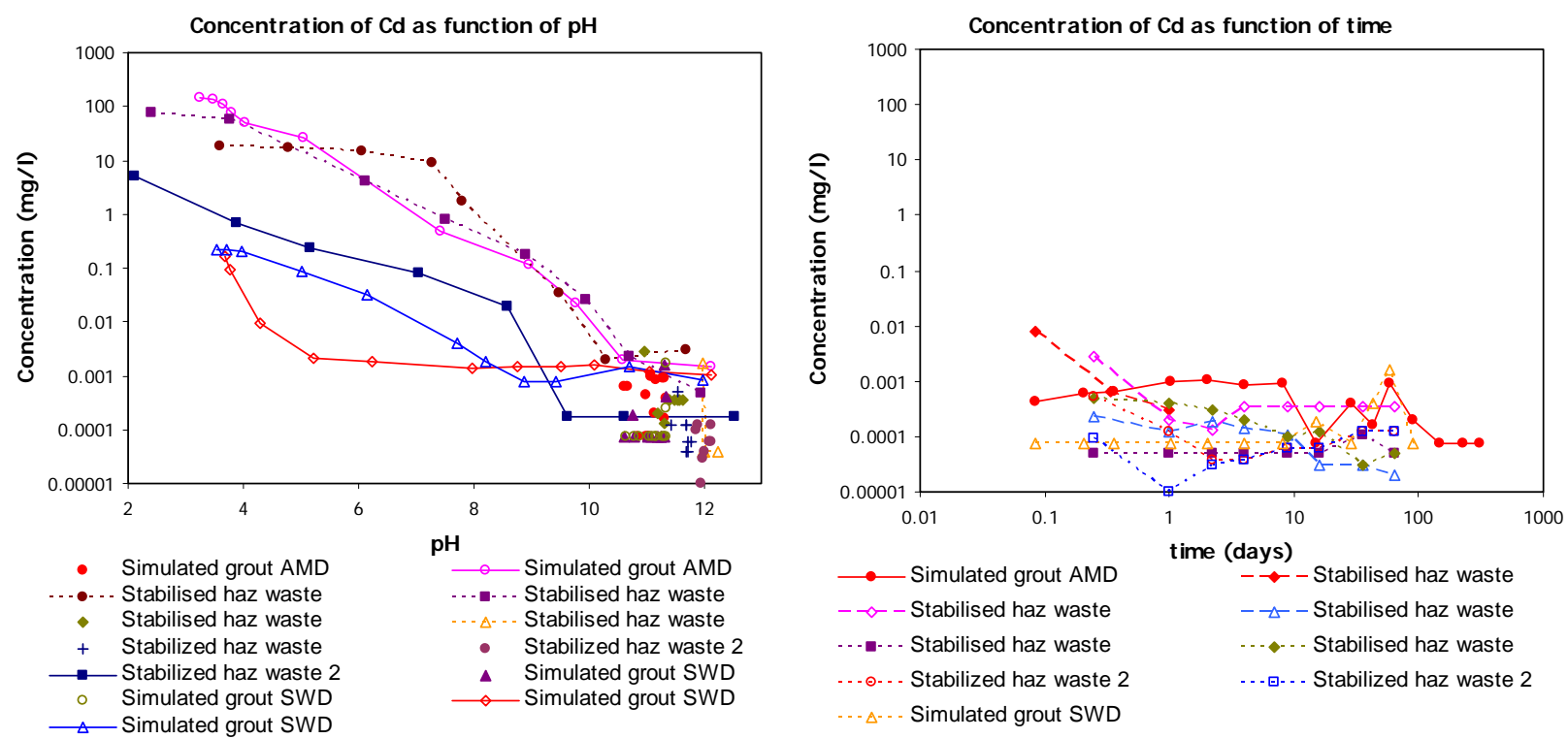

Concentration of $\mathrm{Co}$ as function of $\mathrm{pH}$

Concentration of $\mathrm{Co}$ as function of time
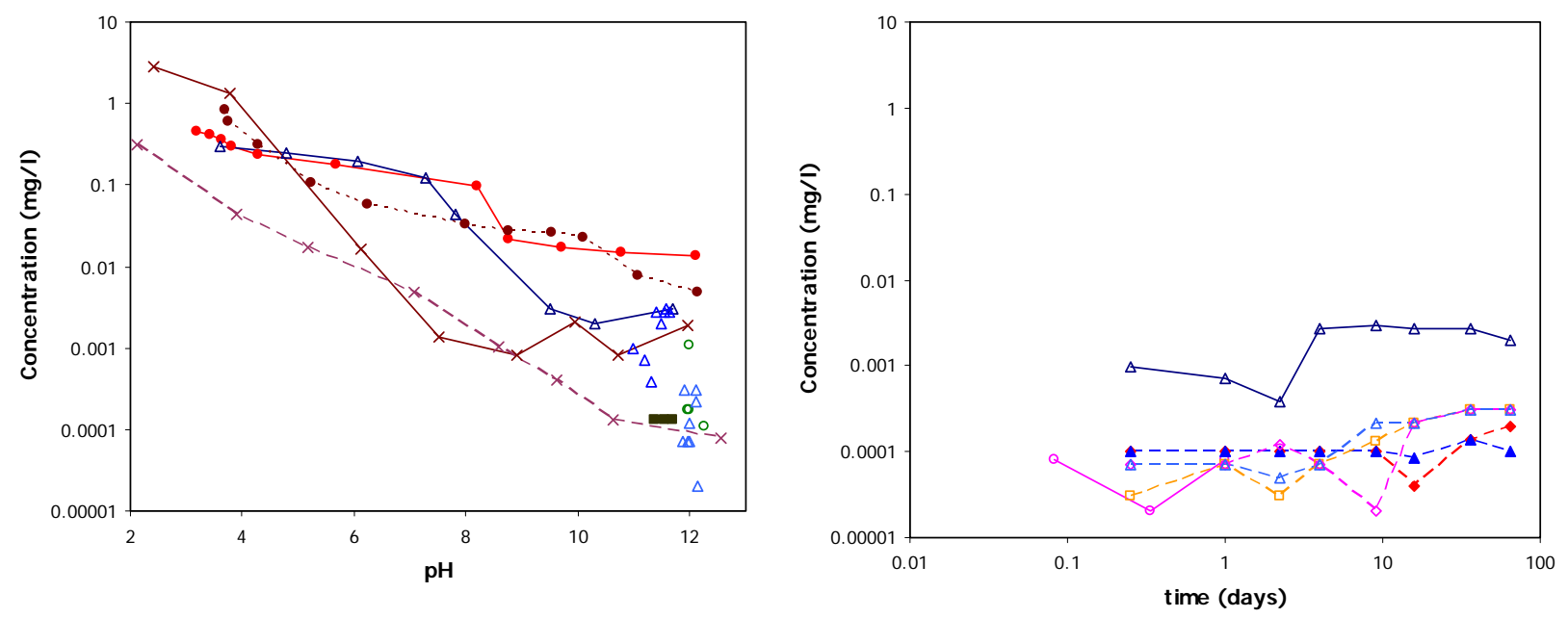

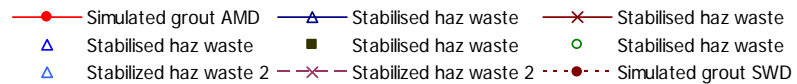

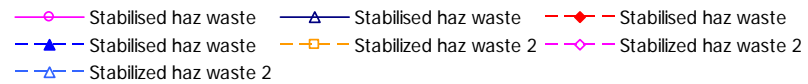

Figure 3. Comparison for grout simulation mixes with cement stabilized hazardous waste.

\subsection{Leaching Test Data for Soil}

Leaching test data for a variety of soils is available in the database. However, for evaluating a specific situation it is recommended to characterize the local material. There are many common characteristics for specific soil types. In most cases, interaction with dissolved and particulate organic matter and sorption onto hydrated iron oxides is most important. Detailed studies on release behavior from soil are available elsewhere (Dijkstra 2007; Dijkstra, Meeussen \& Comans 2004; van der Sloot 2002). 


\subsection{Comparison Between Cement Mortar and Stabilized Waste}

It is useful to see how much difference there is in cement-based material products, ranging from regular concrete to stabilized waste with high waste loading, in terms of leaching behavior. In an earlier paper, this aspect was addressed, and the many similarities in the release behavior indicated that a number of common features were shared among these materials.

\subsection{1 pH Dependence Test}

In Figure 4 the comparison between cement mortar and stabilized waste is given for a selection of a major and a few trace elements.

For $\mathrm{Al}$ it is clear that solubility is controlled by the same or at least very similar mineral phases in all systems under consideration. In the case of $\mathrm{Cd}$, the release reflects the different level of Cd contamination of the materials. The release of $\mathrm{Cr}$ is not fundamentally different for the stabilized waste and the cement mortar. At $\mathrm{pH}>8$ only $\mathrm{Cr}(\mathrm{VI})$ is leachable, as $\mathrm{Cr}(\mathrm{III})$ has a very low leachability in this $\mathrm{pH}$ domain. It is interesting to note, in the case of stabilized waste, that the $\mathrm{Cr}$ release at higher $\mathrm{pH}$ values increases steadily ( $\mathrm{pH}>11$ ), while in another mix the $\mathrm{Cr}$ release decreases. At $\mathrm{pH}>11.5$ ettringite substitution is likely to occur. 

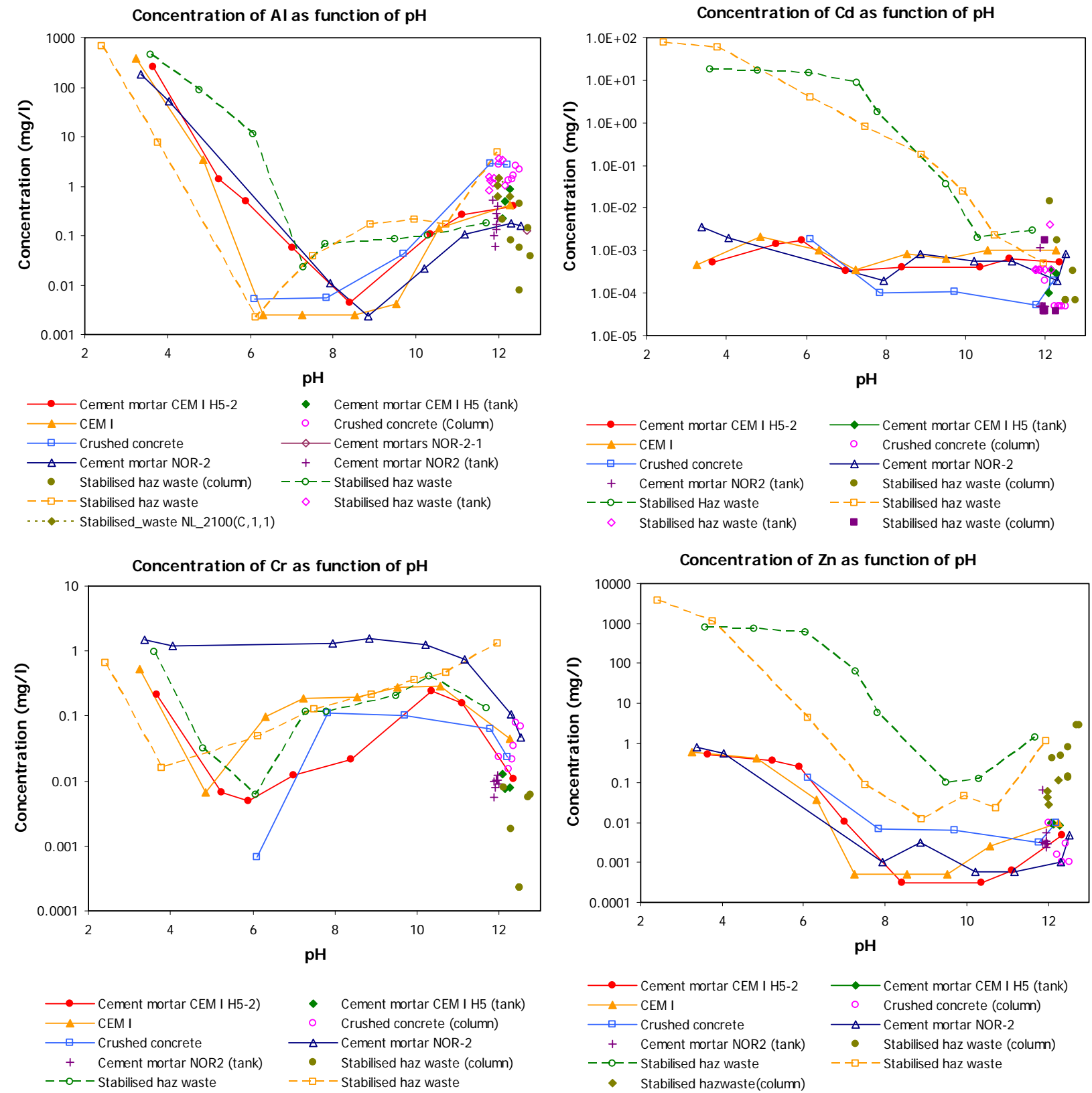

Figure 4. Comparison of release behavior between cement mortar and stabilized waste.

\subsection{Comparison Between Cement Mortar and Concrete}

There is a lot of information on cement mortar leachability and concrete leaching that may be related. Figure 5 illustrates the relation between the leachability of concretes and cement mortars. For Sr there is no noticeable distinction between concrete and cement mortars. All data seem to belong to one population. For As, it appears the leachability from concrete is systematically higher than for cement mortars by an order of magnitude. However, in the case of $\mathrm{Pb}$, results for concrete and cement mortar are mixed over the entire $\mathrm{pH}$ range, which makes $\mathrm{Pb}$ a candidate for solubility control. For $\mathrm{V}$, as for As, a systematic increase seems to occur for concrete relative to that of cement mortar. The reason for this systematic increase is unknown at present. It seems 

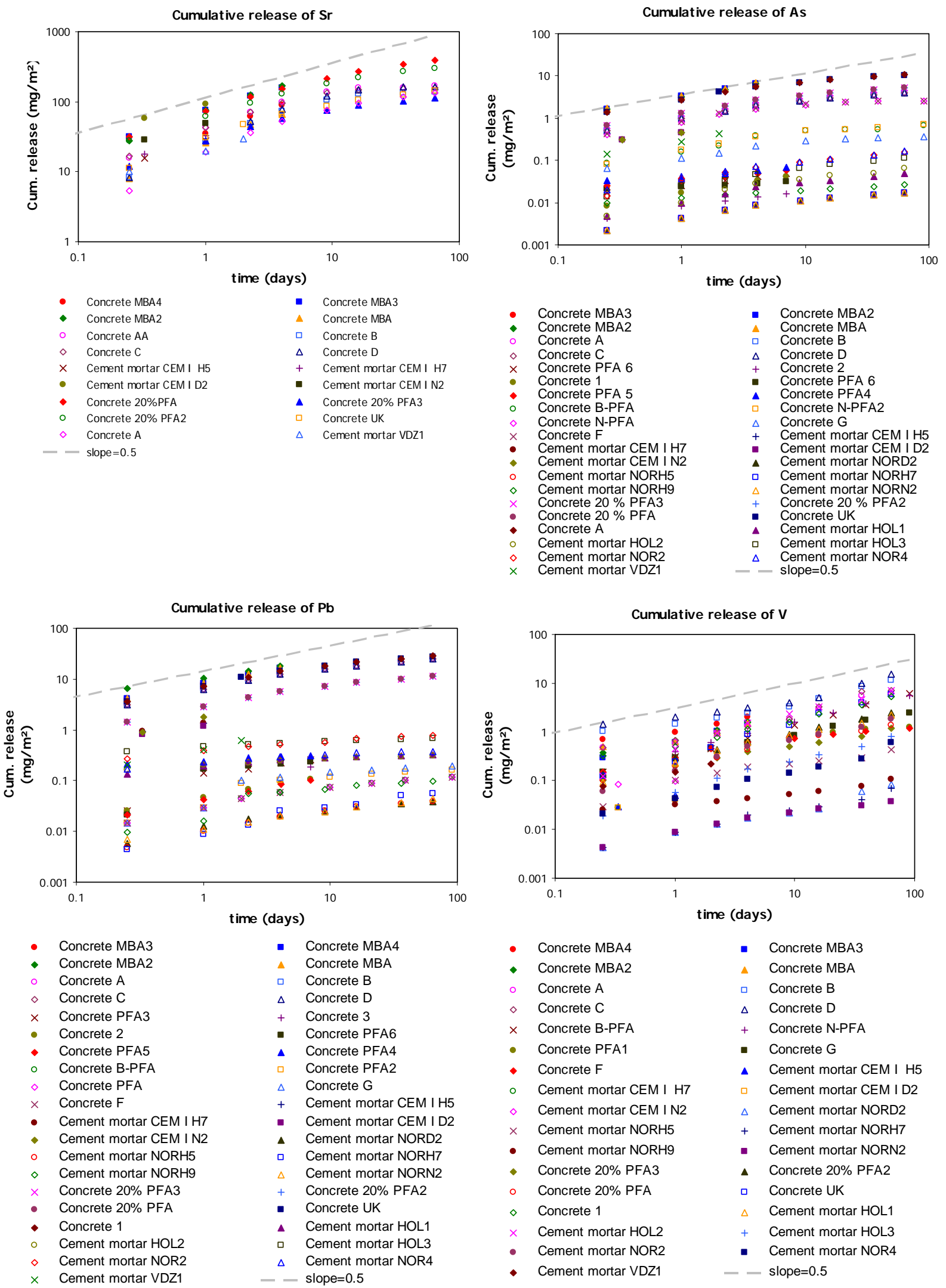

Figure 5. Comparison of concrete and cement mortar leachability. 
unlikely that it is related to different tortuosities between concrete and mortar, as the release of $\mathrm{K}$ and $\mathrm{Na}$ for concrete and mortar show a much narrower range of release than As and V. Some concretes contain fillers based on fly ash and it may not always be known what the precise composition of the concrete is, which results in uncertainty about the starting condition. Only through systematic comparison using the same cement to prepare mortar and concrete using “clean” aggregate, this apparent discrepancy can be resolved.

\subsection{Comparison Between Grout Column Data and Database Data}

Leaching experiments using column testing of size reduced grouts $(<0.8 \mathrm{~mm})$ over long periods of time has been useful to understand the underlying processes governing release (Fuhrmann \& Gillow 2009). These data, which includes several major elements analyzed in conjunction with the measurement of $U$, have been placed in context with percolation test data on size reduced concrete and monolith leach test data for cement mortars under different levels of carbonation. Comparing data in this manner is a bit unconventional, as the different $\mathrm{L} / \mathrm{S}$ data shown in the graph do not correspond directly with the $\mathrm{L} / \mathrm{S}=10$ conditions which are normally used to compare $\mathrm{pH}$ dependence leaching test data. The rationale for this is that several substances show solubilitycontrolled release, which implies that the same concentration in solution is measured despite the varying L/S conditions. Figure 6 shows the comparison for $\mathrm{Al}$ and $\mathrm{K}$ as two base cases. In the case of $\mathrm{Al}$, under almost all circumstances solubility is limited by $\mathrm{Al}$ phases, which may vary depending on $\mathrm{pH}$ conditions, but all leading to the same general leaching characteristic with a relatively narrow bandwidth. The $\mathrm{K}$ data exhibit a horizontal line, indicating virtual independence of $\mathrm{pH}$ on almost all materials. However, when column data are shown in the same graph, the $\mathrm{K}$ concentration at high $\mathrm{pH}$ values (fresh uncarbonated material) is considerably higher than the $\mathrm{L} / \mathrm{S}=10$ condition. As percolation proceeds, $\mathrm{K}$ is washed out of the column and the concentration decreases and at the same time, the $\mathrm{pH}$ decreases due to progressing carbonation. Consequently, the $\mathrm{K}$ concentration cuts across the $\mathrm{L} / \mathrm{S}=10$ data to a very low value at $\mathrm{pH} 8$, with fully carbonated and completely washed out material.
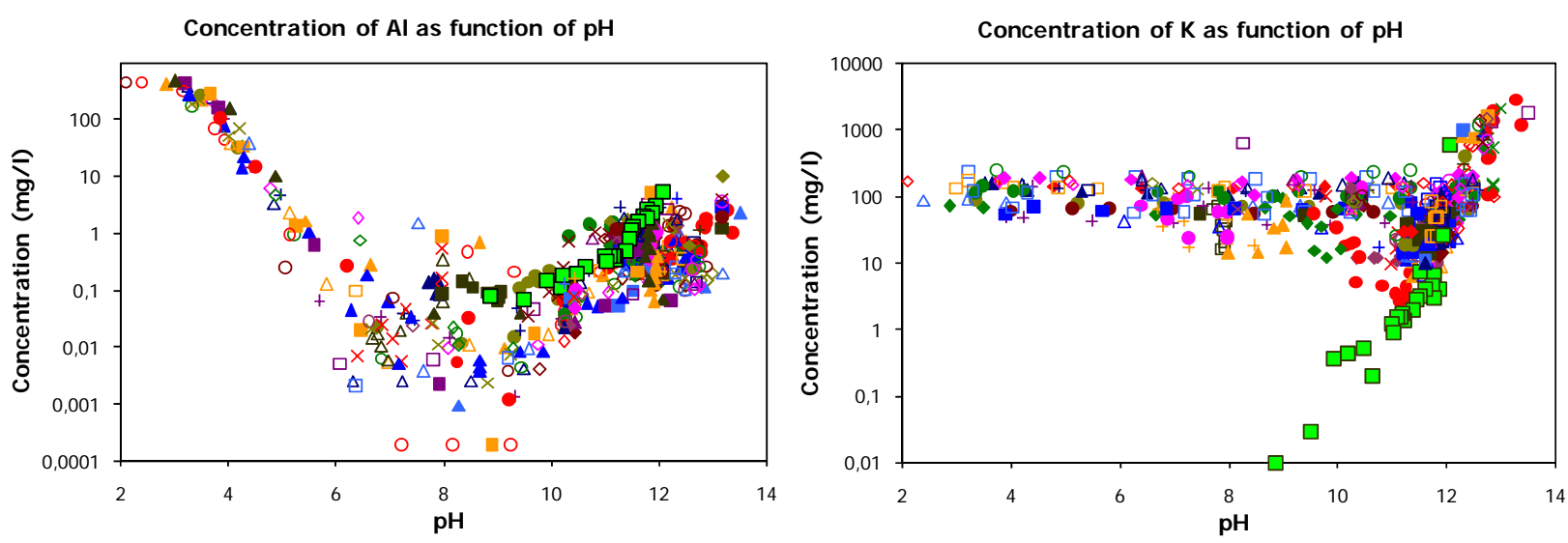

Figure 6. Al and $\mathrm{K}$ leaching data from grout column (green squares (Fuhrmann \& Gillow 2009)) and data from monolith leach test, percolation test, and pH dependence test for cement-based products.

In Figure 7, the graphs are shown for $\mathrm{Ca}, \mathrm{SO}_{4}$ as $\mathrm{S}$, $\mathrm{Si}$ and $\mathrm{Fe}$. In case of $\mathrm{Ca}$, the transformation of the alkaline materials to fully carbonated materials is clear from the $\mathrm{pH}$ decrease to around 8 in the grout columns after around 1000 pore volumes. For the monolithic products that have been exposed to forced carbonation (by bubbling $\mathrm{CO}_{2}$ through the leachant during leaching at different rates), a typical curve decreases from the high 
$\mathrm{pH}$ curve to a minimum at $\mathrm{pH}$ around 9 and then steadily moves up when the $\mathrm{pH}$ reaches 6 . This occurrence may be related to the formation of $\mathrm{HCO}_{3}{ }^{-}$when excess $\mathrm{CO}_{2}$ is applied. In case of the grout column, the Ca response flattens out, which is unexpected given the other data. An explanation is that Ca is present in the feed at a level of around $180 \mathrm{mg} / \mathrm{l}$ (as $\mathrm{CaCl}_{2}$ ), which after passing the column results in a apparent local equilibrium at around $100 \mathrm{mg} / \mathrm{l}$. Sulfate leachability is initially low. As soon as the $\mathrm{pH}$ starts to decrease the leachability could increase, but in view of the large volumes passed through the grout column the concentration remains relatively low. Si appears solubility limited under most conditions. The limited number of Fe data (at low concentrations) agree with the general Fe levels in solution. Si and Fe are very much solubility controlled by mineral phases. Because of the very low Fe concentration levels, only few data were available for the grout column.
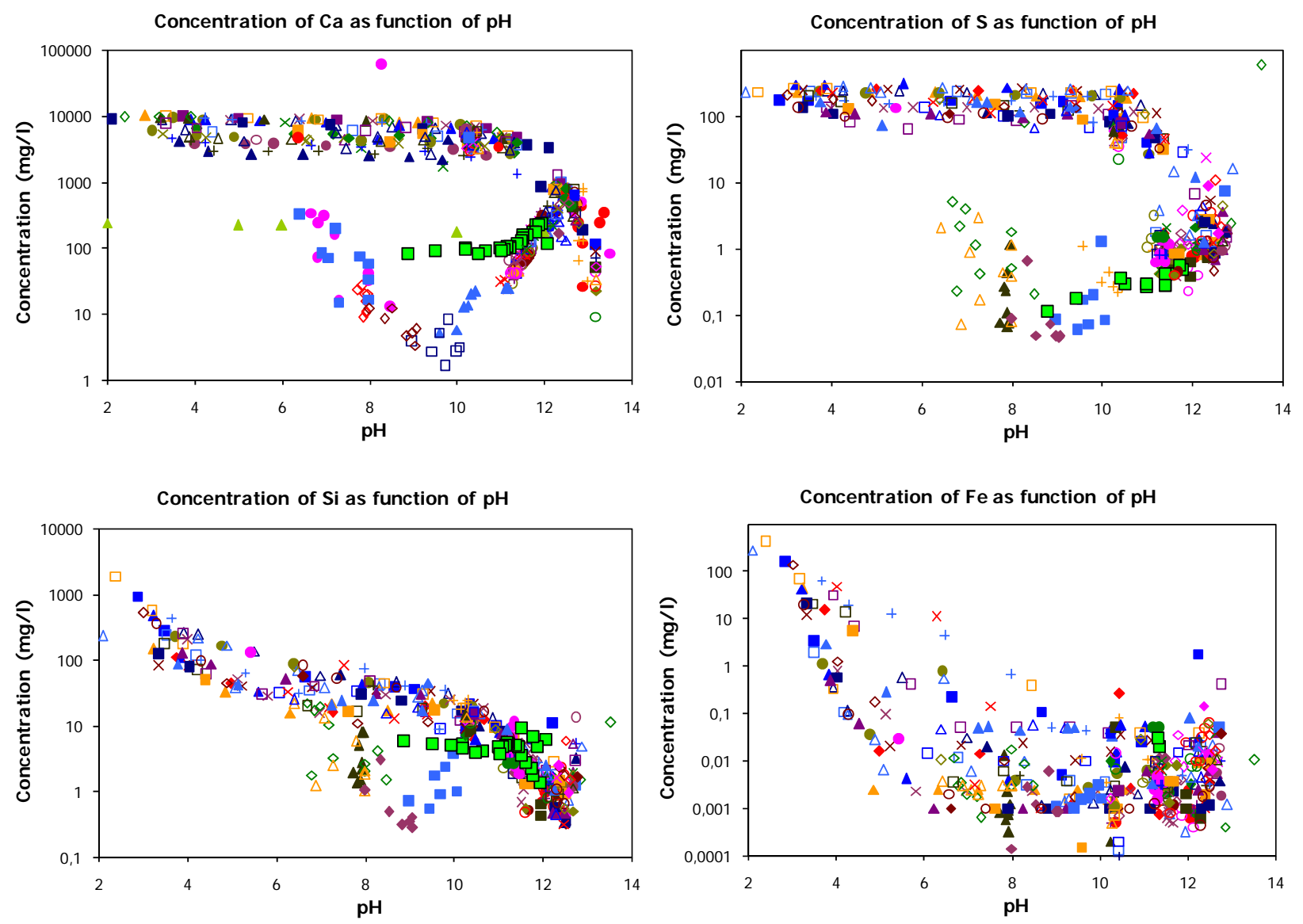

Figure 7. $\mathrm{Ca}, \mathrm{SO}_{4}$ as $\mathrm{S}, \mathrm{Si}$ and Fe leaching data from grout column (green squares (Fuhrmann \& Gillow 2009)) and data from monolith leach test, percolation test and $\mathrm{pH}$ dependence test for cement based products.

In Figure 8 the data for $\mathrm{Mg}, \mathrm{Na}, \mathrm{Cl}$, and $\mathrm{U}$ are shown. $\mathrm{Mg}$ is also solubility-controlled (most likely as brucite). Only at very advanced leaching does the $\mathrm{Mg}$ response become more or less constant.

Na does not show the same behavior as K, which would be expected when Na is in the feed and $\mathrm{K}$ is not. The Na response levels off towards a constant concentration of $75 \mathrm{mg} / \mathrm{l}$, which correspond well with the concentration of $74 \mathrm{mg} / \mathrm{l}$ calculated based on the addition of $\mathrm{NaHCO}_{3}$ at $270 \mathrm{mg} / \mathrm{l}$. The $\mathrm{Cl}$ concentration in the 
grout column eluate is $250 \mathrm{mg} / \mathrm{l}$, Based on the reported feed concentration of $0.5 \mathrm{~g} \mathrm{CaCl}_{2}$, this must have been weighed as $\mathrm{CaCl}_{2} \bullet 2 \mathrm{H}_{2} \mathrm{O}$, as that corresponds with a calculated concentration of $240 \mathrm{mg} / \mathrm{l}$, if no interaction in the column is assumed. For $\mathrm{U}$, there are only data for the grout, and thus $\mathrm{U}$ needs to be analyzed in the simulated grout materials to be tested in the CBP experimental program. These results indicate that there is extensive common ground between the grout and the stabilized hazardous waste leaching behavior.
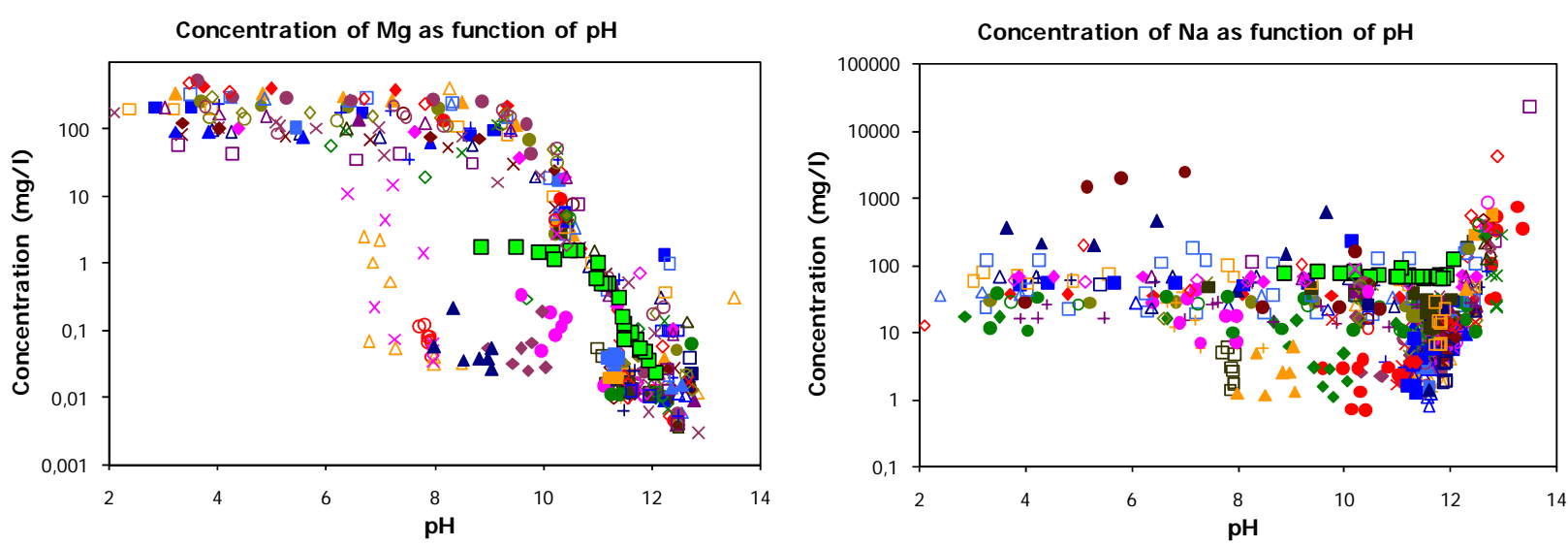

Concentration of $\mathrm{Cl}$ as function of $\mathrm{pH}$

Concentration of $\mathbf{U}$ as function of $\mathrm{pH}$
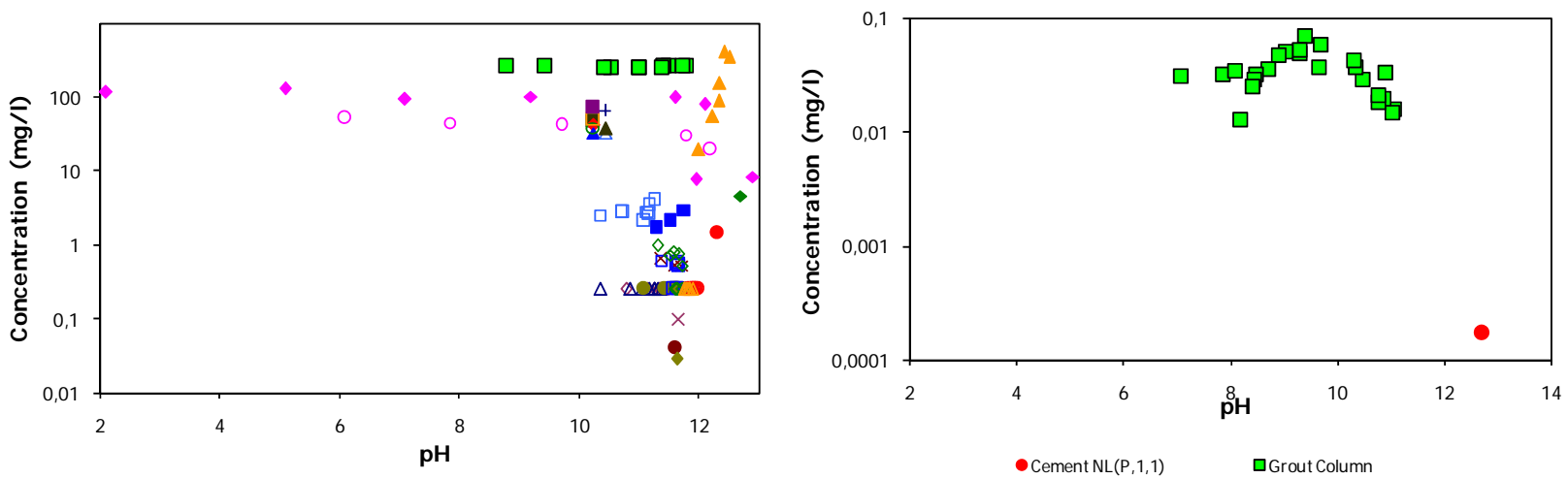

Figure 8. $\mathrm{Mg}, \mathrm{Na}, \mathrm{Cl}$, and $\mathrm{U}$ leaching data from grout column (green squares (Fuhrmann \& Gillow 2009)) and data from monolith leach test, percolation test and pH dependence test for cement-based products.

\subsection{Comparison Between Laboratory Test Data and Core Samples From a Field Site}

An important comparison for leach tests is the comparison of laboratory test data with field observations. This is important because several aspects of leaching and release are affected by conditions that cannot be adequately reproduced in the laboratory. Despite this, the comparison can show to what extent laboratory and field data agree, leading to a narrowing of uncertainty in prediction of long term release. As long as a given condition or range of conditions is not exceeded, concentrations that will be encountered for a very long time can be within fairly narrow bounds. Defining end points is then of crucial importance (see recommendations for experimental work for suggestions in this context). In Figure 9 the relationship between laboratory test data on fresh and field-aged materials is shown in comparison with field leachate results for a stabilized hazardous waste facility. 

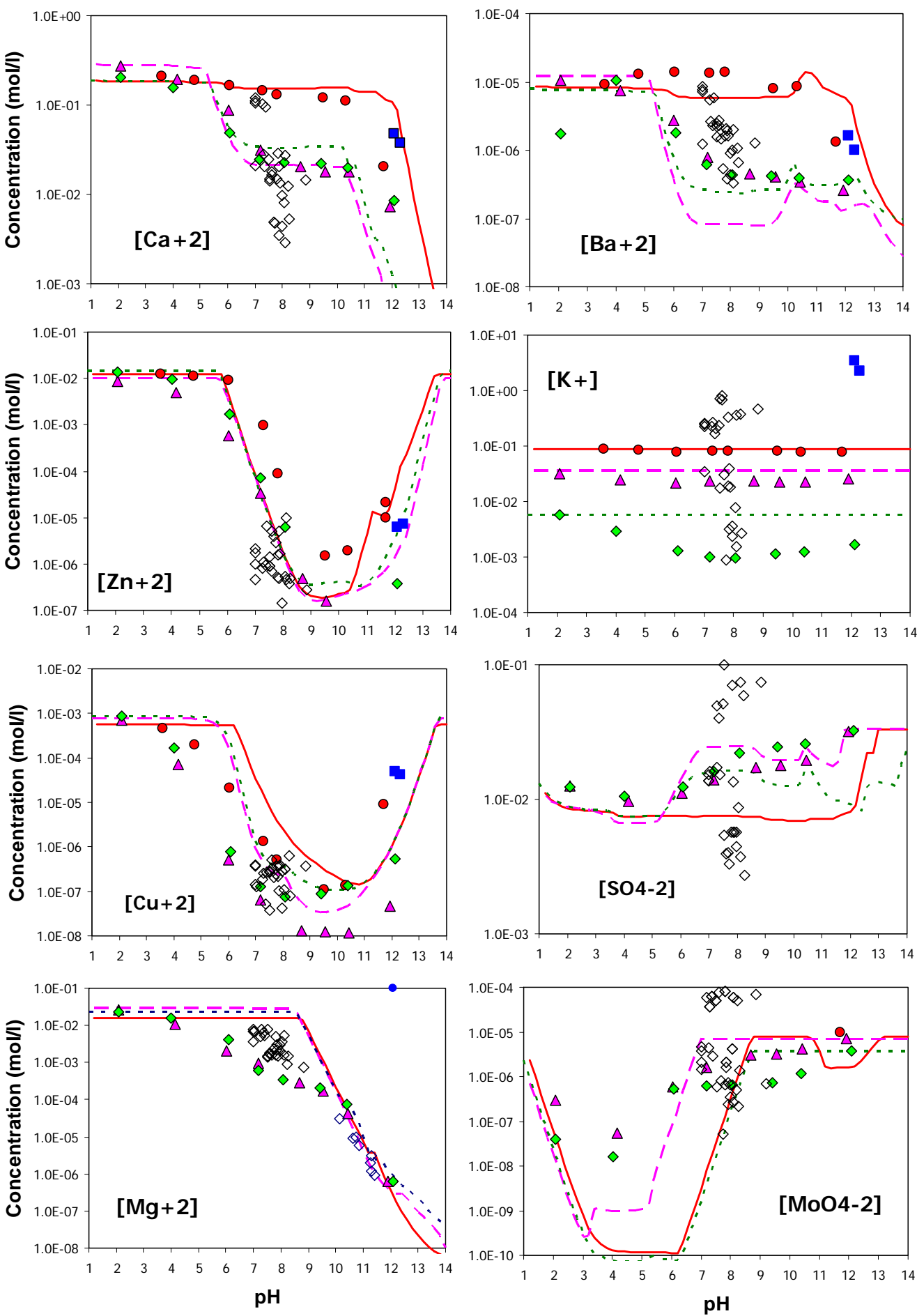

Figure 9. Comparison of laboratory test data for fresh and aged stabilized waste (cores from the field) in comparison with field leachate (van der Sloot et al. 2007b). Legend: Red dot - pH stat fresh material; blue square - first fraction percolation test; green diamonds - pH stat aged material from pilot test cell core (atmosphere exposed); triangles purple - aged material from core (sealed cell); open diamonds - leachate from pilot cell (field scale); red line multi-element modeling of fresh crushed stabilized waste; blue line - model of aged data open cell; purple line model run for aged material from closed cell. 
The comparison illustrated in Figure 9 is very useful as it highlights gaps in the understanding factors affecting release, but it is also important in showing that adequate understanding and control exists for a range of other substances over a wide range of experimental conditions that are relevant for the material under changing exposure conditions. For instance, the behavior of $\mathrm{Ca}, \mathrm{Ba}, \mathrm{Cu}, \mathrm{Zn}, \mathrm{K}$, and $\mathrm{Mg}$ is well understood as evidenced by the associated chemical speciation modeling using LeachXSTM/ORCHESTRA. For Mo, the solubility controlling phase is most likely $\mathrm{PbMoO}_{4}$, but the stability constant in the database is not good enough to reach this conclusion and needs further work. In a number of cases kinetic processes control constituent release; this is likely the case for sulfate.

This type of comparison between laboratory and field results for Saltstone and grout is important to identify, in a similar manner, the controlling factors and thus narrow the uncertainty ranges in long term prediction (see recommendations for further work in Section 12.0, “Conclusions and recommendations”).

\subsection{RELATIONSHIP BETWEEN PH DEPENDENCE TEST AND $\mathrm{K}_{\mathrm{d}}$}

The manner in which a $\mathrm{K}_{\mathrm{d}}$ measurement is performed has similarities with the batch test version of the $\mathrm{pH}$ dependence leaching test for the materials own $\mathrm{pH}$ condition (normal procedure) or with the modified $\mathrm{pH}$ condition. This implies that it should be possible to relate $\mathrm{K}_{\mathrm{d}}$ measurements to the more sophisticated $\mathrm{pH}$ dependence leaching test. When the total composition is available for a material and the results of the $\mathrm{pH}$ dependence test are known, a $\mathrm{K}_{\mathrm{d}}$ as a function of $\mathrm{pH}$ can be calculated as follows:

$$
\begin{aligned}
& \mathrm{K}_{\mathrm{d}}=\mathrm{C}_{\mathrm{T}} / \mathrm{C}_{\mathrm{s}} \\
& \mathrm{C}_{\mathrm{T}} \text { - total content in } \mathrm{mg} / \mathrm{kg} \text { dry matter } \\
& \mathrm{C}_{\mathrm{s}} \text { - concentration in } \mathrm{pH} \text { dependence test eluate in } \mathrm{mg} / \mathrm{l}
\end{aligned}
$$

For the HOL 12 - CEM V/A mortar, this is illustrated for V, Zn, Sr and Mo release from cement mortar in Figure 10 (where total content of V, Zn, Sr and Mo, respectively, are 27.6, 53.6, 101 and $0.8 \mathrm{mg} / \mathrm{kg}$ ). For the relevant $\mathrm{pH}$ range that may occur at the exposed surface of a cement mortar or concrete, which ranges from $\mathrm{pH}$ 8 -12, the changes in $K_{d}$ can be considerable for a metal like $\mathrm{Zn}$, an alkali-earth element like Sr, and for oxyanions like $\mathrm{V}$ and Mo. Note that the $\mathrm{K}_{\mathrm{d}}$ is higher, when de concentration decreases. The concentration in the $\mathrm{pH}$ dependence graph is then mirrored vertically in the $\mathrm{K}_{\mathrm{d}} \mathrm{pH}$ graph. The values of $\mathrm{K}_{\mathrm{d}}$ for $\mathrm{V}$, Sr, and Mo decrease with decreasing $\mathrm{pH}$, while the $\mathrm{K}_{\mathrm{d}}$ for $\mathrm{Zn}$ at first increases and then decreases at a much lower $\mathrm{pH}$ than the oxyanions.

This type of relationship can be established for several substances and nuclides of interest (Kaplan et al. 2008; Serne 2006). This is crucial as it is clear that a $\mathrm{pH}$ gradient will develop over time over the relevant $\mathrm{pH}$ domain to be encountered in concrete or stabilized waste directly or indirectly exposed to the atmosphere. Not covered in this data set are possible changes imposed by a simultaneous change in REDOX state, which will be very noticeable for some substances, e.g., Tc.

\subsection{RELEASE BEHAVIOR OF SUBSTANCES}

Leaching studies on monolithic forms such as cement mortars and stabilized waste forms, have shown the release of different substances is controlled by different mechanisms and controlling factors. Recent work has 

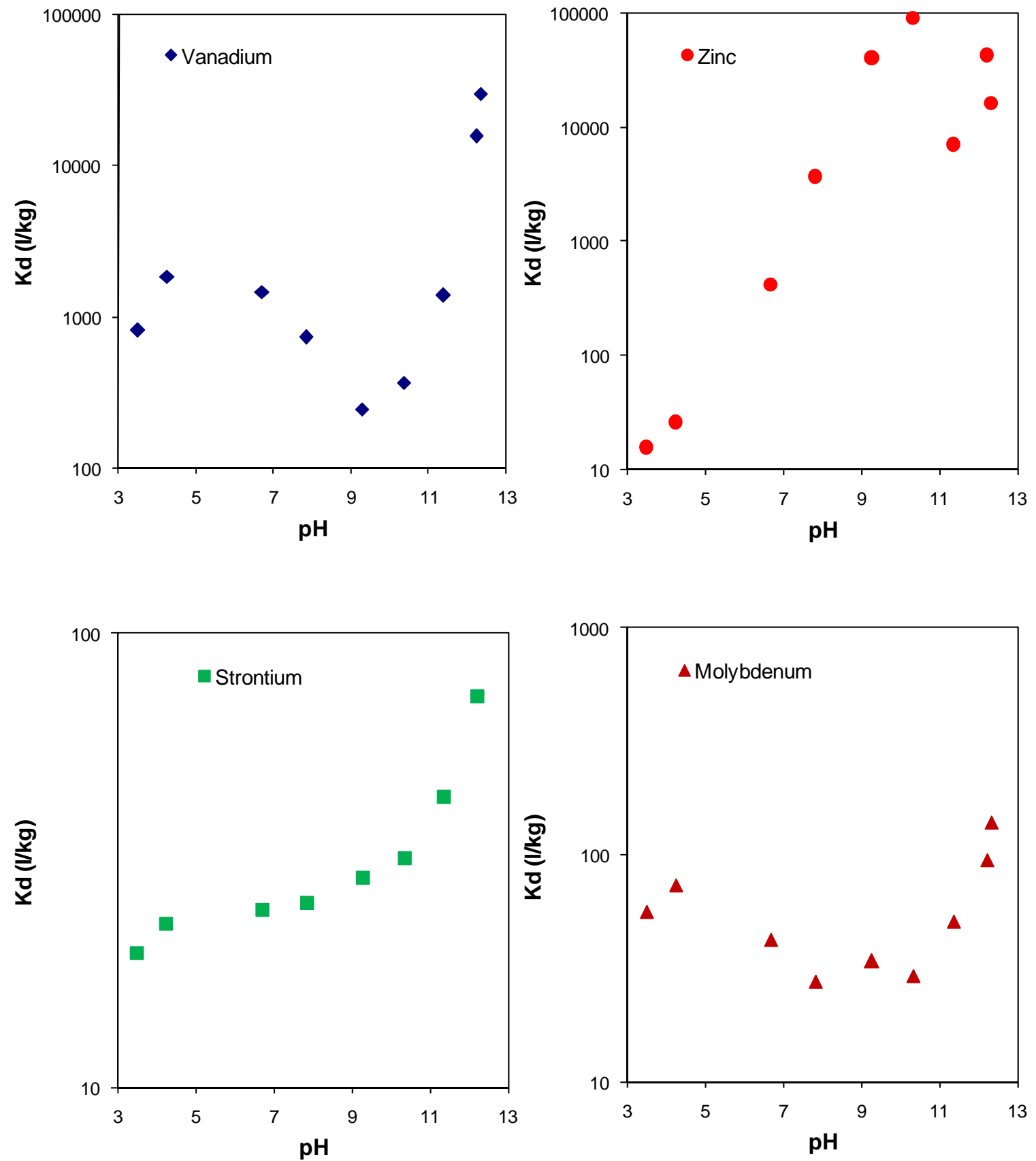

Figure 10. Calculated $\mathrm{K}_{\mathrm{d}}$ for $\mathrm{V}, \mathrm{Zn}, \mathrm{Sr}$, and Mo in cement mortar calculated based on data from the $\mathrm{pH}$ dependence leaching test for HOL 12 - CEM VIA. 
revealed means of identifying such behavior, which is important for assessment of long term release prediction. A distinction needs to be made between substances that are almost inert (i.e., undergo no or very little interaction with the solid matrix) and thus are released uninhibited and those which are not. The inert substances show almost exclusively diffusion driven release from monoliths. The substances that undergo interaction with the matrix can be divided in substances that will show solubility controlled behavior in a percolation test (preliminary draft EPA method 1314 (2009b) similar to CEN/TS 14405 (2004), and ISO/TS 21268-3 (2007a)) with size reduced material, but will feature a release behavior in a monolith leach test (preliminary draft EPA method 1315 (2009c) similar to CEN/TS 15863 (2009)) governed by diffusion, and substances that are solubility controlled under all circumstances of leaching (both in percolation and in monolith leach testing).

The combination of monolith leach tests, percolation tests and $\mathrm{pH}$ dependence tests on size reduced material will, through combination of the rest results, allow conclusions to be drawn on the type of release behavior that controls release of a given substance. Examples of typical cases are given in Figure 11 and Figure 12.

\subsection{Non-interacting Substances}

A good example of a non-interacting (or almost non-reactive) substance is $\mathrm{K}$ (and likely $\mathrm{Na}$ and $\mathrm{Cl}$ in most cases) as shown in Figure 11. This is reflected in the release behavior in the $\mathrm{pH}$ dependence test - no or hardly any dependency on $\mathrm{pH}$; its release behavior in the percolation test, where it shows a slope 1 in the cumulative release until L/S of about 1 and then turns horizontal (i.e., all leachable substance depleted from the system); in the percolation system the concentration goes down continuously with increasing $\mathrm{L} / \mathrm{S}$; and its release behavior in a monolith leach test, where it shows a cumulative release that follows a slope of 0.5 , when no other factors play a role (e.g., depletion and changing tortuosity with release of substantial amount of salt from a stabilized waste with high salt loading, which is the case here). The advantage of the manner of data presentation given below is being able to identify such possible effects. The graph of $\mathrm{pH}$ dependence with concentrations as measured in both the percolation test and monolith leach test is highly illustrative in this respect. The $\mathrm{K}$ concentrations in the first column fractions far exceed the $\mathrm{L} / \mathrm{S}=10$ condition of the $\mathrm{pH}$ dependence test, as it is roughly a factor 30 higher ( $\mathrm{L} / \mathrm{S}=0.3$ reasonable reflects one pore volume), but then upon percolation drops off to very low values. When the concentrations of the monolith test fall well below the concentrations as measured in the $\mathrm{pH}$ dependence test, it is an indication of possible mass transfer limitations or depletion at later stages of the test. In this case of a stabilized waste with a high salt loading, the difference is not as big as for a cement mortar with a much higher tortuosity. The results from a 3-D diffusion model with pure diffusion controlled release for a specimen of the same dimensions as that tested (Figure 11) can be compared to the observed K release behavior (Figure 12). The deviation between predicted and observed results can be attributed to the loss of soluble salts leading to an increased porosity, which in turn leads to a decrease in tortuosity. 


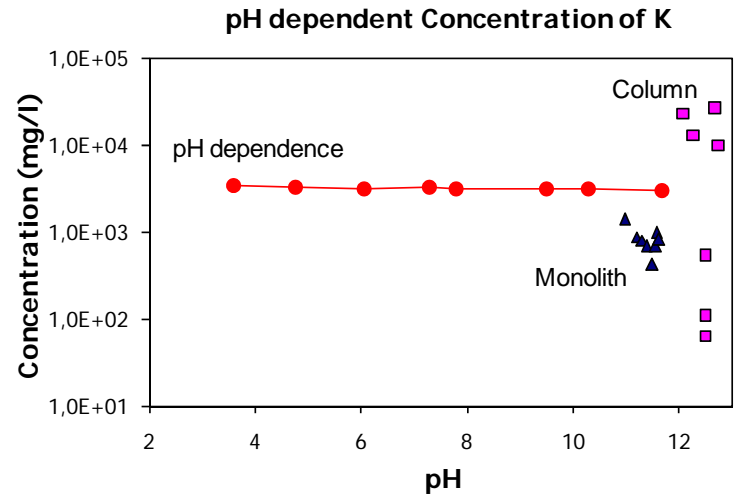

K concentration as function of $L / S$
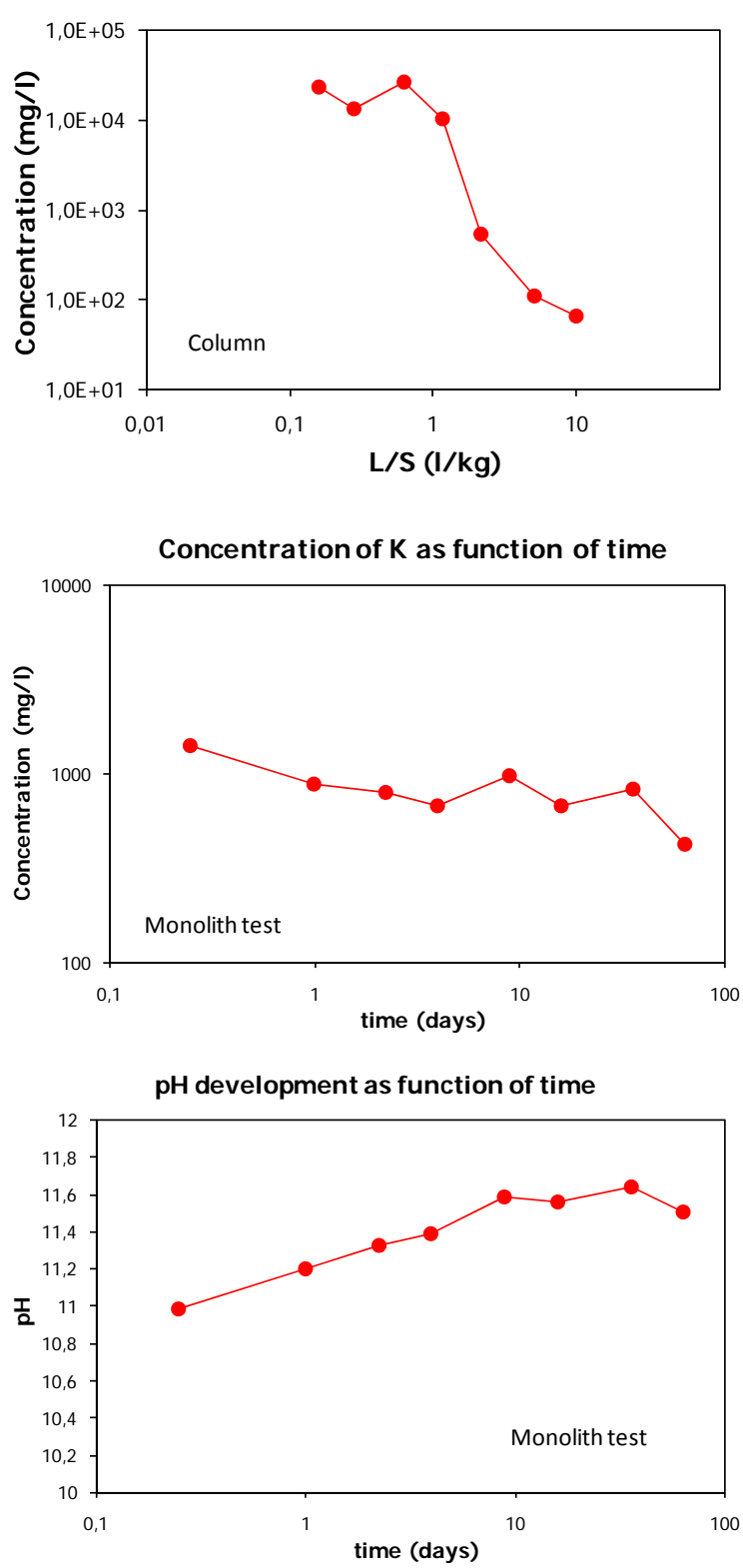

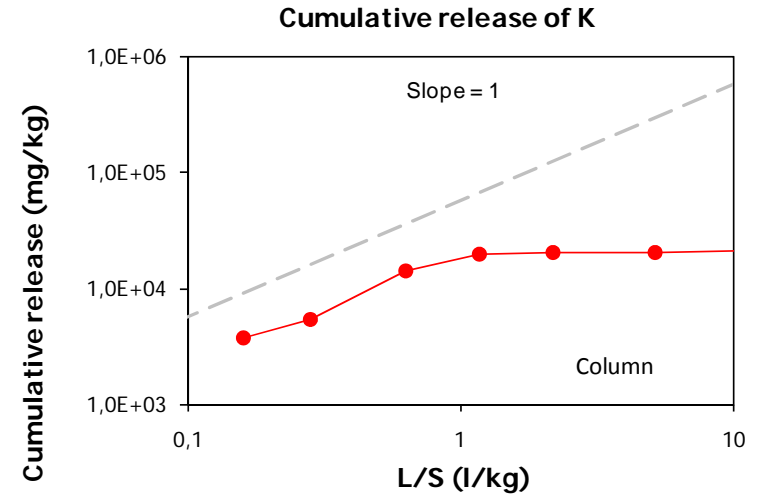

pH development as function of $L / S$
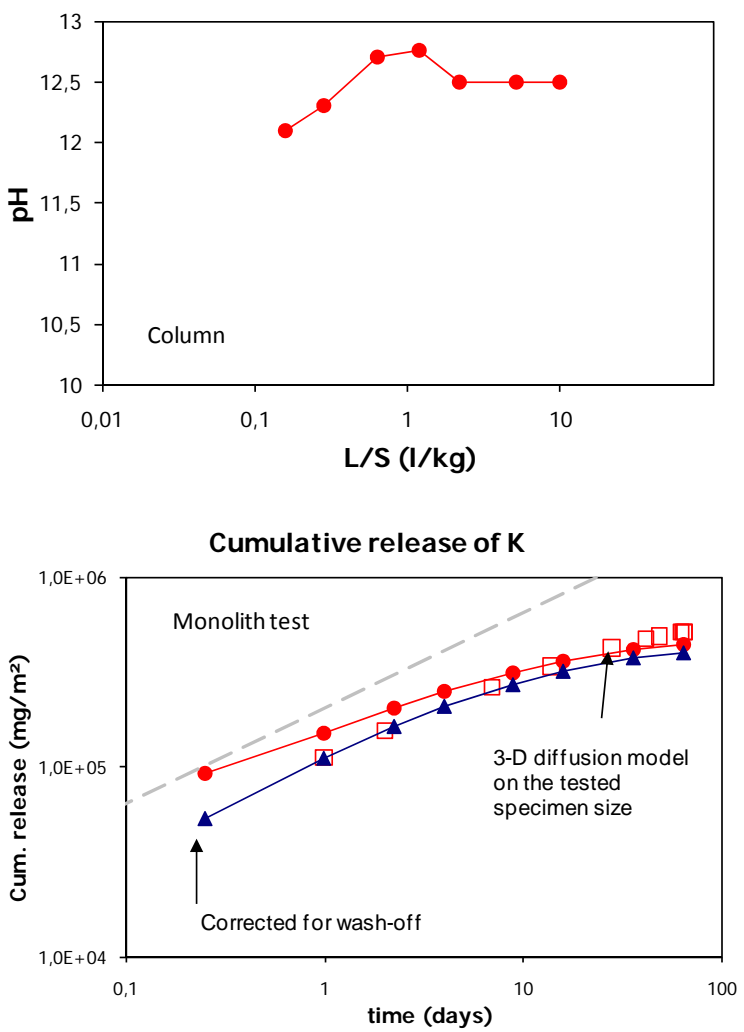

Figure 11. Example of non interacting substance with typical diffusion controlled release. 


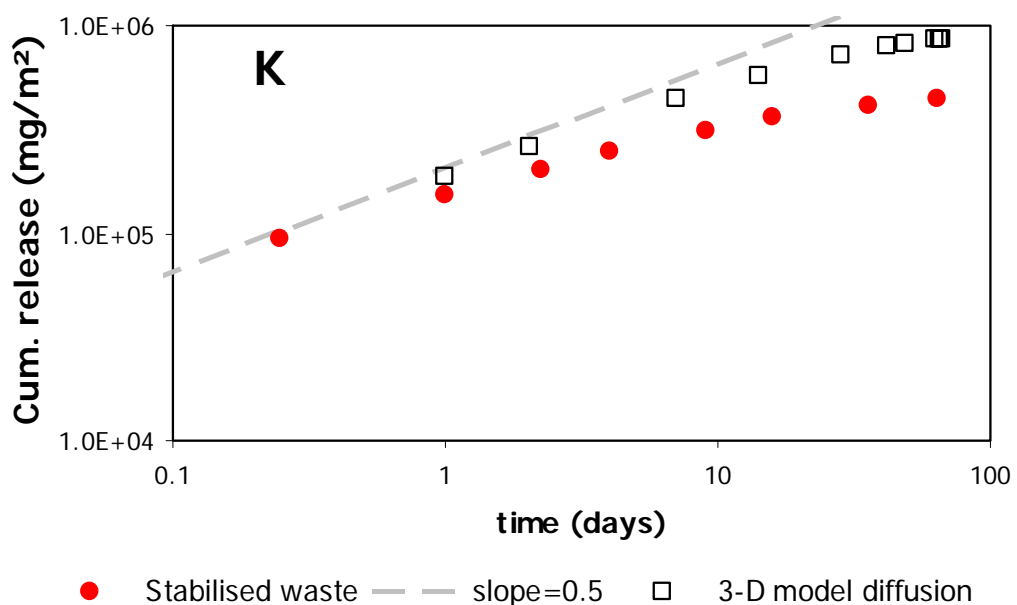

Figure 12. Possible effect of change in tortuosity based on increased porosity by release of substantial amount of soluble salt.

\subsection{Solubility Controlled Substance}

An example of a substance that is solubility controlled under most experimental and field condition is $\mathrm{Mg}$. In Figure 13 the $\mathrm{Mg}$ release results from the percolation test and the monolith leach test on the same material are provided. In case of $\mathrm{Mg}$, the solubility limitation is reflected by the agreement between $\mathrm{pH}$ dependence and the concentrations measured in both the percolation and monolith leach tests. In the percolation test, the slope of 1 in the cumulative release curve as function of L/S is caused by the constant concentration of $\mathrm{Mg}$ in all collected eluate fractions. In the monolith leach test, the constant concentration in spite of the longer contact times of the eluate with the monolith is also indicative of solubility control. In fact, the Mg concentration is slightly higher in the first eluate fractions collected, where the $\mathrm{pH}$ is lower. This type of condition of a substance is very useful for prediction purposes as the concentrations to be expected from the material can be described very well within relatively narrow bounds.

\subsection{Mixed Behavior}

Several substances show behavior that can be solubility limited under one condition and mass transfer limited under another condition. In Figure 14, the release behavior of $\mathrm{Ca}$, that exhibits such behavior, is shown. Ca is solubility limited in the percolation test (where its response agrees with specific mineral phases as shown in Section 5.3, "Chemical Speciation”), while it shows largely diffusion-controlled release in the monolith leach test. The constant concentration in the column eluates and the slope 1 behavior in the cumulative release against L/S reflect solubility-controlled release in the column. However, in the monolith leach test, the response is more diffusion-controlled, and, as in the case of $\mathrm{K}$, Ca is likely affected by a change in tortuosity as salt is leached resulting in larger voids in the surface of the monolith. This phenomenon still needs to be implemented in the model description of the monolith leach test.

The identification of the release controlling factors is crucial for proper long term release behavior prediction. This is not possible with just one test; a combination of tests and different modes of data presentation will bring out the key issues to be considered. It is, therefore, crucial to test the CBP materials with a monolith leach test and, after size reduction, with the $\mathrm{pH}$-dependent leaching test and percolation test. 

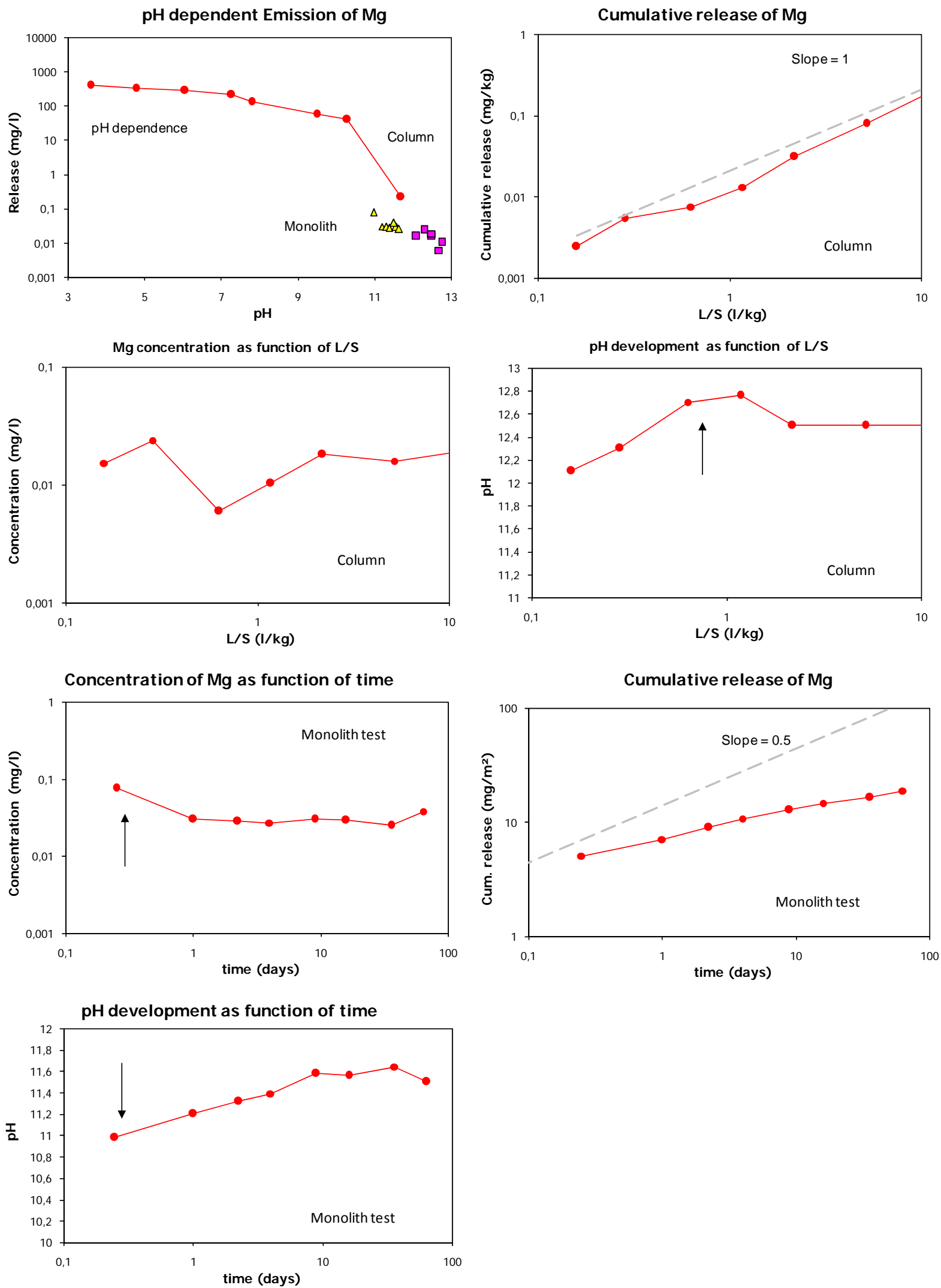

Figure 13. Example of a substance that is solubility controlled under all test conditions. 

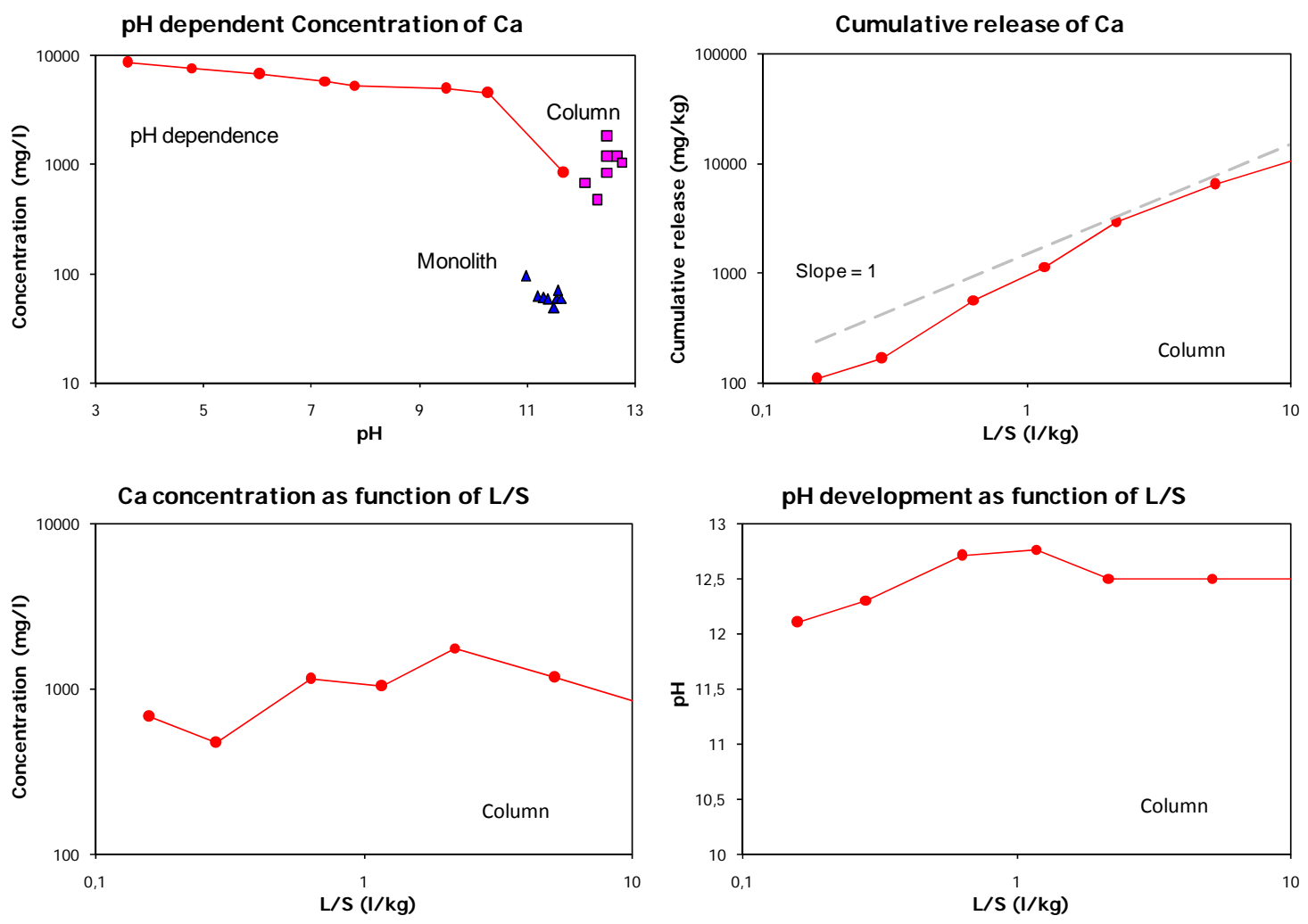

Concentration of $\mathrm{Ca}$ as function of time
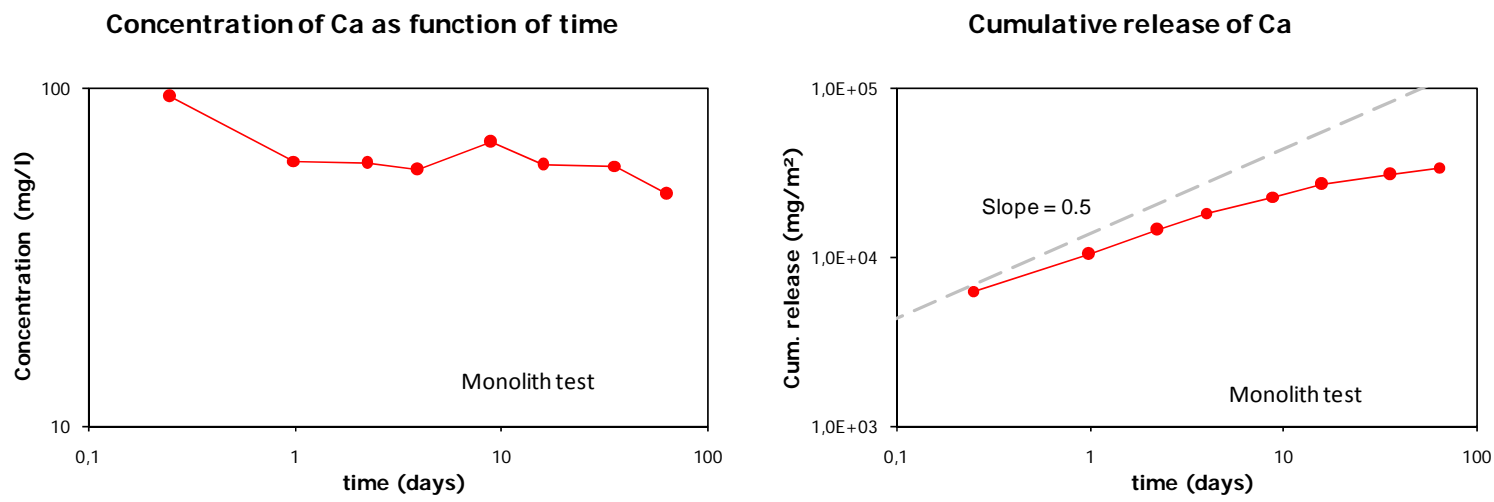

pH development as function of time

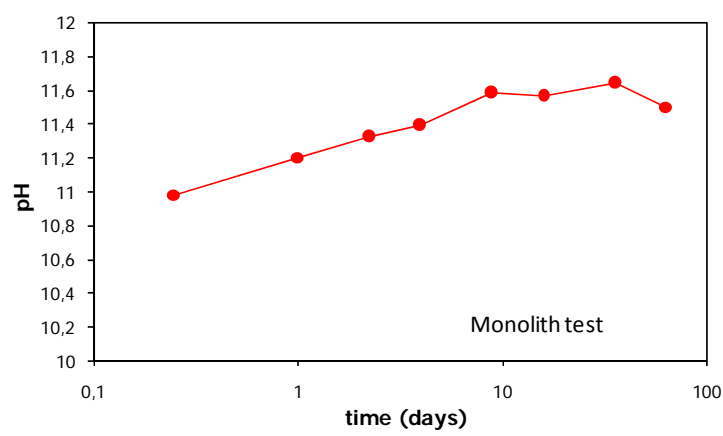

Figure 14. Example of a substance that is solubility controlled in a percolation test and largely diffusion controlled in a monolith leach test. 


\subsection{Simplified Solutions for Assessing Release}

In case of a REDOX or carbonation front and a large difference in leachability between either side of the sharp front, a simplified approach is possible to quantify the release of substances. Examples of such situations are $\mathrm{V}$ release from concrete, which is virtually non-leachable at high $\mathrm{pH}$, but increases in leachability more than 100 fold upon carbonation. In this case, it can be assumed that all of the $\mathrm{V}$ will be leached from the carbonated zone. In reality, some $\mathrm{V}$ will diffuse back towards into high alkaline region, so release will in reality be less than assumed. Knowledge of the progression of the carbonation front from measurement or modeling immediately translates in a $\mathrm{V}$ release that corresponds to the fraction available for leaching without the complicated chemistry. As a first assumption, a square root of time relationship can be assumed for the front progression.

Figure 15 shows that the release of $\mathrm{V}$ as measured with a tank test will change as a function of $\mathrm{pH}$, and it will generally follow the behavior that is measured with a $\mathrm{pH}$ dependence test. This indicates a strong dependence on chemical factors (solubility control). Apparently the $\mathrm{pH}$ dependence test in combination with the monolith leach test can capture the relevant processes occurring upon carbonation. For the Waste Vault and Tank Closure reference cases, the rate of carbonation is at present unknown and initial assumptions need to be made to get an understanding of the potential release of radionuclides that may be sensitive to this factor.

The availability of $\mathrm{V}$ is estimated at $7 \mathrm{mg} / \mathrm{kg}$ from the maximum release at $\mathrm{pH} 10.5$. The density of concrete is on average $2400 \mathrm{~kg} / \mathrm{m}^{3}$. If a carbonation depth of $2 \mathrm{~mm}$ in 10 years for concrete is assumed, a carbonation depth of about $6 \mathrm{~mm}$ in 100 years will be obtained (assuming a square root of time relationship). Assuming full depletion of $\mathrm{V}$ from the carbonated zone corresponds to a normalized release of $\mathrm{V}$ can of about $100 \mathrm{mg} / \mathrm{m}^{2}$ (= $7 \mathrm{mg} / \mathrm{kg} \times 0.006 \mathrm{~m} \times 2400 \mathrm{~kg} / \mathrm{m}^{3}$ ). This release can also be expressed as concentration as a function of time.

For a REDOX front, a similar situation can be foreseen. This would apply to Tc, which is known to be highly mobile under oxidized conditions as technetate. Modeling the REDOX front based on $\mathrm{O}_{2}$ uptake can then provide a measure for the rate of REDOX front movement and consequently provide a measure for the Tc release. Other processes can be considered including back diffusion into the reducing grout as well as retention mechanisms like sorption onto hydrated iron oxide surfaces formed upon oxidation. 

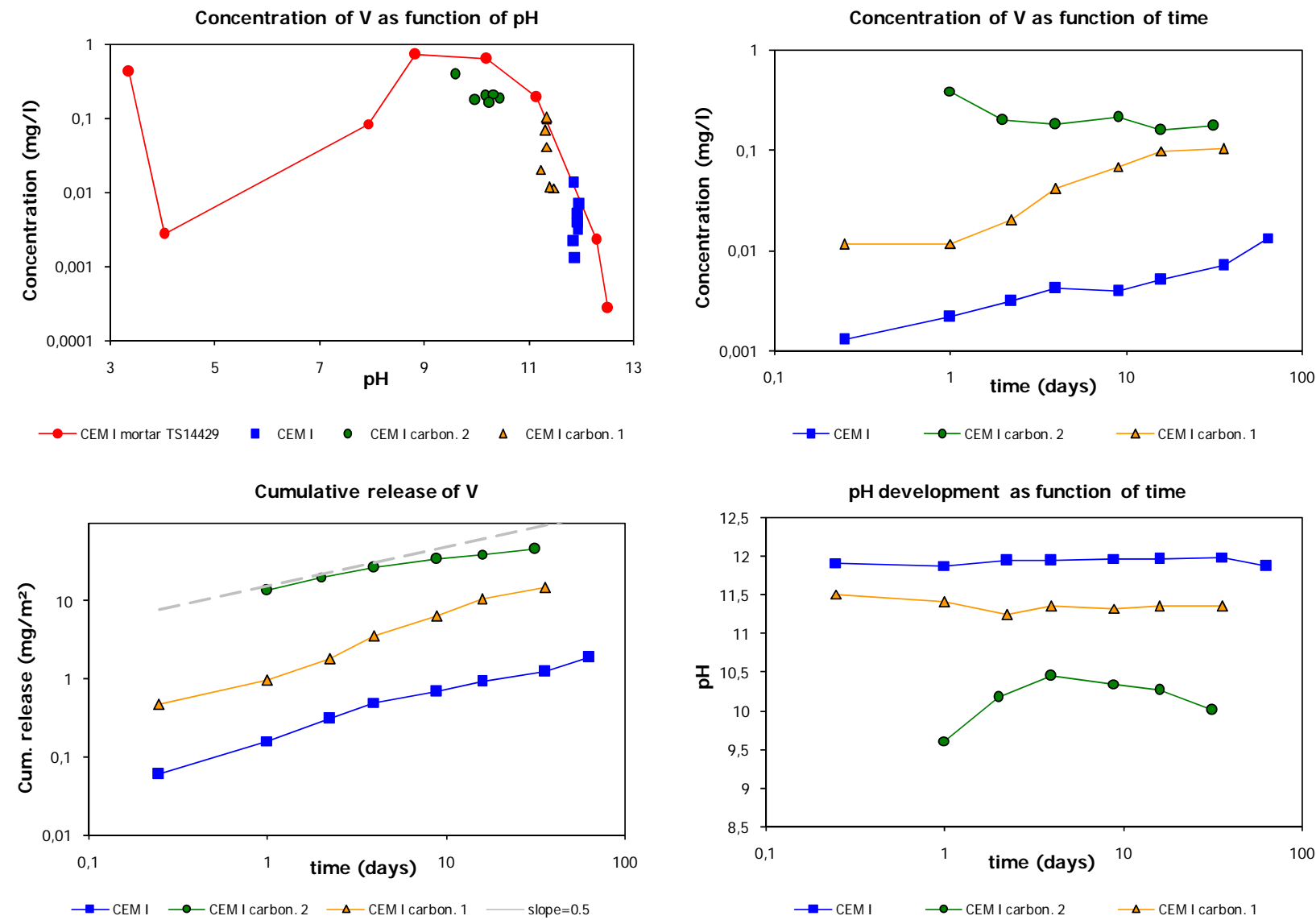

Figure 15. Relationship between monolith leach test data (NEN 7345) and release behavior as a function of $\mathrm{pH}$ (CEN/TS 14429) on crushed mortar for standard test conditions and with different exposure to carbonation $\left(\mathrm{CO}_{2}\right.$ bubbled in the leaching solution). The concentrations of $\mathrm{V}$ measured in the monolith leach test are plotted in the $\mathrm{pH}$ dependence test for comparison.

\subsection{MODELING THE CHEMICAL SPECIATION OF A MATERIAL}

Traditionally cement and concrete chemistry has been focused on the high $\mathrm{pH}$ end of the $\mathrm{pH}$ scale (Lothenbach \& Gruskovnjak 2007; Lothenbach et al. 2008; Lothenbach \& Winnefeld 2006; Lothenbach et al. 2007).

However, when it comes to assessing release from field exposed materials, the surface of alkaline products will be altered due to interaction with $\mathrm{CO}_{2}$ from the atmosphere, which will result in a $\mathrm{pH}$ drop in the surface layer. A pH front will develop and the rate of progress to a large extent will dictate the behavior of individual substances. In addition to $\mathrm{pH}$, the REDOX state of the material plays an important role. Several elements are relatively unaffected by REDOX (provided it does not go very low), but some substances are highly sensitive to this property, such as Tc, Fe, Mn, As, and Cr. Unless sulfide is added to a grout or stabilization mix, the REDOX state is generally not very low $(\mathrm{pH}+$ pe around $8-10$; this property is commonly used in soil science to express REDOX condition (Sumner 2000)). At values of $\mathrm{pH}+$ pe below 6, metal sulfide precipitation occurs. In the following sections, the chemical speciation of the material constituting a reference case (i.e., stabilized waste - concrete - soil) will be addressed. This is important because chemical speciation modeling cannot be performed reliably with too few substances. What can be done in this case is to identify if the 


\section{Demonstration of LeachXSTM/ORCHESTRA Capabilities by Simulating Constituent Release from a Cementitious Waste Form in a Reinforced Concrete Vault}

solubility product of a given substances is exceeded under conditions specified by some other phases considered relevant.

The objective here is to provide a full description of the entire system of major, minor and trace substances with relevant mineral phases, solid solutions and sorption processes controlling release. In subsequent steps, the complexity of the system is increased by adding, in addition to the chemical description (chemical speciation fingerprint - CSF), physical factors and typical exposure conditions while maintaining, as long as technically feasible, verification of model output against experimental data. Although prediction at long time scales is not technically feasible, the complexity in the short term provides sufficient challenge to carry prediction values to really long term scales. This should be done to the extent possible. In some cases, historical analogues can be used where exposure has been far beyond the time scales that are realistically directly assessed. The information source, the type of information and a rough time scale is indicated in Table 1.

Table 1. Source of information, nature of information and relevant time scale covered

\begin{tabular}{|l|l|l|}
\hline \multicolumn{1}{|c|}{ Information Source } & \multicolumn{1}{|c|}{ Information } & \multicolumn{1}{c|}{ Time Scale } \\
\hline Laboratory tests & $\begin{array}{l}\text { Chemical speciation } \\
\text { Mass transfer limitations } \\
\text { Specific interactions } \\
\text { Model parameters }\end{array}$ & Days to weeks \\
\hline Lysimeter and pilot studies & $\begin{array}{l}\text { Effect of field exposure } \\
\text { Atmospheric influences } \\
\text { Hydrological aspects }\end{array}$ & $3-5$ years \\
\hline Full scale operations & $\begin{array}{l}\text { The role of the scale of operation } \\
\text { Monitoring data }\end{array}$ & $\begin{array}{l}10-50 \text { years } \\
\text { Uncertain }\end{array}$ \\
\hline Historic analogues & $\begin{array}{l}\text { Long term processes } \\
\text { Equilibrium condition } \\
\text { Approach of end point }\end{array}$ & \\
\hline
\end{tabular}

\subsection{Materials}

The materials used in modeling are taken from the LeachXS database (for cement mortar, concrete, stabilized waste, simulated grout, and soil) or obtained from CBP partners (Fuhrmann \& Gillow 2009). The data on cement mortars stem from earlier leaching work on cement mortars worldwide (ECRICEM I (van der Sloot et al. 2001) and II (van der Sloot et al. 2008)) and on simulated grout (Garrabrants, Kosson \& DeLapp 2007).

\subsubsection{Cement Mortars and Concrete}

The cement mortars studied cover a wide spectrum of compositions including regular Portland cement (CEM I) and blended cements with fly ash, granulated blast furnace slag, and lime. Appendix A gives the overview of cement types. Based on a comparison between the concrete composition specified by Langton et al. (2009) and the available compositions in the database, cement mortar CEM V/A (HOL12) represents the specified composition rather well. The composition, cement, and mortar properties are given in Table 2, Table 3, and Table 4, respectively. 
Table 2. Composition mortar and concrete CEM VIA (HOL-12)

\begin{tabular}{|lrrr|}
\hline Cement type & Units & $\begin{array}{r}\text { CEM V/A Mortar 32.5 N } \\
\text { (32\% GBFS+20\% FA) }\end{array}$ & $\begin{array}{r}\text { CEM V/A concrete } \\
\text { (32\% GBFS+20\% FA) }\end{array}$ \\
\hline $\mathrm{Si}$ & $\mathrm{mg} / \mathrm{kg}$ & 364507 & 353719 \\
$\mathrm{Al}$ & $\mathrm{mg} / \mathrm{kg}$ & 11530 & 7687 \\
$\mathrm{Fe}$ & $\mathrm{mg} / \mathrm{kg}$ & 4102 & 2735 \\
$\mathrm{Ca}$ & $\mathrm{mg} / \mathrm{kg}$ & 57842 & 38562 \\
$\mathrm{Na}$ & $\mathrm{mg} / \mathrm{kg}$ & 430 & 287 \\
$\mathrm{~K}$ & $\mathrm{mg} / \mathrm{kg}$ & 1716 & 1144 \\
$\mathrm{Mg}$ & $\mathrm{mg} / \mathrm{kg}$ & 7082 & 4722 \\
$\mathrm{~S}$ & $\mathrm{mg} / \mathrm{kg}$ & 2576 & 1717 \\
$\mathrm{Mn}$ & $\mathrm{mg} / \mathrm{kg}$ & 332 & 222 \\
$\mathrm{Ti}$ & $\mathrm{mg} / \mathrm{kg}$ & 822 & 548 \\
$\mathrm{P}$ & $\mathrm{mg} / \mathrm{kg}$ & 194 & 130 \\
$\mathrm{Cl}$ & $\mathrm{mg} / \mathrm{kg}$ & 20 & 13 \\
$\mathrm{LoI}_{\mathrm{CO}}$ as C & $\mathrm{mg} / \mathrm{kg}$ & 0.2 & 0.2 \\
$\mathrm{As} \mathrm{H}_{2} \mathrm{CO}_{3}$ & $\mathrm{mg} / \mathrm{kg}$ & 409 & 273 \\
$\mathrm{Redox} \mathrm{capacity}$ & $\mathrm{mMol} \mathrm{O} / \mathrm{kg}$ & 2046 & 1364 \\
\hline
\end{tabular}

Table 3. Composition mortar and concrete CEM VIA (HOL-12) - trace elements

\begin{tabular}{|lc|}
\hline Cement Type & CEM V/A \\
\hline Chemical Composition & GBFS+20\% FA) \\
$\mathrm{As}$ & $\mathrm{mg} / \mathrm{kg}$ \\
$\mathrm{Be}$ & 46.6 \\
$\mathrm{Cd}$ & 4.32 \\
$\mathrm{Co}$ & 1.91 \\
$\mathrm{Cr}$ & 15.1 \\
$\mathrm{Cu}$ & 114 \\
$\mathrm{Hg}$ & 41.00 \\
$\mathrm{Mn}$ & 0.09 \\
$\mathrm{Ni}$ & 1499 \\
$\mathrm{~Pb}$ & 37.9 \\
$\mathrm{Sb}$ & 169 \\
$\mathrm{Sn}$ & 3.27 \\
$\mathrm{Th}$ & 5.44 \\
$\mathrm{~V}$ & $<1.00$ \\
$\mathrm{Zn}$ & 138 \\
$\mathrm{Ba}$ & 268 \\
$\mathrm{Mo}$ & 425 \\
\hline
\end{tabular}

The calculated mortar composition is: 


$\begin{array}{lrr}\text { Gypsum } & \% & 4.3 \\ \text { Limestone } & \% & 0 \\ \text { Slag } & \% & 24.1 \\ \text { Pozzolan/Fly Ash } & \% & 23.2 \\ \text { Clinker } & \% & 48.4\end{array}$

Table 4. Properties of cement mortar CEM VIA (HOL-12).

\begin{tabular}{|lcc|}
\hline Identification & Units & $\begin{array}{c}\text { CEM V/A 32.5 N } \\
\text { (32\% GBFS+20\% FA) }\end{array}$ \\
\hline Cement & $\mathrm{g}$ & 450 \\
Water & $\mathrm{g}$ & 225 \\
Sand & $\mathrm{g}$ & 1350 \\
W/C & & 0.50 \\
Curing & & $95 \% \mathrm{RH}$ \\
& & \\
Setting time [t1] & $\mathrm{min}$ & 335 \\
Setting time [t2] & $\mathrm{min}$ & 515 \\
Water demand & $\%$ & 30.2 \\
Soundness & $\mathrm{mm}$ & 0.0 \\
& & \\
Mean CS ${ }^{\#}$ [1 day] & $\mathrm{N} / \mathrm{mm}^{2}$ & 3.3 \\
Standard deviation & $\mathrm{N} / \mathrm{mm}^{2}$ & 0.04 \\
Mean CS [2 days] & $\mathrm{N} / \mathrm{mm}^{2}$ & 7.3 \\
Standard deviation & $\mathrm{N} / \mathrm{mm}^{2}$ & 0.28 \\
Mean CS [7 days] & $\mathrm{N} / \mathrm{mm}^{2}$ & 17.1 \\
Standard deviation & $\mathrm{N} / \mathrm{mm}^{2}$ & 0.37 \\
Mean CS [28 days] & $\mathrm{N} / \mathrm{mm}^{2}$ & 34.0 \\
Standard deviation & $\mathrm{N} / \mathrm{mm}^{2}$ & 0.35 \\
& & \\
Specific density & $\mathrm{g} / \mathrm{cm}^{2}$ & 2.80 \\
Blaine & $\mathrm{cm} / \mathrm{g}$ & 3805 \\
\hline CS Compressive & & \\
\hline
\end{tabular}

${ }^{\#} \mathrm{CS}$ is Compressive strength

Table 5 compares the reference concrete (Langton et al. 2009) to the cement mortar HOL-12. It shows reasonable agreement for the composition, which suggests that HOL-12 would be a reasonable representative for the concrete reference case. 
Table 5. Comparison CBP blends with available cement mortars in LeachXS ${ }^{\mathrm{TM}}$ database.

\begin{tabular}{|c|c|c|c|c|c|}
\hline & \multicolumn{2}{|c|}{ Type I/II Ternary Blend } & \multicolumn{2}{|c|}{$\begin{array}{c}\text { Type I/II } \\
\text { Quaternary Blend }\end{array}$} & \multirow[t]{2}{*}{ HOL-12 } \\
\hline & $\mathrm{kg} / \mathrm{m}^{3}$ & $\%$ & $\mathrm{~kg} / \mathrm{m}^{3}$ & $\%$ & \\
\hline Cement & 71.3 & $23 \%$ & 133 & $30 \%$ & $43 \%$ \\
\hline BFS & 163 & $52 \%$ & 178 & $40 \%$ & $32 \%$ \\
\hline FA & 80.1 & $25 \%$ & 103.8 & $23 \%$ & $20 \%$ \\
\hline Lime & & & & & \\
\hline Silica fume & & & 29.7 & $7 \%$ & \\
\hline Gypsum & & & & & $5 \%$ \\
\hline Cementitious & 314.4 & & 444.5 & & 50 \\
\hline Sand & 757 & & 541 & & 750 \\
\hline Sand/Cementitious & & 2.41 & & 1.22 & 3.00 \\
\hline $\mathrm{W} / \mathrm{C}$ & 0.38 & & 0.38 & & 0.5 \\
\hline
\end{tabular}

\subsubsection{Stabilized Waste and Grout}

In the LeachXS database, results are available for hazardous waste, which in terms of chemistry has much in common with waste grouts. In addition, results are available on simulated grouts from studies carried out by Vanderbilt University (Garrabrants, Kosson \& DeLapp 2007).

The compositions of the stabilized waste and simulation grouts are given in Table 6 .

\subsubsection{Soil}

Results for soil can vary widely depending on the nature of the soil, with sandy soil being relatively poor in its retention capabilities, while peat and clay or mixtures of all major types are far more effective in retaining contaminants.

The composition of soil (as availability = maximum in $\mathrm{pH}$ dependence test) is given in Table 7. 
Table 6. Composition of stabilized waste and simulation grouts.

\begin{tabular}{|l|c|c|c|c|c|}
\hline & Simulated grout & Stabilized waste & Reactant & Simulated grout & Stabilized waste \\
\hline Reactant & $\mathrm{mg} / \mathrm{kg}$ & $\mathrm{mg} / \mathrm{kg}$ & & $\mathrm{mg} / \mathrm{kg}$ & $\mathrm{mg} / \mathrm{kg}$ \\
\hline $\mathrm{Ag}$ & 1.6 & not measured & $\mathrm{Mg}$ & 101088 & 3903 \\
\hline $\mathrm{Al}$ & 11794 & 4456 & $\mathrm{Mn}$ & not measured & 175 \\
\hline $\mathrm{As}$ & 1.8 & 0.15 & $\mathrm{Mo}$ & 10.2 & 7.7 \\
\hline $\mathrm{B}$ & not measured & 59 & $\mathrm{Na}$ & 129130 & 25626 \\
\hline $\mathrm{Ba}$ & 108 & 19 & $\mathrm{NH}_{4}^{+}$ & not measured & not measured \\
\hline $\mathrm{Br}$ & not measured & 834 & $\mathrm{Ni}^{+}$ & 21 & 9.3 \\
\hline $\mathrm{Ca}$ & 272000 & 83625 & $\mathrm{NO}_{3^{-}}$ & 363 & not measured \\
\hline $\mathrm{Cd}$ & 1.7 & 178 & $\mathrm{P}$ & 3.2 & 4.7 \\
\hline $\mathrm{Cl}$ & 74 & 53500 & $\mathrm{~Pb}$ & 0.78 & 955 \\
\hline $\mathrm{Cr}$ & 11.2 & 9.7 & $\mathrm{Sb}$ & 0.14 & 4.9 \\
\hline $\mathrm{Cu}$ & 25.8 & 365 & $\mathrm{Se}$ & 26 & 0.46 \\
\hline $\mathrm{F}$ & 40 & 1904 & $\mathrm{Si}$ & 2000 & 3556 \\
\hline $\mathrm{Fe}$ & 11481 & 74 & $\mathrm{SO}_{4}^{-2}$ as S & 4282 & 10656 \\
\hline $\mathrm{H}_{2} \mathrm{CO}_{3}$ & 44000 & 10000 & $\mathrm{Sr}$ & 1436 & 206 \\
\hline $\mathrm{Hg}$ & not measured & not measured & $\mathrm{Th}$ & 50 & not measured \\
\hline $\mathrm{I}$ & 1.04 & not measured & $\mathrm{U}$ & 100 & not measured \\
\hline $\mathrm{K}$ & 5101 & 33815 & $\mathrm{~V}$ & 46 & 0.98 \\
\hline $\mathrm{Li}$ & not measured & 25 & $\mathrm{Zn}$ & 133 & 8015 \\
\hline
\end{tabular}

Table 7. Composition (availability) data for soil

\begin{tabular}{|c|c|c|c|c|c|}
\hline Reactant & $\mathbf{m g} / \mathbf{k g}$ & Reactant & $\mathbf{~ m g} / \mathbf{k g}$ & Reactant & $\mathbf{~ m g / k g}$ \\
\hline $\mathrm{Ag}$ & not measured & $\mathrm{Fe}$ & 2110 & $\mathrm{NO}_{3}{ }^{-}$ & 50 \\
\hline $\mathrm{Al}$ & 635 & $\mathrm{H}_{2} \mathrm{CO}_{3}$ & 10000 & $\mathrm{P}$ & 1934 \\
\hline $\mathrm{As}$ & 17.5 & $\mathrm{Hg}$ & not measured & $\mathrm{Pb}$ & 21 \\
\hline $\mathrm{B}$ & 2.2 & $\mathrm{I}$ & 0.010 & $\mathrm{Sb}$ & 3.5 \\
\hline $\mathrm{Ba}$ & 16.6 & $\mathrm{~K}$ & 54 & $\mathrm{Se}$ & 6.3 \\
\hline $\mathrm{Br}$ & not measured & $\mathrm{Li}$ & 1.2 & $\mathrm{Si}$ & 3040 \\
\hline $\mathrm{Ca}$ & 438 & $\mathrm{Mg}$ & 301.9 & $\mathrm{SO}_{4}^{-2}$ as S & 1083 \\
\hline $\mathrm{Cd}$ & 0.54 & $\mathrm{Mn}$ & 912.0 & $\mathrm{Sr}$ & 2.7 \\
\hline $\mathrm{Cl}$ & 21 & $\mathrm{Mo}$ & 2.4 & $\mathrm{Th}$ & 0.010 \\
\hline $\mathrm{Cr}$ & 3.2 & $\mathrm{Na}$ & 74 & $\mathrm{U}$ & 0.010 \\
\hline $\mathrm{Cu}$ & 4398 & $\mathrm{NH}_{4}^{+}$ & 1.0 & $\mathrm{~V}$ & 0.62 \\
\hline $\mathrm{F}$ & 8.4 & $\mathrm{Ni}$ & 189 & $\mathrm{Zn}$ & 35 \\
\hline
\end{tabular}




\subsection{Geochemical Modeling Approach (Model Parameterization from Laboratory Leaching Test Results)}

Chemical speciation of the eluates obtained from laboratory leaching tests has been calculated with the geochemical reaction/transport model ORCHESTRA (Dijkstra 2007; Meeussen 2003) embedded in the database/expert system LeachXS. Aqueous speciation reactions and selected mineral precipitates were taken from the MINTEQA2 database. Ion adsorption onto organic matter was calculated with the NICA-Donnan model (Kinniburgh et al. 1999), with the generic adsorption reactions as published by Milne et al. (Milne, Kinniburgh \& Tipping 2001; Milne et al. 2003). Adsorption of ions onto iron and aluminum oxides was modeled according to the generalized two layer model of Dzombak and Morel (1990).

The database/expert system LeachXS (www.leachxs.net) was used for data management, e.g., pH dependent leaching data, percolation test data, lysimeter, and field leachate data and for visualization of the calculated and measured results (van der Sloot et al. 2001; van der Sloot et al. 2003; van der Sloot et al. 2007a; van der Sloot et al. 2007b). The coupled LeachXSTM/ORCHESTRA system allows for very quick data retrieval, automatic input generation for modeling, processing of calculated results, and graphical and tabular data presentation.

The input to the model consists of fixed element availabilities, selected possible solubility controlling minerals, active Fe- and Al-oxide sites (where Fe- and Al-oxides are summed and used as input for HFO (Blakemore, Searle \& Daly 1987; Kostka \& Luther III 1994) as described elsewhere (Meima \& Comans 1998)), clay content to quantify clay interaction (NEN 1994), particulate organic matter, and a description of the DOC concentration as a function of $\mathrm{pH}$ (using a polynomial curve fitting procedure). The DOC analysis of the extracts does not represent the reactive part of the dissolved organic matter. Based on experience with similar samples where the quantification among the hydrophilic, fulvic, and humic acid fractions in DOC was quantified, reactive fractions of DOC are defined as a function of $\mathrm{pH}$ (where the lowest proportion of reactive forms at neutral $\mathrm{pH}$ and increases towards both low and high $\mathrm{pH}$ (van Zomeren \& Comans 2007)). A polynomial is fit through the eight data points to represent the reactive DOC at intermediate $\mathrm{pH}$ values. Basically, the speciation of all elements is calculated in a problem definition in the model with one set of parameters. This considerably limits the degrees of freedom in selecting parameters, as improvement of the model for one element may worsen the outcome for other elements. As a starting point for the model calculations, the maximum value as obtained in the $\mathrm{pH}$ dependence leaching test (between $\mathrm{pH} 3$ and 13) was used as the available concentration. It was found that total (leachable) carbonate concentration plays an important role in the model results. This parameter was not measured and was thus estimated based on the total inorganic carbon content. The concentration was adjusted until the major elements (mainly Ca as calcite) showed a reasonably good match with the observed leaching data, as this is the main phase for carbonate in the systems considered. There is a clear need for more data on total (available) carbonate concentrations in waste materials to enhance model predictions.

The mineral phases that were allowed to precipitate were selected after calculation of their respective Saturation Indices (SI) in the original $\mathrm{pH}$ dependence leaching test eluates. Saturation indices were calculated for more than 650 minerals in the thermodynamic database, and a selection of the most likely and relevant phases was made based on the degree of fit over a wide $\mathrm{pH}$ range, the closeness of the SI value to 0 , and expert judgment on the suitability of possible minerals for the waste mixture (e.g., exclusion of high temperature minerals). Generally, minerals were selected if the SI was in the range of -0.2 to 0.2 for more than two $\mathrm{pH}$ data points. When possible, the modeling run combines both $\mathrm{pH}$ dependence test data and percolation test data. The $\mathrm{L} / \mathrm{S}=10$ data from the $\mathrm{pH}$ dependence test were modeled and, in part, fitted by selecting and unselecting mineral phases. The model run included an additional verification run using the same chemical speciation 


\section{Demonstration of LeachXSTM/ORCHESTRA Capabilities by Simulating Constituent Release from a Cementitious Waste Form in a Reinforced Concrete Vault}

fingerprint, but at a lower L/S of 0.3 , to simulate porewater conditions. The outcome of this second embedded run can be compared with the first fraction of the percolation test. The strength of the model prediction does not come as much from the sample modeled, but from the fact that the same chemical speciation fingerprint can be applied to a similar material, which provides a good description within the uncertainties of some of the available modeling parameters. In the modeling of an individual sample, one also has to realize that the mutual interactions in simultaneously modeling 25 or more elements limits the possible choices that can be made, particularly when dealing with sorptive phases where multiple substances compete for the same sites.

\section{Chemical Speciation}

Figure 16, the example model results for cement mortar and grout are compared with the original $\mathrm{pH}$ dependence test data. In all cases, the percolation test data are given for comparison, as the modeling is performed both at $\mathrm{L} / \mathrm{S}=10$ and $\mathrm{L} / \mathrm{S} \sim 0.3$ (all other parameters remaining the same) to assess the validity of the mineral and sorption parameter selection for both a wide $\mathrm{pH}$ range as well as a wide $\mathrm{L} / \mathrm{S}$ range.

The starting point for the modeling are the $\mathrm{L} / \mathrm{S}=10$ leach test data. The optimization of the mineral selection is based on obtaining a prediction that provides an adequate fit between model and actual test results. The low $\mathrm{L} / \mathrm{S}$ modeling (around 0.3) using the first fraction of the percolation test is meant to test whether the same selection of minerals or a slight modification can simultaneously predict the release behavior at low L/S under the assumption that local equilibrium prevails. The L/S of around 0.3 reflects pore water conditions in the column.

Based on the preliminary model run to determine SI values, expert knowledge (including relevant mineral phases formed under ambient conditions) is used to identify a preliminary set of minerals on which to run the model. Based on a criterion of less than $0.1 \%$ of the element present in a given mineral phase, relevant minerals can be selected.

Although some 25 elements are used in the chemical speciation modeling for the cement mortar and the grout, not all elements are presented here (see Appendix B). The information on other elements is available as additional background information to be provided as separate information as part of a CBP database (in development). The input parameters for the modeling are given in

Table 8. These comprise the element availabilities, the mineral selection, the content of clay to the extent relevant, the quantity of reactive Fe- and Al- oxide surfaces, and the reactive part of particulate and dissolved organic matter. The availability is defined as the highest leached amount expressed in $\mathrm{mg} / \mathrm{kg}$ dry matter as obtained in the $\mathrm{pH}$ dependence test. The selection of minerals for the calculation run is wider than the actual minerals found to be of relevance. The latter have been marked with an asterisk. The material properties in terms of element availabilities, Fe- and Al-oxide quantity, clay content, relevant minerals, and reactive particulate (designated as solid humic acid - SHA) and dissolved organic matter (designated as dissolved humic acid - DHA) form a chemical speciation fingerprint (CSF) for the material of interest. This chemical speciation fingerprint is used in subsequent chemical reaction transport modeling as a starting point. It is also a good starting point for any other cement mortar sample or grout sample, since most minerals identified here will be relevant in such unknown samples, while the parameter settings for reactive surfaces may not be too far off.

The multi-element chemical speciation modeling is complex but still proves feasible because run-times are usually within two minutes. In speciation modeling, the outcome of the model result is optimized by iterating changes in the mineral assemblage. A preliminary model run using Saturation Indices is used for guidance in this process. There are multiple interactions taking place, which implies that absolutely wrong choices of a mineral or a sorption property will be manifested as a significant deviation from the actual measurement. As 
the modeling assumes equilibrium, and in the test equilibrium is not fully reached, in some cases a difference between model and measurement cannot be resolved. Such cases can only be recognized by running tests at different contact times. In the work by Dijkstra et al. (2006), this influence of kinetics has been clearly demonstrated. In other cases, the stability constants may not be well defined. This is particularly the case for some less common trace elements like Sb, V, Mo, and a range of radionuclides of interest.

The model prediction shows reasonable agreement between leaching test result and prediction based on the selected minerals. In Appendix C, the model results for a selection of other cement mortars are given using the same mineral selection. The variables in this modeling are the availabilities, which are sample specific as they are derived from the maximum release as expressed in $\mathrm{mg} / \mathrm{kg}$ obtained by multiplying the concentration in $\mathrm{mg} / \mathrm{l}$ as observed in the $\mathrm{pH}$ dependence test (usually the lowest $\mathrm{pH}$ measured) by the liquid to solid ratio (L/S) in $\mathrm{l} / \mathrm{kg}$. In the case of reducing mortars, the REDOX state of the material has been adjusted by modifying the $\mathrm{pH}+$ pe value.

\section{Table 8. Input specification for $\mathrm{pH}$ dependence test modeling of a cement mortar.}

Prediction case Speciation session

Material

Solved fraction DOC

Sum of $\mathrm{pH}$ and pe

L/S

Clay

HFO

SHA

DOC/DHA data

Reactant concentrations

$\begin{array}{cc}\text { Reactant } & \text { mg/kg } \\ \mathrm{Ag}+ & \text { not measured } \\ \mathrm{Al}^{+3} & 2.332 \mathrm{E}+03 \\ \mathrm{H}_{3} \mathrm{AsO}_{4} & 5.060 \mathrm{E}-01 \\ \mathrm{H}_{3} \mathrm{BO}_{3} & 1.221 \mathrm{E}+01 \\ \mathrm{Ba}^{+2} & 1.372 \mathrm{E}+01 \\ \mathrm{Br}^{-} & \text {not measured } \\ \mathrm{Ca}^{+2} & 4.698 \mathrm{E}+04\end{array}$

Polynomial coefficients DOC

$\begin{array}{ll}\text { C0 } & -7.699 \mathrm{E}+00 \\ \text { C1 } & -6.893 \mathrm{E}-16 \\ \text { C2 } & 0.000 \mathrm{E}+00 \\ \text { C3 } & 0.000 \mathrm{E}+00 \\ \text { C4 } & 0.000 \mathrm{E}+00 \\ \text { C5 } & 0.000 \mathrm{E}+00\end{array}$

$$
\text { [DOC] }(\mathrm{kg} / \mathrm{l}) \quad \text { DHA fraction [DHA] }(\mathrm{kg} / \mathrm{l})
$$

1.000E-07

0.20

2.000E-08

Selected Minerals
AA_2CaO_Al2O3_8H2O[s]
AA_2CaO_Al2O3_SiO2_8H2O[s]
AA_2CaO_Fe2O3_8H2O[s]
AA_2CaO_Fe2O3_SiO2_8H2O[s]
AA_3CaO_Al2O3_6H2O[s]
AA_3CaO_Al2O3_CaCO3_11H2O[s]
AA_3CaO_Al2O3_CaSO4_12H2O[s]
AA_3CaO_Fe2O3_6H2O[s] 
Table 8. Continued

$\begin{array}{ccl}\text { Reactant concentrations (continued) } & \text { Selected Minerals (continued) } \\ \mathrm{Cd}^{+2} & 2.414 \mathrm{E}-01 & \text { AA_Al[OH]3[am] } \\ \mathrm{Cl}- & 5.000 \mathrm{E}+01 & \text { AA_Anhydrite } \\ \mathrm{CrO}_{4}{ }^{-2} & 3.055 \mathrm{E}+00 & \text { AA_Brucite } \\ \mathrm{Cu}^{+2} & 2.432 \mathrm{E}+00 & \text { AA_Calcite } \\ \mathrm{F}- & 5.000 \mathrm{E}+01 & \text { AA_CaO_Al2O3_10H2O[s] } \\ \mathrm{Fe}^{+3} & 2.130 \mathrm{E}+02 & \text { AA_Fe[OH]3[microcr] } \\ \mathrm{H}_{2} \mathrm{CO}_{3} & 1.500 \mathrm{E}+04 & \text { AA_Gibbsite } \\ \mathrm{Hg}^{+2} & \text { not measured } & \text { AA_Gypsum } \\ \mathrm{I}- & \text { not measured } & \text { AA_Jennite } \\ \mathrm{K}^{+} & 1.407 \mathrm{E}+03 & \text { AA_Magnesite } \\ \mathrm{Li}^{+} & 6.934 \mathrm{E}+00 & \text { AA_Portlandite } \\ \mathrm{Mg}^{+2} & 4.758 \mathrm{E}+03 & \text { AA_Syngenite } \\ \mathrm{Mn}^{+2} & 2.083 \mathrm{E}+02 & \text { AA_Tobermorite-I } \\ \mathrm{MoO}_{4}^{-2} & 2.939 \mathrm{E}-01 & \text { AA_Tobermorite-II } \\ \mathrm{Na}^{+} & 3.714 \mathrm{E}+02 & \text { Analbite } \\ \mathrm{NH}_{4}{ }^{+} & \text {not measured } & \text { Ca2Cd[PO4]2 } \\ \mathrm{Ni}^{+2} & 3.452 \mathrm{E}+00 & \text { Cd[OH]2[C] } \\ \mathrm{NO}_{3}- & \text { not measured } & \text { Cr[OH]3[A] } \\ \mathrm{PO}_{4}^{-3} & 1.807 \mathrm{E}+00 & \text { Fe_Vanadate } \\ \mathrm{Reactant}^{-2} & \text { mg/kg } & \text { AA_2CaO_Al2O3_8H2O[s] } \\ \mathrm{Pb}^{+2} & 7.106 \mathrm{E}+00 & \text { Magnesite } \\ \mathrm{SO}_{4}^{-2} & 2.000 \mathrm{E}+03 & \text { Manganite } \\ \mathrm{Sb}^{-2} \mathrm{OH}_{6}- & 6.537 \mathrm{E}-02 & \text { Ni[OH]2[s] } \\ \mathrm{SeO}_{4}^{-2} & 2.025 \mathrm{E}-01 & \text { Pb[OH]2[C] } \\ \mathrm{H}_{4} \mathrm{SiO}_{4} & 1.718 \mathrm{E}+03 & \text { Pb2V2O7 } \\ \mathrm{Sr}^{+2} & 5.173 \mathrm{E}+01 & \text { Pb3[VO4]2 } \\ \mathrm{Th}^{+4} & \text { not measured } & \text { PbCrO4 } \\ \mathrm{UO}_{2}{ }^{+} & \text {not measured } & \text { PbMoO4[c] } \\ \mathrm{VO}_{2}{ }^{+} & 1.143 \mathrm{E}+00 & \text { Rhodochrosite } \\ \mathrm{Zn}^{+2} & 3.532 \mathrm{E}+01 & \text { Strontianite } \\ & & \text { Tenorite } \\ & & \text { Willemite } \\ & & \\ & & \end{array}$



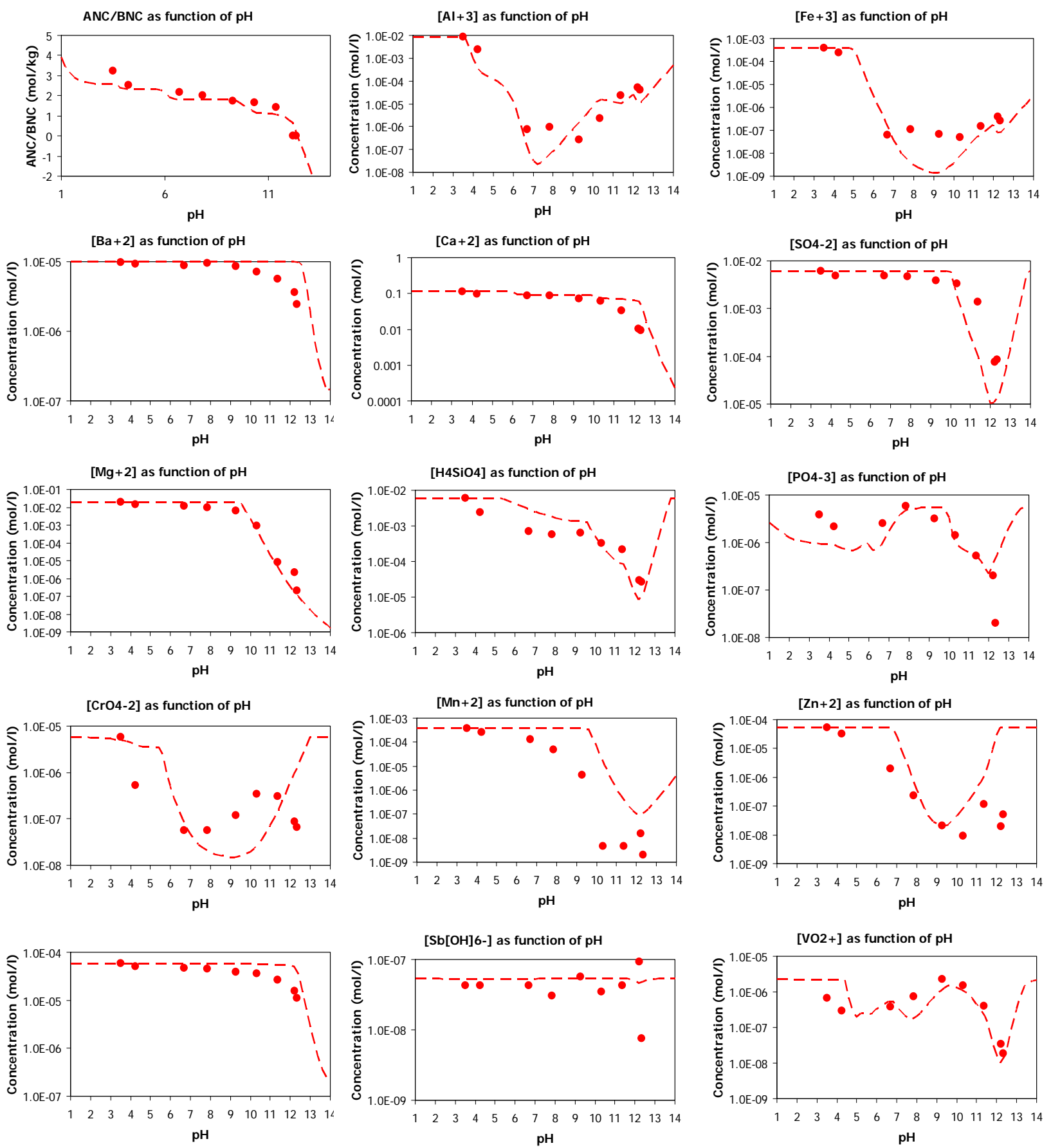

Figure 16. Speciation modeling of cement mortar CEM VIA (HOL-12). Red dots are the measured concentrations in the $\mathrm{pH}$ dependence test and the dotted line is the predicted dissolved concentration form the multi-element multiphase model run. 
In Table 9, the input parameters for a similar calculation to that case of cement mortar are given for a simulated grout. In Figure 17 the model output is given. Many of the same phases that have been used for the modeling of the cement mortars are of importance for modeling the grout. This is consistent with the earlier observation that concrete, stabilized waste, and grout have many similarities in their release as a function of $\mathrm{pH}$. From the more commonly applied percolation tests, tank leach tests, or lysimeter studies this type of conclusion cannot be made. The $\mathrm{pH}$ dependence test in particular is the tool to address the chemical speciation issue underlying release in dynamically controlled systems. The agreement between model prediction and measurement is generally acceptable; however, sulfate is predicted to be predominant in ettringite, whereas the measurements do not point in that direction. This has been observed before in stabilized waste, where sulfate is rather high in comparison with mortars. This needs to be evaluated further.

The next example will help show the modeling capabilities of LeachXSTM/ORCHESTRA. I and Ag were present in the mix. $\mathrm{U}$ and Th are modeled assuming they are present. In future cases, an actual composition is necessary to make better predictions.

In Figure 18, the partitioning of phases (minerals and sorption) is given for Ag, I, U, Th, and Sr. Only in the case of Ag, Sr, and I can the measurements can be compared with the prediction. In the case of I, there is a phase missing because the measurements point at a low dissolved concentration at low $\mathrm{pH}$, while that is not captured in the modeling. This will require some further checking into possible mineral phases.

Adding new substances and minerals is not a problem in LeachXSTM/ORCHESTRA. The sorption parameters worked out by Dijkstra (2010) can be implemented and used in later rounds of modeling. 
Table 9. Input specification for $\mathrm{pH}$ dependence test modeling of a simulated grout.

\begin{tabular}{|c|c|c|c|c|c|c|}
\hline \multirow{2}{*}{$\begin{array}{l}\text { Prediction case } \\
\text { Speciation session }\end{array}$} & \multicolumn{2}{|c|}{ US_AMD-tank55 Si } & \multicolumn{4}{|c|}{ DOC/DHA data } \\
\hline & \multicolumn{2}{|c|}{ US_AMD-tank3 } & pH & [DOC] (kg/l) & DHA fraction & [DHA] (kg/l) \\
\hline \multirow[t]{2}{*}{ Material } & \multirow{2}{*}{\multicolumn{2}{|c|}{ AMD_SR2 $(P, 1,1)$}} & 1.00 & $1.000 \mathrm{E}-04$ & 0.80 & 8.000E-05 \\
\hline & & & 3.20 & $1.000 \mathrm{E}-04$ & 0.32 & $3.200 \mathrm{E}-05$ \\
\hline Solved fraction DOC & \multicolumn{2}{|l|}{0.2} & 3.41 & $1.000 \mathrm{E}-04$ & 0.31 & 3.100E-05 \\
\hline Sum of pH and pe & \multicolumn{2}{|l|}{11.00} & 3.63 & $1.000 \mathrm{E}-04$ & 0.30 & 3.000E-05 \\
\hline L/S & \multicolumn{2}{|c|}{10.0000 l/kg } & 3.81 & $1.000 \mathrm{E}-04$ & 0.25 & 2.500E-05 \\
\hline Clay & \multicolumn{2}{|c|}{$0.000 \mathrm{E}+00 \mathbf{~ k g} / \mathbf{k g}$} & 4.29 & $1.000 \mathrm{E}-04$ & 0.20 & $2.000 \mathrm{E}-05$ \\
\hline HFO & \multicolumn{2}{|c|}{$5.000 \mathrm{E}-03$ kg/kg } & 5.67 & $1.000 \mathrm{E}-04$ & 0.12 & $1.200 \mathrm{E}-05$ \\
\hline \multirow[t]{2}{*}{ SHA } & \multirow{2}{*}{\multicolumn{2}{|c|}{$1.500 \mathrm{E}-03 \mathrm{~kg} / \mathbf{k g}$}} & 8.20 & $1.000 \mathrm{E}-04$ & 0.10 & 1.000E-05 \\
\hline & & & 8.76 & $1.000 \mathrm{E}-04$ & 0.10 & $1.000 \mathrm{E}-05$ \\
\hline \multicolumn{3}{|l|}{ Polynomial coeficients } & 9.70 & $1.000 \mathrm{E}-04$ & 0.15 & $1.500 \mathrm{E}-05$ \\
\hline Co & \multicolumn{2}{|l|}{$-4.075 E+00$} & 10.79 & $1.000 \mathrm{E}-04$ & 0.22 & 2.200E-05 \\
\hline C1 & \multicolumn{2}{|l|}{ 5.828E-02 } & 12.11 & $1.000 \mathrm{E}-04$ & 0.30 & 3.000E-05 \\
\hline $\mathrm{C} 2$ & \multicolumn{2}{|l|}{$-9.081 E-02$} & 14.00 & $1.000 \mathrm{E}-04$ & 0.40 & 4.000E-05 \\
\hline C3 & \multicolumn{2}{|l|}{ 1.200E-02 } & & & & \\
\hline C4 & \multicolumn{2}{|l|}{$-4.234 \mathrm{E}-04$} & & & & \\
\hline C5 & \multicolumn{2}{|l|}{$0.000 \mathrm{E}+00$} & & & & \\
\hline \multicolumn{7}{|c|}{ Reactant concentrations } \\
\hline Reactant & mg/kg & Reactant & $\mathrm{mg} / \mathrm{kg}$ & Reactant & mg/kg & \\
\hline $\mathrm{Ag}^{+}$ & $1.568 \mathrm{E}-01$ & $\mathrm{H}_{3} \mathrm{AsO}_{4}$ & $2.909 \mathrm{E}+02$ & $\mathrm{Ni}^{+2}$ & $1.004 \mathrm{E}+01$ & \\
\hline $\mathrm{Al}^{+3}$ & $6.899 \mathrm{E}+03$ & $\mathrm{H}_{3} \mathrm{BO}_{3}$ & not measured & $\mathrm{NO}_{3}^{-}$ & not measured & \\
\hline $\mathrm{Ba}^{+2}$ & $5.919 \mathrm{E}+01$ & $\mathrm{H}_{4} \mathrm{SiO}_{4}$ & $1.481 \mathrm{E}+03$ & $\mathrm{~Pb}^{+2}$ & $6.272 \mathrm{E}+02$ & \\
\hline $\mathrm{Br}^{-}$ & not measured & $\mathrm{Hg}^{+2}$ & $1.000 \mathrm{E}+00$ & $\mathrm{PO}_{4}^{-3}$ & not measured & \\
\hline $\mathrm{Ca}^{+2}$ & $4.508 \mathrm{E}+04$ & $\mathrm{I}^{-}$ & $7.434 \mathrm{E}+00$ & $\mathrm{Sb}[\mathrm{OH}]^{6-}$ & $1.167 \mathrm{E}+02$ & \\
\hline $\mathrm{Cd}^{+2}$ & $1.300 \mathrm{E}+03$ & $\mathrm{~K}^{+}$ & $1.467 \mathrm{E}+03$ & $\mathrm{SeO}_{4}^{-2}$ & $1.108 \mathrm{E}+03$ & \\
\hline $\mathrm{Cl}^{-}$ & $1.108 \mathrm{E}+02$ & $\mathrm{Li}^{+}$ & not measured & $\mathrm{SO}_{4}^{-2}$ & $2.390 \mathrm{E}+03$ & \\
\hline $\mathrm{CrO}_{4}^{-2}$ & $1.778 \mathrm{E}+01$ & $\mathrm{Mg}^{+2}$ & $1.238 \mathrm{E}+04$ & $\mathrm{Sr}^{+2}$ & $2.213 \mathrm{E}+02$ & \\
\hline $\mathrm{Cu}^{+2}$ & $4.934 \mathrm{E}+00$ & $\mathrm{Mn}^{+2}$ & $6.806 \mathrm{E}+03$ & $\mathrm{Th}^{+4}$ & $1.000 \mathrm{E}+00$ & \\
\hline $\mathrm{F}^{-}$ & $5.000 \mathrm{E}+01$ & $\mathrm{MoO}_{4}{ }^{-2}$ & not measured & $\mathrm{UO}_{2}^{+}$ & $1.000 \mathrm{E}+00$ & \\
\hline $\mathrm{Fe}^{+3}$ & $2.007 \mathrm{E}+03$ & $\mathrm{Na}^{+}$ & $1.210 \mathrm{E}+04$ & $\mathrm{VO}_{2}^{+}$ & $7.735 \mathrm{E}+01$ & \\
\hline $\mathrm{H}_{2} \mathrm{CO}_{3}$ & $1.000 \mathrm{E}+04$ & $\mathrm{NH}_{4}^{+}$ & not measured & $\mathrm{Zn}^{+2}$ & $5.648 \mathrm{E}+02$ & \\
\hline Selected Minerals & & & & & & \\
\hline AA_3CaO_Al2O3_6H2 & $2 \mathrm{O}[\mathrm{s}]$ & $\mathrm{Cd}[\mathrm{OH}] 2[\mathrm{C}]$ & & $\mathrm{Pb} 3[\mathrm{VO} 4] 2$ & & \\
\hline AA_Brucite & & $\mathrm{Cd} 4[\mathrm{OH}] 6 \mathrm{~S}$ & & $\mathrm{PbMoO} 4[\mathrm{c}]$ & & \\
\hline AA_Calcite & & CdSiO3 & & $\mathrm{PbSeO} 4$ & & \\
\hline AA_Fe[OH]3[am] & & Cerrusite & & Plattnerite & & \\
\hline AA_Magnesite & & Corkite & & Pyrolusite & & \\
\hline AA_Portlandite & & $\mathrm{Cr}[\mathrm{OH}] 3[\mathrm{C}]$ & & Rhodochrosite & & \\
\hline $\mathrm{Al} 4[\mathrm{OH}] 10 \mathrm{SO} 4$ & & $\mathrm{Cu}[\mathrm{OH}] 2[\mathrm{~s}]$ & & Schoepite & & \\
\hline Atacamite & & $\mathrm{Cu} 3[\mathrm{AsO} 4] 2$ & 2:6H2O & $\mathrm{SrSeO} 4$ & & \\
\hline beta-TCP & & FeAsO4:2H2 & & Strontianite & & \\
\hline Birnessite & & Fluorite & & Thorianite & & \\
\hline Bixbyite & & Hinsdalite[2] & & Uranophane & & \\
\hline Boehmite & & Iodyrite & & Willemite & & \\
\hline Bunsenite & & Langite & & Zincite & & \\
\hline $\mathrm{Ca} 2 \mathrm{~V} 2 \mathrm{O} 7$ & & Manganite & & $\mathrm{Zn}[\mathrm{OH}] 2[\mathrm{E}]$ & & \\
\hline Ca3[AsO4]2:6H2O & & $\mathrm{Pb}[\mathrm{OH}] 2[\mathrm{C}]$ & & $\mathrm{ZnO}$ [Active] & & \\
\hline Carnotite & & Pb2O3 & & & & \\
\hline
\end{tabular}



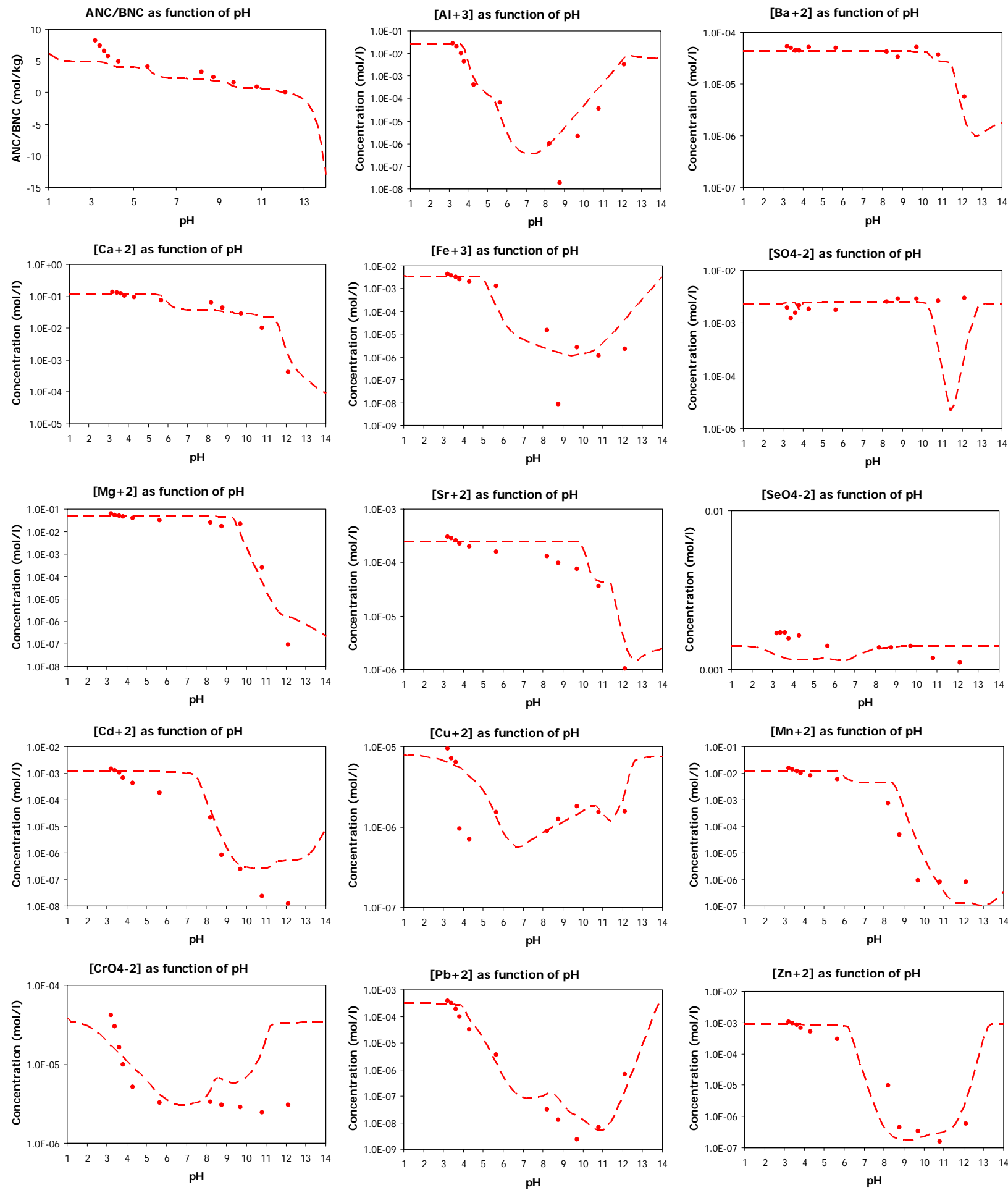

Figure 17. Model prediction of $\mathrm{pH}$ dependent leaching behavior of a simulated grout. Red dots are the measured concentrations in the $\mathrm{pH}$ dependence test and the dotted line is the predicted dissolved concentration form the multi-element multiphase model run. 

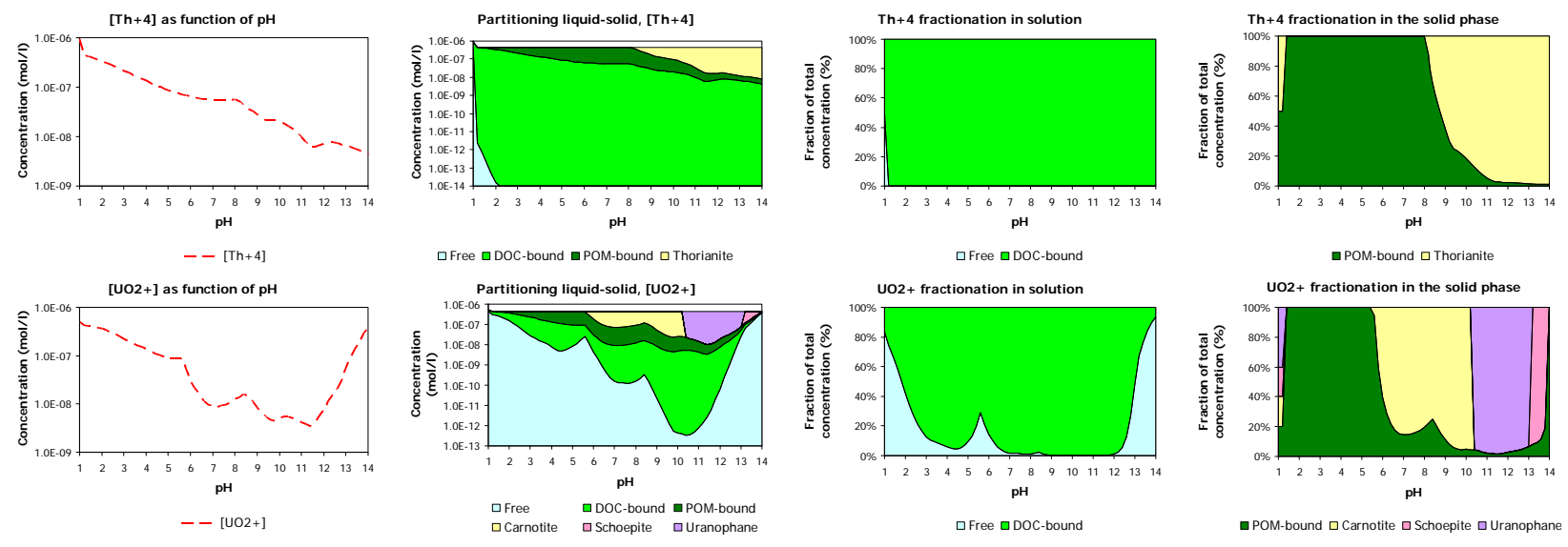

POM-bound $\square$ Thorianite
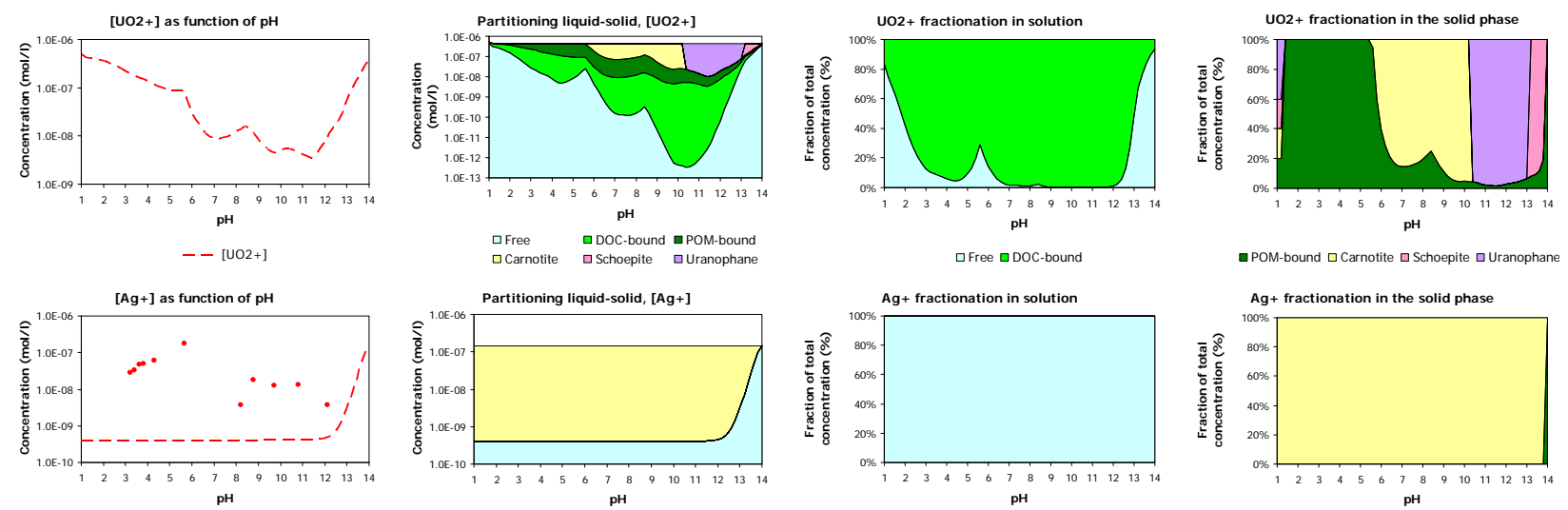

- Academic grout mix - - $[\mathrm{Ag}+]$

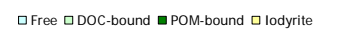

$\square$ Free $\square$ DOC-bound

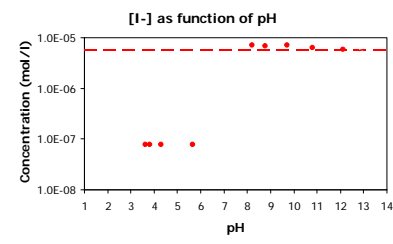

Partitioning liquid-solid, [1-]
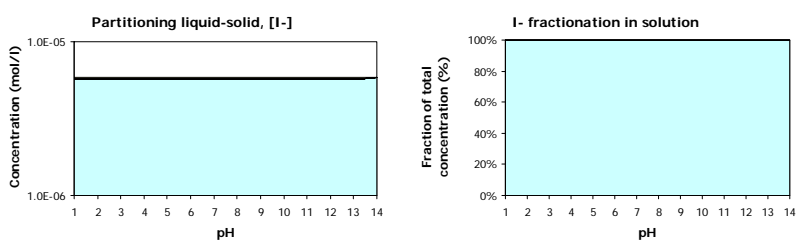

a POM-bound 口। lodyrite

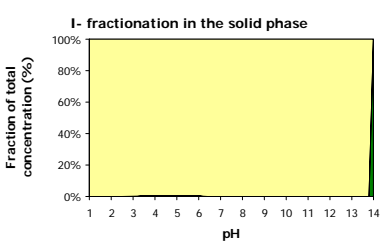

a POM-bound alodyrite

[Sr+2] as function of $\mathrm{pH}$
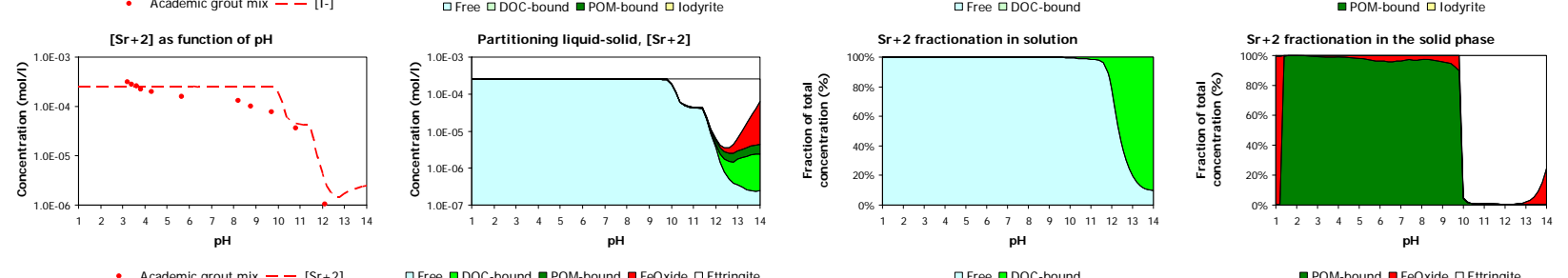

$\square$ Free $\square$ DOC-bound $\square$ POM-bound $\square$ FeOxide $\square$ Ettringite

aFree $\square$ DOC-bound

a POM-bound $\square$ FeOxide $\square$ Ettringite

Figure 18. Modeled release of $\mathrm{Ag}, \mathrm{I}, \mathrm{Sr}, \mathrm{Th}$, and $\mathrm{U}$ from a simulated grout as a function of $\mathrm{pH}$ and the associated partitioning between mineral and sorptive phases.

\subsection{Percolation Controlled Release}

Table 10 lists the input parameters for a model run for percolation in the case that a grout or stabilized waste is fully degraded upon carbonation and cracking. This is a worst-case scenario from which it can be found the extent to which retention capacity for critical substances prevents their release (Figure 19). For many elements, the release is well represented. However, for $\mathrm{Cr}$ the release is substantially over-predicted, which may be due to possible over-estimation of the release of $\mathrm{Cr}$ as $\mathrm{Cr}$ (III) - DOC mobile complex. Further work would be required to properly capture the $\mathrm{Cr}$ behavior. It is possible to obtain additional information on the partitioning within the column from this run, which provides insight into mineral or sorptive phases controlling the release of substances. If so desired, it is also possible to extract the speciation in solution (all dissolved forms). 
Table 10. Input parameters for percolation modeling of stabilized waste.

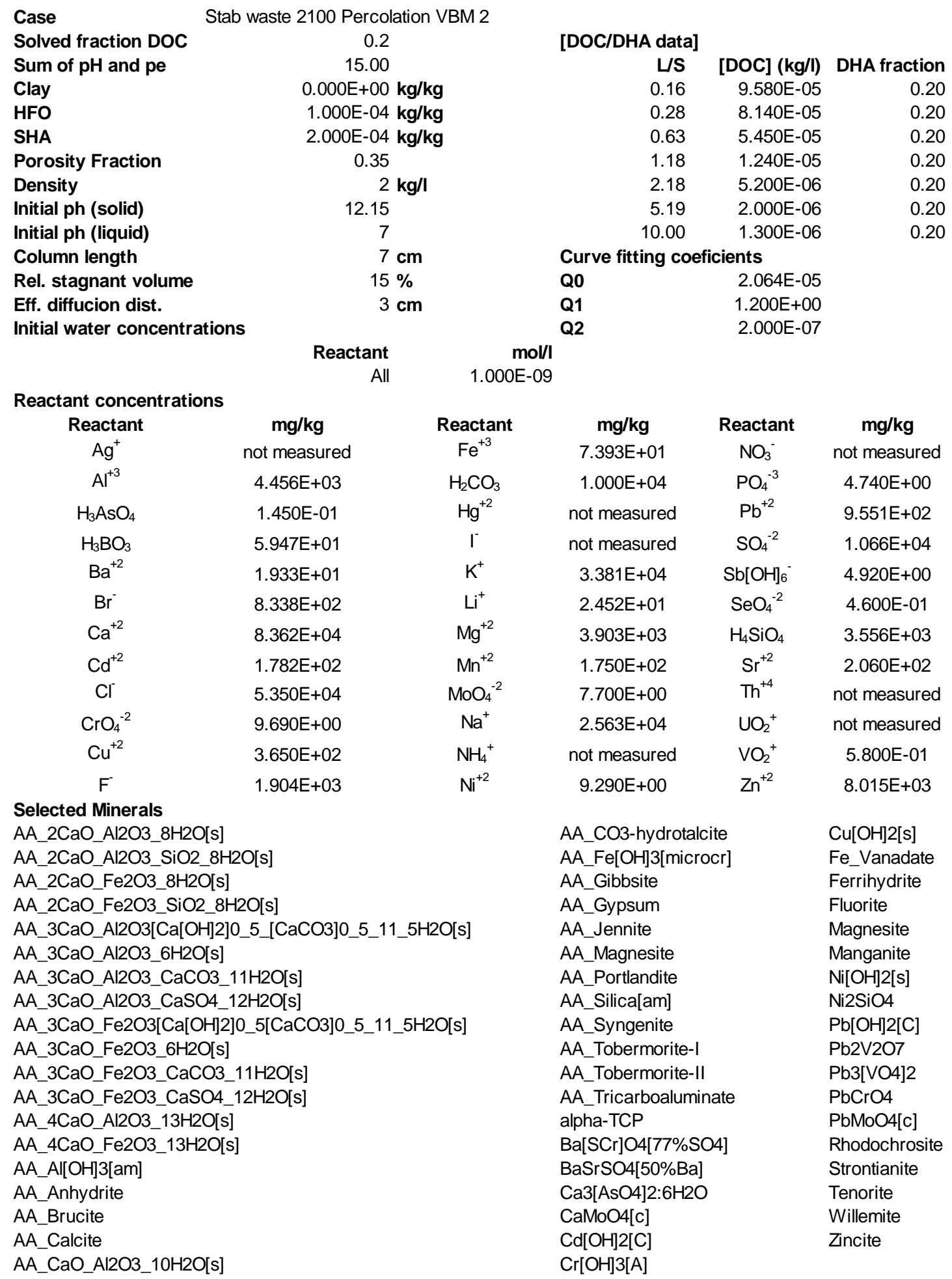


Cumulative release of $\mathrm{Ca}+2$

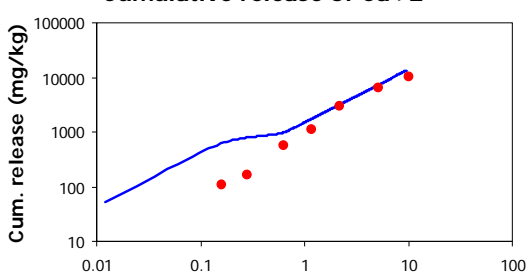

Cumulative release of $\mathrm{Pb}+2$

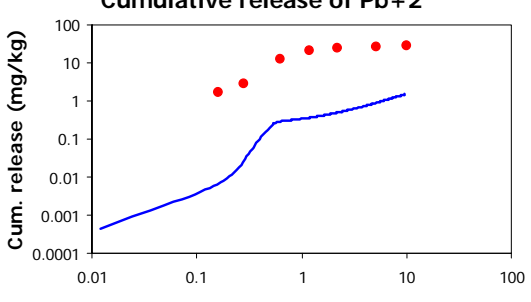

Cumulative release of $\mathrm{Cl}$

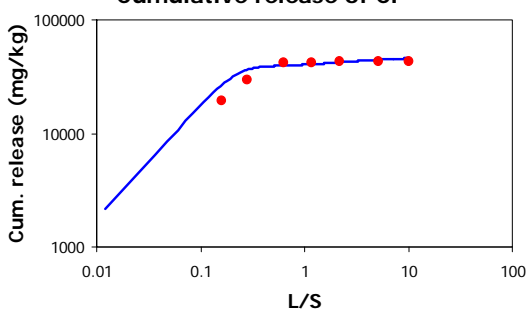

Cumulative release of $\mathrm{Fe}+3$

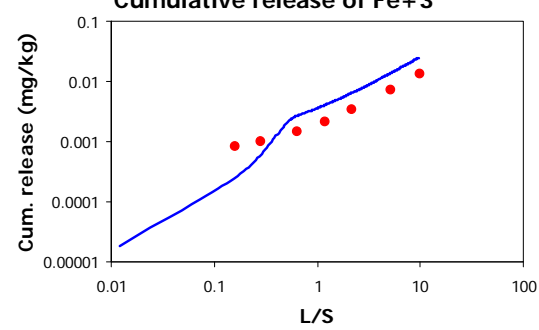

Cumulative release of SO4-2

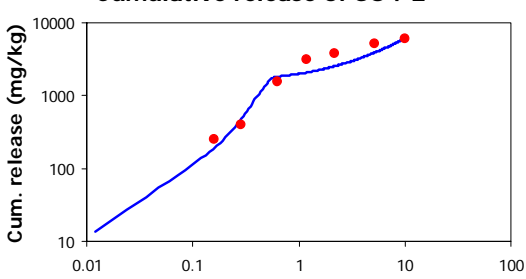

Cumulative release of $\mathrm{Zn}+2$
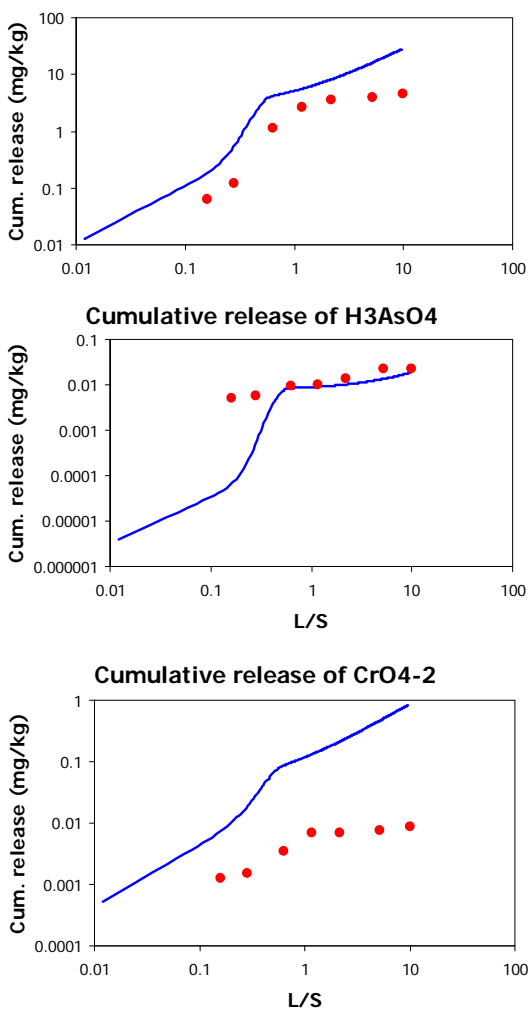

Cumulative release of F-

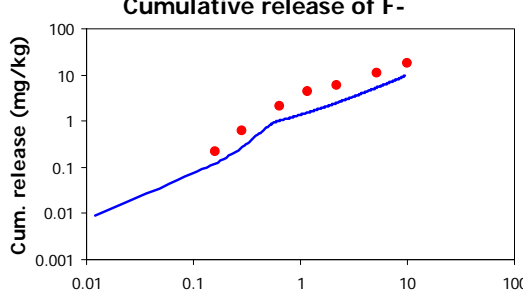

Cumulative release of MoO4-2
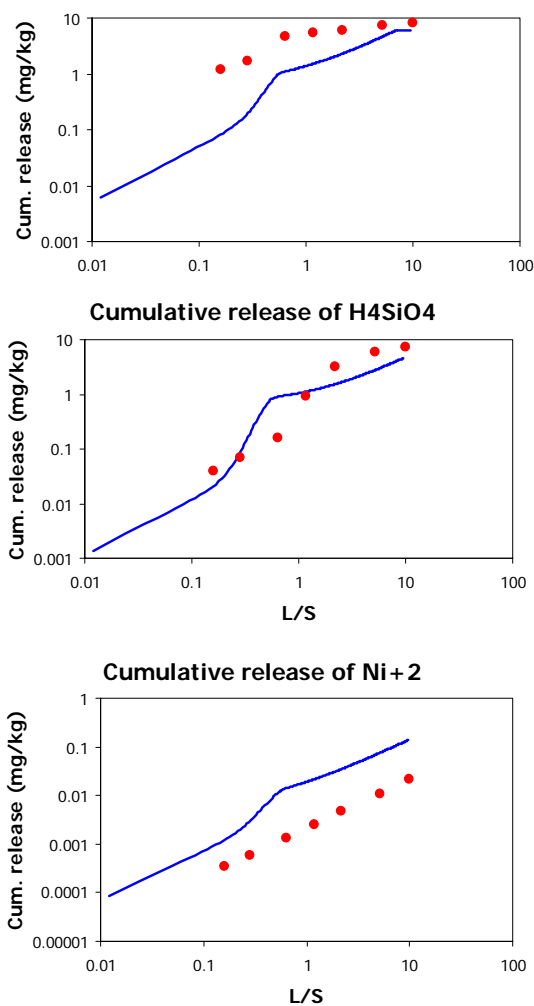

Figure 19. Cumulative release as obtained from full mechanistic modeling in comparison with measurements according to a monolith leach test with leachant renewal.

\subsection{Mass Transfer Limited Release from Monolithic Products}

A separate model within LeachXS ${ }^{\mathrm{TM}}$ /ORCHESTRA allows the modeling of release from a test specimen in a standard laboratory leaching test (NEN 7345, CEN/TS 15863, EPA Draft Method 1315). The basic model allows modifications to be made in the chemistry, renewal times, contact solution, and monolith properties (e.g., dimensions and density). An example of modeling the release as measured in a laboratory leaching test is given in Table 11 (input parameters) and Figure 20 (model results). Apart from the concentration per fraction, it is also possible to extract the concentration as a function of depth into the sample. 
Table 11. Input specification for the monolith leach test on cement mortar NOR2.

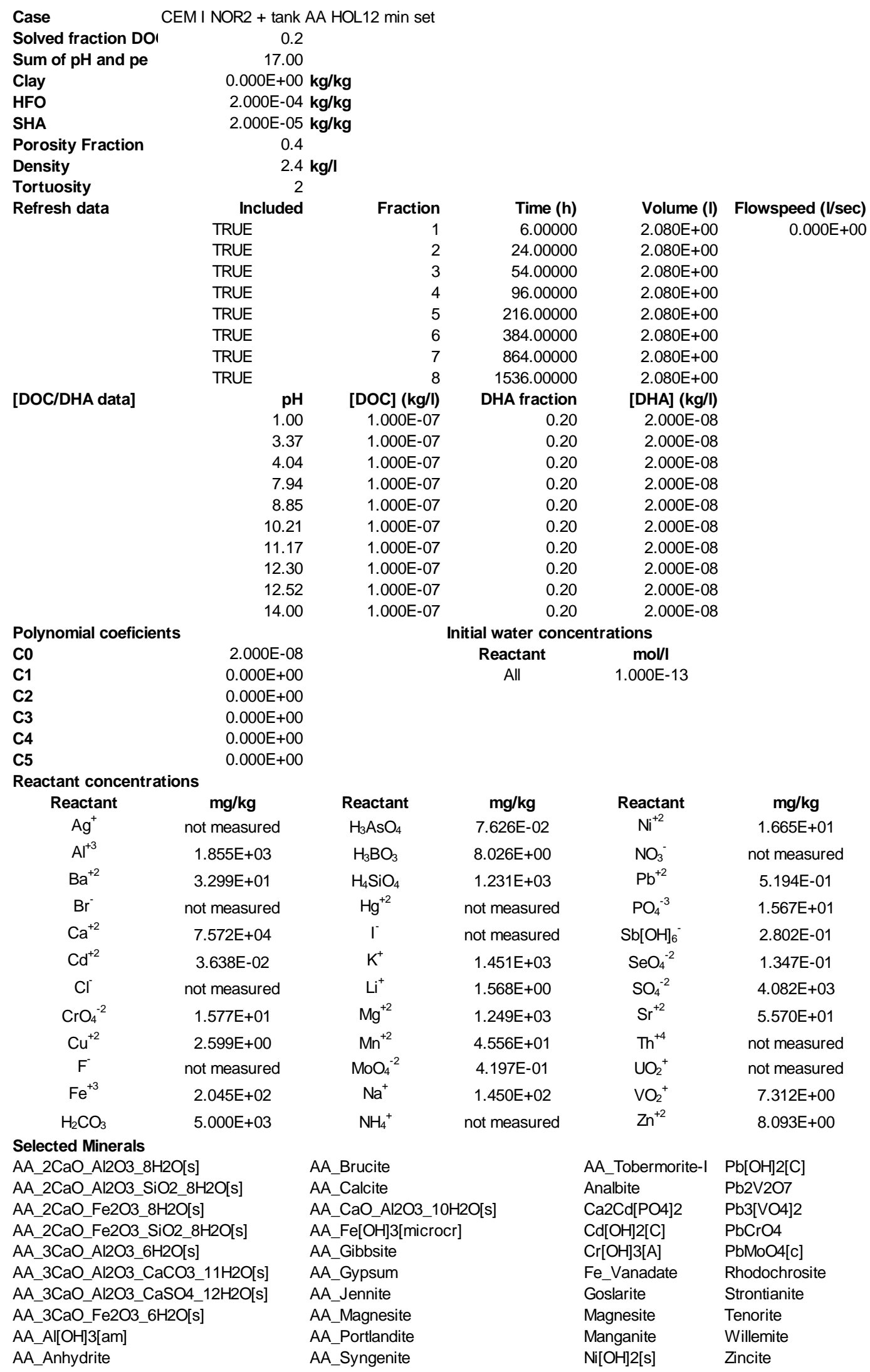



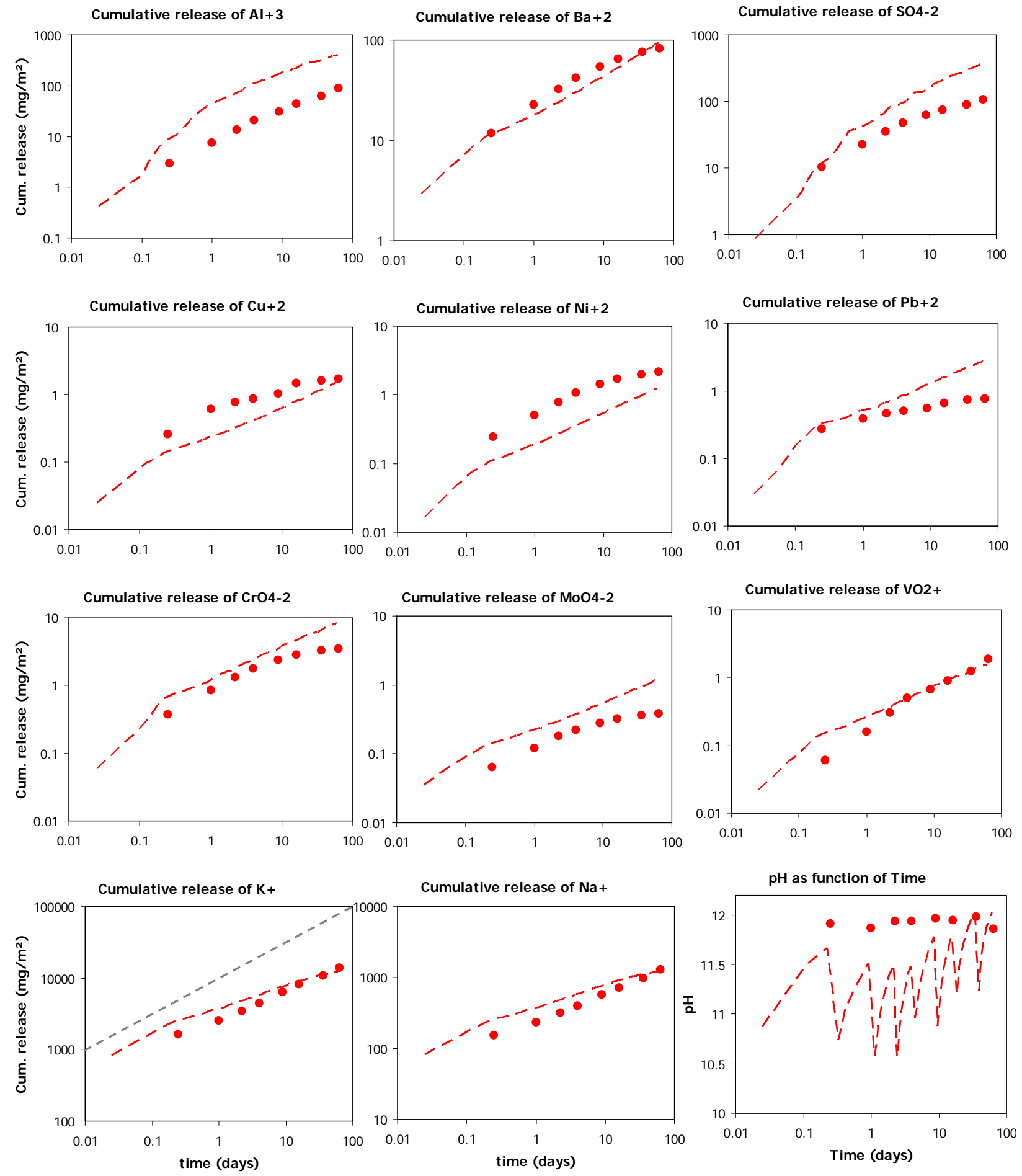

Figure 20. Cumulative release from cement mortar NOR2 measured and modeled using LeachXS ${ }^{\mathrm{TM}} /$ ORCHESTRA. 


\subsection{Alternative Uncertainty Evaluation}

Based on the modeling of the $\mathrm{pH}$ dependence test data obtained for cement mortars as described in Section 4.2, "Solubility Controlled Substance," the results can be merged into a single graph illustrating the variability among different mortars for $\mathrm{Al}, \mathrm{Ca}, \mathrm{SO}_{4}$, and $\mathrm{Si}$ concentrations (Figure 21 and Figure 22). In these figures, data from a column test on crushed concrete and data from porewater measurements are included for comparison. The latter data agree well with the overall concentration patterns as a function of $\mathrm{pH}$. The model results for $\mathrm{Ca}$ and sulfate show fairly narrow uncertainty ranges including almost all measured data. In the $\mathrm{pH}$ range from 7 to 11 , larger uncertainty exists for $\mathrm{Al}$ as model predictions show more discrete forms not reproducing the observations, which leads to the question of why the data points are very continuous and the model predictions deviate in a systematic manner. This may be a kinetic issue or the fact that equilibriumbased model cannot adequately describe some systems not in complete equilibrium. For $\mathrm{Si}$, the $\mathrm{pH}$ range of 5 to 10 has a larger uncertainty with a maximum uncertainty around $\mathrm{pH}$ 8.5. These results can be compared with the data shown in section, where stochastic modeling is applied based on total composition of the mortar (see Section 7.5, "Results"). Because pH and REDOX changes take place in the surface of the exposed materials, it is important to obtain a good description of release behavior over the entire $\mathrm{pH}$ range from 13 to 8 covering a range of conditions from mildly reducing to fully oxidized conditions at relatively low L/S (liquid to solid) or L/A (liquid to area) conditions. 


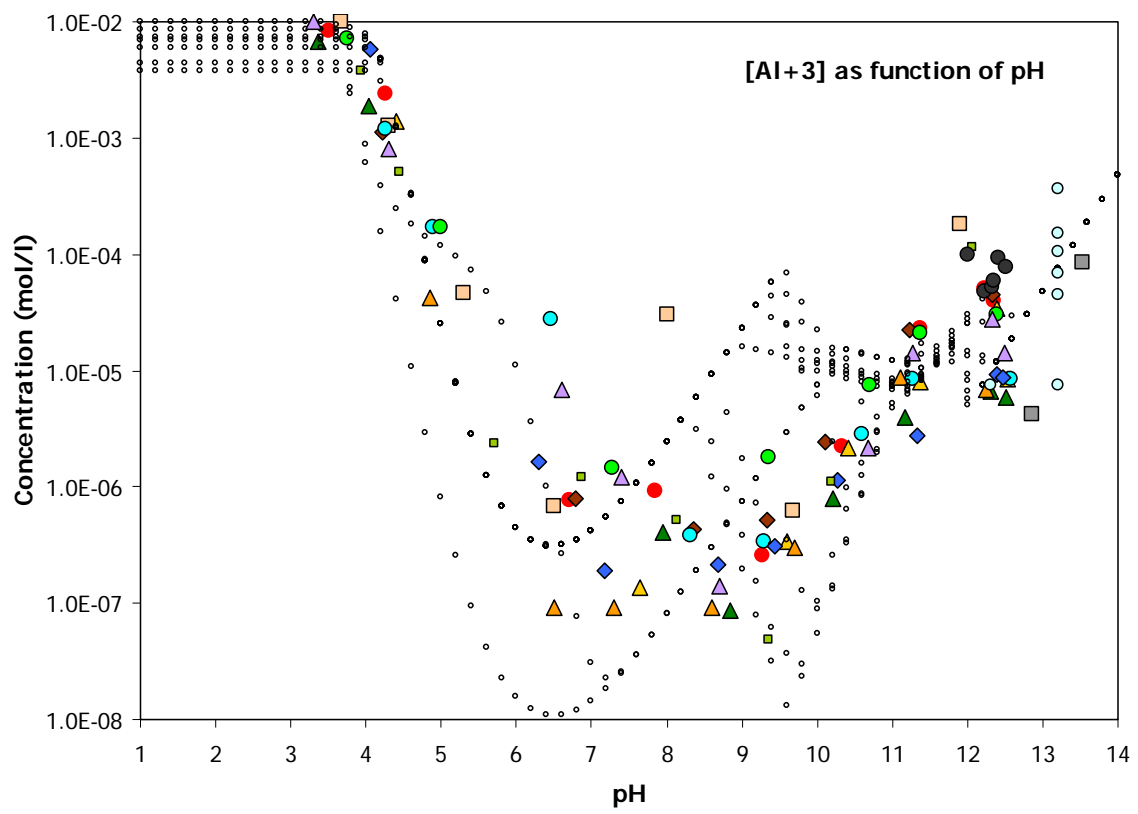

\begin{tabular}{|c|c|c|c|c|}
\hline - CEM V/A $32.5 \mathrm{~N}$ & - [CEM V/A $32.5 \mathrm{~N}$ & $\triangle$ CEM I H5 & $\circ[\mathrm{H}-5]$ & 口CEM III/B \\
\hline • [CEM III/B] & $\diamond$ CEM I H6 & $\cdot[\mathrm{H} 6]$ & O CEM I N2 & $\circ[\mathrm{N} 2]$ \\
\hline$\triangle$ CEM I NOR2 & •[NOR2] & O CEM I D2 & $\circ[\mathrm{D} 2]$ & $\triangle C E M$ I VDZ1 \\
\hline •[VDZ1] & $\diamond$ CEM IIB HOL3 & $\circ[\mathrm{HOL} 3]$ & 口 CEM II HOL2 & $\circ[\mathrm{HOL} 2]$ \\
\hline$\triangle \mathrm{CEM}$ I W2 & - [W2] & - Column L/S0.1-10 & $\square$ Higher pH & o Pore water \\
\hline
\end{tabular}

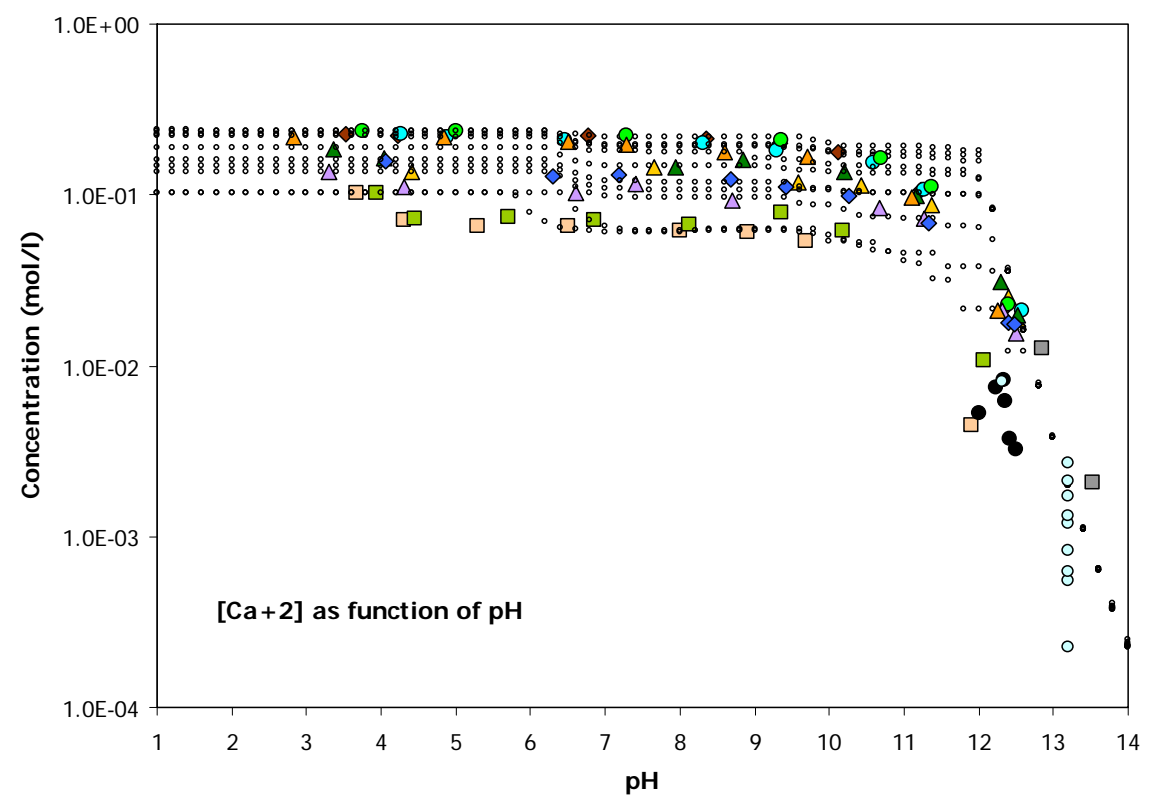

\begin{tabular}{|c|c|c|c|c|}
\hline - CEM V/A $32.5 \mathrm{~N}$ & - [CEM V/A 32.5 & $\triangle$ CEM I H5 & $\circ[\mathrm{H}-5]$ & $\square$ CEM III/B \\
\hline$\cdot[$ CEM III/B] & $\diamond \mathrm{CEM}$ I H6 & $\circ[\mathrm{H} 6]$ & O CEM I N2 & $\circ[\mathrm{N} 2]$ \\
\hline$\triangle$ CEM I NOR2 & $\circ[N O R 2]$ & O CEM I D2 & $\circ[\mathrm{D} 2]$ & $\triangle$ CEM I VDZ1 \\
\hline • [VDZ1] & $\diamond$ CEM IIB HOL3 & $\circ[\mathrm{HOL} 3]$ & $\square$ CEM II HOL2 & $\cdot[\mathrm{HOL} 2]$ \\
\hline$\triangle \mathrm{CEM} I \mathrm{~W} 2$ & $\circ[\mathrm{W} 2]$ & - Column L/S0.1-10 & $\square$ Higher pH & o Pore water \\
\hline
\end{tabular}

Figure 21. Synthesized model outputs of Al and Ca for different cement mortars using the same mineral composition using only sample specific composition. 


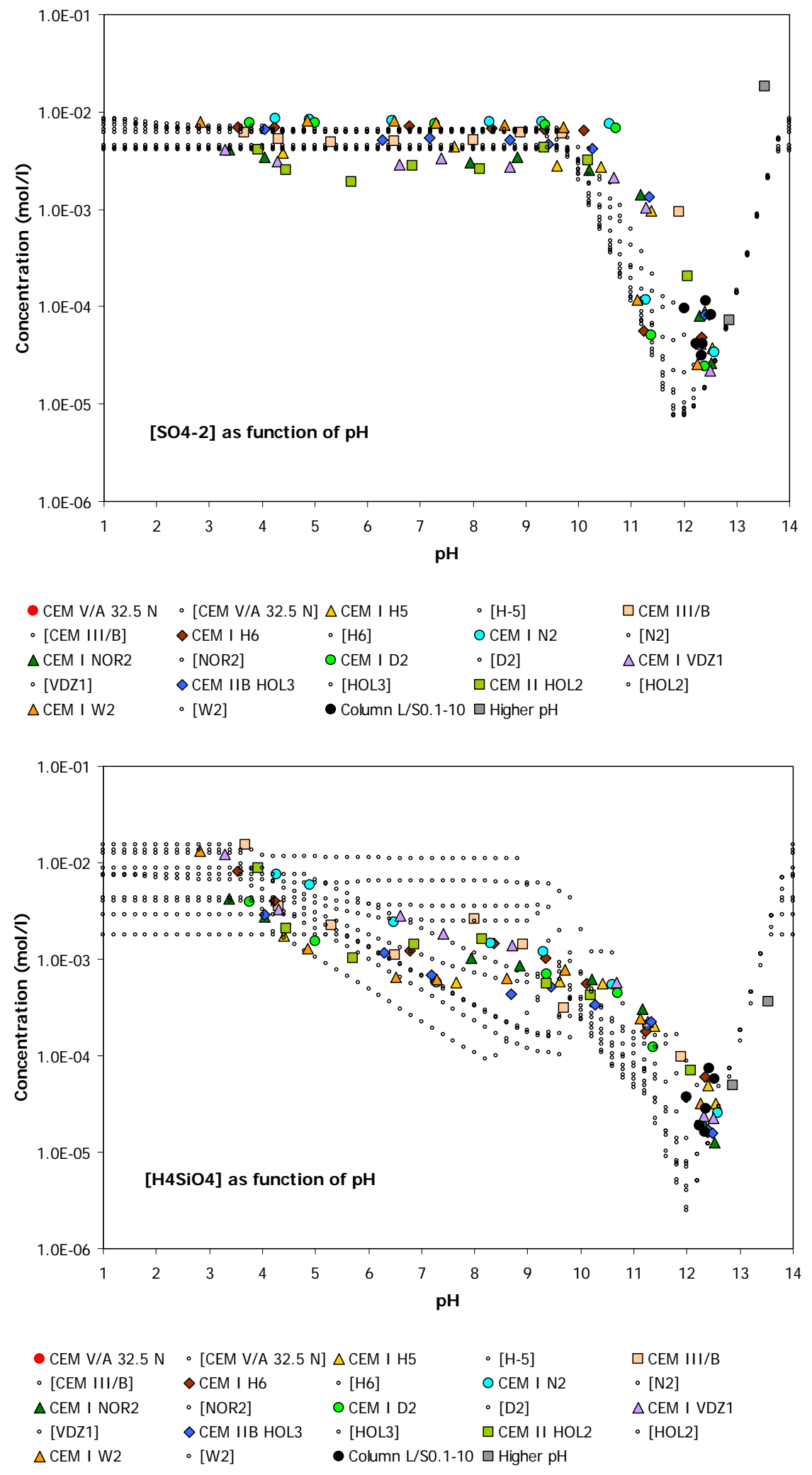

Figure 22. Synthesized model outputs of sulfate and Si for different cement mortars using the same mineral composition using only sample specific composition. 


\subsection{STABILIZED WASTE - CONCRETE BARRIER - SOIL SYSTEM}

For both the Saltstone Vault and Tank Closure reference cases, the same basic scenario applies, which is reflected in Figure 23 and Figure 24, respectively. Two basic models describing the interactions at the waste barrier interface and the release from the waste into the soil are defined. One is based on transport by diffusion only, and the other takes water flow into account. The latter simulates a severely cracked waste form. The simple scenario of a stabilized waste layer in contact with the concrete barrier and the concrete in contact with the natural soil is an over-simplification. Subsequent stages of model development need to also take $\mathrm{CO}_{2}$ and $\mathrm{O}_{2}$ uptake into account. In Section 9.0, "Demonstration of reaction - diffusion calculations," the ORCHESTRA model that is capable of capturing these aspects is discussed. In the next stage of model development, the functionality to deal with $\mathrm{O}_{2}$ and $\mathrm{CO}_{2}$ uptake will be embedded in LeachXS to extend the capability to take the gas interaction into account and facilitate the user friendly input/output handling.

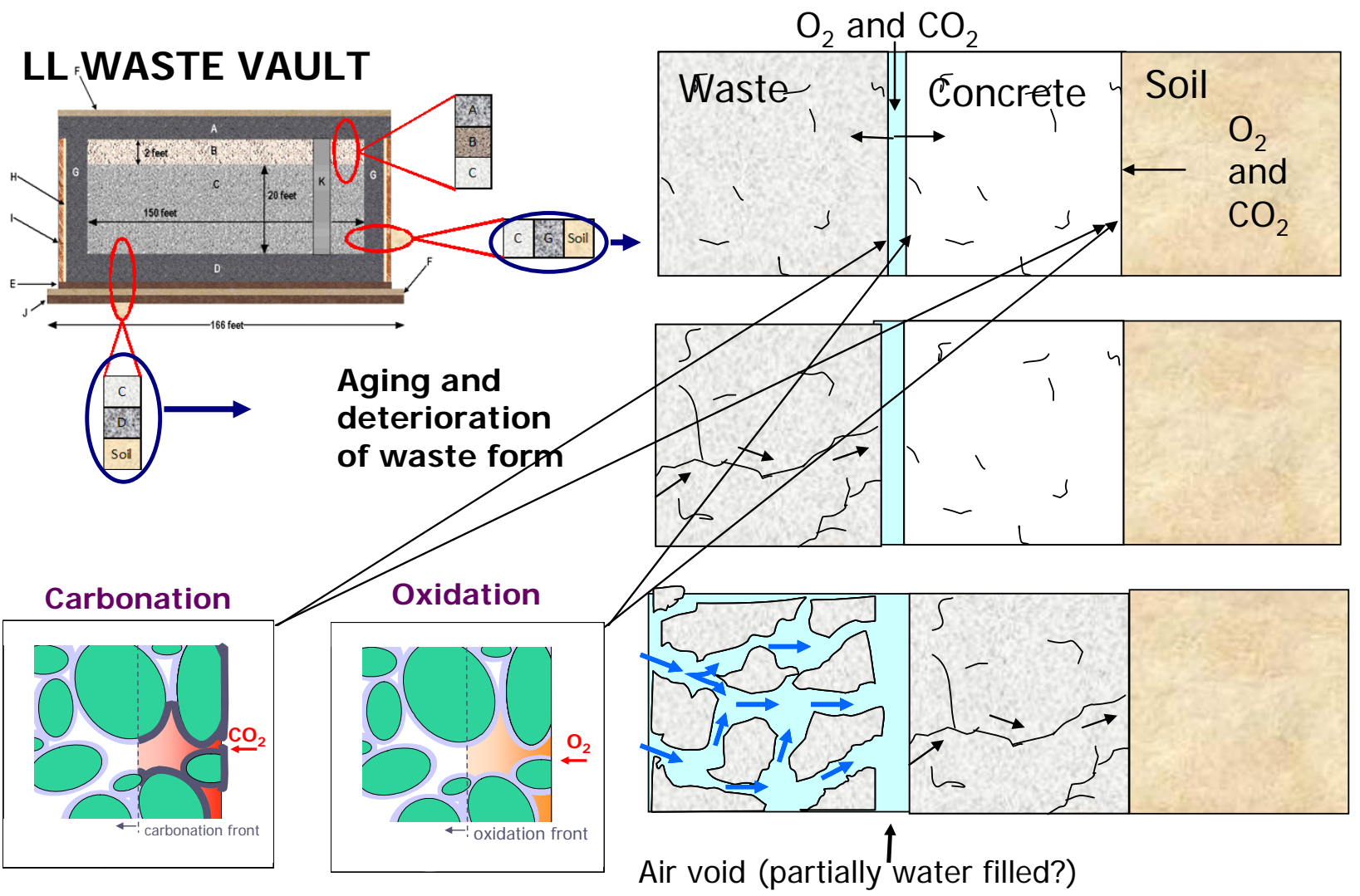

Figure 23. Aging processes and the conceptualization of the processes governing release from the waste vault through the cementitious barrier to the surrounding soil. 
TANK CLOSURE

\section{POSSIBLE CHANGES IN THE TANK CLOSURE SYSTEM AT LONG TERM}
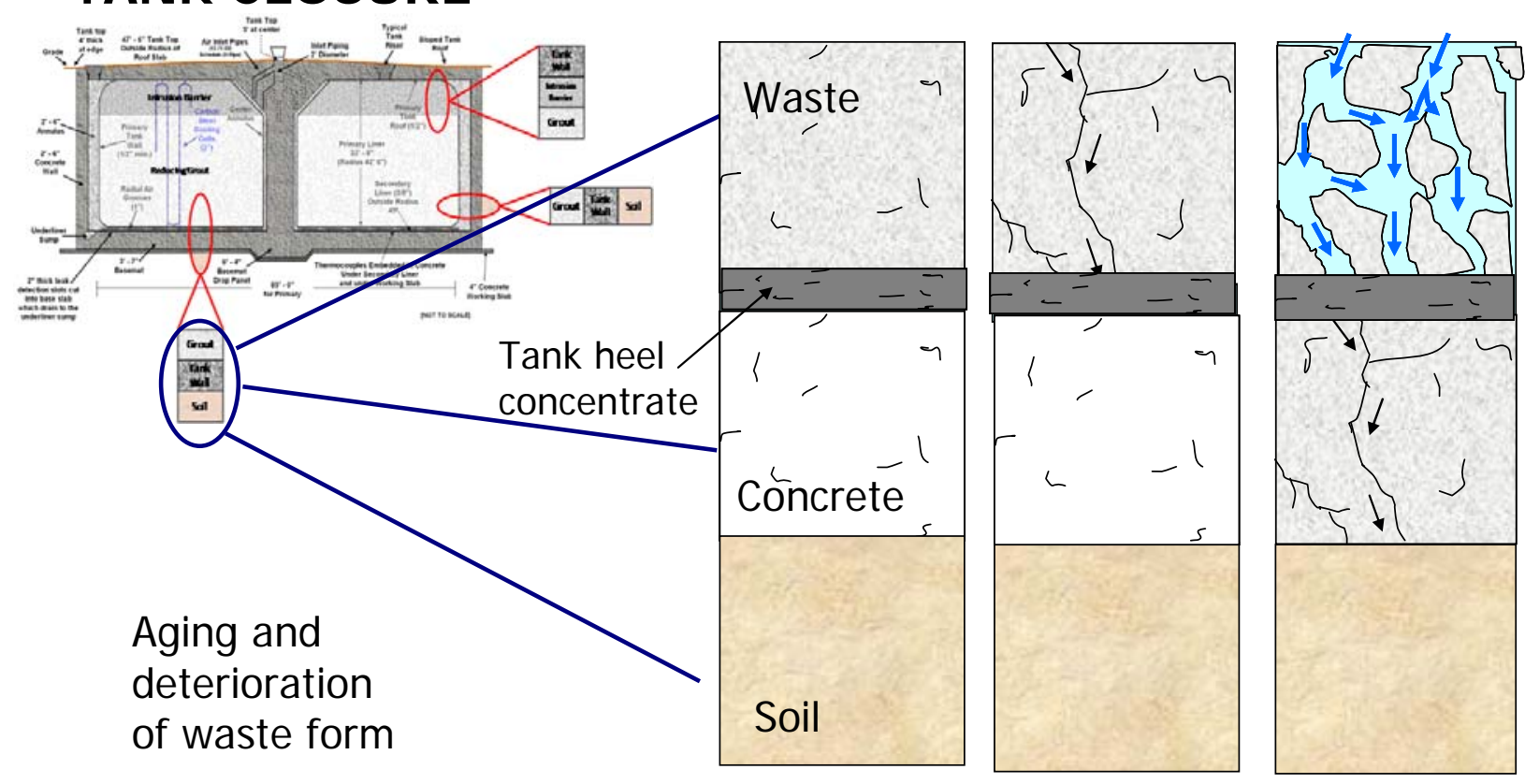

Figure 24. Aging processes and the conceptualization of the processes governing release from grout used in tank closure through the cementitious barrier to the surrounding soil.

The information described in Section 2.0, "Comparison of test data," concerning the materials constituting the connected layers is used as input to the models describing the chemical processes and interactions taking place when grout comes in contact with the cementitious barrier. Similarly, the interaction between the concrete and soil is taken into account.

\subsection{Transport by Diffusion Only}

The transport of mobile constituents in a series of measurements was modeled, which demonstrated that even in the case of a very mobile substance, the concentration in the barrier itself is higher initially. A steady state situation develops relatively quickly where the barrier provides a certain resistance, but the release will progress steadily. This situation is illustrated for K in Figure 25.

The diffusion-based system is defined by the chemical speciation fingerprint (CSF) of the constituting materials, the thickness of the layers, and the physical factors describing the transfer like the tortuosity, porosity, and density. In Table 12, the input parameters for the model run are given. Results of the modeling are given in Figure 26 and Figure 27 for U, Sr, Pb, and Mg. The model includes more than 25 elements with many potentially relevant mineral and sorptive phases; it is remarkable that such a complex system converges. A major improvement in the running time has been achieved, which implies that in a few hours several years of actual release can be successfully modeled. The amount of output that must be processed is considerable, which is a strength of LeachXS ${ }^{\mathrm{TM}}$, as in a matter of seconds all graphical output is generated. The results show the kinds of interactions taking place at the interface between stabilized waste and concrete and between concrete and soil due to large gradients in concentration between major, minor, and trace substances as well as 
gradients in $\mathrm{pH}, \mathrm{REDOX}$, and organic matter. All of these factors play a role in the net release. Often new phases precipitate $(\mathrm{Pb}, \mathrm{Sr})$, which cannot be captured by a $\mathrm{K}_{\mathrm{d}}$-type approach. The role of organic matter even at low concentrations cannot be ignored because it is a major carrier for trace contaminants. Once in a DOC complexed form, the complex can travel faster than the reactive free ion, as the mobility of DOC complexes are somewhat retarded relative to mobile salts due to their bulky structure, but not significantly (e.g., $\mathrm{pD}_{\text {eff }}$ for $\mathrm{Cl}$ is around 9.5, while $\mathrm{pD}_{\text {eff }}$ for $\mathrm{DOC}$ is around 10.5, expressed as the negative log of the effective diffusion coefficient).

This type of modeling is in its infancy, and thus verification is still needed to ensure proper performance. Experimental verification should be pursued wherever possible.

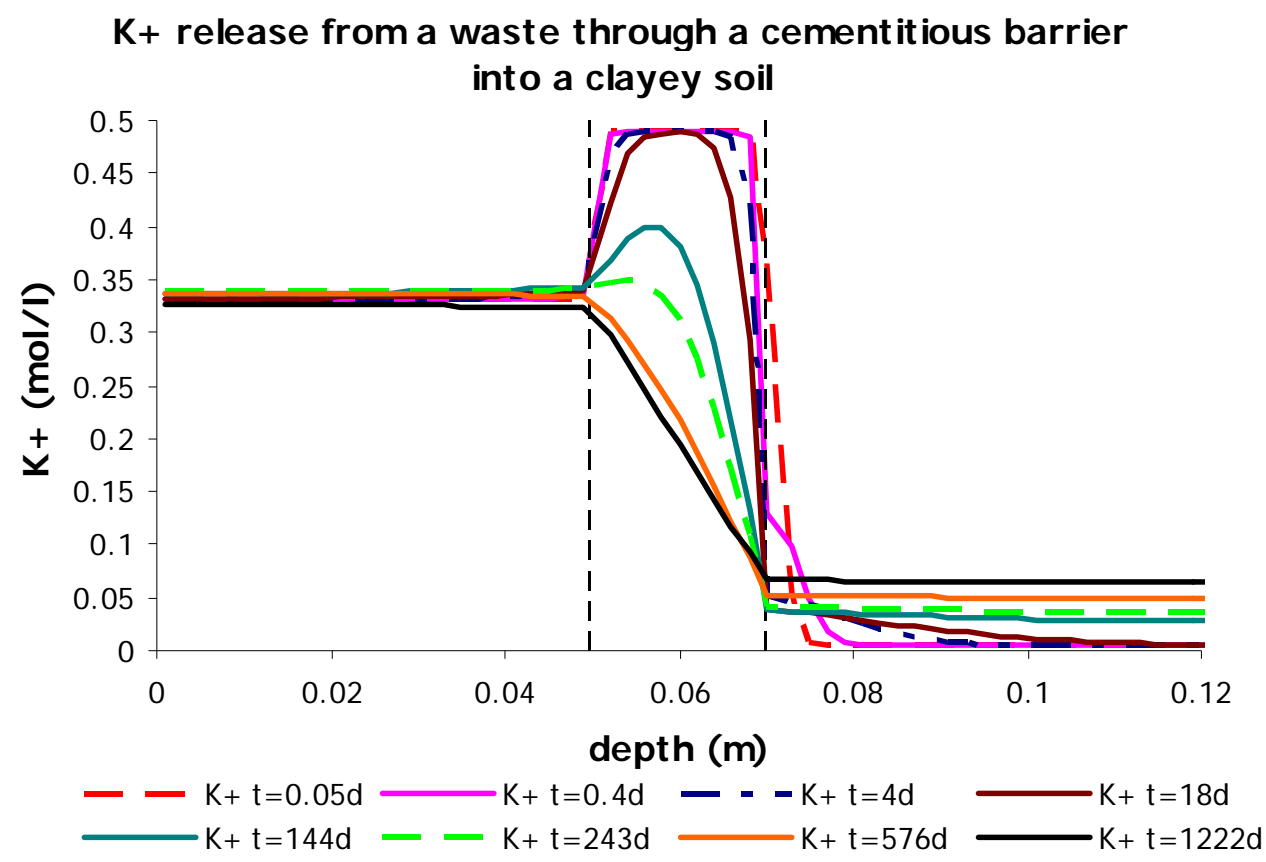

Figure 25. Smoothing out of an initial gradient over a barrier with a specified porosity and tortuosity. 
Table 12. Input parameters for 3-layer diffusion model.

Diffusion Case

Layer overview
Waste SWD - CEM II HOL12 - Soil

\begin{tabular}{lcccc}
\multicolumn{1}{c}{$\mathrm{pH}$} & 10.5 & 11.5 & 6.5 & \\
Material & SWD_SR2 & HOL12 & Zinc_Soil & \\
Length & 10.00 & 3.00 & 10.00 & $\mathrm{~cm}$ \\
Porosity frc & 0.40 & 0.10 & 0.35 & \\
Tortuosity & 3.00 & 10.00 & 2.00 & \\
Density & 1.70 & 2.40 & 1.70 & $\mathrm{~kg} / \mathrm{dm}^{3}$
\end{tabular}

Duration

300 days

Time distribution

Square root

Selected Minerals
[UO2]3[PO4]2

$\mathrm{Ba}[\mathrm{SCr}] \mathrm{O} 4[96 \% \mathrm{SO} 4]^{*}$
Bixbyite*
Bunsenite
Carnotite*
Ca2Cd[PO4]2
Ca2V2O7
Ca2Zn3[PO4]3OH
Ca4Cd[PO4]3OH*
CaZincate
Cd[OH]2[C]
Cd4[OH]6SO4*
Cerrusite*
Cr[OH]3[C]
Cu[OH]2[s]
Cu3[AsO4]2:6H2O*
CuCO3[s]
Dioptase
Fe_Vanadate
FeAsO4:2H2O
Fluorite*
Hydromagnesite

AA_2CaO_Al2O3_8H2O[s]

AA_2CaO_Al2O3_SiO2_8H2O[s] *

AA_2CaO_Fe2O3_8H2O[s]

AA_2CaO_Fe2O3_SiO2_8H2O[s]

AA_3CaO_Al2O3_6H2O[s]

AA_3CaO_Fe2O3_6H2O[s]

AA_Al[OH]3[am] *

AA_Brucite*

AA_Calcite*

AA_CaO_Al2O3_10H2O[s]*

AA_Fe[OH]3[am]*

AA_Gypsum*

AA_Jennite

AA_Magnesite*

AA_Portlandite

AA_Tobermorite-I

Albite[low]*

Analbite

B_UO2[OH]2

$\mathrm{BaSrSO} 4[50 \% \mathrm{Ba}]$

* Minerals identified as relevant beyond a $0.1 \%$ contribution.

$\begin{array}{ll}\text { Illite[2] } & \text { Strontianite } \\ \text { Jarosite-H } & \text { Tenorite } \\ \text { Kaolinite* } & \text { Th[OH]4[s] } \\ \text { Laumontite } & \text { ThF4:2.5H2O } \\ \text { Manganite } & \text { Thorianite } \\ \text { Ni[OH]2[s]* } & \text { Tyuyamunite } \\ \text { Ni2SiO4* } & \text { UO3[C] } \\ \text { NiCO3[s] } & \text { Uraninite } \\ \text { Otavite } & \text { Uranophane } \\ \text { Pb[OH]2[C]* } & \text { Willemite* } \\ \text { Pb2O3 } & \text { Zincite* } \\ \text { Pb4[OH]6SO4 } & \\ \text { PbCrO4 } & \\ \text { PbSeO4 } & \\ \text { Pb2V2O7* } & \\ \text { Pb3[VO4]2* } & \\ \text { PbMoO4[c]* } & \\ \text { Rhodochrosite } & \\ \text { Rutherfordine } & \\ \text { Sb[OH]3[s] } & \\ \text { Schoepite } & \end{array}$




\section{Table 12 Continued}

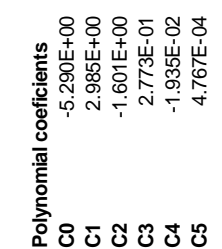

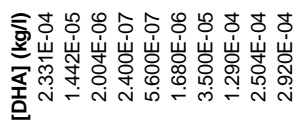

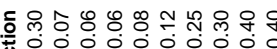

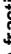

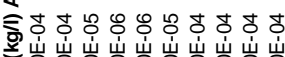

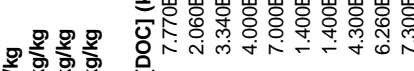

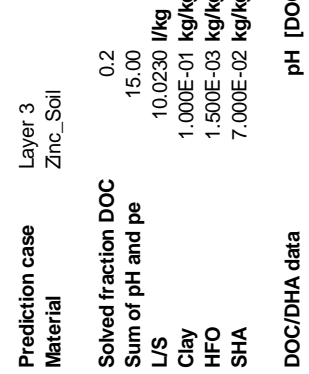

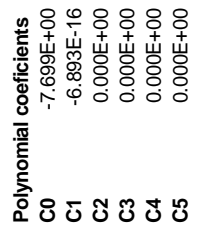

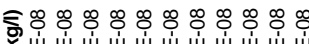

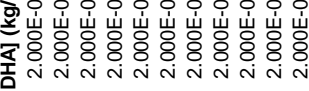

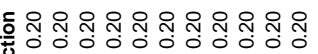

远

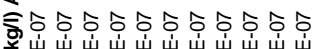

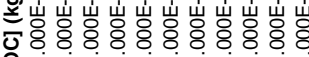

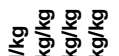

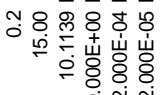

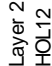

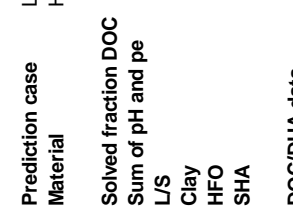

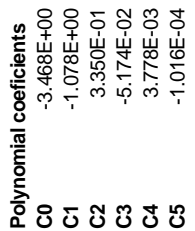

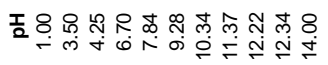

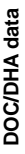

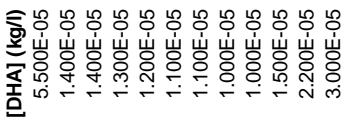

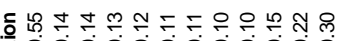

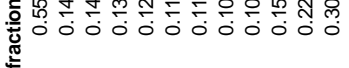

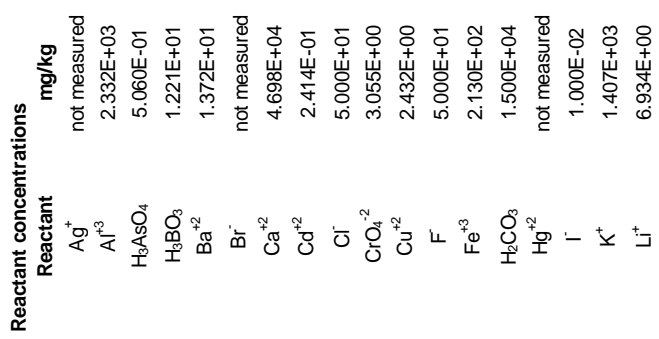

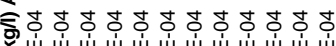

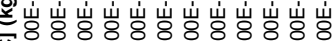

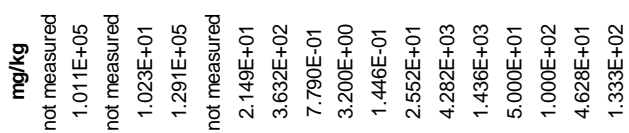

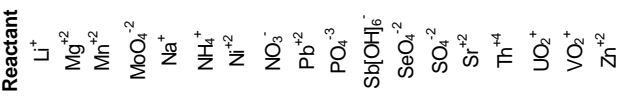

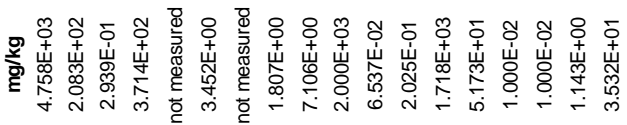

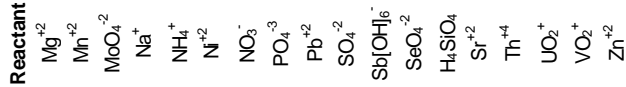
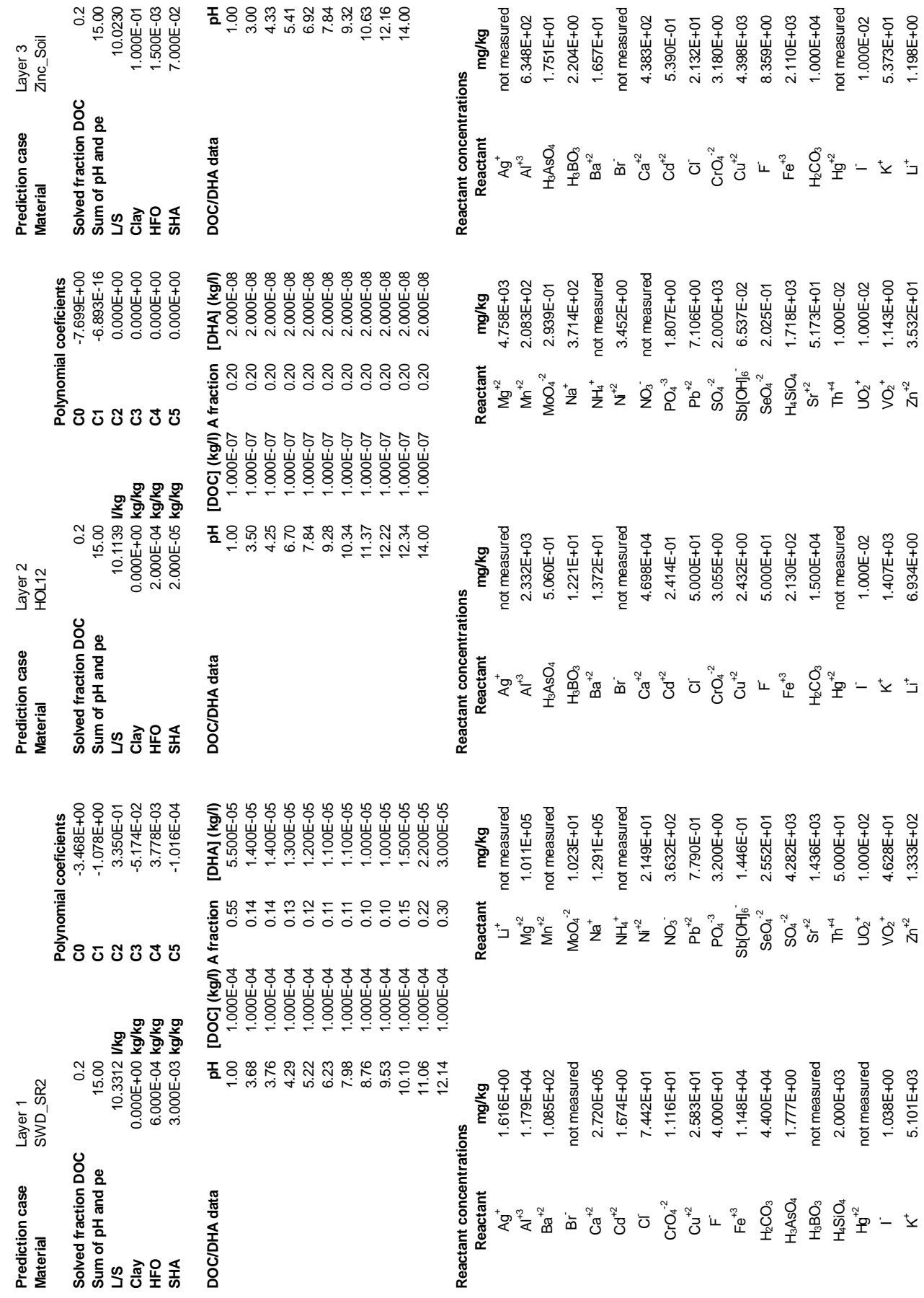

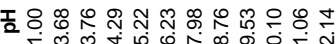

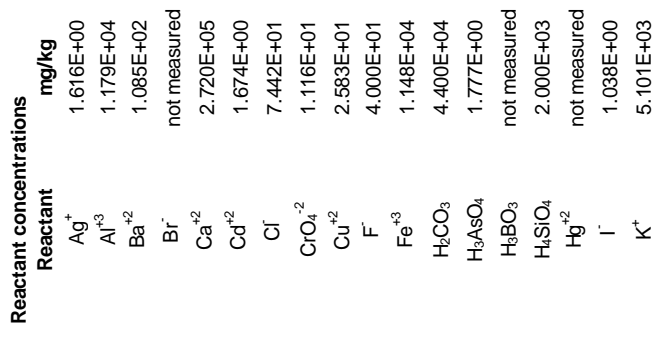


Distribution profile for $\mathbf{0 2}+$ after 139 days

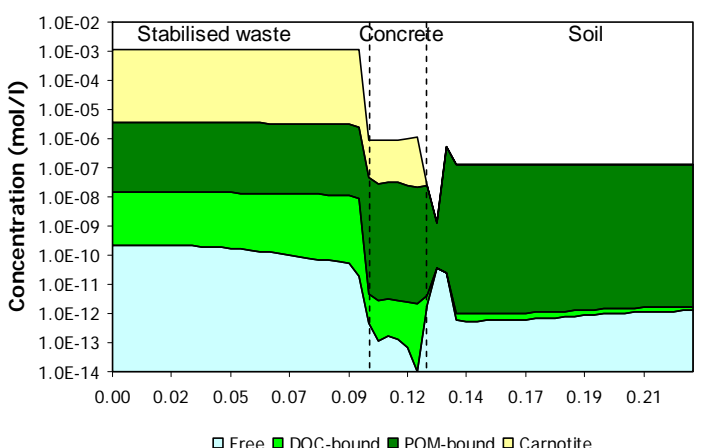

Distribution profile for $\mathbf{0 2}+$ after 27 days

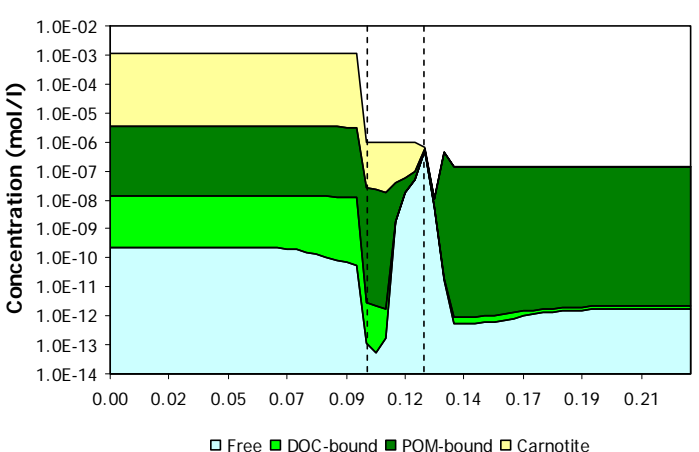

Distribution profile for $\mathbf{0 2 +}$ after 12 days

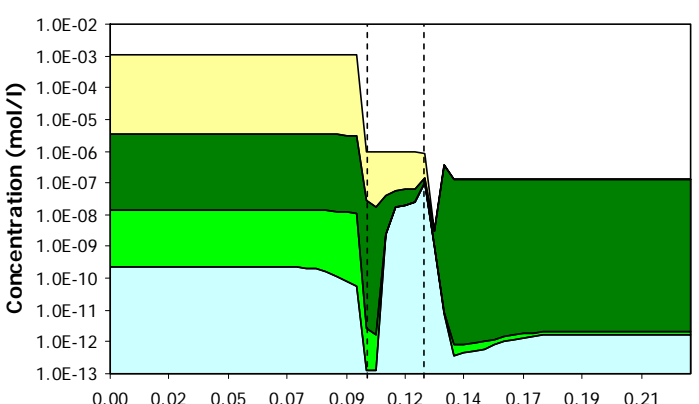

$\square$ Free $\square$ DOC-bound $\square$ POM-bound $\square$ Carnotite

Distribution profile for $\mathbf{0 2}+$ after 3 days

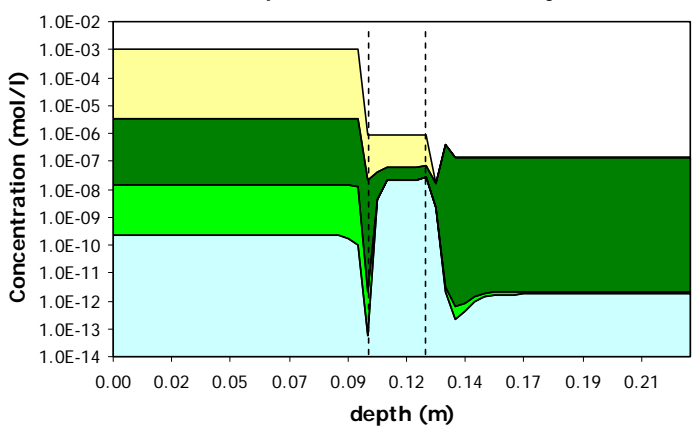

$\square$ Free $\square$ DOC-bound $\square$ POM-bound $\square$ Carnotite
Distribution profile for $\mathrm{Sr}+2$ after 139 days

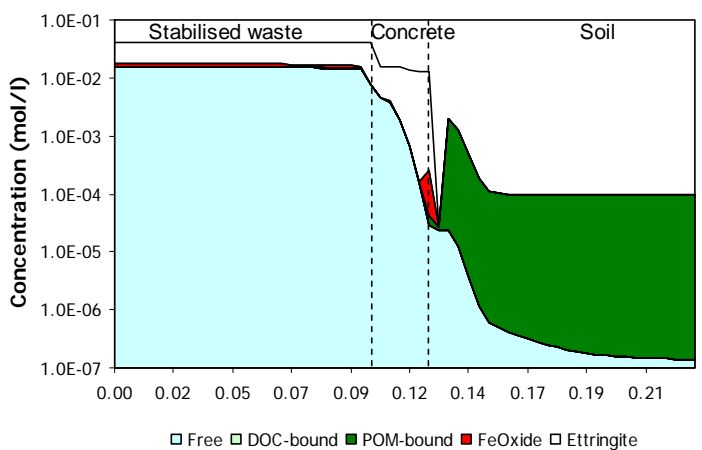

Distribution profile for $\mathrm{Sr}+2$ after 27 days

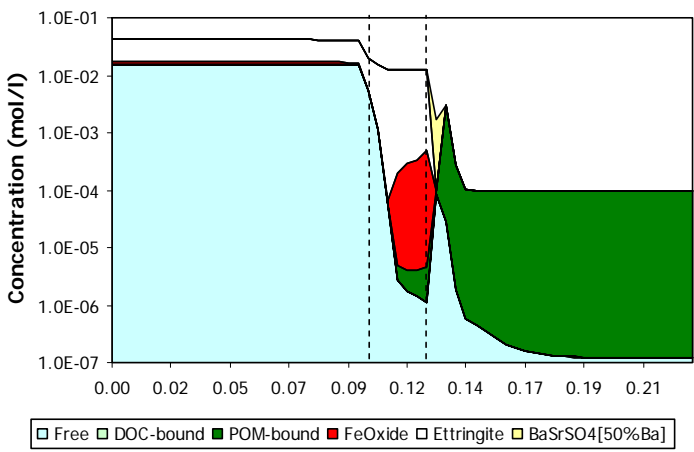

Distribution profile for $\mathrm{Sr}+2$ after 12 days

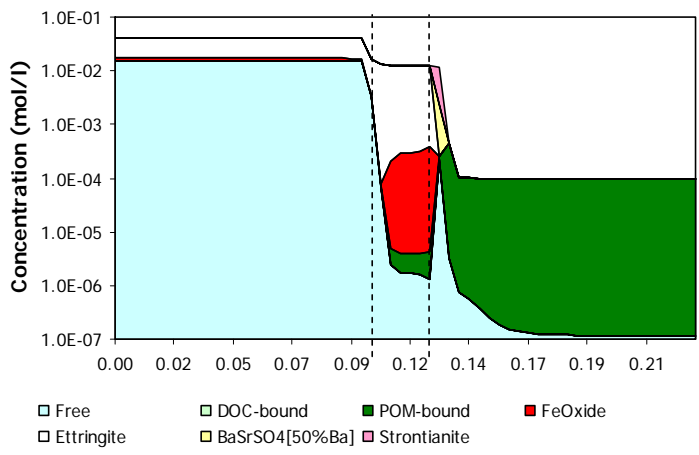

Distribution profile for $\mathrm{Sr}+2$ after 3 days

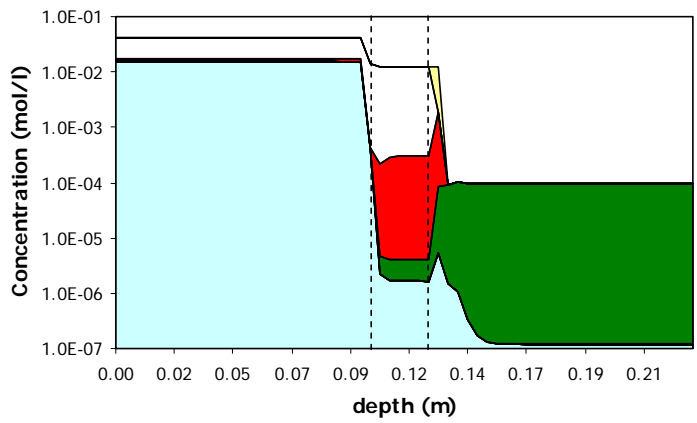

$\square$ Free $\square$ DOC-bound $\square$ POM-bound $\square$ FeOxide $\square$ Ettringite $\square$ Strontianite

Figure 26. Diffusion profiles for $\mathrm{U}$ and $\mathrm{Sr}$ for the stabilized waste - concrete - soil system. 
Distribution profile for $\mathrm{Pb}+2$ after 139 days

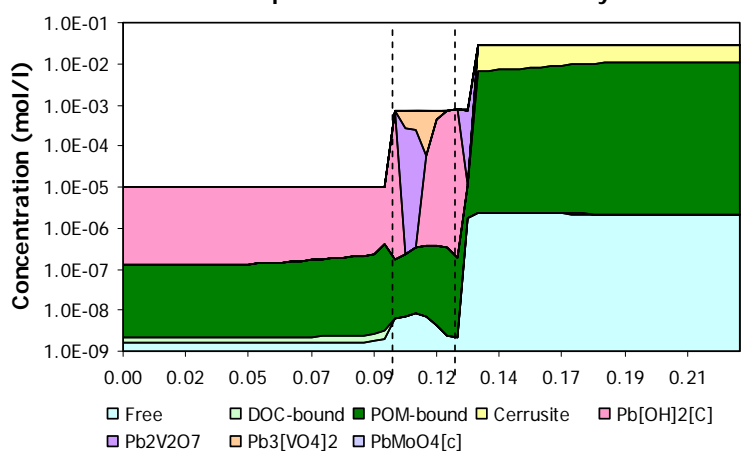

Distribution profile for $\mathbf{P b}+2$ after 27 days

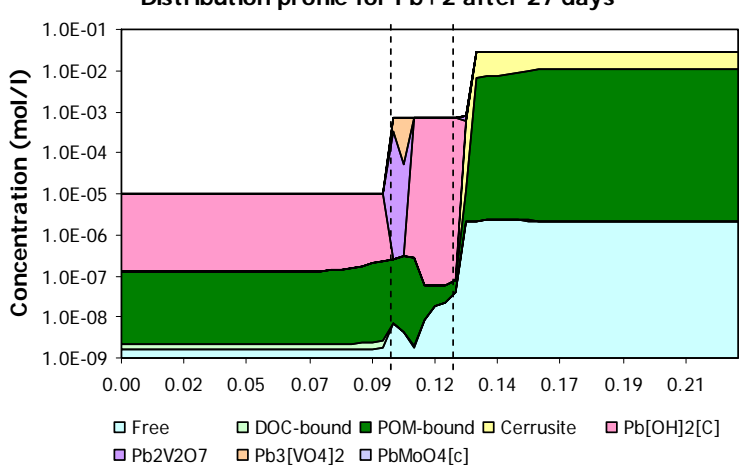

Distribution profile for $\mathrm{Pb}+2$ after 12 days

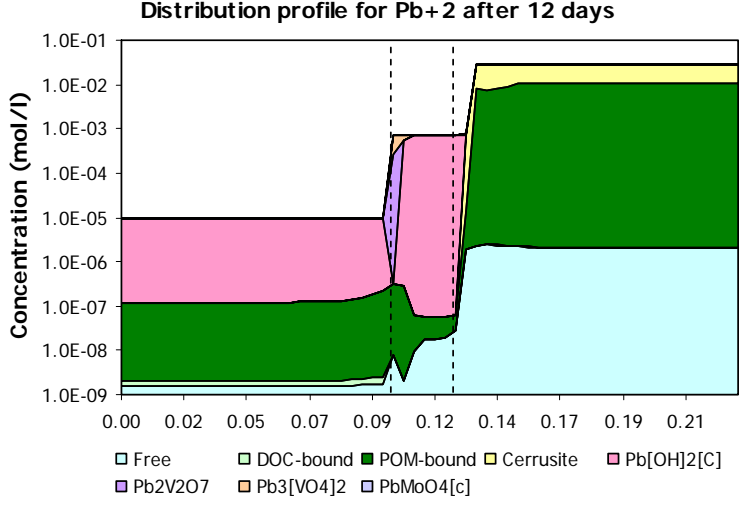

Distribution profile for $\mathbf{P b}+\mathbf{2}$ after 3 days

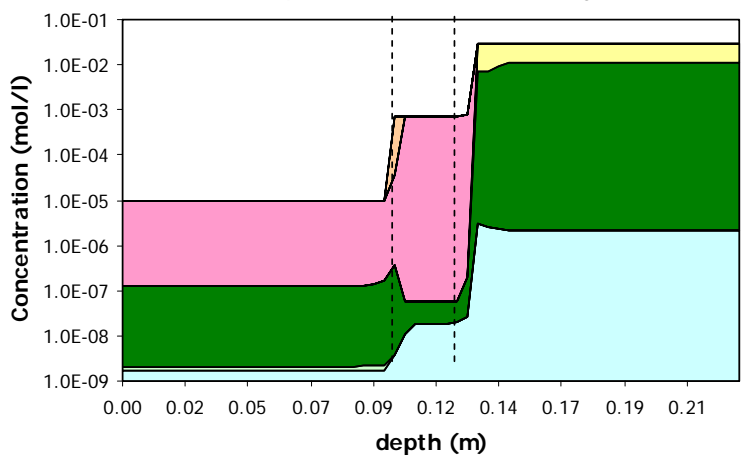

$\square$ Free $\quad \square$ DOC-bound $\square$ POM-bound $\square$ Cerrusite $\square \mathrm{Pb}[\mathrm{OH}] 2[\mathrm{C}]$ $\mathrm{PPb} 2 \mathrm{~V} 2 \mathrm{O} 7 \mathrm{PP} 3[\mathrm{VO} 4] 2 \quad \mathrm{PbMoO} 4[\mathrm{c}]$
Distribution profile for $\mathbf{M g}+2$ after 139 days

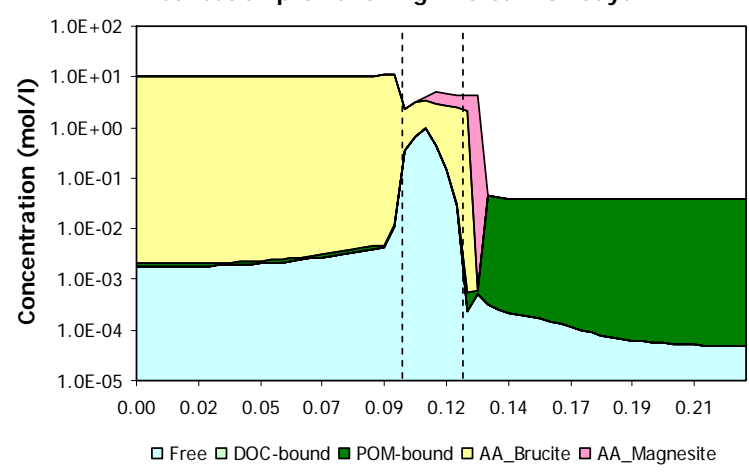

Distribution profile for $\mathbf{M g}+\mathbf{2}$ after 75 days

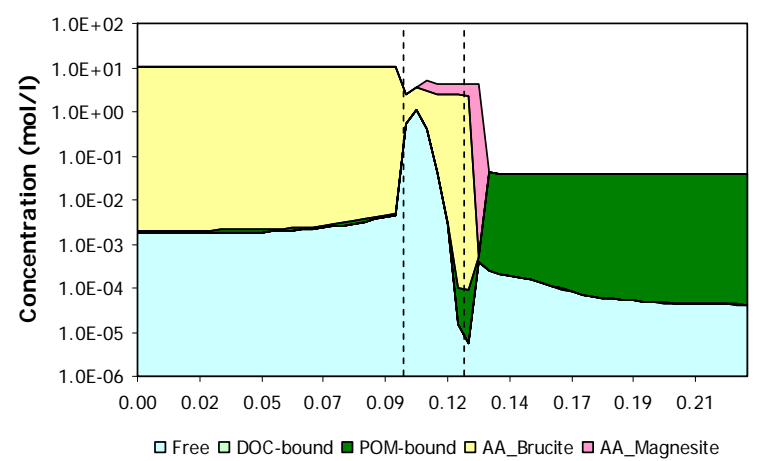

Distribution profile for $\mathbf{M g}+\mathbf{2}$ after 27 days

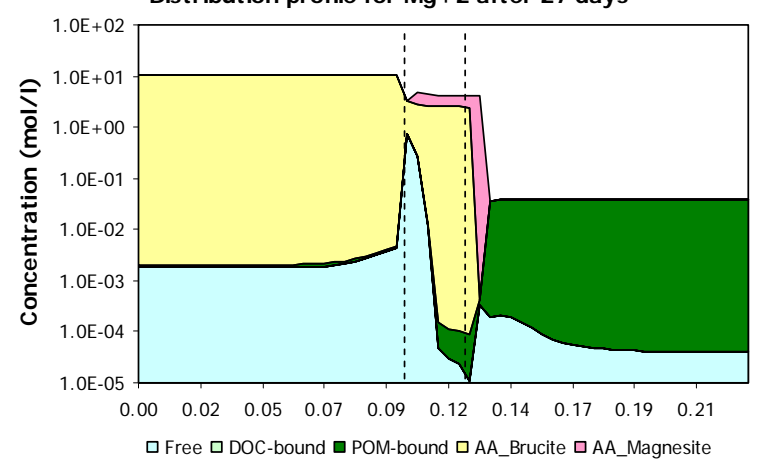

Distribution profile for $\mathbf{M g}+2$ after 3 days

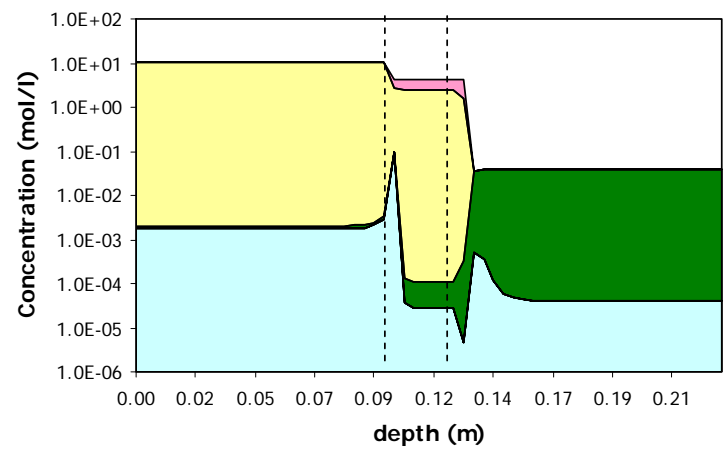

$\square$ Free $\square$ DOC-bound $\square$ POM-bound $\square$ AA_Brucite $\square$ AA_Magnesite

Figure 27. Diffusion profiles for $\mathrm{Pb}$ and $\mathrm{Mg}$ for the stabilized waste - concrete - soil system. 


\section{Demonstration of LeachXSTM/ORCHESTRA Capabilities by Simulating Constituent Release from a Cementitious Waste Form in a Reinforced Concrete Vault}

The three-layer model with diffusion using relatively small dimensions is useful to identify the processes controlling release and the phases being formed upon contact between layers with significantly different chemical compositions. It is important to provide a large number of possible phases, as it is not known beforehand which phases are likely to form at these interfaces.

\subsection{Transport by Percolation (Degradation Case)}

For the three layer system with transport by flow, the option exists to take stagnant zones into account. A similar grout - cementitious barrier - soil combination was used to evaluate the effect of low flow conditions on release. The input specifications are given in Table 13. In Figure 28, the concentration profiles of solid and liquid phases are given as a function of depth (left to right: stabilized waste - concrete - soil). The flow is also in this direction. Results for Mo and $\mathrm{Sr}$ are given. In terms of increasing modeling speed, it is promising that for a complex model, more than 5 years of field leaching is represented in just 3 hours of run time. These results show the Mo and Sr moving from the waste through the barrier into the soil. For both Mo and Sr, it is clear that precipitation occurs directly in the soil adjacent to the concrete. The rate of Mo dissolution appears constant as the concentration does not change appreciably with $\mathrm{CaMoO}_{4}$ as the solubility controlling phase. Sr is fairly readily released from the waste and enters the concrete barrier where it precipitates as strontianite. Key aspects for the next period of research will be to define the experimental exposure conditions, verify model performance where possible against experimental data, and include additional radionuclides.

Table 13. Input parameters for the percolation in the 3-layer system (i.e., stabilized waste concrete - soil).

\begin{tabular}{|c|c|c|c|c|c|}
\hline Flow Case & \multicolumn{2}{|c|}{ Waste Stab waste - CEM II HOL12 - Soil } & & \multirow[b]{2}{*}{6.5} & \\
\hline Layer overview & $\mathrm{pH}$ & 12.5 & 12.8 & & \\
\hline & Material & Stabilized waste & HOL12 & Soil & \\
\hline & Length & 50.00 & 20.00 & 100.00 & $\mathrm{~cm}$ \\
\hline & Porosity & 0.45 & 0.20 & 0.35 & \\
\hline & Stagnant phase \% & 50.00 & 80.00 & 202.00 & \\
\hline & Density & 1.80 & 2.40 & 1.80 & $\mathrm{~kg} / \mathrm{dm}^{3}$ \\
\hline Duration & 300 & days & & & \\
\hline Time distribution & Square root & & & & \\
\hline Solution composit & & $\mathrm{Mol} / \mathrm{l}$ & $\mathrm{pH}$ & $\mathrm{pe}+\mathrm{pH}$ & \\
\hline & All & 1.00E-09 & 5 & 15 & \\
\hline & $\mathrm{CO}_{3}{ }^{-2}$ & $5.00 \mathrm{E}-06$ & & & \\
\hline Flow & 1.00E-06 & $1 / \mathrm{m}^{2} / \mathrm{s}$ & & & \\
\hline
\end{tabular}


Table 13 Continued

\begin{tabular}{|c|c|c|c|c|c|c|c|c|}
\hline \multirow{3}{*}{$\begin{array}{l}\text { Prediction case } \\
\text { Material }\end{array}$} & \multicolumn{8}{|l|}{ Layer 1} \\
\hline & \multicolumn{4}{|c|}{ Stabilised waste NL $(P, 6,1)$} & \multicolumn{4}{|c|}{ Reactant concentrations } \\
\hline & \multicolumn{4}{|c|}{$\begin{array}{ll}\text { Polynomial coeficients }\end{array}$} & \multicolumn{2}{|c|}{ Reactant $\mathrm{mg} / \mathrm{kg}$} & \multirow{2}{*}{$\begin{array}{c}\text { Reactant } \\
\mathrm{Mg}^{+2}\end{array}$} & \multirow{2}{*}{$\begin{array}{c}\mathbf{~ m g} / \mathbf{k g} \\
3.903 \mathrm{E}+03\end{array}$} \\
\hline Solved fraction DOC & \multicolumn{2}{|l|}{0.2} & $\mathrm{CO}$ & $-6.217 \mathrm{E}+00$ & $\mathrm{Ag}^{+}$ & not measured & & \\
\hline Sum of pH and pe & \multicolumn{2}{|l|}{15.00} & C1 & 1.083E-01 & $\mathrm{Al}^{+3}$ & 4.456E+03 & $\mathrm{Mn}^{+2}$ & $1.750 \mathrm{E}+02$ \\
\hline L/S & \multicolumn{2}{|c|}{$10.0000 \mathrm{l} / \mathrm{kg}$} & $\mathbf{C 2}$ & $-4.421 E-02$ & $\mathrm{H}_{3} \mathrm{AsO}_{4}$ & $1.450 \mathrm{E}-01$ & $\mathrm{MoO}_{4}^{-2}$ & $7.700 \mathrm{E}+00$ \\
\hline Clay & \multicolumn{2}{|c|}{$0.000 \mathrm{E}+00 \mathrm{~kg} / \mathbf{k g}$} & C3 & $4.854 \mathrm{E}-03$ & $\mathrm{H}_{3} \mathrm{BO}_{3}$ & 5.947E+01 & $\mathrm{Na}^{+}$ & $2.563 E+04$ \\
\hline HFO & \multicolumn{2}{|c|}{$3.000 \mathrm{E}-05 \mathrm{~kg} / \mathbf{k g}$} & C4 & $-1.590 \mathrm{E}-04$ & $\mathrm{Ba}^{+2}$ & $1.933 \mathrm{E}+01$ & $\mathrm{NH}_{4}^{+}$ & not measured \\
\hline \multirow[t]{2}{*}{ SHA } & \multirow{2}{*}{\multicolumn{2}{|c|}{$2.000 \mathrm{E}-04 \mathbf{~ k g} / \mathbf{k g}$}} & \multirow[t]{2}{*}{ C5 } & $0.000 \mathrm{E}+00$ & $\mathrm{Br}^{-}$ & $8.338 \mathrm{E}+02$ & $\mathrm{Ni}^{+2}$ & $9.290 \mathrm{E}+00$ \\
\hline & & & & & $\mathrm{Ca}^{+2}$ & $8.362 E+04$ & $\mathrm{NO}_{3}^{-}$ & not measured \\
\hline \multirow[t]{11}{*}{ DOC/DHA data } & \multicolumn{3}{|c|}{$\mathrm{pH}[\mathrm{DOC}](\mathrm{kg} / \mathrm{l}) \mathrm{A}$ fraction } & [DHA] (kg/l) & $\mathrm{Cd}^{+2}$ & $1.782 \mathrm{E}+02$ & $\mathrm{PO}_{4}^{-3}$ & $4.740 \mathrm{E}+00$ \\
\hline & 1.00 & $3.521 \mathrm{E}-06$ & 0.20 & 7.042E-07 & $\mathrm{Cl}^{-}$ & $5.350 \mathrm{E}+04$ & $\mathrm{~Pb}^{+2}$ & $9.551 \mathrm{E}+02$ \\
\hline & 3.60 & 3.200E-06 & 0.20 & $6.400 \mathrm{E}-07$ & $\mathrm{CrO}_{4}^{-2}$ & $9.690 \mathrm{E}+00$ & $\mathrm{SO}_{4}^{-2}$ & $1.066 \mathrm{E}+04$ \\
\hline & 4.78 & 3.100E-06 & 0.20 & $6.200 \mathrm{E}-07$ & $\mathrm{Cu}^{+2}$ & $3.650 \mathrm{E}+02$ & $\mathrm{Sb}[\mathrm{OH}]_{6}^{-}$ & $4.920 \mathrm{E}+00$ \\
\hline & 6.06 & 1.900E-06 & 0.20 & 3.800E-07 & $\mathrm{F}^{-}$ & $1.904 \mathrm{E}+03$ & $\mathrm{SeO}_{4}^{-2}$ & $4.600 \mathrm{E}-01$ \\
\hline & 7.28 & $2.400 \mathrm{E}-06$ & 0.20 & $4.800 \mathrm{E}-07$ & $\mathrm{Fe}^{+3}$ & $7.393 E+01$ & $\mathrm{H}_{4} \mathrm{SiO}_{4}$ & $3.556 \mathrm{E}+03$ \\
\hline & 7.80 & $2.200 \mathrm{E}-06$ & 0.20 & 4.400E-07 & $\mathrm{H}_{2} \mathrm{CO}_{3}$ & $1.000 \mathrm{E}+04$ & $\mathrm{Sr}^{+2}$ & $2.060 \mathrm{E}+02$ \\
\hline & 9.50 & 3.100E-06 & 0.20 & $6.200 \mathrm{E}-07$ & $\mathrm{Hg}^{+2}$ & not measured & $\mathrm{Th}^{+4}$ & not measured \\
\hline & 10.30 & $2.300 \mathrm{E}-06$ & 0.20 & $4.600 \mathrm{E}-07$ & I & not measured & $\mathrm{UO}_{2}^{+}$ & not measured \\
\hline & 11.69 & 3.000E-06 & 0.20 & $6.000 \mathrm{E}-07$ & $\mathrm{~K}^{+}$ & $3.381 E+04$ & $\mathrm{VO}_{2}^{+}$ & 9.800E-01 \\
\hline & 14.00 & 3.577E-06 & 0.20 & 7.155E-07 & $\mathrm{Li}^{+}$ & $2.452 \mathrm{E}+01$ & $\mathrm{Zn}^{+2}$ & $8.015 E+03$ \\
\hline \multicolumn{9}{|c|}{ Selected Minerals } \\
\hline \multicolumn{4}{|c|}{ AA_2CaO_Al2O3_SiO2_8H2O[s] } & \multicolumn{2}{|l|}{ AA_Gibbsite } & $\mathrm{Ca}[\mathrm{AsO} 4] 2: 6 \mathrm{H} 2 \mathrm{O}$ & \multicolumn{2}{|c|}{$\mathrm{Pb} 2[\mathrm{OH}] 3 \mathrm{Cl}$} \\
\hline \multicolumn{4}{|c|}{ AA_3CaO_Al2O3[Ca[OH]2]0_5_[CaCO3]0_5_11_5H2O[s] } & AA_Gypsum & & $\mathrm{Ca} 4 \mathrm{Cd}[\mathrm{PO} 4] 3 \mathrm{Cl}$ & $\mathrm{Pb} 2 \mathrm{~V} 2 \mathrm{O} 7$ & \\
\hline AA_3CaO_Al2O3_CaC & $3 \_11 \mathrm{H} 2 \mathrm{O}[\mathrm{s}]$ & & & AA_Jennite & & $\mathrm{CaMoO} 4[\mathrm{c}]$ & $\mathrm{Pb} 3[\mathrm{VO} 4] 2$ & \\
\hline AA_3CaO_Al2O3_CaS & $4 \_12 \mathrm{H} 2 \mathrm{O}[\mathrm{s}]$ & & & AA_Magnesite & & $\mathrm{Cd}[\mathrm{OH}] 2[\mathrm{C}]$ & $\mathrm{PbMoO} 4[\mathrm{c}$ & \\
\hline AA_4CaO_Al2O3_13H2 & & & & AA_Portlandite & & $\mathrm{Cr}[\mathrm{OH}] 3[\mathrm{~A}]$ & Rhodochro & osite \\
\hline AA_Al[OH]3[am] & & & & AA_Tricarboalu & uminate & $\mathrm{Cu}[\mathrm{OH}] 2[\mathrm{~s}]$ & Strontianite & \\
\hline AA_Anhydrite & & & & alpha-TCP & & Fluorite & Wairakite & \\
\hline AA_Brucite & & & & Analbite & & Hausmannite & Willemite & \\
\hline AA_Calcite & & & & $\mathrm{Ba}[\mathrm{SCr}] \mathrm{O} 4[77 \%$ & $\%$ SO4] & Laumontite & Zincite & \\
\hline AA_CaO_Al2O3_10H2C & & & & BaSrSO4[50\% & $\mathrm{Ba}]$ & $\mathrm{Ni}[\mathrm{OH}] 2[\mathrm{~s}]$ & $\mathrm{Zn}[\mathrm{OH}] 2[\mathrm{E}$ & \\
\hline AA_CO3-hydrotalcite & & & & Bobierite & & $\mathrm{Pb}[\mathrm{OH}] 2[\mathrm{C}]$ & & \\
\hline
\end{tabular}


Table 13 Continued

\begin{tabular}{|c|c|c|c|c|c|c|c|c|}
\hline $\begin{array}{l}\text { Prediction case } \\
\text { Material }\end{array}$ & \multicolumn{8}{|c|}{ Polynomial coeficients } \\
\hline Solved fraction DOC & \multicolumn{2}{|l|}{0.2} & $\mathrm{CO}$ & $-7.699 \mathrm{E}+00$ & Reactant & $\mathrm{mg} / \mathrm{kg}$ & Reactant & $\mathrm{mg} / \mathrm{kg}$ \\
\hline Sum of pH and pe & \multicolumn{2}{|l|}{15.00} & C1 & $-6.893 E-16$ & $\mathrm{Ag}^{+}$ & not measured & $\mathrm{Mg}^{+2}$ & $4.758 \mathrm{E}+03$ \\
\hline L/S & \multicolumn{2}{|c|}{10.1139 l/kg } & $\mathrm{C} 2$ & $0.000 \mathrm{E}+00$ & $\mathrm{Al}^{+3}$ & $2.332 \mathrm{E}+03$ & $\mathrm{Mn}^{+2}$ & $2.083 \mathrm{E}+02$ \\
\hline Clay & \multicolumn{2}{|c|}{$0.000 E+00$ kg/kg } & C3 & $0.000 E+00$ & $\mathrm{H}_{3} \mathrm{AsO}_{4}$ & 5.060E-01 & $\mathrm{MoO}_{4}^{-2}$ & 2.939E-01 \\
\hline HFO & \multicolumn{2}{|c|}{$2.000 \mathrm{E}-04 \mathrm{~kg} / \mathbf{k g}$} & C4 & $0.000 E+00$ & $\mathrm{H}_{3} \mathrm{BO}_{3}$ & $1.221 E+01$ & $\mathrm{Na}^{+}$ & $3.714 \mathrm{E}+02$ \\
\hline SHA & \multicolumn{2}{|c|}{$2.000 E-05$ kg/kg } & C5 & $0.000 \mathrm{E}+00$ & $\mathrm{Ba}^{+2}$ & $1.372 \mathrm{E}+01$ & $\mathrm{NH}_{4}^{+}$ & not measured \\
\hline & & & & & $\mathrm{Br}^{-}$ & not measured & $\mathrm{Ni}^{+2}$ & $3.452 \mathrm{E}+00$ \\
\hline \multirow[t]{12}{*}{ DOC/DHA data } & $\mathrm{pH}$ & [DOC] (kg/l) & DHA fraction & [DHA] (kg/l) & $\mathrm{Ca}^{+2}$ & $4.698 \mathrm{E}+04$ & $\mathrm{NO}_{3}^{-}$ & not measured \\
\hline & 1.00 & $1.000 \mathrm{E}-07$ & 0.20 & 2.000E-08 & $\mathrm{Cd}^{+2}$ & $2.414 \mathrm{E}-01$ & $\mathrm{PO}_{4}^{-3}$ & $1.807 \mathrm{E}+00$ \\
\hline & 3.50 & $1.000 \mathrm{E}-07$ & 0.20 & $2.000 \mathrm{E}-08$ & $\mathrm{Cl}^{-}$ & $5.000 \mathrm{E}+01$ & $\mathrm{~Pb}^{+2}$ & $7.106 \mathrm{E}+00$ \\
\hline & 4.25 & $1.000 \mathrm{E}-07$ & 0.20 & 2.000E-08 & $\mathrm{CrO}_{4}^{-2}$ & $3.055 \mathrm{E}+00$ & $\mathrm{SO}_{4}^{-2}$ & $2.000 E+03$ \\
\hline & 6.70 & $1.000 \mathrm{E}-07$ & 0.20 & $2.000 \mathrm{E}-08$ & $\mathrm{Cu}^{+2}$ & $2.432 \mathrm{E}+00$ & $\mathrm{Sb}[\mathrm{OH}]_{6}^{-}$ & 6.537E-02 \\
\hline & 7.84 & $1.000 \mathrm{E}-07$ & 0.20 & $2.000 \mathrm{E}-08$ & $\mathrm{~F}^{-}$ & $5.000 E+01$ & $\mathrm{SeO}_{4}^{-2}$ & $2.025 \mathrm{E}-01$ \\
\hline & 9.28 & 1.000E-07 & 0.20 & $2.000 \mathrm{E}-08$ & $\mathrm{Fe}^{+3}$ & $2.130 \mathrm{E}+02$ & $\mathrm{H}_{4} \mathrm{SiO}_{4}$ & $1.718 \mathrm{E}+03$ \\
\hline & 10.34 & $1.000 \mathrm{E}-07$ & 0.20 & $2.000 \mathrm{E}-08$ & $\mathrm{H}_{2} \mathrm{CO}_{3}$ & $1.500 \mathrm{E}+04$ & $\mathrm{Sr}^{+2}$ & $5.173 \mathrm{E}+01$ \\
\hline & 11.37 & $1.000 \mathrm{E}-07$ & 0.20 & $2.000 \mathrm{E}-08$ & $\mathrm{Hg}^{+2}$ & not measured & $\mathrm{Th}^{+4}$ & $1.000 \mathrm{E}-02$ \\
\hline & 12.22 & $1.000 \mathrm{E}-07$ & 0.20 & $2.000 \mathrm{E}-08$ & $i$ & 1.000E-02 & $\mathrm{UO}_{2}^{+}$ & $1.000 \mathrm{E}-02$ \\
\hline & 12.34 & $1.000 \mathrm{E}-07$ & 0.20 & $2.000 \mathrm{E}-08$ & $\mathrm{~K}^{+}$ & $1.407 \mathrm{E}+03$ & $\mathrm{VO}_{2}^{+}$ & $1.143 \mathrm{E}+00$ \\
\hline & 14.00 & $1.000 \mathrm{E}-07$ & 0.20 & $2.000 \mathrm{E}-08$ & $\mathrm{Li}^{+}$ & $6.934 \mathrm{E}+00$ & $\mathrm{Zn}^{+2}$ & $3.532 \mathrm{E}+01$ \\
\hline \multicolumn{9}{|l|}{ Selected Minerals } \\
\hline \multicolumn{3}{|c|}{$[\mathrm{UO} 2] 3[\mathrm{PO} 4] 2$} & \multicolumn{3}{|c|}{ AA_Calcite } & B_UO2[OH]2 & \multicolumn{2}{|l|}{$\mathrm{PbCrO} 4$} \\
\hline \multicolumn{3}{|c|}{ AA_2CaO_Al2O3_8H2O[s] } & \multicolumn{3}{|c|}{ AA_CaO_Al2O3_10H2O[s] } & $\mathrm{Ca} 2 \mathrm{Cd}[\mathrm{PO} 4] 2$ & \multicolumn{2}{|l|}{$\mathrm{PbMoO} 4[\mathrm{c}]$} \\
\hline \multicolumn{3}{|c|}{ AA_2CaO_Al2O3_SiO2_8H2O[s] } & \multicolumn{3}{|c|}{ AA_Fe[OH] $3[$ microcr $]$} & Carnotite & Rhodochrosite & \\
\hline $\mathrm{AA}$-2CaO_Fe2O3_8 $\mathrm{H} 2$ & $2 \bar{O}[s]$ & & AA_Gibbsite & & & $\mathrm{Cd}[\mathrm{OH}] 2[\mathrm{C}]$ & Schoepite & \\
\hline $\mathrm{AA} 2 \mathrm{CaO} \mathrm{Fe} 2 \mathrm{O} 3 \mathrm{SiO}$ & $28 \mathrm{H} 2 \mathrm{O}[\mathrm{s}]$ & & AA_Gypsum & & & $\mathrm{Cr}[\mathrm{OH}] 3[\mathrm{~A}]$ & Strontianite & \\
\hline AA_3CaO_Al2O3_6 $2 \mathrm{H}$ & $\mathrm{O}[\mathrm{s}]$ & & AA_Jennite & & & Fe_Vanadate & Tenorite & \\
\hline AA_3CaO_Al2O3_CaC & O3_11H2O[s] & & AA_Magnesite & & & Magnesite & $\mathrm{Th}[\mathrm{OH}] 4[\mathrm{~s}]$ & \\
\hline AA_3CaO_Al2O3_CaS & $\mathrm{O} 4 \_12 \mathrm{H} 2 \mathrm{O}[\mathrm{s}]$ & & AA_Portlandite & & & Manganite & Tyuyamunite & \\
\hline AA_3CaO_Fe2O3_6H2 & $\mathrm{O}[\mathrm{s}]$ & & AA_Syngenite & & & $\mathrm{Ni}[\mathrm{OH}] 2[\mathrm{~s}]$ & บO3[C] & \\
\hline $\mathrm{AA} \_\mathrm{Al}[\mathrm{OH}] 3[\mathrm{am}]$ & & & AA_Tobermorite & & & $\mathrm{Pb}[\mathrm{OH}] 2[\mathrm{C}]$ & Uranophane & \\
\hline AA_Anhydrite & & & AA_Tobermorite & & & $\mathrm{Pb} 2 \mathrm{~V} 2 \mathrm{O} 7$ & Willemite & \\
\hline AA_Brucite & & & Analbite & & & $\mathrm{Pb} 3[\mathrm{VO} 4] 2$ & & \\
\hline
\end{tabular}




\section{Table 13 Continued}

Prediction case Layer 3

Material Zinc_Soil $(P, 1,2)$

$\begin{array}{lc}\text { Solved fraction DC } & 0.2 \\ \text { Sum of } \mathrm{pH} \text { and pe } & 15.00 \\ \text { L/S } & 10.0230 \mathrm{l} / \mathbf{k g} \\ \text { Clay } & 1.000 E-01 \mathrm{~kg} / \mathbf{k g} \\ \text { HFO } & 1.500 E-03 \mathrm{~kg} / \mathbf{k g} \\ \text { SHA } & 7.000 E-02 \mathrm{~kg} / \mathbf{k g}\end{array}$

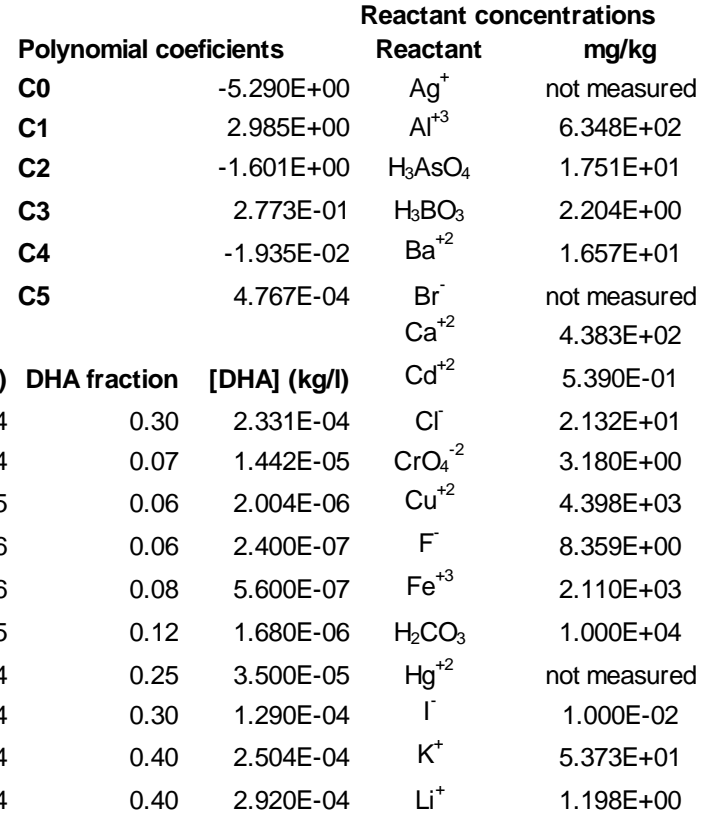

Illite[2]

Kaolinite

Laumontite

LDH_Zn

Magnesite

Microcline

MnHPO4[C]

Monticellite

Montmorillonite

$\mathrm{Ni}[\mathrm{OH}] 2[\mathrm{~s}]$

$\mathrm{Ni2SiO4}$

$\mathrm{NiCO} 3[\mathrm{~s}]$
Otavite

$\mathrm{Pb}[\mathrm{OH}] 2[\mathrm{C}]$

$\mathrm{Pb} 3[\mathrm{VO} 4] 2$

$\mathrm{Pb} 4[\mathrm{OH}] 6 \mathrm{SO} 4$

$\mathrm{PbCrO} 4$

PbMoO4[c]

Pyrophyllite

Rhodochrosite

$\mathrm{Sb}[\mathrm{OH}] 3[\mathrm{~s}]$

Schoepite

Strontianite

Tenorite

$\begin{array}{cc}\text { Reactant } & \mathbf{m g} / \mathbf{k g} \\ \mathrm{Mg}^{+2} & 3.019 \mathrm{E}+02 \\ \mathrm{Mn}^{+2} & 9.120 \mathrm{E}+02 \\ \mathrm{MoO}_{4}^{-2} & 2.400 \mathrm{E}+00 \\ \mathrm{Na}^{+} & 7.416 \mathrm{E}+01 \\ \mathrm{NH}_{4}^{+} & 1.000 \mathrm{E}+00 \\ \mathrm{Ni}^{+2} & 1.888 \mathrm{E}+02 \\ \mathrm{NO}_{3}{ }^{-} & 5.000 \mathrm{E}+01 \\ \mathrm{PO}_{4}^{-3} & 2.066 \mathrm{E}+01 \\ \mathrm{~Pb}^{+2} & 1.934 \mathrm{E}+03 \\ \mathrm{SO}_{4}^{-2} & 1.083 \mathrm{E}+03 \\ \mathrm{Sb}^{-2} \mathrm{OH}_{6}{ }^{-} & 3.485 \mathrm{E}+00 \\ \mathrm{SeO}_{4}^{-2} & 6.299 \mathrm{E}+00 \\ \mathrm{H}_{4} \mathrm{SiO}_{4} & 3.040 \mathrm{E}+03 \\ \mathrm{Sr}^{+2} & 2.734 \mathrm{E}+00 \\ \mathrm{Th}^{+4} & 1.000 \mathrm{E}-02 \\ \mathrm{UO}_{2}{ }^{+} & 1.000 \mathrm{E}-02 \\ \mathrm{VO}_{2}{ }^{+} & 6.170 \mathrm{E}-01 \\ \mathrm{Zn}^{+2} & 3.450 \mathrm{E}+01\end{array}$

$\mathrm{Th}[\mathrm{OH}] 4[\mathrm{~s}]$

ThF4:2.5H2O

Tyuyamunite

UO3[C]

Uranophane

Willemite

Zincite

$\mathrm{Zn}[\mathrm{OH}] 2[\mathrm{~A}]$

Zn-Rockbridgite

$\mathrm{C} 2 \mathrm{Cd}[\mathrm{PO} 4] 2$

Ca4C 3 [PO $3 \mathrm{OH}$

Hydromagnesite

Illite[1] 
Concentration profile Mo04-2 - 2048 days

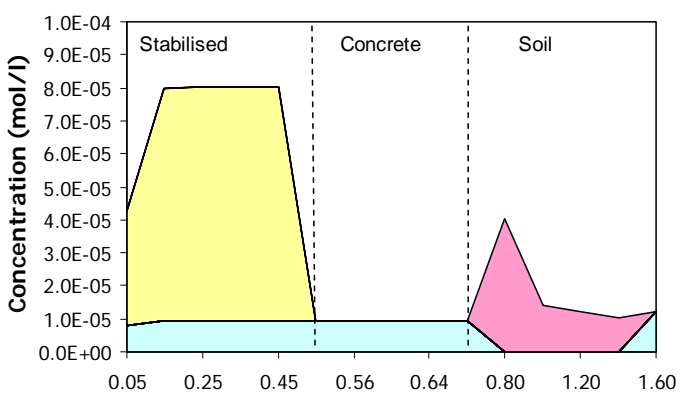

$\square$ Free $\square$ DOC-bound $\square$ POM-bound $\square$ FeOxide $\square \mathrm{CaMoO} 4[\mathrm{c}] \square \mathrm{PbMoO} 4[\mathrm{c}]$

Concentration profile Mo04-2 - 1024 days

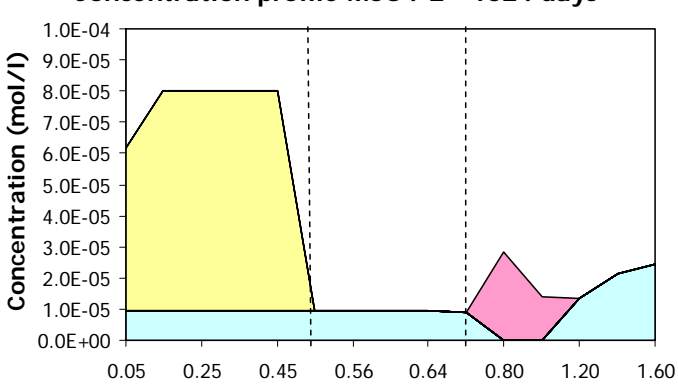

$\square$ Free $\square$ DOC-bound $\square$ POM-bound $\square$ FeOxide $\square \mathrm{CaMoO} 4[\mathrm{c}] \square \mathrm{PbMoO} 4[\mathrm{c}]$

Concentration profile MoO4-2 -256 days

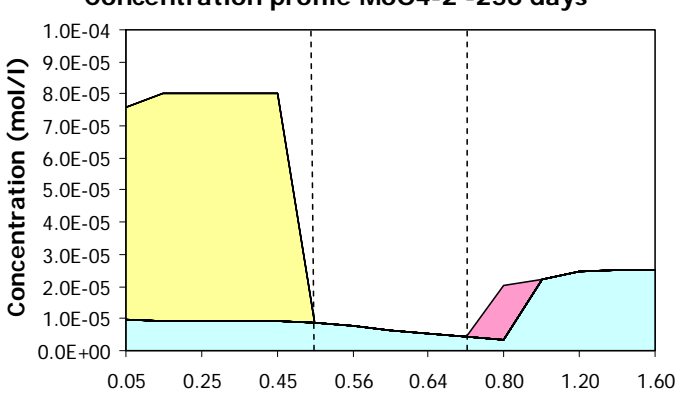

$\square$ Free $\mathrm{DDOC}$-bound $\square \mathrm{POM}$-bound $\square$ FeOxide $\square \mathrm{CaMoO} 4[\mathrm{c}] \square \mathrm{PbMoO} 4[\mathrm{c}]$

Concentration profile MoO4-2 - 32 days

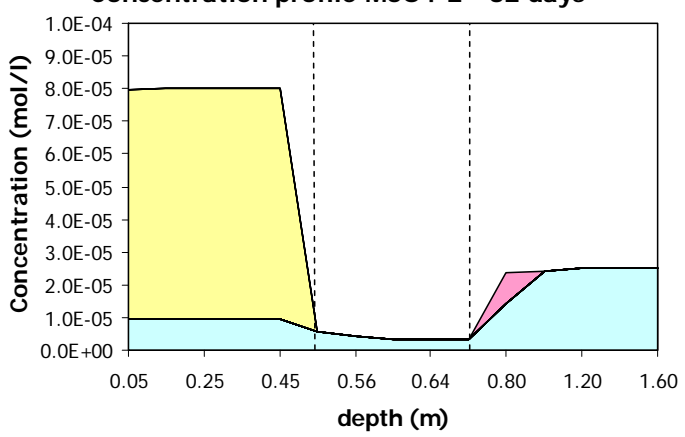

$\square$ Free $\square$ DOC-bound $\square$ POM-bound $\square$ FeOxide $\square$ CaMoO4[c] $\square$ PbMoO4[c]

Figure 28. Transport by percolation from cracked stabilized waste through cementitious

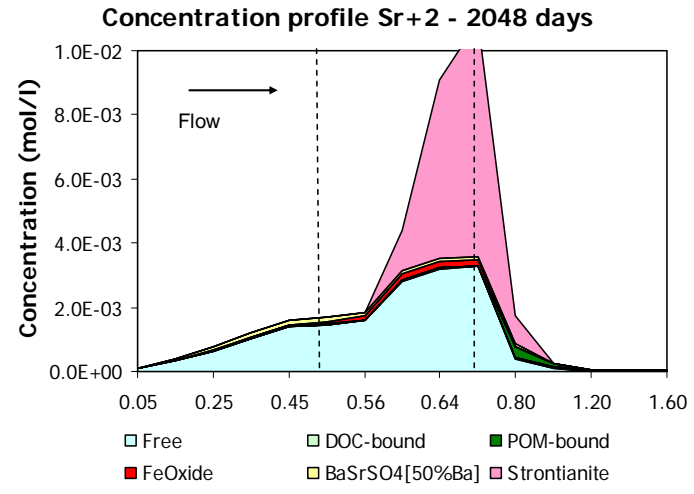

Concentration profile $\mathrm{Sr}+2$ - 1024 days

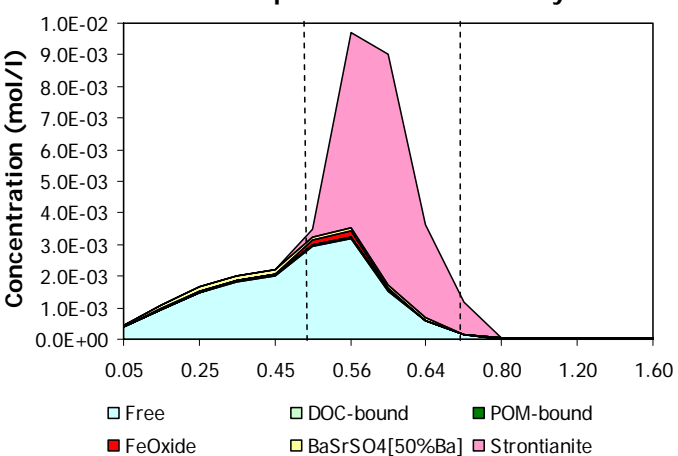

Concentration profile $\mathrm{Sr}+2$ - 256 days

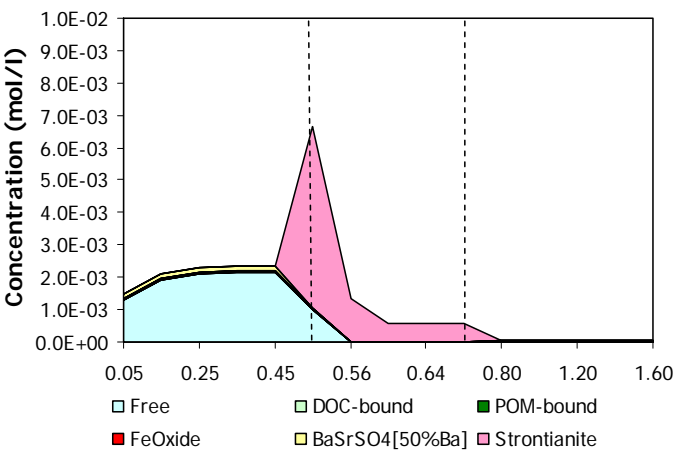

Concentration profile $\mathrm{Sr}+2$ - 32 days

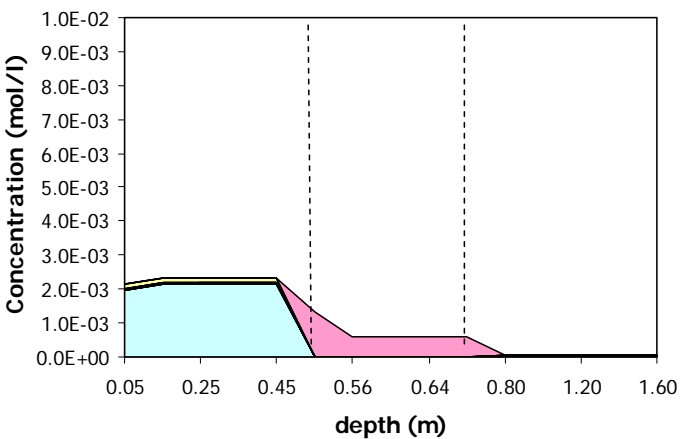

$\begin{array}{ll}\square \text { Free } & \square \text { DOC-bound } \quad \square \text { POM-bound } \\ \square \text { FeOxide } & \square \text { BaSrSO4[50\%Ba] } \square \text { Strontianite }\end{array}$

\section{barrier into soil.
Fing}




\subsection{DEMONSTRATION OF THE EVALUATION OF UNCERTAINTY AND ACCURACY IN CHEMICAL EQUILIBRIUM CALCULATIONS}

\subsection{Description}

Chemical equilibrium calculations form the basis for the contaminant release calculations with the LAO model. These calculations typically involve a large group of elements and reactions and require an extensive set of input parameters, each with an inherent level of uncertainty. The most important input parameters include reaction constants, total element concentrations, $\mathrm{pH}$, and REDOX potentials (expressed as $\mathrm{pH}+\mathrm{pe}$ ). Uncertainty in these input parameters will lead to uncertainty in the calculated equilibrium conditions, including the distribution of dissolved and solid forms. This will directly affect calculated element mobility and leaching rates. Therefore, it is important to evaluate the uncertainty in model predictions given reasonable estimates of the uncertainties in key input parameters.

In addition to an estimate of the degree of uncertainty in the predictions, it is also crucial to have insight into the accuracy of the model itself. This can be obtained by comparing model predictions to independent experimental data.

\subsection{Chemical Model}

The set of chemical reactions selected to represent a cement equilibrium model within ORCHESTRA was taken from the work of Lothenbach and others (Lothenbach \& Gruskovnjak 2007; Lothenbach et al. 2008; Lothenbach \& Winnefeld 2006; Lothenbach et al. 2007). For purposes of this study, the macro elements, Ca, $\mathrm{Al}, \mathrm{Si}, \mathrm{SO}_{4}$, and $\mathrm{OH}$, were considered (see Table 14 for a complete list of reactions). The same model is used in combination with diffusion modules to calculate reactive transport in Section 9.0, "Demonstration of reaction - diffusion calculations". The C-S-H phase is not modeled as a fixed stoichiometry mineral but instead as an ideal solid solution of Jennite and Tobermorite. The ratio of these two end-members in the solid solution is variable and is calculated as a function of the solution composition.

The selected average macro composition of the solid fraction of cementitious material is given in Table 14 .

A total elemental composition of the system is required as input for the calculations. The total amount of each chemical component is assumed to take part in the equilibrium reactions. For $\mathrm{Ca}, \mathrm{Al}$, and $\mathrm{SO}_{4}$, the total analytical composition can be used. For $\mathrm{Si}$, a large portion is present in an "unavailable" form (e.g., sand and gravel), and this portion of the total Si will not be in equilibrium with the rest of the components within experimental time frames. Therefore, the amount of available Si is chosen to be equal to the total amount of silica present in the cement binder.

Table 14. Total elemental composition used as model input.

\begin{tabular}{|l|l|}
\hline Element & $\mathbf{M o l} / \mathbf{k g}$ \\
\hline $\mathbf{C a}$ & 2 \\
\hline $\mathbf{A l}$ & 1 \\
\hline $\mathbf{S i}$ & 1 \\
\hline $\mathbf{O H}$ & adjusted to make system electro neutral \\
\hline $\mathbf{S O}_{\mathbf{4}}$ & 0.1 \\
\hline
\end{tabular}




\subsection{Monte-Carlo Approach}

Because of the numerical complexity of the equilibrium model, a direct analytical evaluation of uncertainty in output is not possible. Another option is to apply a Monte Carlo approach in which input parameters are randomly selected according to a given probability distribution. This method is relatively simple but computationally more demanding. The LeachXSTM_ORCHESTRA model is especially suitable to this method because all model parameters are given as inputs at runtime and can thus be easily varied. The selected parameters and uncertainty distributions are listed in Table 15. The sources of uncertainties considered represent measurement errors and heterogeneity.

Table 15. Input parameters varied in uncertainty analysis. Values provided are for the assumed standard deviation about the mean.

\begin{tabular}{|l|l|}
\hline Input Parameter & Relative (Gaussian distribution) \\
\hline Total element concentration & $10 \%$ \\
\hline Reaction constants & $20 \%$ \\
\hline pH & .1 unit \\
\hline pe & 2 units \\
\hline Ionic strength & $10 \%$ \\
\hline
\end{tabular}

Because of the many interactions considered in the equilibrium model, the degree of uncertainty in the output will most likely depend on the selected set of chemical reactions as well as the chemical conditions for which the model is applied. It is thus important to choose the model and conditions to best represent those encountered in the model simulations within the CBP context. Thus the cement chemistry model developed by Lothenbach and others (Lothenbach \& Gruskovnjak 2007; Lothenbach et al. 2008; Lothenbach \& Winnefeld 2006; Lothenbach et al. 2007) is used, which describes the interactions between the major elements listed in Table 16. These interactions determine $\mathrm{pH}$ and REDOX changes over time and are important for structural stability. 
Table 16. Chemical reactions used in thermodynamic model.

\begin{tabular}{|c|c|c|}
\hline Name & Reaction & $\log K$ \\
\hline & Aqueous: & \\
\hline $\mathrm{AlOH}+2$ & $1 \mathrm{Al}+3-1 \mathrm{H}++1 \mathrm{H} 2 \mathrm{O}$ & -4.99 \\
\hline AISO4+ & $1 \mathrm{Al}+3+1 \mathrm{SO} 4-2$ & 3.02 \\
\hline $\mathrm{Al}[\mathrm{OH}] 2+$ & $1 \mathrm{Al}+3-2 \mathrm{H}++2 \mathrm{H} 2 \mathrm{O}$ & -10.1 \\
\hline $\mathrm{Al}[\mathrm{OH}] 3$ & $1 \mathrm{Al}+3-3 \mathrm{H}++3 \mathrm{H} 2 \mathrm{O}$ & -16 \\
\hline Al[OH]4- & $1 \mathrm{Al}+3-4 \mathrm{H}++4 \mathrm{H} 2 \mathrm{O}$ & -23 \\
\hline Al[SO4]2- & $1 \mathrm{Al}+3+2 \mathrm{SO} 4-2$ & 4.92 \\
\hline СaOH+ & $1 \mathrm{Ca}+2-1 \mathrm{H}++1 \mathrm{H} 2 \mathrm{O}$ & -12.598 \\
\hline CaSO4 & $1 \mathrm{Ca}+2+1 \mathrm{SO} 4-2$ & 2.309 \\
\hline H2SiO4-2 & $-2 \mathrm{H}++1 \mathrm{H} 4 \mathrm{SiO} 4$ & -21.619 \\
\hline H3SiO4- & $-1 \mathrm{H}++1 \mathrm{H} 4 \mathrm{SiO} 4$ & -9.93 \\
\hline HSO4- & $1 \mathrm{H}++1 \mathrm{SO} 4-2$ & 1.987 \\
\hline \multirow[t]{2}{*}{ OH- } & $-1 \mathrm{H}^{+}+1 \mathrm{H} 2 \mathrm{O}$ & -13.998 \\
\hline & Precipitates: & \\
\hline Gypsum & $1 \mathrm{Ca}+2+2 \mathrm{H} 2 \mathrm{O}+1 \mathrm{SO} 4-2$ & 4.6 \\
\hline Portlandite & $1 \mathrm{Ca}+2-2 \mathrm{H}++2 \mathrm{H} 2 \mathrm{O}$ & -22.8 \\
\hline Al-ettringite & $2 \mathrm{Al}+3+6 \mathrm{Ca}+2-12 \mathrm{H}++38 \mathrm{H} 2 \mathrm{O}+3 \mathrm{SO} 4-2$ & -57.092 \\
\hline $\mathrm{Al}[\mathrm{OH}] 3[\mathrm{am}]$ & $1 \mathrm{Al}+3-3 \mathrm{H}++3 \mathrm{H} 2 \mathrm{O}$ & -9.242 \\
\hline C2AH8 & $2 \mathrm{Al}+3+2 \mathrm{Ca}+2-10 \mathrm{H}++13 \mathrm{H} 2 \mathrm{O}$ & -60.436 \\
\hline C3AH6 & $2 \mathrm{Al}+3+3 \mathrm{Ca}+2-12 \mathrm{H}++12 \mathrm{H} 2 \mathrm{O}$ & -81.152 \\
\hline C3AS0.8H4.4 & $2 \mathrm{Al}+3+3 \mathrm{Ca}+2-12 \mathrm{H}++13.6 \mathrm{H} 2 \mathrm{O}+0.8 \mathrm{H} 4 \mathrm{SiO} 4$ & -68.8676 \\
\hline C4AH13 & $2 \mathrm{Al}+3+4 \mathrm{Ca}+2-14 \mathrm{H}++20 \mathrm{H} 2 \mathrm{O}$ & -104.588 \\
\hline CAH10 & $2 \mathrm{Al}+3+1 \mathrm{Ca}+2-8 \mathrm{H}++14 \mathrm{H} 2 \mathrm{O}$ & -38.5 \\
\hline SiO2[min] & $-1 \mathrm{H} 2 \mathrm{O}+1 \mathrm{H} 4 \mathrm{SiO} 4$ & 2.592 \\
\hline Monosulfoaluminate & $2 \mathrm{Al}+3+4 \mathrm{Ca}+2-12 \mathrm{H}++18 \mathrm{H} 2 \mathrm{O}+1 \mathrm{SO} 4-2$ & -72.732 \\
\hline \multirow[t]{2}{*}{ Stratlingite } & $2 \mathrm{Al}+3+2 \mathrm{Ca}+2-10 \mathrm{H}++11 \mathrm{H} 2 \mathrm{O}+1 \mathrm{H} 4 \mathrm{SiO} 4$ & -50.228 \\
\hline & CSH Solid Solution & \\
\hline CSH - Jennite & $1.667 \mathrm{Ca}+2-3.3333 \mathrm{H}++2.3333 \mathrm{H} 2 \mathrm{O}+1 \mathrm{H} 4 \mathrm{SiO} 4$ & -30.422 \\
\hline CSH - Tobermorite & $0.8333 \mathrm{Ca}+2-1.6667 \mathrm{H}++0.6667 \mathrm{H} 2 \mathrm{O}+1 \mathrm{H} 4 \mathrm{SiO} 4$ & -12.262 \\
\hline
\end{tabular}

\subsection{Experimental Data}

The experimental data for cement mortars used the LeachXS database is a generic total composition. These data give the $\mathrm{pH}$ dependent solubility of the macro elements over a wide range of different cement types with different total element compositions as obtained using the pH-dependence test CEN/TS 14429 (2005).

\subsection{Results}

The macro element concentrations measured in different cement samples show remarkably similar behavior. Apparently, the variation in composition within "normal" ranges does not cause large differences in $\mathrm{pH}$ dependent solubility behavior for the macro elements. The calculated results show that the model is able to predict overall trends. The effect of combined uncertainty in the model depends on the elements and on the conditions. 
When an element is completely soluble, only the total amount and its variation is important.

When the element is precipitated, the dissolved concentration depends on solubility product and concentrations of other components in the precipitate. Under conditions where the net solubility is (in)directly affected by a large number of chemical reactions, the overall uncertainty is large. This is, for example, the case for sulfate at alkaline conditions (see Figure 32). However, the uncertainty is relatively small in comparison with the effects of $\mathrm{pH}$ (at the chosen uncertainty levels in the input parameters). In the case of $\mathrm{Al}$, the data do not agree well with the experimental data. This is largely caused by the ratio between $\mathrm{Al}, \mathrm{Si}$, and sulfate. Since the equilibrium modeling is based on a single system and in practice there may be a mixture of conditions, the next step may require distinguishing between a non-carbonated highly alkaline matrix and a partially carbonated zone with other mineral composition to better describe the measurements. Figure 29 through Figure 32 can be compared to Figure 21 and Figure 22. The data were obtained by comparing model runs on test specimens with a single set of minerals and sorptive phases.

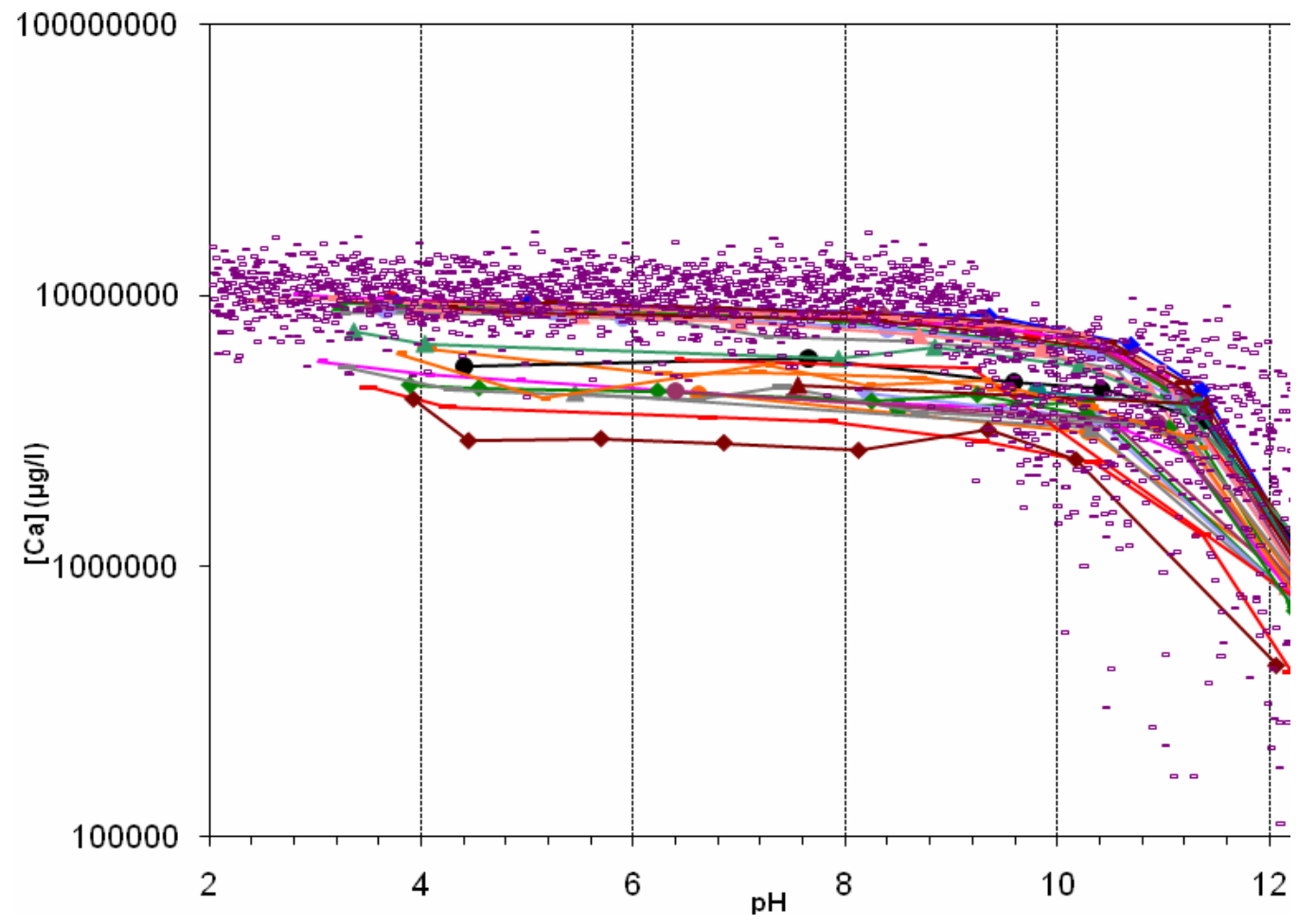

Figure 29. Calcium concentrations as a function of $\mathrm{pH}$. 


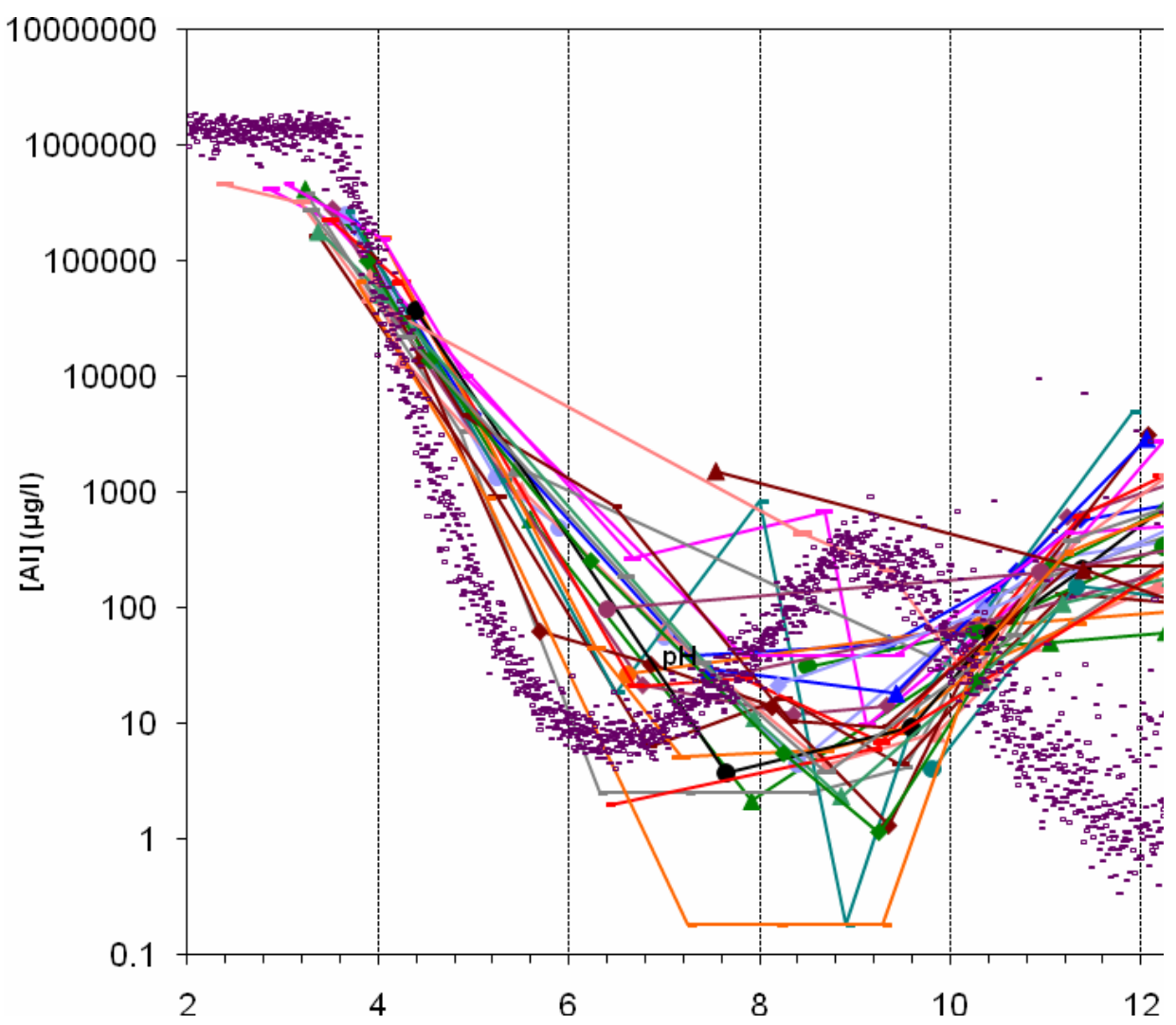

Figure 30. Al concentrations as a function of $\mathrm{pH}$.

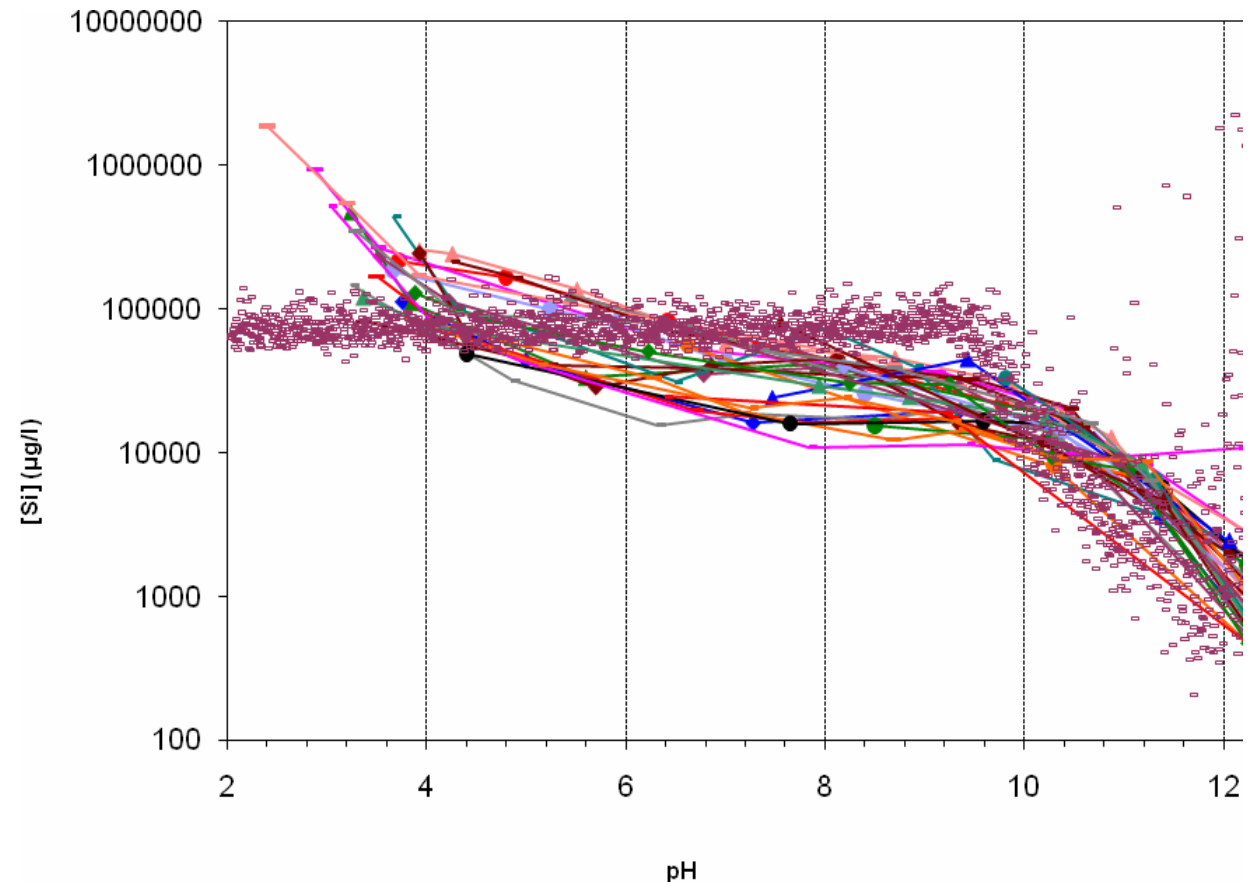

Figure 31. Si concentrations as a function of $\mathrm{pH}$. 


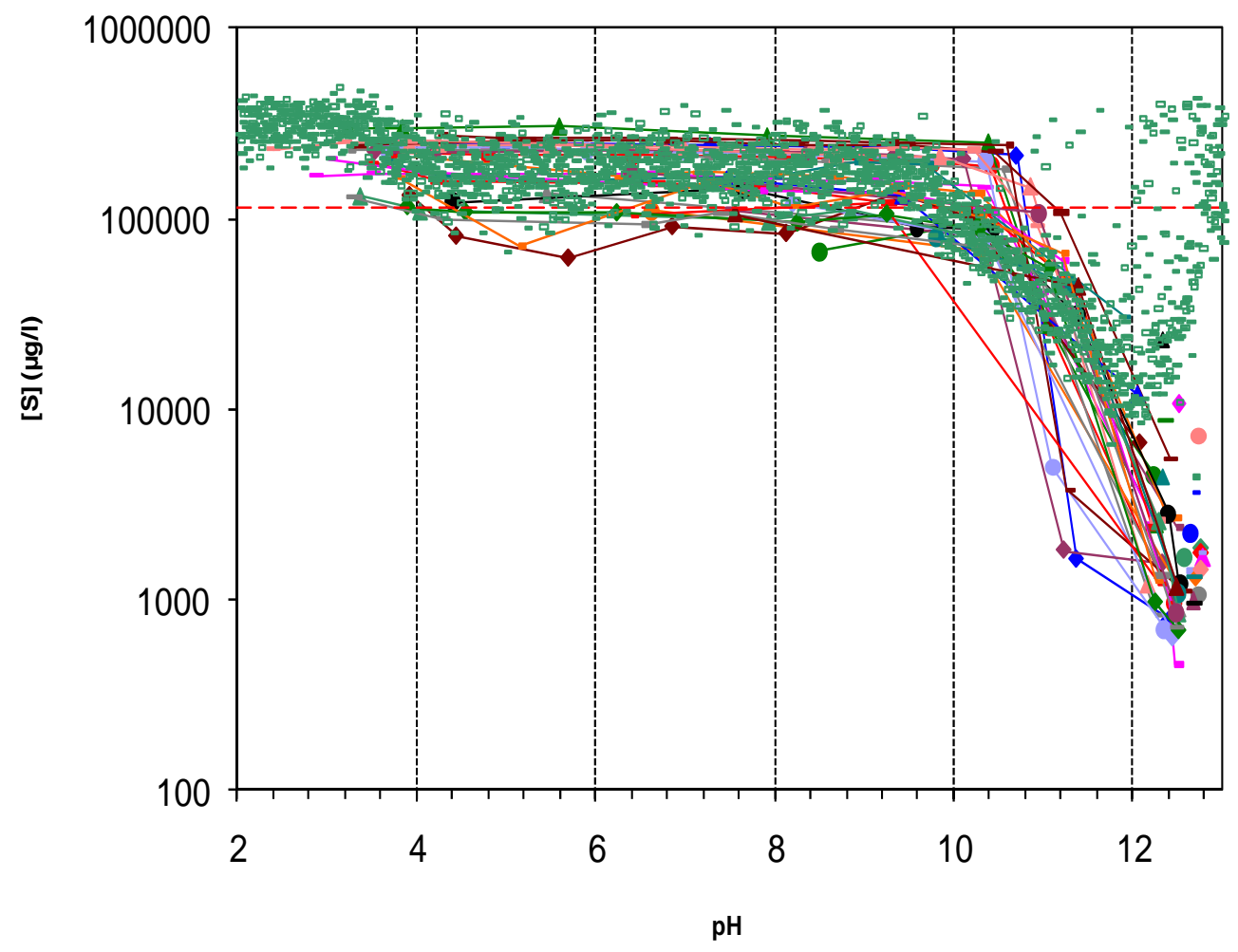

Figure 32. $\mathrm{SO}_{4}$ concentrations as a function of $\mathrm{pH}$.

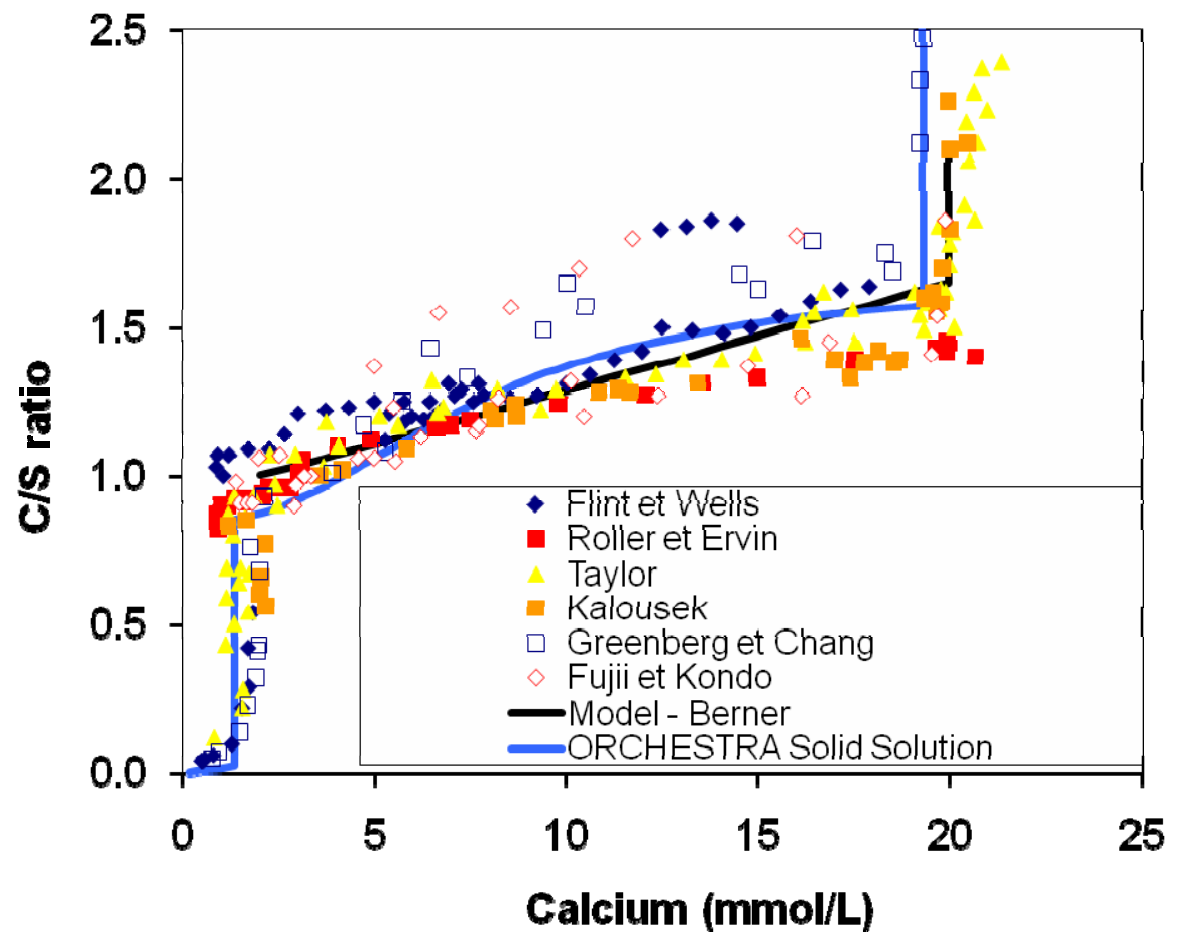

Figure 33. Calculated C/S ratio in cement solid phase. 
Comparison of the calculated C/S ratios with the empirical model by Berner (1988) give very similar results to the solid solution model reported by Lothenbach and others (Lothenbach \& Gruskovnjak 2007; Lothenbach et al. 2008; Lothenbach \& Winnefeld 2006; Lothenbach et al. 2007) that was implemented in ORCHESTRA. Both models appear to give a good description of the data. At low calcium concentrations, the C-S-H phase is not stable and will dissolve forming $\mathrm{SiO}_{2}$ in the process. This will happen when the system is carbonated and calcium precipitates as calcite. The transformation from C-S-H to calcite with the apparent change in C/S ratio of the combined precipitates is predicted well by the ORCHESTRA model.

At high calcium concentrations, portlandite $\left(\mathrm{CaOH}_{2}\right)$ will precipitate. In Berner's approach, portlandite is treated as part of the C-S-H, so effectively the C/S ratio increases with this reaction. The conditions under which incongruent dissolution of C-S-H and precipitation of portlandite occurs are predicted well. The variable $\mathrm{C} / \mathrm{S}$ ratio in the region where C-S-H is stable is predicted somewhat differently, but not obviously better or worse than the fitted linear model.

\subsection{DEMONSTRATION OF THE USE OF PREDOMINANCE DIAGRAMS TO EVALUATE CHEMICAL CHANGES AS A RESULT OF AGING}

\subsection{Description}

Predominance diagrams are diagrams that show the predicted predominant chemical form of a chosen element as a function of two input variables. Probably the most well known examples of such diagrams are the so called $\mathrm{pH}$ - pe diagrams, where $\mathrm{pH}$ and REDOX potential (pe) are chosen as input parameters. Because the predominant form of an element is often related to its behavior, such a diagram can also be used to indicate, for example, mobility or toxicity as a function of system parameters. Predominance diagrams can also be used to visualize the effect of changes in system parameters on mobility or toxicity. This is particularly relevant for those cementitious systems that are not in equilibrium with the environment and will change over time from alkaline to near neutral as a result of carbonation and oxidation. The initial conditions of the material and the path followed through the diagram can be calculated and plotted.

The traditional way to construct such diagrams is to derive analytical expressions for the boundaries between the different predominance areas. This is numerically rapid, once the boundary expressions are derived, but requires some simplifying assumptions for the chemical system under consideration. The most important assumptions are a constant aqueous activity of the predominant species and no effect of ionic strength. These assumptions only work for complexation plus precipitation of pure phases. Adsorption and solid solutions cannot be taken into account. An alternative approach followed here is to calculate chemical speciation for a x$\mathrm{y}$ grid of conditions, and to use the result to determine the predominant species and plot this in a graph. For a single graph of $200 \times 200$ points, 40,000 equilibrium calculations are required, which with ORCHESTRA on current computer hardware requires several seconds of calculation time.

In the examples here, predominance diagrams are constructed for the macro elements $\mathrm{Ca}, \mathrm{Al}, \mathrm{Si}$, and $\mathrm{SO}_{4}$, in a cementitious system relevant for the CBP (Saltstone). This is initially a reducing alkaline material. Upon reaction with $\mathrm{CO}_{2}$ and $\mathrm{O}_{2}$, the conditions change over time. Results of a separate simulation in which is allowed to react with these gases are plotted in all the diagrams. These calculations are sensitive to the chosen initial reducing conditions and to the rate at which the reaction with takes place. Results are indicative, as 
parameters have been assumed that are currently not known in detail for the materials of relevance for the CBP.

Predominance diagrams are also calculated for a number of trace elements. The results for U, Cr, and Tc are especially interesting as these elements have $\mathrm{pH}$-dependent and strong REDOX-dependent solubilities.

\subsection{Description of the Chemical Model System}

Predominance diagrams are calculated with the chemical model as represented by the macro element reactions in Table 17 in combination with the chemical composition of Saltstone. In addition to this model, the relevant reactions for the radionuclides $\mathrm{Tc}, \mathrm{U}$, and $\mathrm{Cr}$ are taken from the Lawrence Livermore thermodynamic Database (referred to as thermo.com . V8.R6. full ${ }^{1}$ ). The only physical parameter required for these calculations is the liquid solid ratio (L/S), which was estimated to be $0.8 \mathrm{~L} / \mathrm{kg}$ for Saltstone under saturated conditions.

Table 17. Total elemental composition of Saltstone as used for predominance calculations.

\begin{tabular}{|l|l|}
\hline Element & $\mathbf{M o l} / \mathbf{k g}$ \\
\hline $\mathbf{C a}$ & 1.234 \\
\hline $\mathrm{Si}$ & 1.395 \\
\hline $\mathrm{Al}$ & 0.480 \\
\hline $\mathrm{SO}_{\mathbf{4}}$ & 0.0394 \\
\hline Ionic strength & Calculated \\
\hline
\end{tabular}

\subsection{Predominance Diagrams for Selected Elements}

\subsubsection{Calcium}

According to calculations (see Figure 34), the predominant calcium forms at alkaline $\mathrm{pH}$ are the solid forms $\mathrm{C}-\mathrm{S}-\mathrm{H}$, calcium aluminum sulfate, and, at very high $\mathrm{pH}$, portlandite. Below $\mathrm{pH}$ 8, the predominant form of calcium is dissolved calcium ion. This result depends on the ratio between the total amounts of calcium and other elements present. In this system, the amount of sulfate present is not sufficient to allow all calcium ions to precipitate as gypsum, although gypsum is a stable solid phase at low $\mathrm{pH}$. This is visible in the sulfate predominance diagram (Figure 38). Another important reactant for calcium is $\mathrm{CO}_{2}$ with which it precipitates as calcite. In this system, the amount of carbonate is assumed to be low as expected in fresh Saltstone. Over time, this is likely to change, which will result in a $\mathrm{pH}$ change. The plotted data points in the predominance diagram indicate the $\mathrm{pH}$ and pe changes expected to occur when Saltstone is allowed to gradually react with atmosphere oxygen and $\mathrm{CO}_{2}$.

Starting at alkaline and reduced conditions, the system will gradually become more oxidized and subsequently the $\mathrm{pH}$ will decrease towards neutral values as a result of reaction with $\mathrm{CO}_{2}$.

1 The thermo.com. V8. R6. full database is available at http://www.geology.uiuc.edu/Hydrogeology/thermo/thermo.com.v8.r6\%2B.dat. 


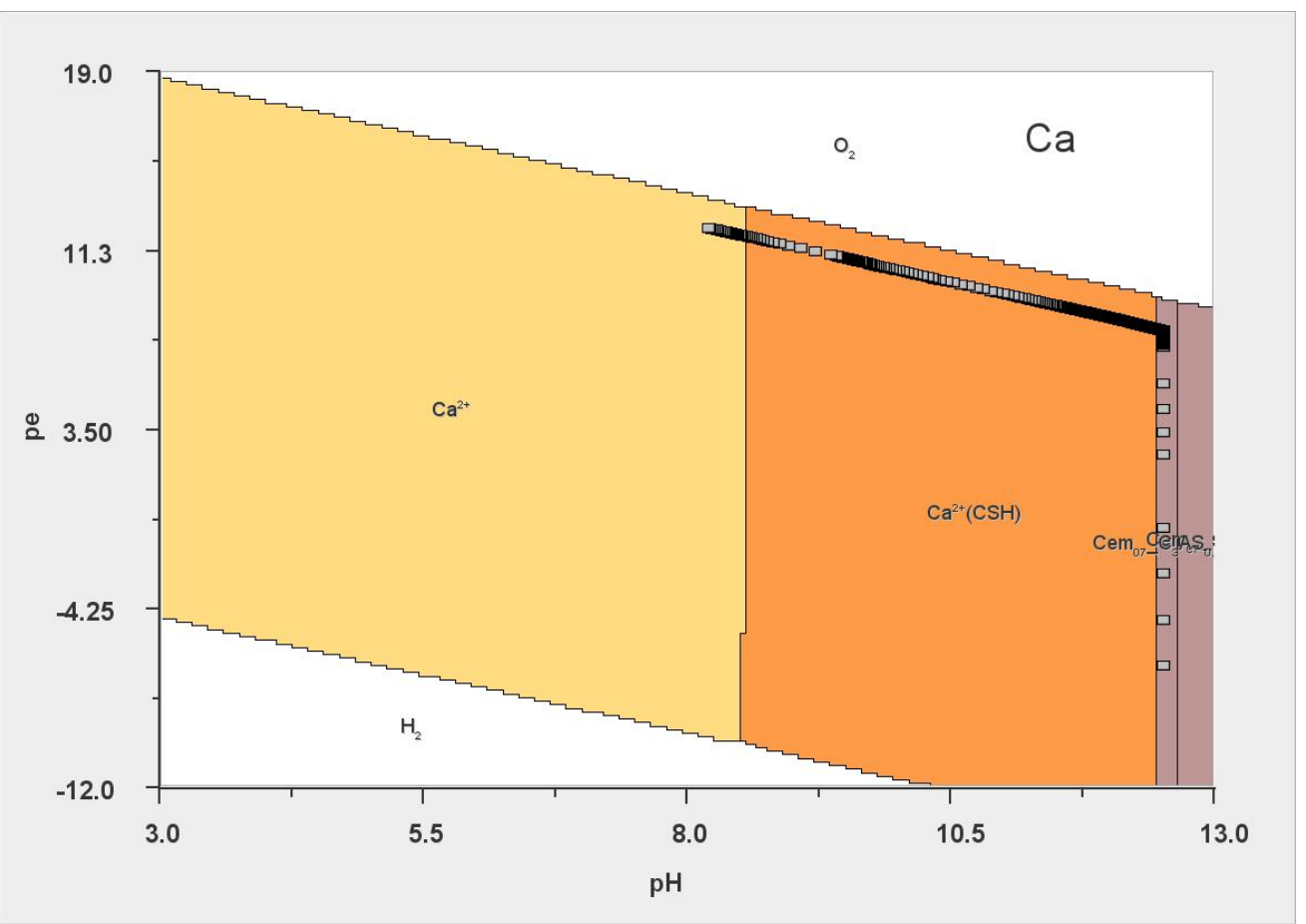

Figure 34. Predominance diagram for $\mathrm{Ca}$.

\subsubsection{Silicon}

Thermodynamically the most stable form containing silica at high $\mathrm{pH}$ is $\mathrm{C}-\mathrm{S}-\mathrm{H}$, just as for Ca (Figure 35). At low $\mathrm{pH}$, C-S-H will dissolve to form $\mathrm{SiO}_{2}$, while at high $\mathrm{pH}$, the main form will be dissolved $\mathrm{H}_{2} \mathrm{SiO}_{4}{ }^{2-}$. From this result, it follows that the mobility of silica is not likely to be very sensitive to REDOX or pH conditions. Only at very alkaline conditions are dissolution and mobilization of silica likely to occur. 


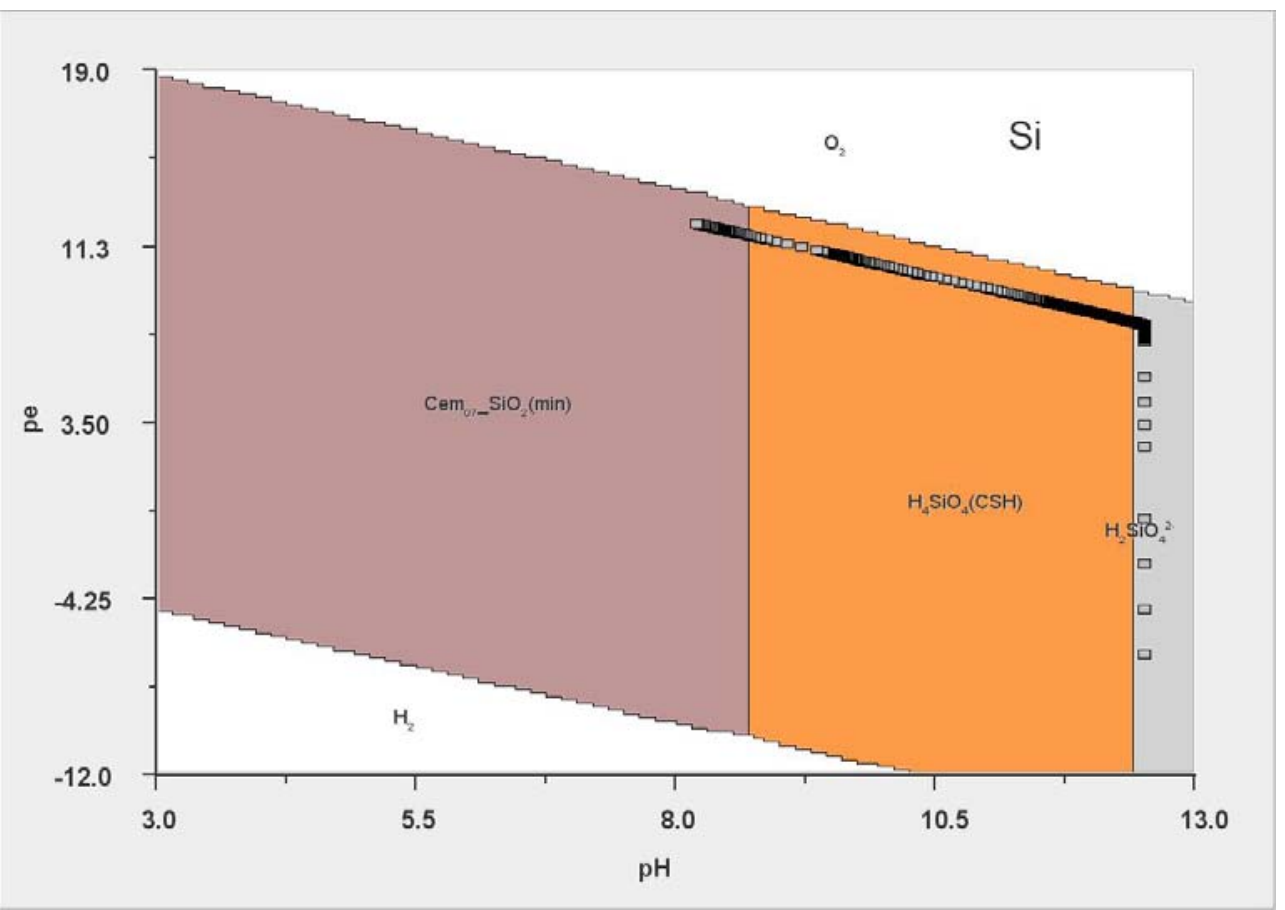

Figure 35. Predominance diagram for Si.

\subsubsection{Predominance Diagram for Al}

The most stable forms containing aluminum in Saltstone system are calcium aluminum silicate at high pH values and aluminum hydroxide at lower $\mathrm{pH}$ values (Figure 36).

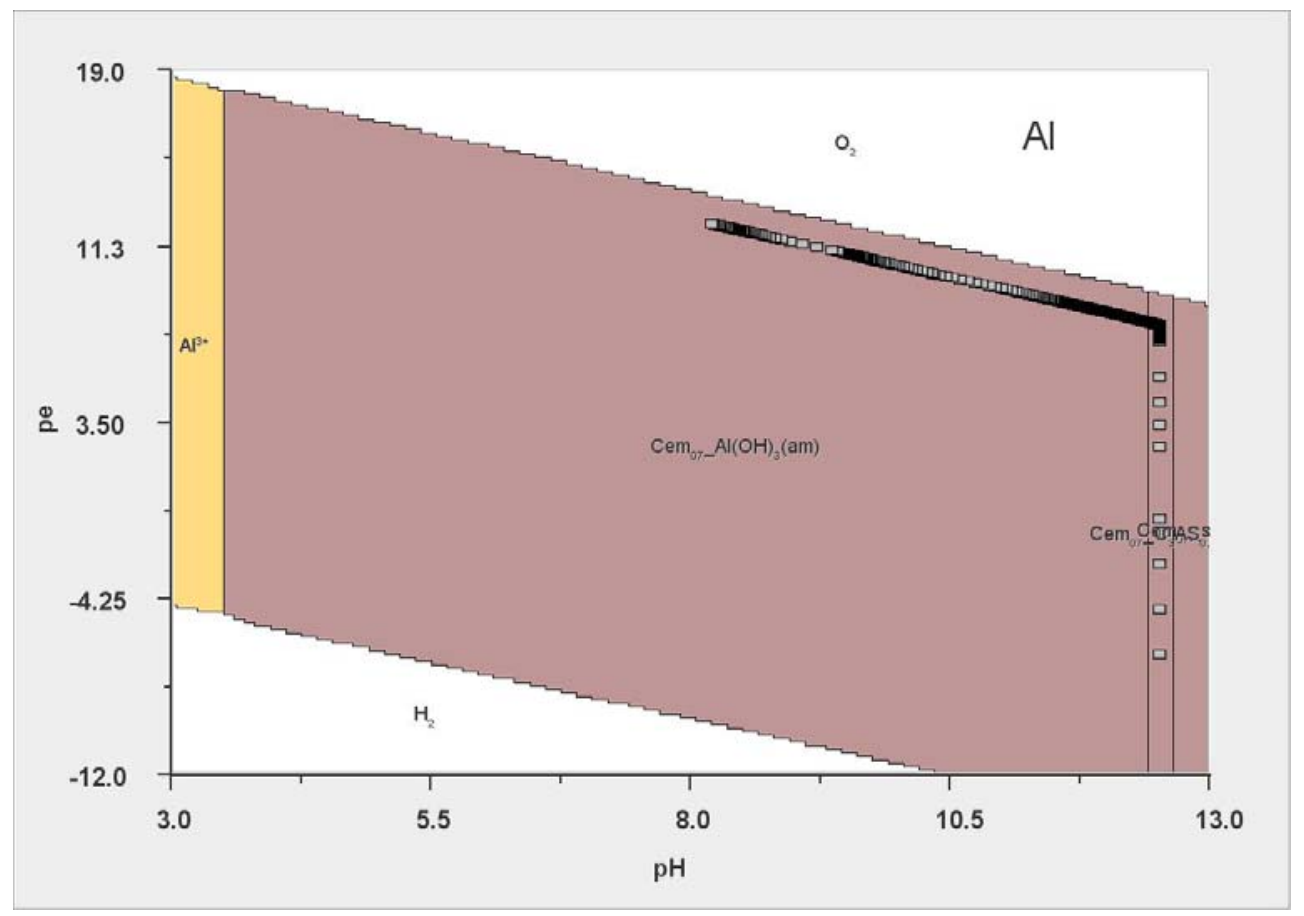

Figure 36. Predominance diagram for Al. 


\section{Demonstration of LeachXS TM/ORCHESTRA Capabilities by Simulating \\ Constituent Release from a Cementitious Waste Form in a Reinforced Concrete Vault}

\subsubsection{Predominance Diagram for S}

For sulfur, the predominance diagram under Saltstone conditions is of great interest. The behavior of sulfur is sensitive to REDOX as well as $\mathrm{pH}$ conditions. Figure 37 shows that under reduced conditions the sulfide form pyrite is stable. These sulfides are mobile when there is not sufficient metals present to form metal sulfide precipitates. Under oxidized conditions, the sulfate forms are predominant. Precipitation of gypsum is important at low $\mathrm{pH}$, while dissolved $\mathrm{NaSO}_{4}{ }^{-}$appears to be thermodynamically the most stable form at high $\mathrm{pH}$. The stability of $\mathrm{NaSO}_{4}{ }_{4}^{-}$results from the high Na concentration in the Saltstone and is unusual for cementitious systems. The formation of this complex makes sulfate much more soluble and mobile, and the usual cementitious sulfate minerals (e.g., ettringite and thaumasite) are much more soluble. This is illustrated in Figure 38, where the predominance diagram is recalculated at a sodium concentration $10 \%$ of that in Saltstone.

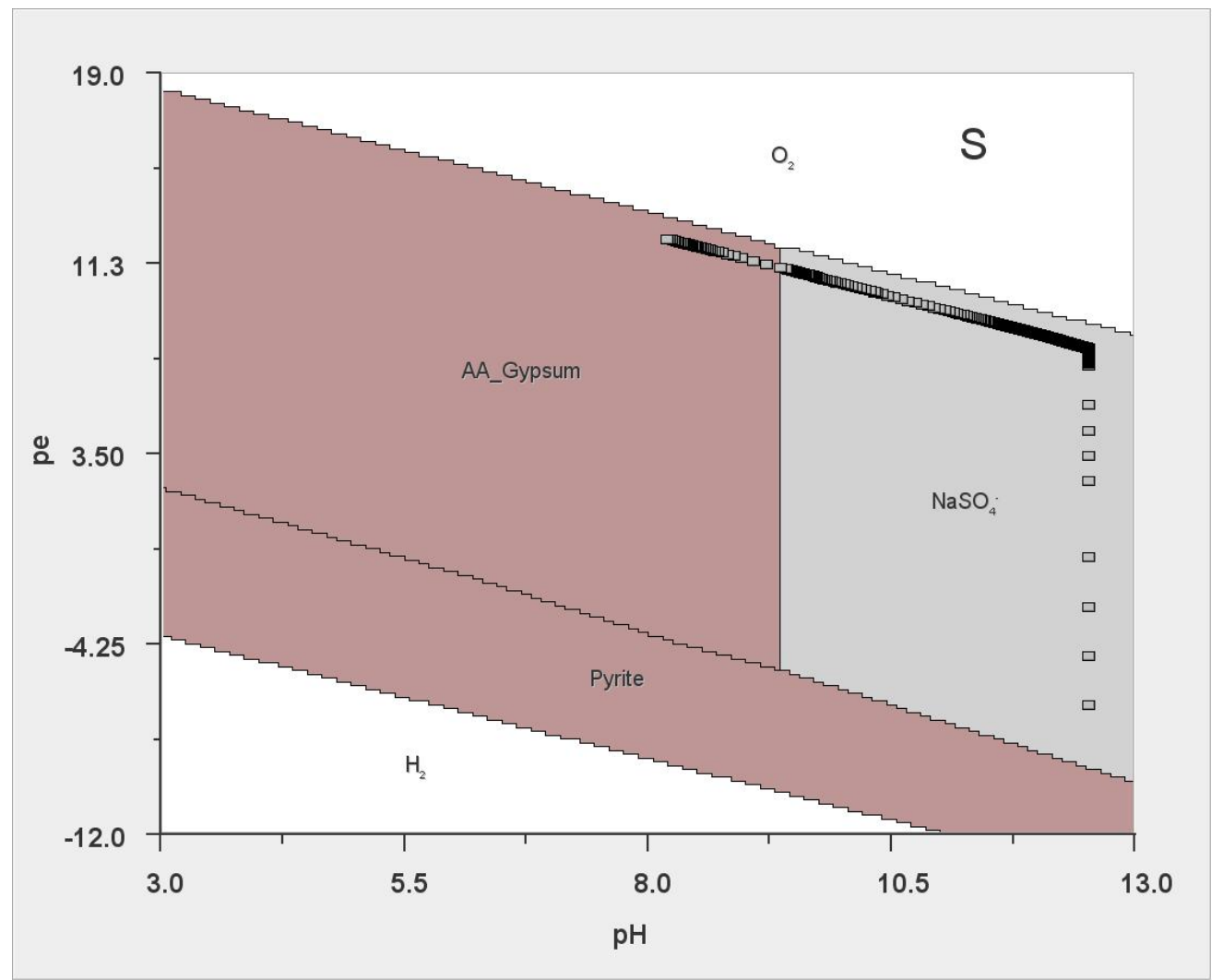

Figure 37. Predominance diagram for sulfur. 


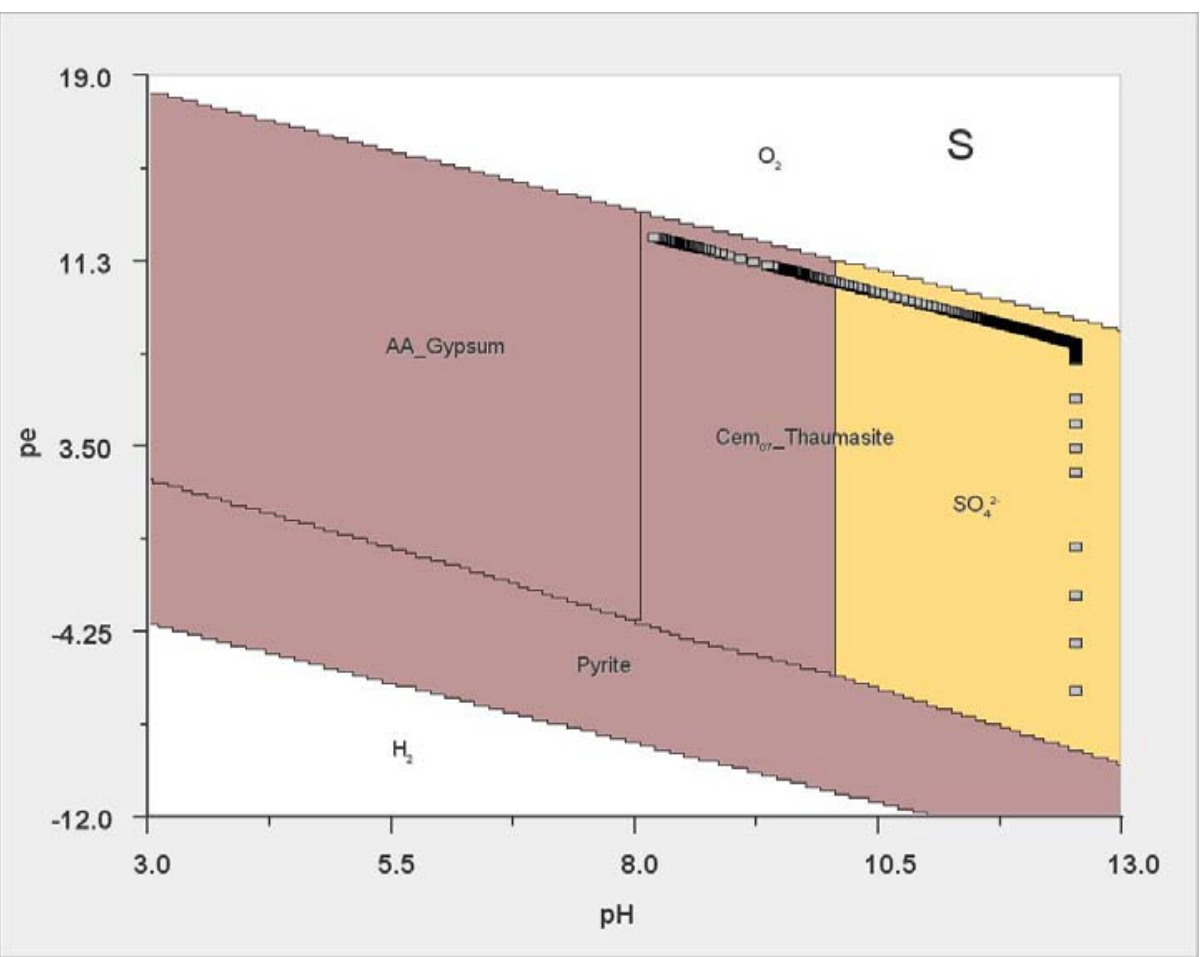

Figure 38. Predominance diagram for sulfur at reduced Na concentrations.

\subsubsection{Predominance Diagram for Tc}

To calculate the stable thermodynamic forms for technetium, an appropriate set of equilibrium reactions was added from the Lawrence Livermore database as shown in Table 18.

Table 18. Equilibrium reactions taken into account for Tc.

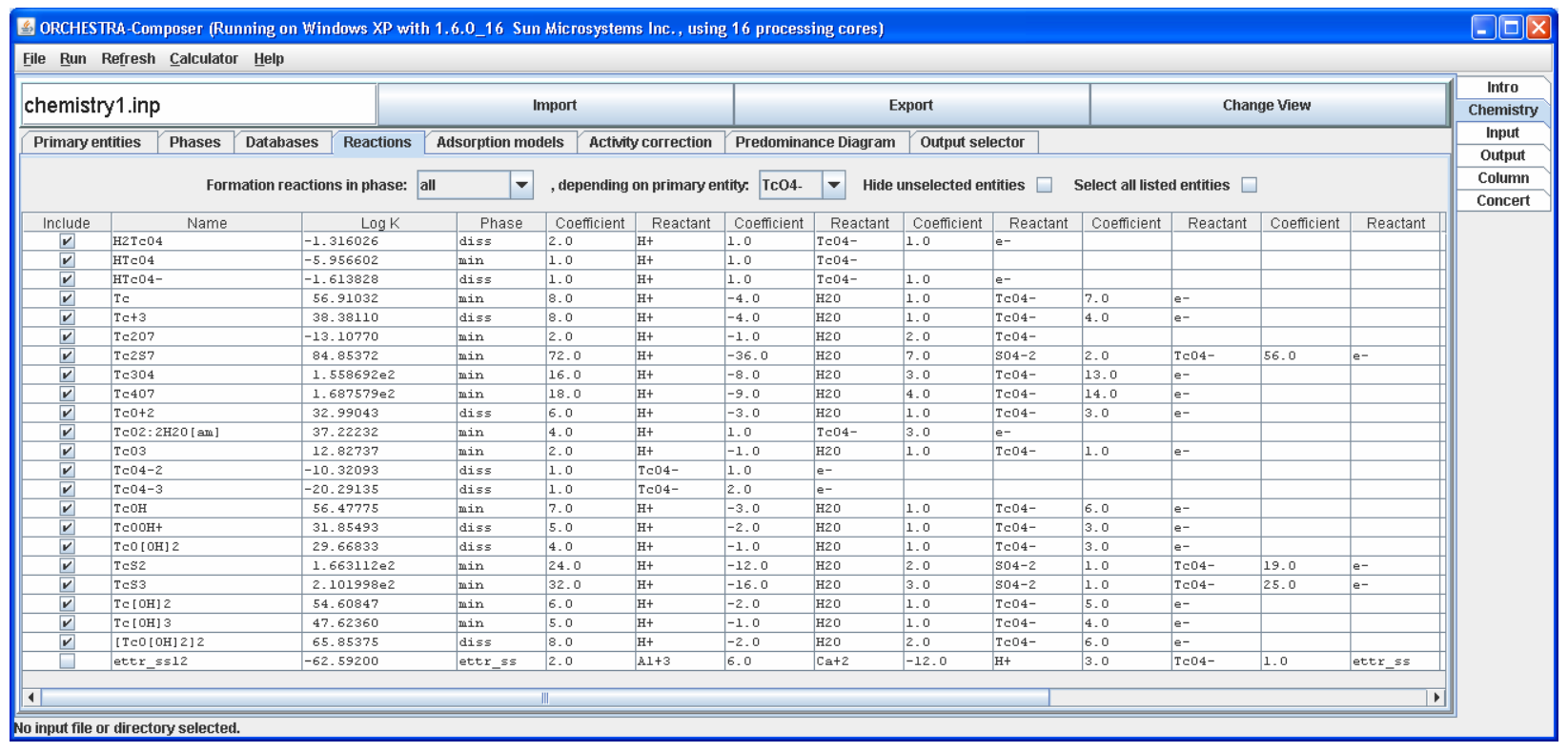


Figure 39 shows the predominance diagram for Tc, showing that the stability of Tc is affected by REDOX and $\mathrm{pH}$ conditions. Under reduced conditions, technetium is stable. As these forms are less soluble than the oxidized forms, technetium will be less soluble and mobile under reduced conditions. The diagram also shows that, upon oxidation and carbonation of the system, oxidized and more mobile forms of technetium will become predominant as time progresses indicating that mobilization of technetium is likely to occur over time.

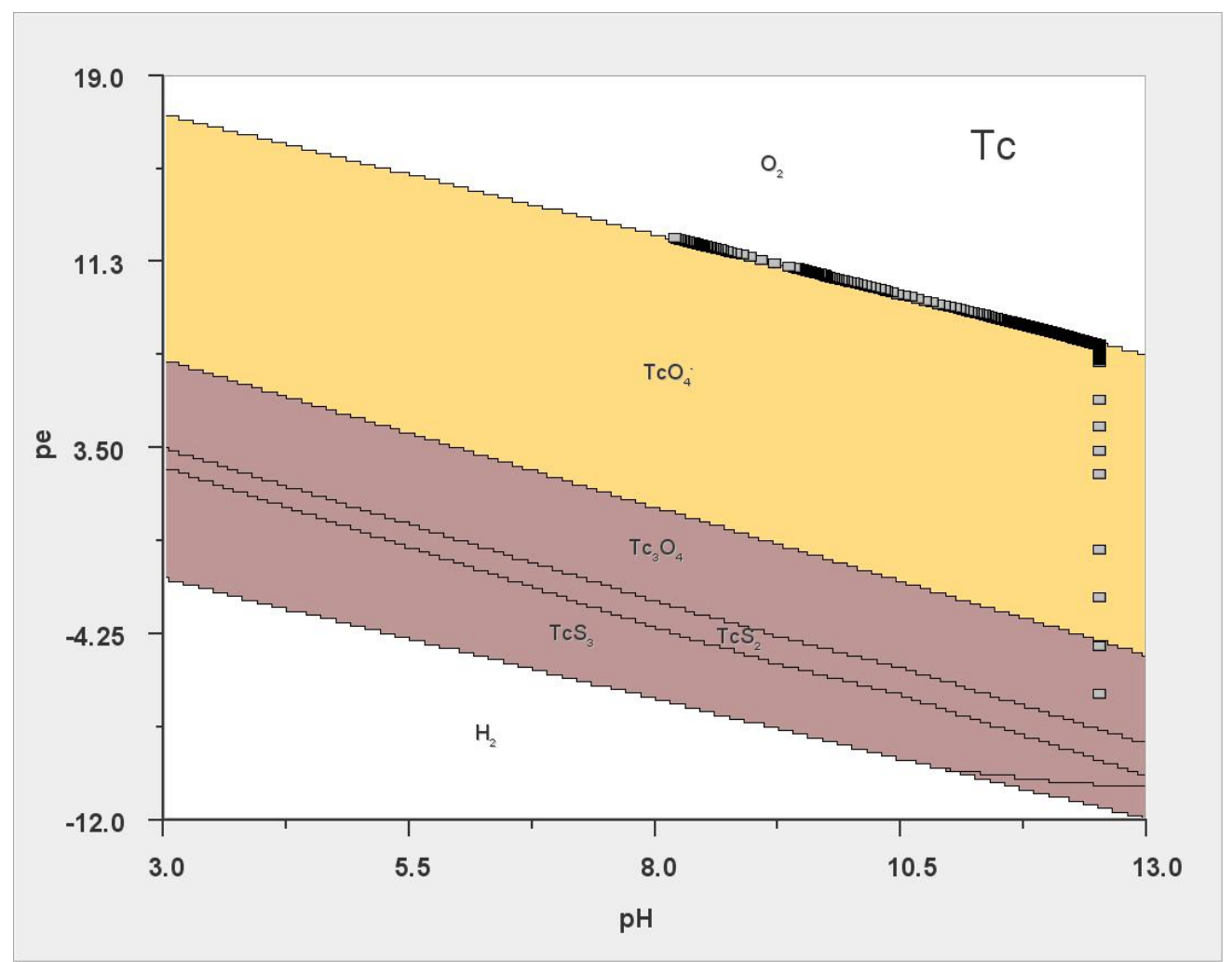

Figure 39. Predominance diagram for Tc.

\subsubsection{Predominance Diagram for $U$}

The predominant forms of uranium are also sensitive to REDOX and $\mathrm{pH}$ (Figure 40). However, under the conditions that are likely to occur in cementitious materials under oxidation or carbonation, precipitated mineral forms will remain the main uranium phase. This implies that, according to the thermodynamic model, oxidation or carbonation of a cementitious system will not lead to increased uranium mobility. Furthermore, the calculated total dissolved concentrations of uranium are very low. 


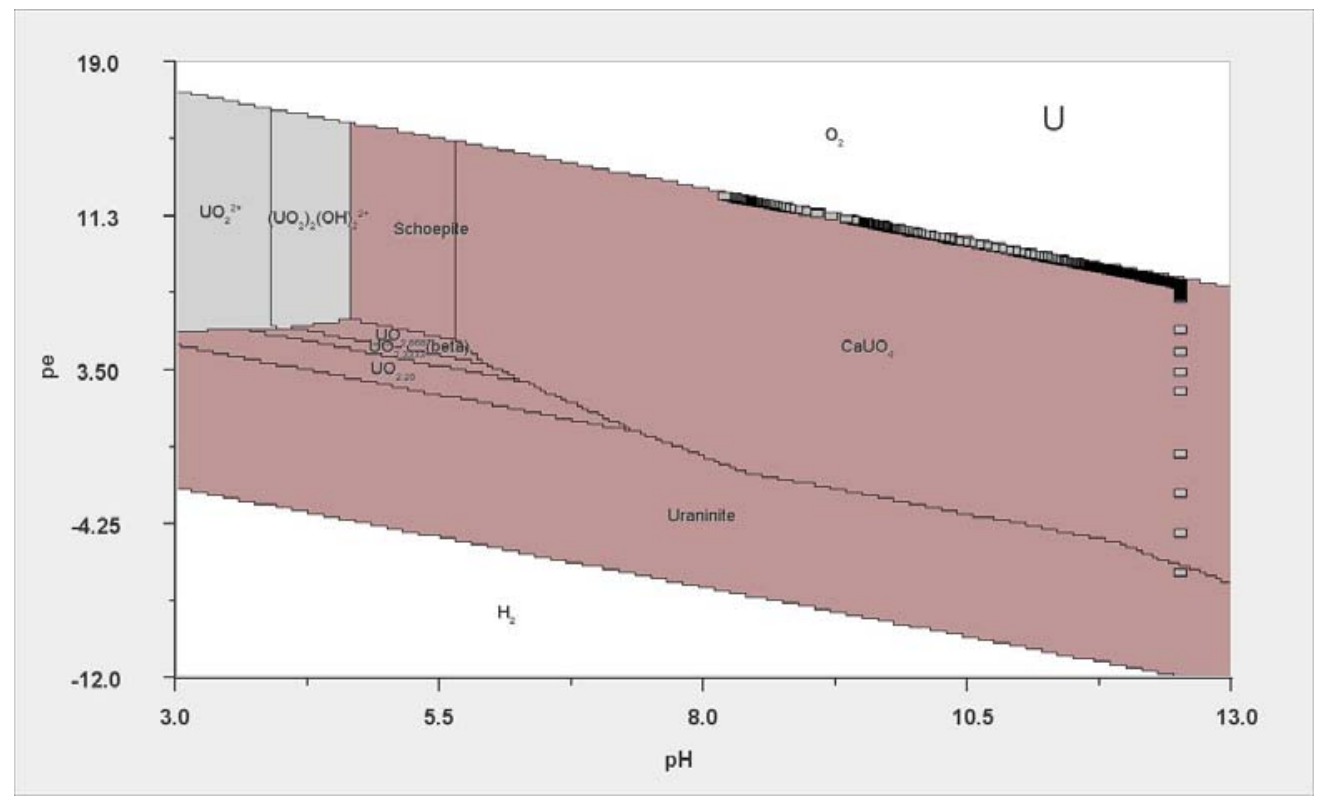

Figure 40. Predominance diagram for $U$.

\subsubsection{Predominance Diagram for $\mathrm{Cr}$}

The behavior of chromium is affected by $\mathrm{pH}$ and REDOX. At low REDOX conditions, $\mathrm{Cr}^{+3}$ forms are stable, which are not very soluble at any $\mathrm{pH}$ but especially not at high $\mathrm{pH}$. As a result, chromium will not be very mobile under reduced conditions. Upon oxidation, chromate will become the predominant form, and because this form is much more soluble, chromium will be much more mobile under these conditions. Chromium is thus likely to become more mobile upon the oxidation or carbonation of cementitious materials. This behavior is very similar to that of technetium. 


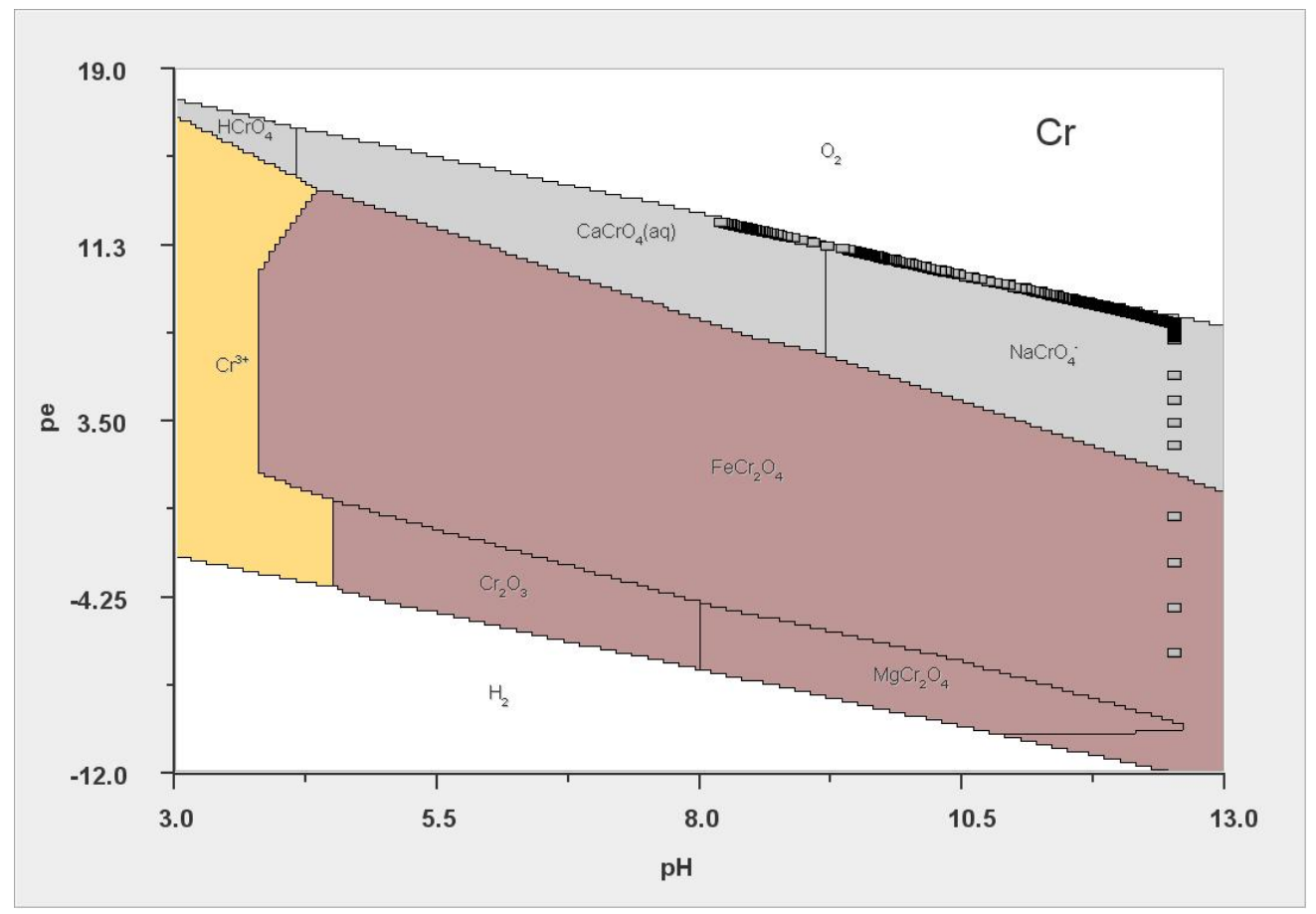

Figure 41. Predominance diagram for $\mathrm{Cr}$.

\subsubsection{Predominance Diagram for $\mathrm{Sr}$}

The predominance diagram for strontium is presented in Figure 42. Under oxidizing conditions, the precipitation of strontium sulfate is predicted. Under reducing conditions, strontium sulfate will dissolve because of the conversion of sulfate to sulfide. There is only a limited set of equilibrium reactions for strontium available in the Lawrence Livermore database. The chemical similarity between calcium and strontium would mean that strontium could replace calcium in part of the (large set) of calcium minerals. 


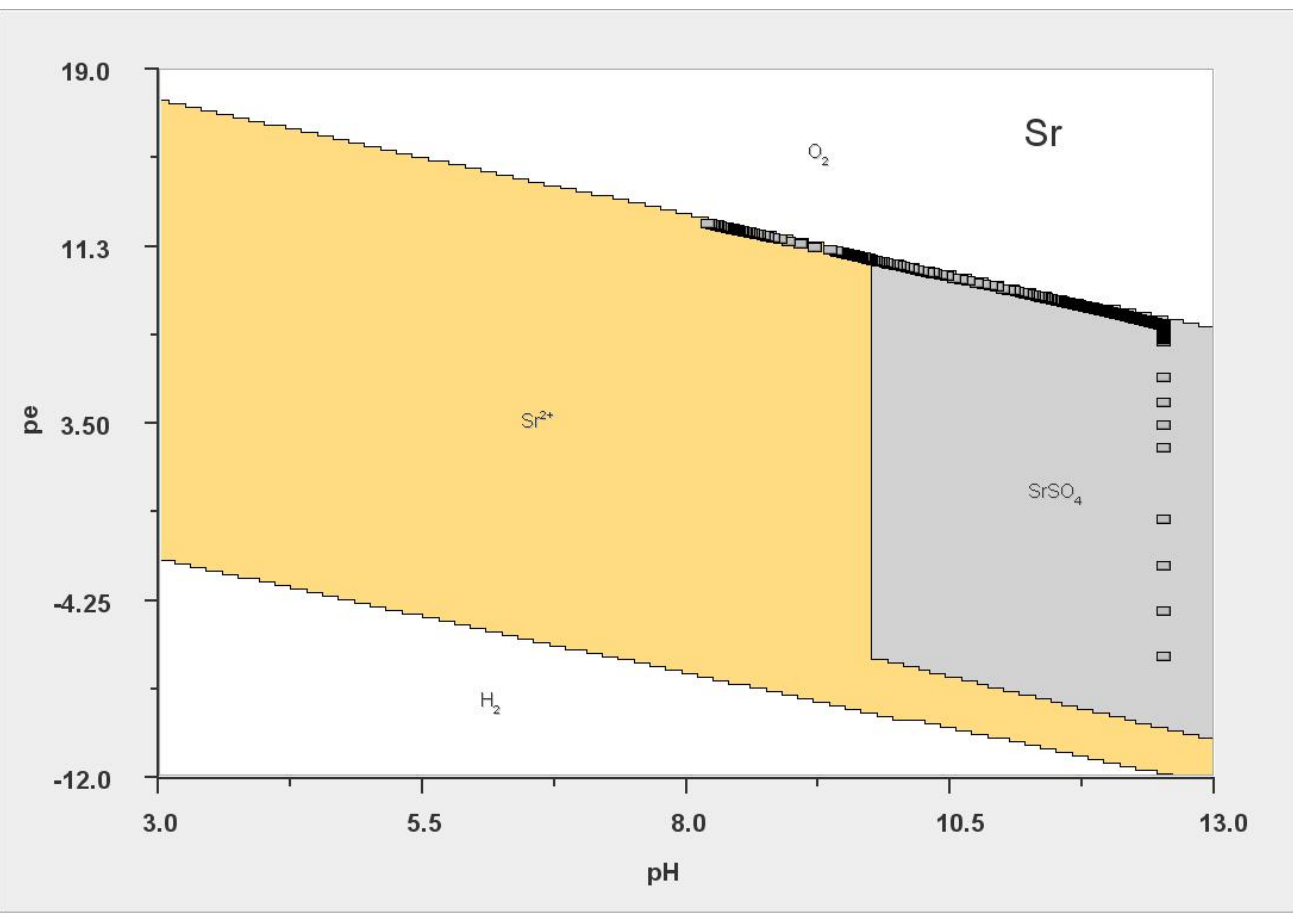

Figure 42. Predominance diagram for Sr.

\subsection{DEMONSTRATION OF REACTION - DIFFUSION CALCULATIONS}

In this section, how the chemical equilibrium model described in the previous chapters can be used in combination with a diffusion module to calculate reactive transport in reactive porous systems will be demonstrated. The main underlying assumptions for this type modeling are that the distribution of dissolved, solid, adsorbed, and gaseous forms for an element are determined by local thermodynamic equilibrium, and that only the gaseous and dissolved ions are mobile and will take part in the diffusion process. The equilibrium module calculates the equilibrium distribution of all components over the different forms/phases at each point in space, and the transport module uses this information to calculate an effective diffusion coefficient and mass transport by diffusion.

In reactive porous systems, such as concrete or soil, there is feed-back between the chemical reactions of different substances and between chemistry and transport processes. For example, changes in chemistry, such as $\mathrm{pH}$ or REDOX potential, can make substances more or less mobile and substances can affect each other's mobility. Such interactions make transport of different substances interdependent (multi-component transport). Therefore, to understand (or predict) the behavior of one component, it is necessary to understand the macro chemistry of the whole system.

\subsection{Overall System Model Description}

The transport system is composed of three distinct one-dimensional layers that represent a layer of waste material, a layer of barrier material, and a layer of adjacent soil. Within this system, the chemical and transport processes are simulated that are responsible for leaching contaminants from the waste material through the 
barrier into the soil. At the same time, diffusion of oxygen and carbon dioxide from the environment into the three layer system and their effect on $\mathrm{pH}$ and REDOX potential are taken into account.

All systems make use of the same set of chemical equilibrium reactions (see Table 14, Table 15, and Table 16).

The physical dimensions of the system, which is comprised of three layers with distinct physical-chemical properties, are:

- $\quad$ Waste layer $=10 \mathrm{~m}$ (semi infinite)

- $\quad$ Cementitious barrier layer $=20 \mathrm{~cm}$

- $\quad$ Soil layer $=50 \mathrm{~cm}$, receiving soil material

\subsubsection{Chemical Composition of Materials Used}

The composition of the material used in the simulations is:

Waste material: total composition taken from Saltstone description in Langton et al. (2009).

Concrete: total composition taken from Cement type IV mixture in Langton et al. (2009).

Soil: clean soil at pH 7 from LeachXS database.

\subsubsection{Physical Parameters of Materials Used}

The van Genuchten parameters (including porosity) of the layers are:

Tortuosity of waste: 5

Tortuosity of concrete: 5

Tortuosity of soil: 1.5

At $70 \%$ relative humidity (RH), conditions are close to water saturation in concrete as well as in the Saltstone. The soil gets much dryer than under saturated conditions, and thus less permeable to diffusion, but remains relatively permeable in comparison with the adjacent concrete boundary.

\subsubsection{Boundary Conditions}

The size of the waste layer is chosen according to the physical dimensions of the Saltstone containers. The boundary conditions in the soil layer that is not in contact with the concrete layer are set at a fixed concentration at the outer boundary. At any position in the system, total element fluxes are calculated and can be given as output.

\subsubsection{Spatial Discretization}

The system is discretized into 100 cells, consisting of 40 waste material cells, 40 concrete barrier cells, and 20 soil layer cells. The cells within the concrete barrier have a thickness of $0.5 \mathrm{~cm}$. The soil and waste layer cells have a variable thickness, starting at $0.5 \mathrm{~cm}$ at the concrete boundary and increasing in size with increasing distance from this boundary. 


\subsubsection{Oxygen and Carbonate Fluxes}

To simulate the effects of oxygen and carbonate entering the system, a flux of oxygen and $\mathrm{CO}_{2}$ was imposed on the soil layer. The rate of this flux is relative to the difference between the calculated oxygen and $\mathrm{CO}_{2}$ partial pressures in the soil solution and the atmosphere.

Effectively, this means that there is equilibrium with atmospheric oxygen and $\mathrm{CO}_{2}$ in the soil at some distance from the concrete barrier but not initially at the alkaline barrier surface.

\subsubsection{Time Domain Considered}

Simulations were performed for a time period of 1000 years.

\subsubsection{Constituents Considered}

The following major constituents ( $\mathrm{Ca}, \mathrm{Al}, \mathrm{Si}, \mathrm{SO}_{4}, \mathrm{Mg}, \mathrm{Fe}$, and $\mathrm{CO}_{3}$ ) and parameters $\mathrm{pH}$ and REDOX potential are considered.

As trace constituents $\mathrm{Na}, \mathrm{K}, \mathrm{Sr}, \mathrm{Cr}, \mathrm{U}$, and Tc have been modeled.

\subsubsection{Results}

The results of the multi-component transport calculations are presented here in the form of concentration gradients in the profile across the three layers at different times. The same calculations also give information on fluxes over any cell boundary in the calculation domain (e.g., total fluxes for each element over the barriersoil boundary). Full information on chemical speciation or any other chemical parameter can also be requested. It is necessary to define the required set of output variables before a model run, because it is impossible to export all available output variables by default, as this would produce vast amounts of data.

\subsubsection{Na Concentration Profiles}

$\mathrm{Na}$ is an example of a mobile element that shows little chemical interaction with the solid phase. As a result, it will be relatively mobile and diffusion will only be significantly affected by the physical parameters of the system, with tortuosity being the most important parameter. The diffusion behavior of Na can give an indication of the mobility of very mobile ions in this system.

The concentration profiles of Na show the initial high Na concentrations in the Saltstone and diffusion of Na through the barrier and soil towards the sink at $10.7 \mathrm{~m}$ at the right soil boundary.

After 5 years, Na is starting to appear at the outside of the concrete barrier. This time is determined by the tortuosity of the barrier. The different gradients in Saltstone, barrier, and soil are directly related to differences in effective tortuosity. Due to the high porosity of the Saltstone, its tortuosity is much lower (faster diffusion) so gradients here are less steep than in the barrier. After 25 years, the maximum diffusion rates of Na through the barrier are reached. These will slowly decline over time as a result of the gradients developing in the Saltstone. 


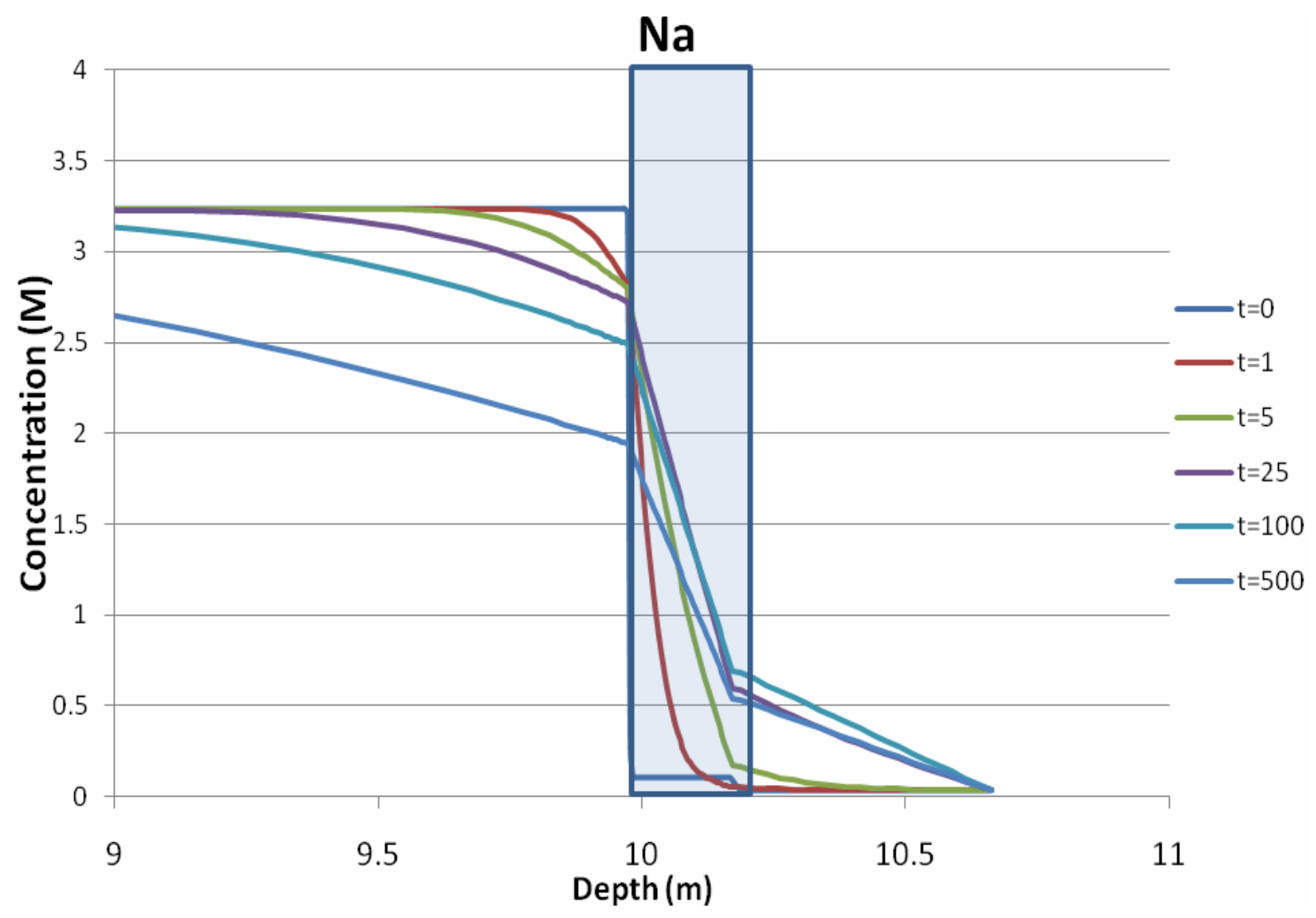

Figure 43. Calculated dissolved Na profiles.

\subsubsection{Calculated pH Profiles}

From the concentrated $\mathrm{pH}$ profiles in Figure 44, it can be observed that the initial calculated $\mathrm{pH}$ in the Saltstone, barrier, and adjacent soil layer is $11.8,12.8$, and 7 , respectively.

At the Saltstone barrier interface, the $\mathrm{pH}$ will initially increase as a result of the chemical interactions taking place. The main driving force for this $\mathrm{pH}$ increase is the dissolution of portlandite from the barrier via the diffusion of calcium from the barrier into the Saltstone. At the barrier-soil interface, there is a high $\mathrm{pH}$ front that slowly extends into the soil layer. Uptake of $\mathrm{CO}_{2}$ lowers the $\mathrm{pH}$. The calculated $\mathrm{pH}$ is the result of the balance between the transport of alkalinity from the barrier to the soil and the uptake of $\mathrm{CO}_{2}$ by the soil. 


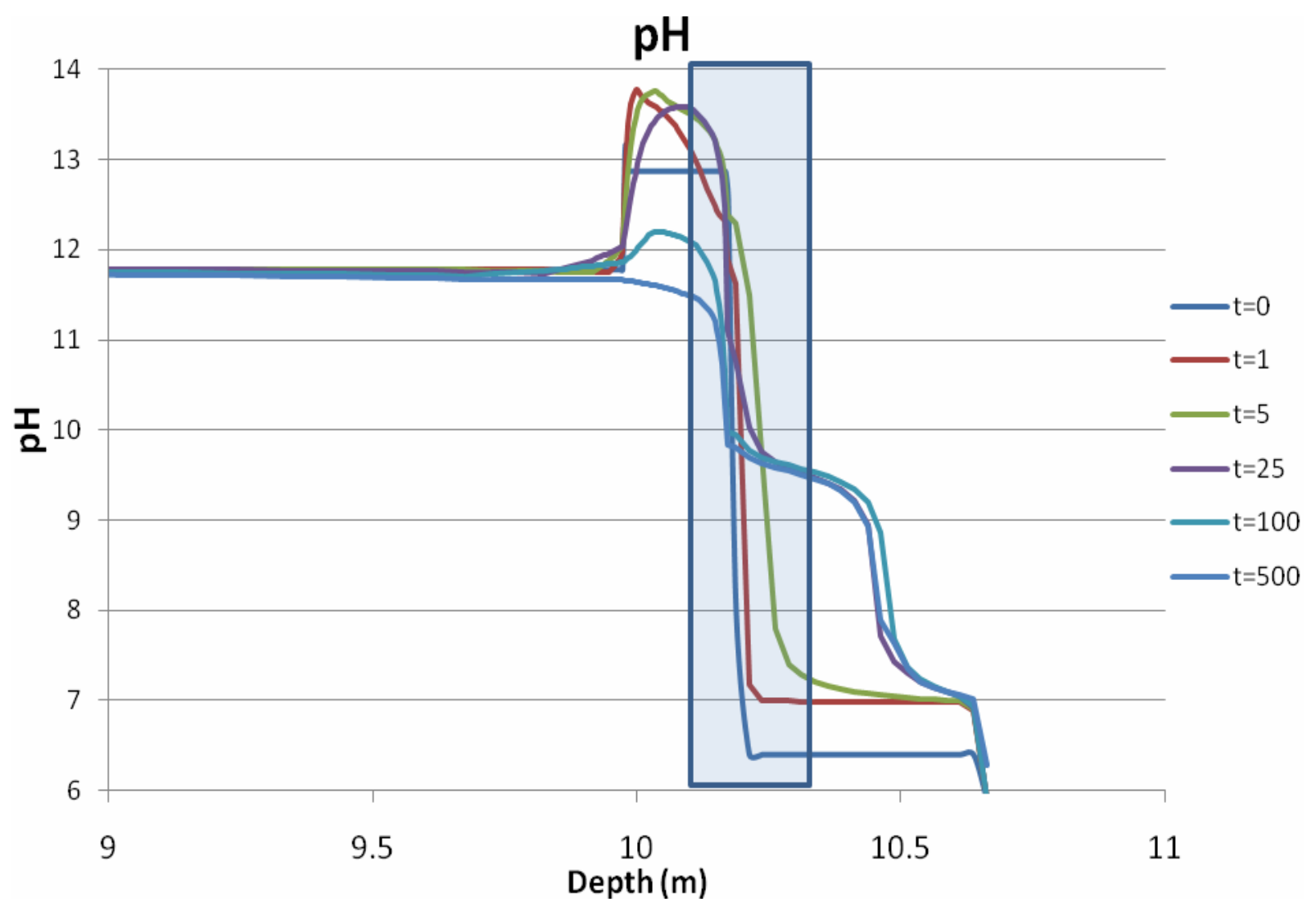

Figure 44. Calculated pH profiles.

The calculated position of the $\mathrm{pH}$ front depends on the description of the chemistry of the different layers, and also on the estimated $\mathrm{CO}_{2}$ uptake rates. It can be seen that even after 500 years of simulated time, both the barrier and the Saltstone are still close to $\mathrm{pH}$ 12. Regardless of the exact position, such a $\mathrm{pH}$ gradient will be important for substances that have $\mathrm{pH}$ dependent solubility and mobility. Substances that have a low mobility at high $\mathrm{pH}$ could be mobilized in the very long term by a decrease in $\mathrm{pH}$. Substances that have a high mobility at high $\mathrm{pH}$ are likely to diffuse out of the Saltstone, through the barrier, and subsequently accumulate in the area where the $\mathrm{pH}$ decreases.

The assumption in these calculations was that all transport of elements between the Saltstone and the outer environment takes place via diffusion through the concrete barrier.

If, in reality, there is direct contact between the atmosphere and the Saltstone, oxidation and carbonation of the outer Salt stone layer will occur much faster than calculated here. This would result in much faster and deeper penetration of the $\mathrm{pH}$ and REDOX fronts into the Saltstone material. This can affect leaching rates of $\mathrm{pH}$ and REDOX sensitive elements from the Saltstone.

\subsubsection{Calculated REDOX Profiles}

The REDOX (pe) profiles (Figure 45) show the calculated REDOX potential profiles as a function of time. The reduced Saltstone initially has a pe of -4 , while the barrier and soil are assumed to be in equilibrium with atmospheric oxygen. The initial REDOX conditions in the Saltstone are such that technetium will predominantly be present in reduced and precipitated form (see Figure 39) and thus be relatively immobile. 
Note the extreme gradient in REDOX potential at the Saltstone - barrier boundary. The REDOX gradients seem to change position only slightly over time, although oxygen is diffusing in from the soil towards the Saltstone. This is caused by the large buffer capacity of the Saltstone, and by the fact that the calculated REDOX potential is also affected by the $\mathrm{pH}$. A decrease in pe will tend to increase the $\mathrm{pH}$ and vice versa. This is illustrated by the apparent decrease of the pe value in the soil, which is the result of the increased $\mathrm{pH}$.

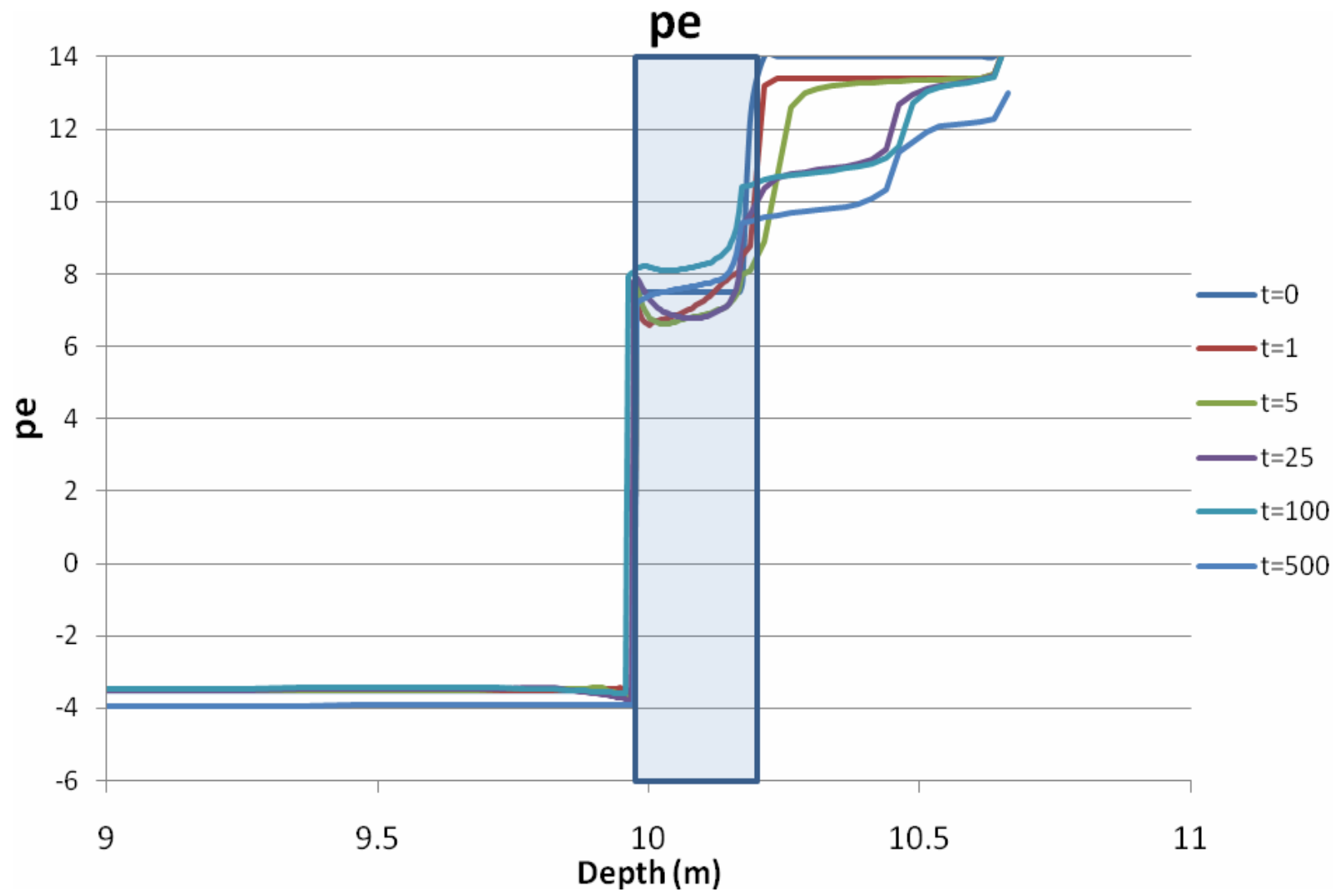

Figure 45. Calculated pe (REDOX condition) profiles.

\subsubsection{Calculated Ca Profiles}

Calcium is the first example of a reactive element for which the solubility and concentrations depend strongly on the $\mathrm{pH}$ and $\mathrm{CO}_{2}$ levels (due to calcite precipitation). In Figure 46, the dissolved Ca concentrations in the Saltstone and in the barrier are low in comparison with the soil solution. This result is in contrast to the total Ca concentration, which is much higher in both the Saltstone and barrier. As a result, Ca has a tendency to diffuse from the soil towards the barrier, which is against the direction of the total concentration gradient.

The changes in Ca concentrations are not the result of direct Ca diffusion but of changes in the Ca solubility as a result of changes in the $\mathrm{pH}$ and $\mathrm{CO}_{2}$ concentrations. In the soil adjacent to the concrete barrier, the $\mathrm{pH}$ increases and $\mathrm{CO}_{2}$ is taken up. This leads to precipitation of calcite and makes Ca less soluble. 


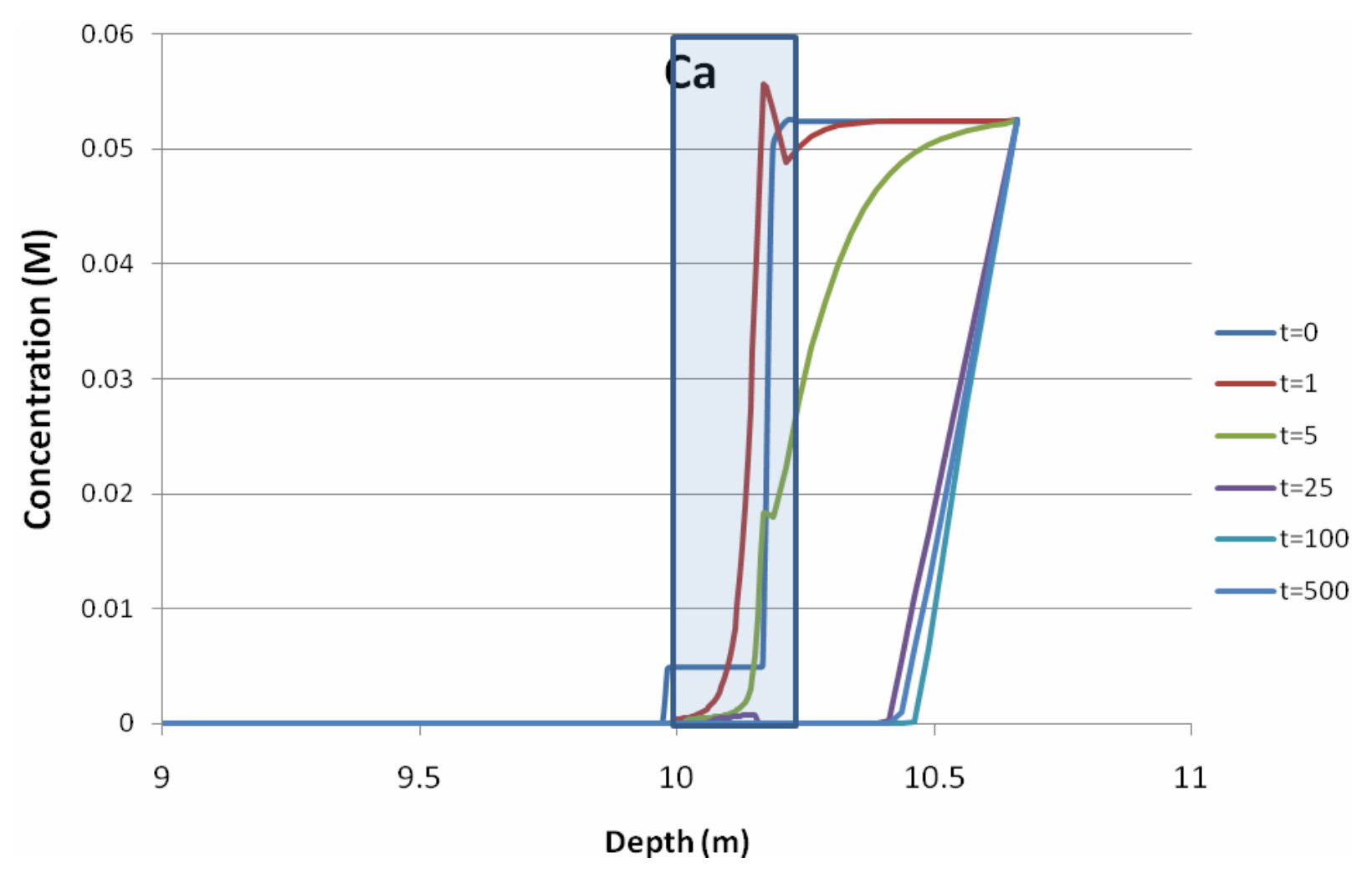

Figure 46. Calculated dissolved Ca concentration profiles.

\subsubsection{Calculated Al Profiles}

Aluminum is another element for which mobility is strongly determined by solubility. For aluminum, the solubility depends on $\mathrm{pH}$ as well as on the Si concentration (Figure 47). 


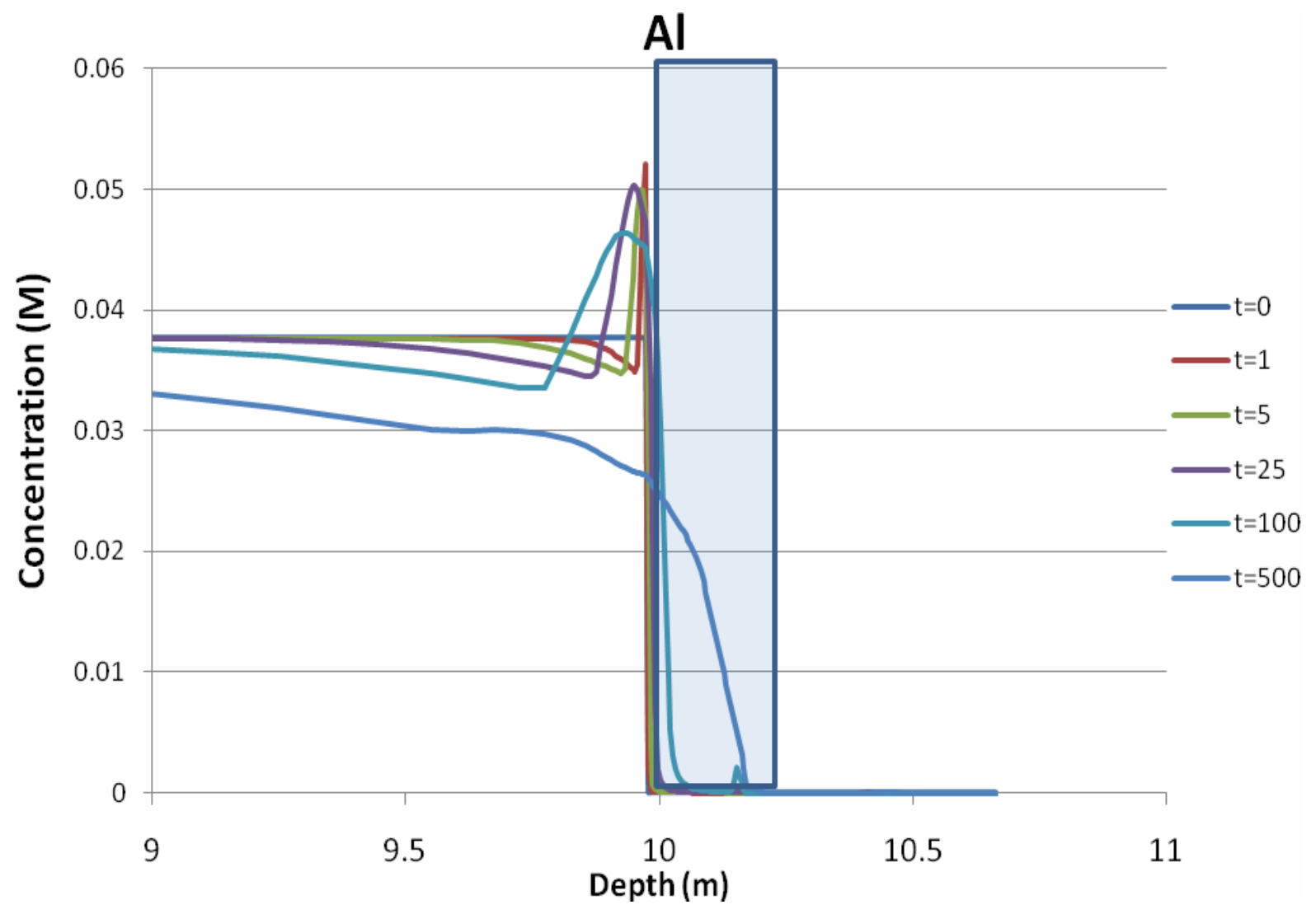

Figure 47. Calculated dissolved Al profiles.

According to the calculations, the solubility of $\mathrm{Al}$ is lower in the barrier than in the Saltstone. The high $\mathrm{pH}$ front diffusing from the barrier into the Saltstone initially increases aluminum concentrations in the Saltstone. Note that the $\mathrm{pH}$ dependent solubility of $\mathrm{Al}$ prevents $\mathrm{Al}$ from diffusing through the barrier in a similar way as $\mathrm{Na}$, although the dissolved concentration gradient would suggest otherwise. Effectively, the Al that diffuses from the Saltstone into the barrier precipitates in the barrier, reducing its concentration there.

\subsubsection{Calculated S Profiles}

The calculated profiles for S, or total sulfate (Figure 48), are very similar to those obtained for Al. However, S diffusion rates through the barrier appear to be higher than those predicted for Al. After 25 years, $\mathrm{SO}_{4}$ appears to diffuse through the barrier in a similar way to Na.

According to the model, the high dissolved Na levels in the Saltstone will make $\mathrm{S}$ more soluble than in other cementitious systems due to the formation of a $\mathrm{NaSO}_{4}$ - complex (see Figure 37 and Figure 38). At the Saltstone - barrier boundary, initially the sulfate concentrations increase sharply. This is the result of the dissolution of sulfate-containing minerals in the concrete barrier caused by the changed local chemical composition in contact with the Saltstone pore solution. This change in composition appears to dissolve sulfate rather than to precipitate more sulfate. After 25 years, this effect has ceased and concentration gradients are then dominated by ion diffusion rather than by dissolution or precipitation effects. 


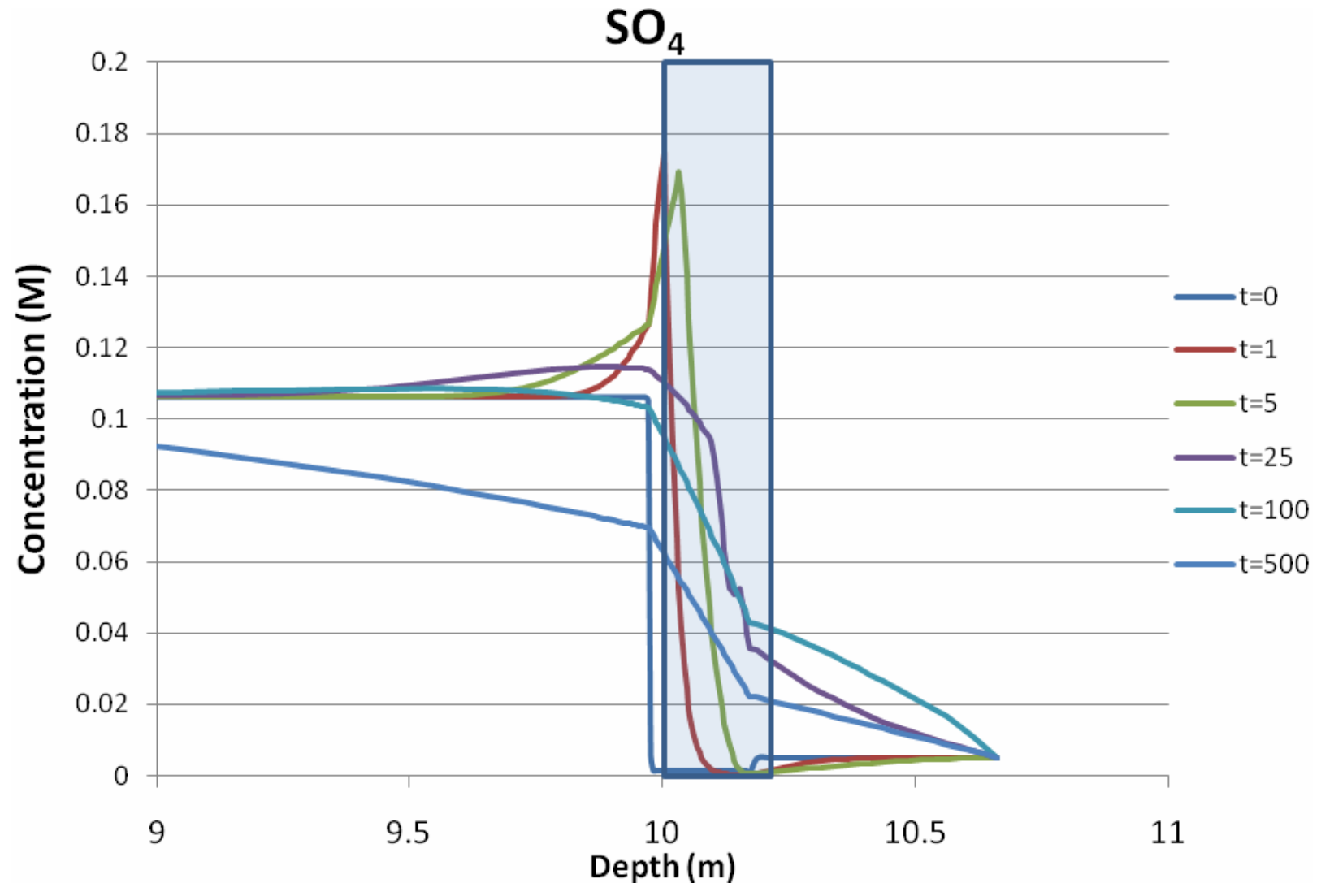

Figure 48. Dissolved total $\mathrm{SO}_{4}$ concentration profiles.

\subsubsection{Calculated $\mathrm{O}_{2}$ Profiles}

The calculated dissolved $\mathrm{O}_{2}$ profiles (Figure 49) show the concentration gradients from the oxidized soil layer towards the reduced Saltstone. $\mathrm{O}_{2}$ diffuses through the barrier and then reacts with the reduced Saltstone material. Diffusion rates through the barrier are low because at the chosen moisture content $(70 \% \mathrm{RH})$ the barrier material is still $96 \%$ water saturated. This means that gas diffusion will only play a minor role.

The model does not currently take into account the possible effects of heterogeneity in porosity. Cracks or fractions of pores with larger dimensions, i.e., those that would be gas filled at $70 \% \mathrm{RH}$, would have a significant effect on gas diffusion rates. 


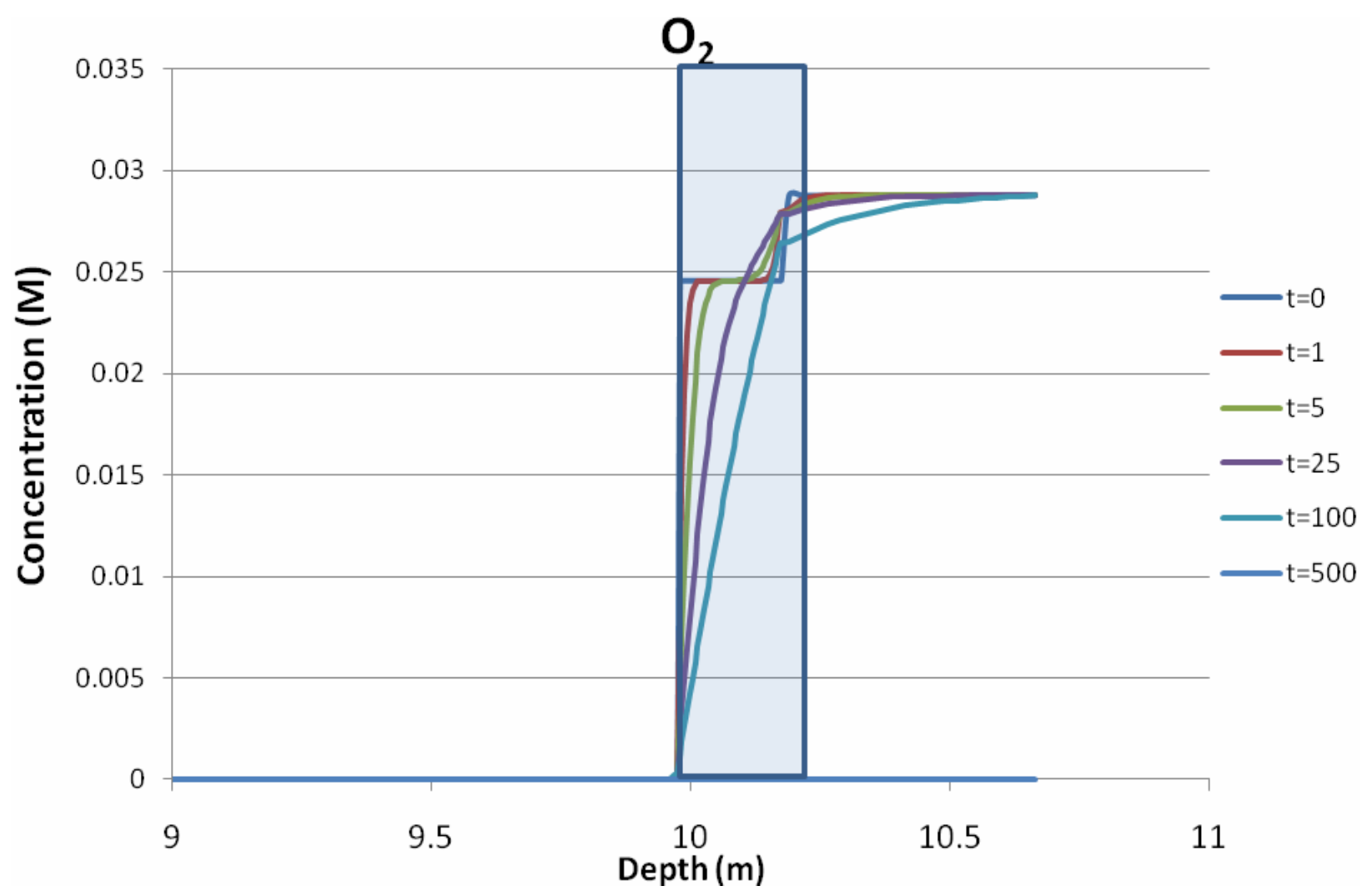

Figure 49. Calculated total dissolved oxygen profiles.

\subsubsection{Calculated $\mathrm{CO}_{2}$ Profiles.}

The calculated $\mathrm{CO}_{2}$ gradients in the system show the effect of $\mathrm{CO}_{2}$ uptake in the soil layer as shown in Figure 50. Initially this $\mathrm{CO}_{2}$ reacts with $\mathrm{Ca}$ to form calcite and does not show up in the solution. At longer timescales, this reaction has a decreasing effect on the $\mathrm{pH}$, and as a result this calcite becomes slightly more soluble, and so $\mathrm{CO}_{2}$ concentrations in solution increase. At very long times, this affects the $\mathrm{pH}$ in the complete barrier which at that time becomes carbonated and less alkaline.

The precipitated amounts of $\mathrm{CO}_{2}$ can be observed in the calcite profiles (Figure 51). Here it can be seen that calcite precipitates where $\mathrm{CO}_{2}$ enters the barrier and dissolves C-S-H and other Ca minerals to form calcite. 


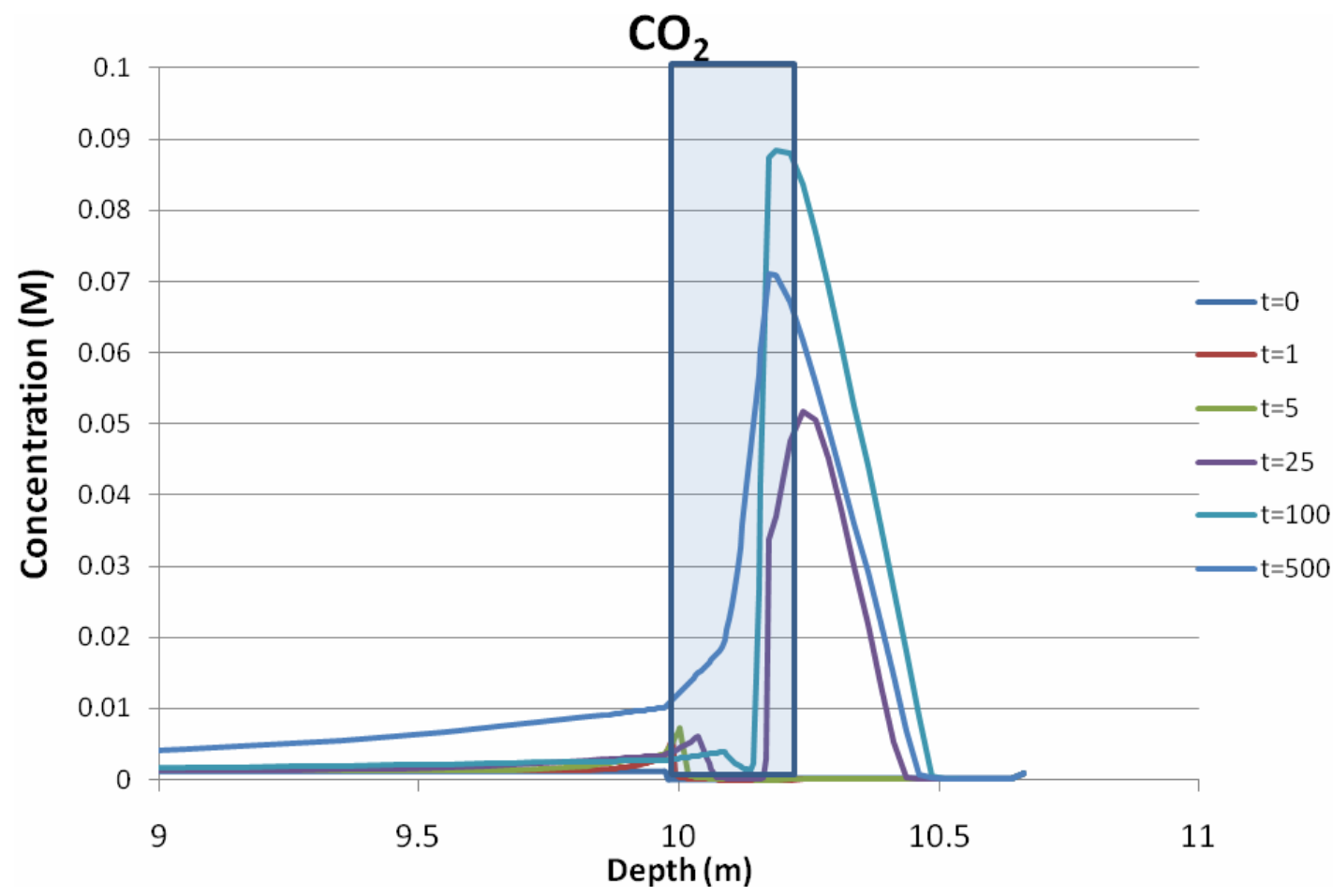

Figure 50. Total dissolved $\mathrm{CO}_{2}$ concentration profiles.

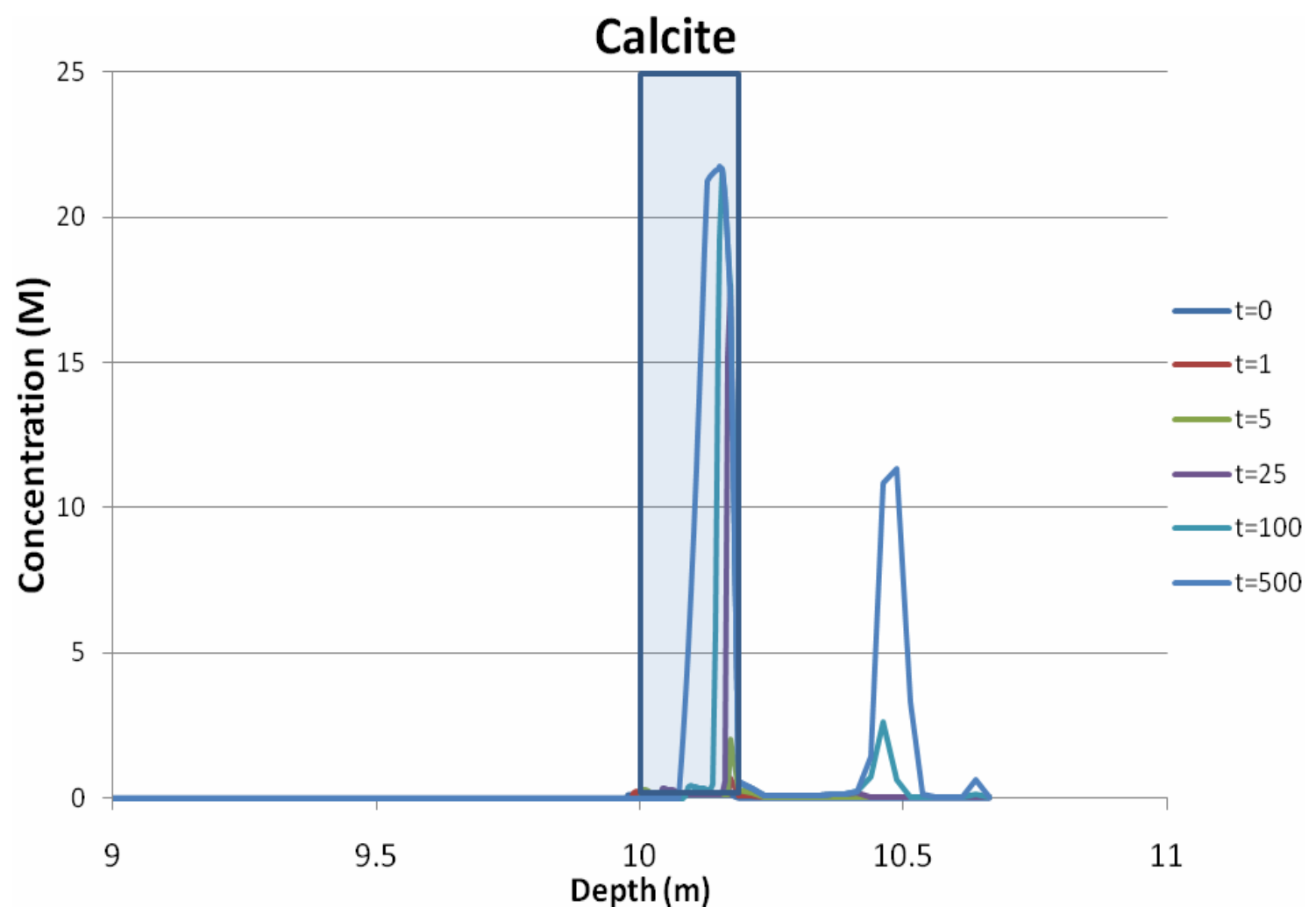

Figure 51. Calcite concentration profiles. 


\subsubsection{Calculated Tc Concentration Profiles}

The technetium concentration profiles (Figure 52) show a concentration peak at the waste - barrier boundary. This is caused by the fact that initially in the reduced Saltstone waste material technetium is present in both reduced and precipitated form. Upon exposure to oxygen, oxidation of technetium will occur and it will be converted to $\mathrm{TcO}_{4}{ }^{-}$. This form is much more soluble than the reduced forms (see also Figure 39). After oxidation, dissolved technetium can diffuse through the concrete barrier in a manner similar to Na. Because in the calculations the concrete barrier is initially oxidized, oxidation of the Saltstone and mobilization of technetium starts immediately at the contact zone between reduced Saltstone and the oxidized barrier. After 525 years, technetium is predicted to diffuse through the barrier, which is very similar to the behavior of a mobile ion such as Na. The total formation rate of oxidized Tc will depend on the diffusion rate of oxygen through the barrier towards the Saltstone. Note that part of the evolving technetium will diffuse further.

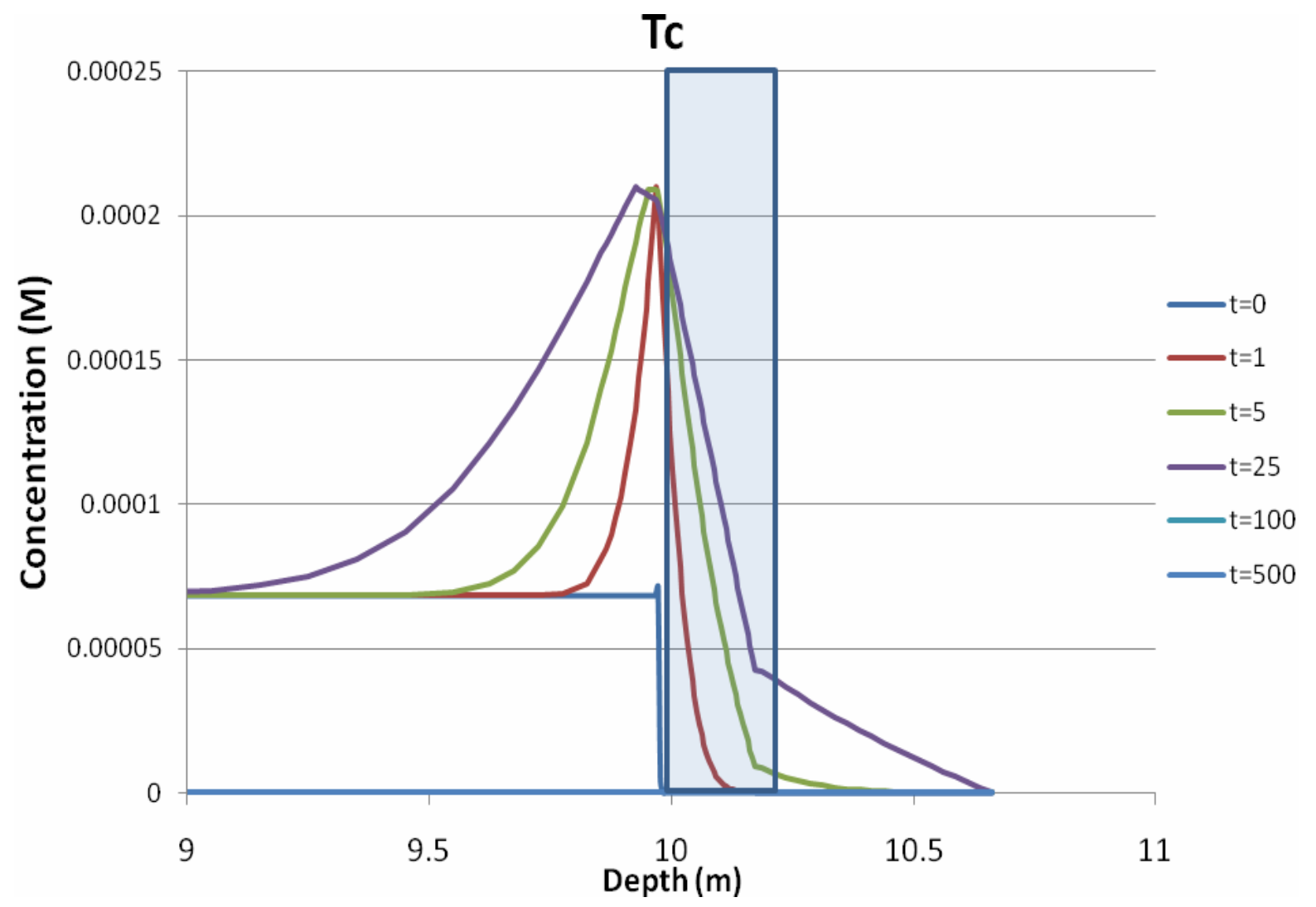

Figure 52. Dissolved Tc concentration profiles.

In the calculations, the only route by which oxygen can reach the reduced Saltstone is through the concrete barrier. If in reality there are other routes by which air can come in contact with Saltstone, such as cracks or (sheet) drains, local mobilization of technetium can occur.

This can be particularly important if air access is combined with the possibility for water flow. In that case, mobilized technetium can diffuse relative quickly into drain water and leach from the system. Leaching rates 
estimations based on homogeneous average REDOX conditions of the Saltstone would be much lower than leaching rates based on local chemical conditions. Oxidation of Saltstone as a whole could take centuries or longer, while oxidation of the outer surface and leaching of technetium could start within years.

\subsubsection{Ettringite Profiles}

Formation of ettringite is an important factor in the process of sulfate attack. The three-layer reactive transport simulations presented here predict if, and at what position within the waste and cement barrier layers, ettringite will form. These predictions are based on the local total elemental composition in combination with the thermodynamic equilibrium model. In contrast with other models, the overall mineral composition is given as output, and not used as input information (i.e., minerals are allowed to precipitate depending on their solubility under given experimental conditions).

From the calculated profiles in Figure 53, it follows that etttingite is only thermodynamically stable within the concrete barrier and not within in the Saltstone waste material or soil layer. The sulfate concentrations in the predicted pore solutions for Saltstone are higher than those in the cementitious barrier. The sulfate ions do diffuse into the barrier from the Saltstone (see Figure 48), but instead of precipitating in the barrier, the other ions diffusing into the barrier change the conditions so that the ettringite present dissolves and reprecipitates deeper in the barrier. A similar process occurs at the barrier - soil barrier, where ettringite also dissolves. After 25 years, it is possible to see that ettringite is only present in the center of the barrier and after longer times it has completely disappeared.

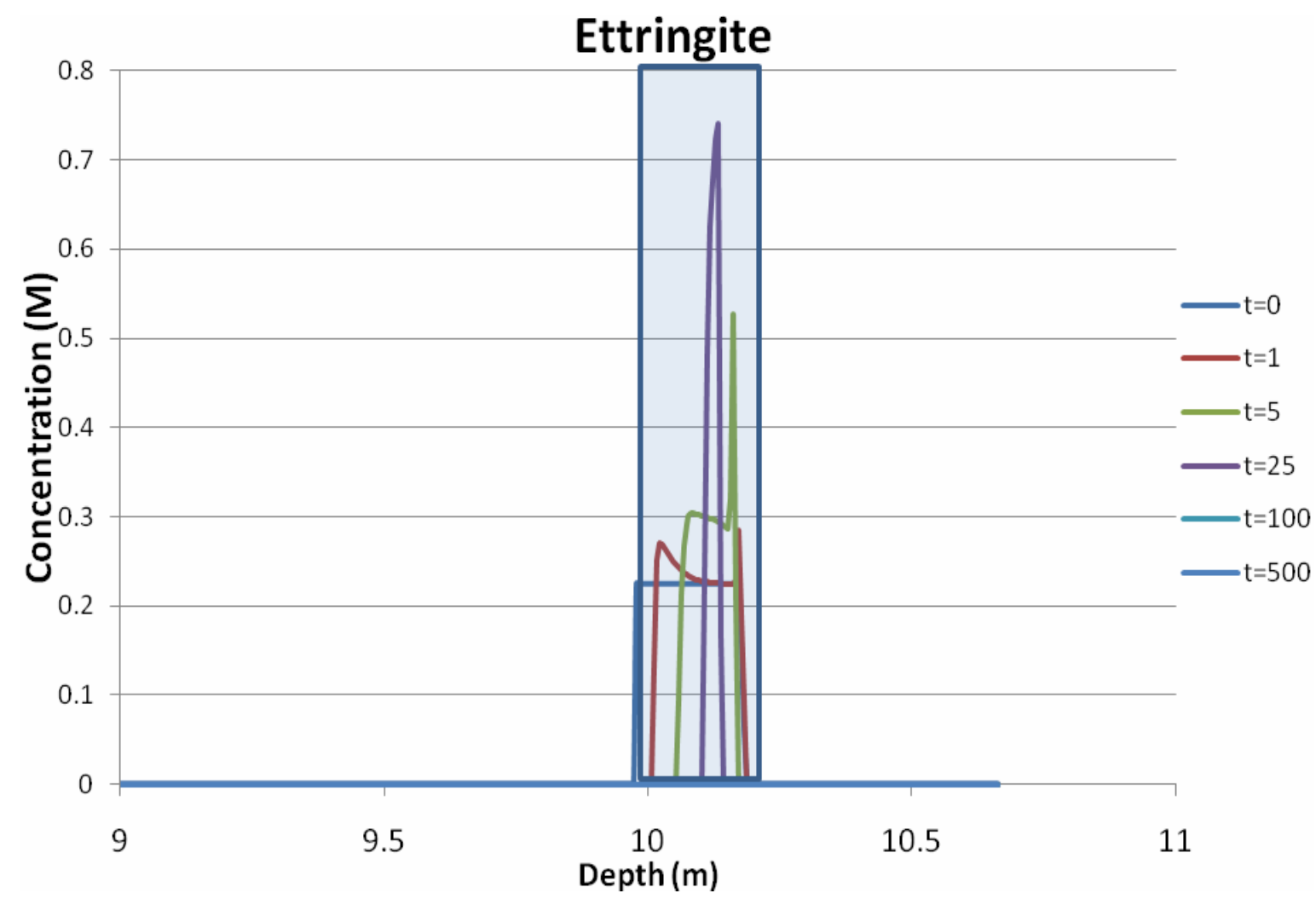

Figure 53. Calculated concentrations of Ettringite as a function of depth. 


\section{Demonstration of LeachXSTM/ORCHESTRA Capabilities by Simulating \\ Constituent Release from a Cementitious Waste Form in a Reinforced Concrete Vault}

According to these simulations, the composition of the pore solution of the Saltstone will not induce ettringite precipitation, which means that sulfate attack as a result of the concrete barrier in contact with salt stone will not occur. However, the prediction of ettringite precipitation is quite sensitive to predicted $\mathrm{pH}$ and activities of all ions involved. In the high salt concentrations present, this is not a trivial task.

It would thus be advisable to evaluate these predictions with experimental measurements on the materials involved, including measurements to identify the presence of ettringite in Saltstone, or the formation of ettringite in cementitious material in contact with solutions of composition similar to Saltstone pore water, would be important to perform.

\subsection{MODELING SULFATE ATTACK AND CRACKING}

ORCHESTRA is used as the basis for modeling sulfate attack resulting from ettringite formation, which is expected to occur as a result of sulfate from the waste entering the concrete barrier. The methodology includes diffusion of ions in and out of the structure, chemical reactions which lead to dissolution and precipitation of solids, and mechanical damage accumulation using a continuum damage mechanics approach. Diffusion of ions is assumed to be driven by concentration gradients as well as by chemical activity gradients. Chemical reactions are assumed to occur under a local equilibrium condition, which is considered to be valid for diffusion-controlled reaction mechanisms. A macro-scale representation of mechanical damage is used in this model, which reflects the cracking state of the structure. The mechanical and diffusion properties are modified at each time step based on the accumulated damage. The model is calibrated and validated using experimental results obtained from the literature. The usefulness of the model in evaluating the mineralogical evolution and mechanical deterioration of the structure is demonstrated. A full description of the model and its outputs are provided in a separate article by the authors (Sarkar et al. 2010).

\subsection{EVALUATION OF REFERENCE CASE SIMULATIONS}

\subsection{Waste Vault}

\subsubsection{Hypothesis Used}

In the reference scenario for the waste vault, a three layer diffusion system is used as a conceptual model. The main assumption for this model is that contaminant leaching rates from the waste material to the outer environment are determined by diffusion of dissolved ions and gases through the barrier layer. The model calculates gradients for all elements and gases in waste, barrier and adjacent soil, and uses this information to calculate release and uptake (for $\mathrm{O}_{2}$ and $\mathrm{CO}_{2}$ ) fluxes, taking into account thermodynamic equilibrium of elements over solid, dissolved and gaseous phases. Two diffusion models are available. The first is based on more than 25 substances, more than 30 minerals, sorption on iron oxide phase, particulates, and dissolved organic matter, and taking into account only diffusion under saturated conditions. The second model considers partial saturation and transport of substances and gasses by diffusion with a more limited set of substances and mineral phases.

\subsubsection{Alternative Hypotheses}

In the situation of a real vault, it is highly possible that diffusion through the barrier is not the only route by which exchange with the environment can occur. If, for example, there is some space between the waste 


\section{Demonstration of LeachXSTM/ORCHESTRA Capabilities by Simulating \\ Constituent Release from a Cementitious Waste Form in a Reinforced Concrete Vault}

material and the barrier (e.g., in the form of a sheet drain), this space would provide a much faster route for $\mathrm{O}_{2}$ and $\mathrm{CO}_{2}$ to enter the system, and to oxidize and carbonate the adjacent waste material. Furthermore, the same channel could also function as a drain, and transport substances very rapidly to (and through) the bottom of the vault if the vault is not completely watertight from the top. This transport route would be much quicker than diffusion-controlled transport through a cementitious barrier. This would require a 1-D diffusion model with full chemistry for the quantification of release using a very low infiltration rate. This model could be set up by modifying the current three-layer model. The possible gas interaction in this case is available in ORCHESTRA and can be readily implemented in LeachXS ${ }^{\mathrm{TM}}$ to facilitate data handling and scoping activities (including selection of boundary conditions).

\subsubsection{Consequences for Predicted Release Rates}

In case the cover of the vault is not completely waterproof and flow channels through or around the waste material exist or will develop over time as a result of cracking, diffusion will still be an important process determining contaminant release, but predicted release rates, especially over longer timescales, will be much greater due to the shorter flow paths. In the same way oxidation and carbonation of the waste material will also proceed much faster, which is relevant for waste materials that obtain their retention capacity from their reducing properties.

The progression of both the carbonation and REDOX front are of major relevance for the release of radionuclides. As discussed in Section 4.4, "Simplified Solutions for Assessing Release," the release of anionic species can be described in a simplified manner by assuming that the entire leachable amount is released from the carbonated and or oxidized layer. The amount that diffuses back into the waste body can be neglected at first. The modeling of the rate of carbonation/ oxidation is feasible within LeachXSTM/ORCHESTRA. Key issues for this modeling are preliminary estimates of the water influx and the degree of air access.

Even though the calculation of diffusion through a concrete barrier and from a waste material to a flow channel

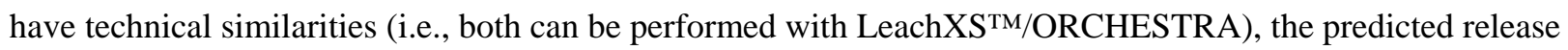
rates will be very different. Selection of the most appropriate conceptual model is thus essential for realistic release rate predictions.

\subsubsection{Possible Effects of Colloids}

Apart from the physical configuration of the system, another important factor in determining release rates, especially of relatively immobile substances, is chemical binding to colloidal particles. Substances that would be relatively insoluble, and thus immobile, in pure water, can effectively become much more mobile by adsorption onto organic colloids (McCarthy \& Zachara 1989). This is a well known process in soil systems, where for example heavy metals such as copper and lead can become much more mobile as a result of adsorption onto dissolved organic carbon (DOC). Since DOC has been found to be present in simulated waste forms, the role of dissolved organic carbon as a mobile complexant is possible and should be evaluated for very water-insoluble substances with a high affinity for organic matter (both solid and dissolved).

\subsubsection{Retention under Oxidized Conditions}

The oxidation of a grout is expected to lead to complete mobilization of substances. Upon oxidation, new reactive phases are formed such as hydrated Fe(III) oxide, which is formed upon oxidation of Fe(II) and has been shown to be a very efficient scavenger for many trace substances. In work presented by Cantrell (2009), this was proposed as a reason for partial Tc retention under oxidized conditions. Verification of such a 


\section{Demonstration of LeachXS TM/ORCHESTRA Capabilities by Simulating \\ Constituent Release from a Cementitious Waste Form in a Reinforced Concrete Vault}

retention mechanism is important, as retention within the waste form provides the best guarantee for considerably reduced release.

\subsection{Tank Closure}

The tank closure case is in many ways similar to the waste vault case. The cementitious waste matrix is also in "contact" with a cementitious barrier. However, in this case a steel wall separates the grout from the concrete. As in the case of the vault scenario, water that may come in from the top could either accumulate in the tank or ultimately find a route to the outside world via a leak in the tank. Similarly, air may enter the tank and lead to carbonation/oxidation of the grout. As in the case of the waste vault, the rate of the carbonation and oxidation fronts are crucial for the release of radionuclides of interest. These rates are also determined by reactiondiffusion processes. Modeling is quite similar to the waste vault, but with an extra uncertainty factor being the corrosion rate of steel, which is possibly influenced by the grout composition. This corrosion rate is crucial for the long term release projection.

\subsection{Spent Fuel Pool}

In the spent fuel pool, the chemical composition of the water in the pool can be analyzed in a relatively simple manner since it is readily accessible. It would be very useful to have this information available in addition to element concentration profiles in the pool wall material. As long as the contaminated water remains in the pool, release rates of contaminants will be determined by diffusion rates through the pool wall material.

However, if and when cracks develop in this wall, these cracks would form a convective flow path through which water plus dissolved contaminants could flow relatively quickly. The amount of water plus dissolved substances flowing through these cracks would render chemical interaction with the concrete surface walls of the crack less important than in case of homogeneous diffusion. This would mean that the concentrations in the solution are hardly affected by the concrete wall chemistry and thus solutions leaving the wall through a crack will be very similar to those in the tank solution. In that case, dispersion of radionuclides will be more affected by interaction in the adjacent soil than by the properties of the wall material.

Existing wall material with developed concentration profiles for a range of radio nuclides would present extremely useful experimental information for evaluating current models for radionuclide migration in cementitious materials. If practical, it would be very useful to take cores from a spent fuel pool wall and analyze radionuclide concentration profiles. This kind of information is relevant for evaluating the general radionuclide diffusion model for cementitious materials as is used as a sub-model in all the different scenarios discussed here. Prior to such action, it is possible to model the uptake of radionuclides and other constituents by using the tank leaching model, but now also specifying the composition of the pool water, which serves as the leachant. Radionuclides in the pool water will exhibit a gradient towards the concrete, which will favor diffusion into the concrete matrix. In addition, the high $\mathrm{pH}$ may act as a sink for some radionuclides (less soluble at high $\mathrm{pH}$ ). This information is relevant for decontamination and decommissioning (D\&D).

\subsection{Decontamination and Decommissioning}

The information obtained from analyzing cores of construction applications exposed to more or less active solutions can be important when making decisions on how to handle certain material streams in Decontamination \& Decommissioning (D\&D). Information on regular D\&D waste has relevance for some discussions related to $\mathrm{D} \& \mathrm{D}$ activities. 


\subsection{CONCLUSIONS AND RECOMMENDATIONS}

\subsection{Main Conclusions of This Work}

1. The LeachXS ${ }^{\mathrm{TM}}$ database contains a unique set of $\mathrm{pH}$ dependent solubility data, along with percolation test, tank test, and field data for a wide range of elements for different types of cementitious materials (mortars, concretes, grouts, soils), which are relevant for the CBP. This was demonstrated by analyzing the data on grout columns alongside the existing information in the LeachXS database, which resulted in quite comparable data for the major elements.

2. This LeachXS pH-dependent solubility data clearly shows that the solubility of many elements is strongly affected by $\mathrm{pH}$ and that there are large differences between the behavior of different elements. From a release modeling perspective, the high $\mathrm{pH}$ chemistry of cement and concrete needs to be extended to behavior under mild alkaline to almost neutral $\mathrm{pH}$ conditions. Carbonation will affect the outer layers of grout and concrete and as such will influence the release of substances over time $\mathrm{pH}$ dependent $\mathrm{K}_{\mathrm{d}}$ 's can be derived from a $\mathrm{pH}$-dependent leaching test to easily compare data used in a PA with alternative approaches to release description

3. The LeachXS dataset clearly demonstrates that the behavior of these elements in different types of cementitious materials is actually very similar. This is most likely due to the fact that apparently the same chemical environment is created by the addition of cement, which in turn dictates the release behavior of a suite of substances in a remarkable systematic manner.

4. Based on this observation, it is proposed to introduce a distinction in release behavior of the very mobile species and the less mobile species. This distinction can be made from the proposed laboratory testing protocols ( $\mathrm{pH}$ dependence, percolation, and monolith testing).

5. Predicting diffusion and leaching rates of substances in cementitious materials that are likely to change $\mathrm{pH}$ over time requires modeling of $\mathrm{pH}$ development over time and of $\mathrm{pH}$-dependent element solubility.

6. The REDOX conditions in initially reducing grouts and concrete barriers and how these change over time are important factors in determining leaching rates of contaminants. Adequate prediction requires understanding of the chemical processes involved and implementation of processes within a reactive transport model framework.

7. Carbonation and oxidation involves multi-component interactions between different substances and various mineral phases and diffusion processes. Numerical modeling requires a reactive transport code that can accommodate advanced chemical interaction models as well as diffusion processes. Only through verification with information from practice will it be possible to anticipate influences that cannot be inferred from laboratory work. Experience from other fields can help in this respect. At this point, it is hard to tell what level of detail will be necessary to make adequate predictions, as simplifications will undoubtedly lead to larger uncertainty margins.

8. Uncertainty should be taken into account in both data and model results. In this report, two approaches were presented both leading to the same conclusion that in the equilibrium modeling applied for the basic characterization of release from concrete, the ratio of $\mathrm{Al}, \mathrm{Si}$, and $\mathrm{SO}_{4}$ in terms of composition is crucial. Monte Carlo simulations give useful insight into the sensitivity of the combined model for uncertainty in input parameters.

9. The LeachXSTM/ORCHESTRA combination can be used to simulate release behavior in laboratory tests, which because of the complex combination of physical and chemical influences, is not a trivial achievement. It has been shown that the three layer diffusion and three layer flow model with full chemistry are numerically stable and since July, 2009 run about a factor 100 faster than before. 
10. Observations from interactions at interfaces illustrate the extent to which substances mobilize and reprecipitate when large gradients exist between conditions in the adjoining matrices (e.g., grout concrete; concrete - soil).

11. Predominance diagrams, continuing the projected path of $\mathrm{pH}$ and REDOX change over time, indicate the relevant stability domains of the various substances, including several radionuclides of interest. In view of the potential relevance of often small quantities of mobile forms relative to the main forms, extraction of partitioning data will be needed along the perceived trajectory of $\mathrm{pH}$ and REDOX change.

12. The chemical and transport models as developed in LeachXSTM/ORCHESTRA can be used as building blocks for composing specific release scenarios that constitute the reference cases. The modeling of transport has been extended to take into account carbonation and oxidation as illustrated by the model output for Tc.

13. The output of the chemical and transport model can be used as input for other models as shown in the work on sulfate attack and damage mechanics (Sarkar et al. 2010). It was possible to include the damage mechanics in ORCHESTRA, which thus allowed us to couple the full chemistry and mechanical stresses in one code, greatly improving the computational speed of the model.

\subsection{Recommendations for Further Work}

1. Evaluation of the accuracy of the thermodynamic equilibrium model for radio nuclides in cementitious materials should be carried out by comparing the predicted solubility with experimental solubility data. Results of these evaluations will give insight into the level of accuracy and uncertainty in the calculated mobilities and transport rates of the different elements. This can be done by evaluating existing batch equilibration data, which are available from SRNL (Kaplan et al. 2008).

2. It is important that this evaluation is also carried out on fully carbonated materials because cementitious materials change over time due to carbonation and oxidation. This should not be done by exposing an intact specimen to carbonation, which will produce only superficial changes, but on a size reduced material specimen under moist conditions. This will provide a rapid answer to a key question: What release behavior can be expected at this end point? On this pre-treated material, percolation and $\mathrm{pH}$ dependence tests should be carried out.

3. Evaluating the accuracy of reactive transport modeling by analyzing diffusion profiles in cores from actual field sites is important as a benchmark for the prediction of long term behavior. Stabilized waste that is $30-40$ years old may not reflect state of the art disposal practice, but experimental data on this material will definitely give insight. A 30 to 40 year exposure should already give a good indication of long-term conditions, if model and experimental data over that period match and no major factors are overlooked.

4. A similar evaluation could be made by analyzing concrete cores taken from storage tanks or other concrete structures that have held radioactive waste, which could form an ideal tracer uptake experiment. Analyzing the depth profiles of the uptake of various radionuclides will provide insight into the relevant processes in concrete. When something is known about the duration of the contact and the composition of the solution, the profile can be verified with modeling. Concrete from a spent fuel basin could also be a good candidate.

5. Evaluation of the performance of the reactive transport model on existing diffusion data in a LeachXS tank test for non-radioactive substances in cementitious materials, e.g., simulated grout, should prove useful. 


\section{Demonstration of LeachXSTM/ORCHESTRA Capabilities by Simulating Constituent Release from a Cementitious Waste Form in a Reinforced Concrete Vault}

6. We should investigate how the model uncertainty in the chemical model can be taken into account in the transport and leaching model in a practical and efficient way. This will provide very useful information on the level of uncertainty in the predicted leaching rates, but currently would take a huge computational effort.

7. To quantify any difference between mortar and concrete it is recommended to test the CBP reference concrete and the cement mortar but without the coarse aggregate and plasticizers.

\subsection{REFERENCES}

Berner, UR 1988, 'Modelling the incongruent dissolution of hydrated cement minerals', Radiochimica Acta, vol. 44/45, pp. 387-393.

Blakemore, LC, Searle, PL \& Daly, BK 1987, Methods for chemical analysis of soils, New Zealand Bureau Scientific Report 80, NZ Soil Bureau, Lower Hutt, New Zealand.

Cantrell, KJ 2009, 'Contaminant Release from Residual Waste in Single Shell Tanks at the Hanford Site, Washington, USA', Performance Assessment Community of Practice Technical Exchange Meeting: Modeling the Performance of Engineered Systems for Closure and Near-Surface Disposal, 13-14 July 2009, Salt Lake City, UT. Available from: http://www.cresp.org/PACOP/index.html.

CEN 2004, CEN/TS 14405: Characterization of waste - Leaching behaviour tests - Up-flow percolation test (under specified conditions), European Committee for Standardization (CEN), Brussels, Belgium.

CEN 2005, CEN/TS 14429: Characterization of waste - Leaching behaviour tests - Influence of pH on leaching with initial acid/base addition, European Committee for Standardization (CEN), Brussels, Belgium.

CEN 2009, CEN/TS 15863 Dynamic monolith leach test, CEN/TC 292, WG6.

Dijkstra, JJ 2007, 'Development of a consistent geochemical modelling approach for leaching and reactive transport processes in contaminated materials', Ph.D. thesis, Wageningen University, Wageningen, the Netherlands.

Dijkstra, JJ 2010, Estimates of radionuclide sorption parameters for natural organic matter (NICA-Donnan) and Hydrous Ferric Oxide (Generalized Two Layer Model, GTLM), CBP document in preparation, Energy Research Centre of the Netherlands; Cementitious Barriers Partnership, Petten, The Netherlands.

Dijkstra, JJ, Meeussen, JCL \& Comans, RNJ 2004, 'Leaching of heavy metals from contaminated soils: An experimental and modeling study', Environmental Science \& Technology, vol. 38, no. 16, pp. 4390-4395.

Dijkstra, JJ, van der Sloot, HA \& Comans, RNJ 2006, 'The leaching of major and trace elements from MSWI bottom ash as a function of pH and time', Applied Geochemistry, vol. 21, no. 2, pp. 335-351.

Dzombak, DA \& Morel, FMM 1990, Surface complexation modelling: hydrous ferric oxide, John Wiley \& Sons, Inc., New York.

Fuhrmann, M \& Gillow, J 2009, 'Fate of uranium in contact with West Valley grouts', Draft manuscript, U.S. Nuclear Regulatory Commission, Washington, DC.

Garrabrants, AC, Kosson, DS \& DeLapp, RC 2007, Leaching Results and Interpretation of Constituent Release from a Representative Low-activity Waste Treated with Reducing Grout, Consortium for Risk Evaluation with Stakeholder Participation (CRESP), Nashville, TN. Available from: http://www.cresp.org/. 


\section{Demonstration of LeachXSTM/ORCHESTRA Capabilities by Simulating Constituent Release from a Cementitious Waste Form in a Reinforced Concrete Vault}

Grathwohl, P, Halm, D, Bonilla, A, Broholm, M, Burganos, V, Christophersen, M, Comans, RNJ, Gaganis, P, Gorostiza, I, Hohener, P, Kjeldsen, P \& van der Sloot, HA 2003, Guideline for groundwater risk assessment at contaminated sites (GRACOS), EVK1-CT-1999-00029, Tübingen, Germany. Available from: http://www.eugris.info/.

Grathwohl, P \& van der Sloot, HA 2007, 'Groundwater risk assessment at contaminated sites (GRACOS): test methods and modelling approaches', in Groundwater Science and Policy, ed. P Quevauviller, Royal Society of Chemistry, London.

ISO 2007a, ISO/TS 21268-3: Soil quality — Leaching procedures for subsequent chemical and ecotoxicological testing of soil and soil materials Part 3: Up-flow percolation test, International Organization for Standardization (ISO), Geneva, Switzerland. Available from: http://www.iso.org/.

ISO 2007b, ISO/TS 21268-4: Soil quality -- Leaching procedures for subsequent chemical and ecotoxicological testing of soil and soil materials -- Part 4: Influence of $\mathrm{pH}$ on leaching with initial acid/base addition, International Organization for Standardization (ISO), Geneva, Switzerland. Available from: http://www.iso.org/.

Kaplan, DI, Roberts, K, Coates, J, Siegfried, M \& Sierkiz, S 2008, Saltstone and Concrete Interactions with Radionuclides: Sorption (Kd), Desorption, and Reduction Capacity Measurements, SRNS-STI-2008-00045, Savannah River Nuclear Solutions, LLC, Aiken, SC.

Kinniburgh, DG, van Riemsdijk, WH, Koopal, LK, Borkovec, M, Benedetti, MF \& Avena, MJ 1999, 'Ion binding to natural organic matter: competition, heterogeneity, stoichiometry and thermodynamic consistency', Colloids and Surfaces A: Physicochemical and Engineering Aspects, vol. 151, no. 1-2, pp. 147-166.

Kosson, DS, van der Sloot, HA, Sanchez, F \& Garrabrants, AC 2002, 'An Integrated Framework for Evaluating Leaching in Waste Management and Utilization of Secondary Materials', Environmental Engineering Science, vol. 19, no. 3, pp. 159-204.

Kostka, JE \& Luther III, GW 1994, 'Partitioning and speciation of solid phase iron in saltmarsh sediments', Geochimica et Cosmochimica Acta, vol. 58, no. 7, pp. 1701-1710.

Langton, CA, Kosson, DS, Garrabrants, AC \& Brown, KG 2009, 'Reference Cases for Use in the Cementitious Barriers Partnership', WM'2009, Phoenix, Arizona. Available from: http://www.osti.gov/bridge/ as SRNL-STI2009-00005.

Lothenbach, B \& Gruskovnjak, A 2007, 'Hydration of alkali-activated slag: Thermodynamic modelling', Advances in Cement Research, vol. 19, no. 2, pp. 81-92.

Lothenbach, B, Matschei, T, Möschner, G \& Glasser, FP 2008, 'Thermodynamic modelling of the effect of temperature on the hydration and porosity of Portland cement', Cement and Concrete Research, vol. 38, no. 1, pp. 1-18.

Lothenbach, B \& Winnefeld, F 2006, 'Thermodynamic modelling of the hydration of Portland cement', Cement and Concrete Research, vol. 36, no. 2, pp. 209-226.

Lothenbach, B, Winnefeld, F, Alder, C, Wieland, E \& Lunk, P 2007, 'Effect of temperature on the pore solution, microstructure and hydration products of Portland cement pastes', Cement and Concrete Research, vol. 37, no. 4, pp. 483-491.

McCarthy, JE \& Zachara, JM 1989, 'Subsurface transport of contaminants', Environmental Science \& Technology, vol. 23, no. 5, pp. 496-502.

Meeussen, JCL 2003, 'ORCHESTRA: An object-oriented framework for implementing chemical equilibrium models', Environmental Science \& Technology, vol. 37, no. 6, pp. 1175-1182. 
Meima, JA \& Comans, RNJ 1998, 'Application of surface complexation/precipitation modeling to contaminant leaching from weathered municipal solid waste incinerator bottom ash', Environmental Science \& Technology, vol. 32, no. 5, pp. 688-693.

Milne, CJ, Kinniburgh, DG \& Tipping, E 2001, 'Generic NICA-Donnan model parameters for proton binding by humic substances', Environmental Science \& Technology, vol. 35, no. 10, pp. 2049-2059.

Milne, CJ, Kinniburgh, DG, van Riemsdijk, WH \& Tipping, E 2003, 'Generic NICA-Donnan model parameters for metal-ion binding by humic substances', Environmental Science \& Technology, vol. 37, no. 5, pp. 958-971.

NEN 1994, NEN 5753: Soil - Determination of clay content and particle size distribution of soil samples by sieve and pipet, Netherlands Normalization Institute (NEN), Delft, The Netherlands. Available from: http://www2.nen.nl/.

NEN 1995, NEN 7345: Leaching Characteristics of Solid Earthy and Stony Building and Waste Materials Leaching Tests - Determination of the Leaching of Inorganic Components from Buildings and Monolithic Waste Materials with the Diffusion Test, Netherlands Normalization Institute (NEN), Delft, The Netherlands. Available from: http://www2.nen.nl/.

Sarkar, S, Mahadevan, S, Meeussen, JCL, van der Sloot, HA \& Kosson, DS 2010, 'Numerical simulation of cementitious materials degradation under external sulfate attack', Cement \& Concrete Composites, vol. 32, no. 3, pp. 241-252.

Serne, J 2006, 'Technical Issues on Laboratory Methodology to Assess Long-term Release of Contaminants from Grout/Cement in the Vadose Zone', EM20 Cement Workshop, 13 December 2006. Available from: http://srnl.doe.gov/grout_present/2b_04_serne.pdf.

Sumner, ME (ed.) 2000, Handbook of Soil Science, CRC Press LLC, Boca Raton, FL.

Tiruta-Barna, LR, Barna, R \& Moszkowicz, P 2000, 'Modeling of solid/liquid/gas mass transfer for environmental evaluation of cement-based solidified waste', Environmental Science \& Technology, vol. 35, no. 1, pp. 149-156.

USEPA 2009a, Draft Method 1313: Leaching Test (Liquid-Solid Partitioning as a Function of Extract pH) for Constituents in Solid Materials using a Parallel Batch Extraction Test, United States Environmental Protection Agency, Washington, DC.

USEPA 2009b, Draft Method 1314: Leaching Test (Liquid-Solid Partitioning as a Function of Liquid-to-Solid Ratio) for Constituents in Solid Materials using an Up-flow Percolation Column Test, United States Environmental Protection Agency, Washington, DC.

USEPA 2009c, Draft Method 1315: Leaching Test (Mass Transfer Rates) for Constituents in Monolithic or Compacted Granular Materials using a Semi-Dynamic Tank Leaching Test, United States Environmental Protection Agency, Washington, DC.

van der Sloot, HA 2002, 'Harmonisation of leaching/extraction procedures for sludge, compost, soil and sediment analyses', in Methodologies for Soil and Sediment Fractionation Studies, ed. P Quevauviller, Royal Society Of Chemistry, London.

van der Sloot, HA \& Dijkstra, JJ 2004, Development of horizontally standardized leaching tests for construction materials: a material based or release based approach?, ECN C--04-060, Energy Research Center of The Netherlands, Petten, The Netherlands. Available from: http://www.ecn.nl/docs/society/leaching/C04060.pdf. 
van der Sloot, HA, Heasman, L \& Quevauviller, P (eds) 1997, Harmonization of Leaching/Extraction Tests, Volume 70, Elsevier Science, Amsterdam.

van der Sloot, HA, Hoede, D, Rietra, RPJJ, Stenger, R, Lang, T, Schneider, M, Spanka, G, StoltenbergHansson, E \& Lerat, A 2001, Environmental Criteria for Cement-based Products - ECRICEM I, ECN C--01069, Energy Research Center of The Netherlands, Petten, The Netherlands. Available from: http://www.ecn.nl/publications/.

van der Sloot, HA, Seignette, P, Comans, RNJ, van Zomeren, A, J.J.Dijkstra, Meeussen, H, Kosson, DS \& Hjelmar, O 2003, 'Evaluation of environmental aspects of alternative materials using an integrated approach assisted by a database/expert system', in Advances in Waste Management \& Recycling, September 2003, University of Dundee, Dundee, Scotland, pp. 769-790.

van der Sloot, HA, van Zomeren, A, Dijkstra, JJ, Meeussen, JCL, Comans, RNJ \& Scharff, H 2007a, 'Prediction of the leaching behaviour of waste mixtures by chemical speciation modelling', in Landfill modelling, eds A Haarstrick \& T Reichel, Environmental Sanitary Engineering Centre (CISA), Cagliari, Italy.

van der Sloot, HA, van Zomeren, A, Meeussen, JCL, Seignette, P \& Bleijerveld, R 2007b, 'Test method selection, validation against field data, and predictive modelling for impact evaluation of stabilised waste disposal', Journal of Hazardous Materials, vol. 141, no. 2, pp. 354-369.

van der Sloot, HA, van Zomeren, A, Stenger, R, Schneider, M, Spanka, G, Stoltenberg-Hansson, E \& Dath, P 2008, Environmental CRIteria for CEMent based products ECRICEM Phase I: Ordinary Portland Cements; Phase II: Blended Cements, ECN E--08-011, Energy Research Center of The Netherlands, Petten, The Netherlands. Available from: http://www.ecn.nl/publications/.

van Zomeren, A \& Comans, RNJ 2007, 'Measurement of humic and fulvic acid concentrations and dissolution properties by a rapid batch procedure', Environmental Science \& Technology, vol. 41, no. 19, pp. 6755-6761. 


\section{APPENDIX A CEMENT MORTARS}


In Table A.1 the cement mortars that have been studied in ECRICEM I and II (van der Sloot et al. 2001; van der Sloot et al. 2008) are listed (abbreviations used: GBFS - granulated blast furnace slag; LS - lime stone; FA - coal fly ash; P - pozzolan)

Table A.1. Cement types studied.

\begin{tabular}{|c|c|}
\hline Cement Type & Cement Constituents \\
\hline \multicolumn{2}{|c|}{ Commercial Portland Cements } \\
\hline CEM I & Clinker, gypsum, filler \\
\hline CEM I & Clinker, gypsum \\
\hline CEM I & Clinker, gypsum, filler \\
\hline CEM II-L & Clinker, gypsum, lime-stone (14 \%) \\
\hline CEM I & Clinker, gypsum \\
\hline CEM I & Clinker, gypsum, filler \\
\hline CEM I & Clinker, gypsum, filler \\
\hline CEM I & Clinker, gypsum, filler \\
\hline CEM I & Clinker, gypsum, filler \\
\hline CEM I-HS & Clinker, gypsum \\
\hline \multicolumn{2}{|l|}{ Slag Cements } \\
\hline CEM III/B & $80 \%$ GBFS \\
\hline CEM III/B $32.5 \mathrm{~N}$ & $66 \%$ GBFS \\
\hline CEM II/B-S 32.5 R & $29 \%$ GBFS \\
\hline CEM II/B-S 32.5 R & $29 \%$ GBFS \\
\hline CEM II/A-S 32.5 R & $20 \%$ GBFS \\
\hline CEM III/A 32.5 & $69 \%$ GBFS + 5\% LS \\
\hline \multicolumn{2}{|l|}{ CEM II/A-S 32.5 R } \\
\hline \multirow{2}{*}{\multicolumn{2}{|c|}{$\begin{array}{l}\text { CEM II/B-S } 32.5 \text { R } \\
\text { Composite Cements (with one component) }\end{array}$}} \\
\hline & \\
\hline CEM II/B-V $32.5 \mathrm{~N}$ & $33 \% \mathrm{FA}$ \\
\hline CEM II/A-V $42.5 \mathrm{~N}$ & $10 \% \mathrm{FA}$ \\
\hline CEM II/A-V & with chromate reduction and $17 \% \mathrm{FA}$ \\
\hline CEM II/B-Q & $32 \% \mathrm{P}$ \\
\hline CEM II/B-P 32.5 R & $26 \%$ Trass $(\mathrm{P})$ \\
\hline CEM II/B-L & $28 \% \mathrm{LS}$ \\
\hline CEM II/A-L 32.5 R & $13 \% \mathrm{LS}$ \\
\hline CEM II/A-LL 32.5 R & $13 \%$ LS \\
\hline \multicolumn{2}{|c|}{ Composite Cements (with more than one component) } \\
\hline CEM V/A $32.5 \mathrm{~N}$ & $32 \%$ GBFS+20\% FA \\
\hline CEM V/A $32.5 \mathrm{~N}$ & $23 \%$ GBFS+22\% FA \\
\hline CEM II/B-M 32.5 R & $33 \%$ GBFS+9\% LS \\
\hline CEM IV/A 32.5 R & $15 \% \mathrm{FA}+17 \% \mathrm{P}$ \\
\hline CEM II/B-M 32.5 R & $14 \%$ GBFS+12\% LS+5\% FA \\
\hline CEM II/B-T 42.5 R & Burnt Oil Shale \\
\hline CEM I & without LD slag in raw mix \\
\hline CEM I & with LD slag in raw mix \\
\hline CEM I 42.5 R & with chromate reduction \\
\hline \multicolumn{2}{|l|}{ Portland Cements } \\
\hline CEM I & without LD slag in raw mix \\
\hline CEM I & with LD slag in raw mix \\
\hline CEM I 42.5 R & with chromate reduction \\
\hline
\end{tabular}




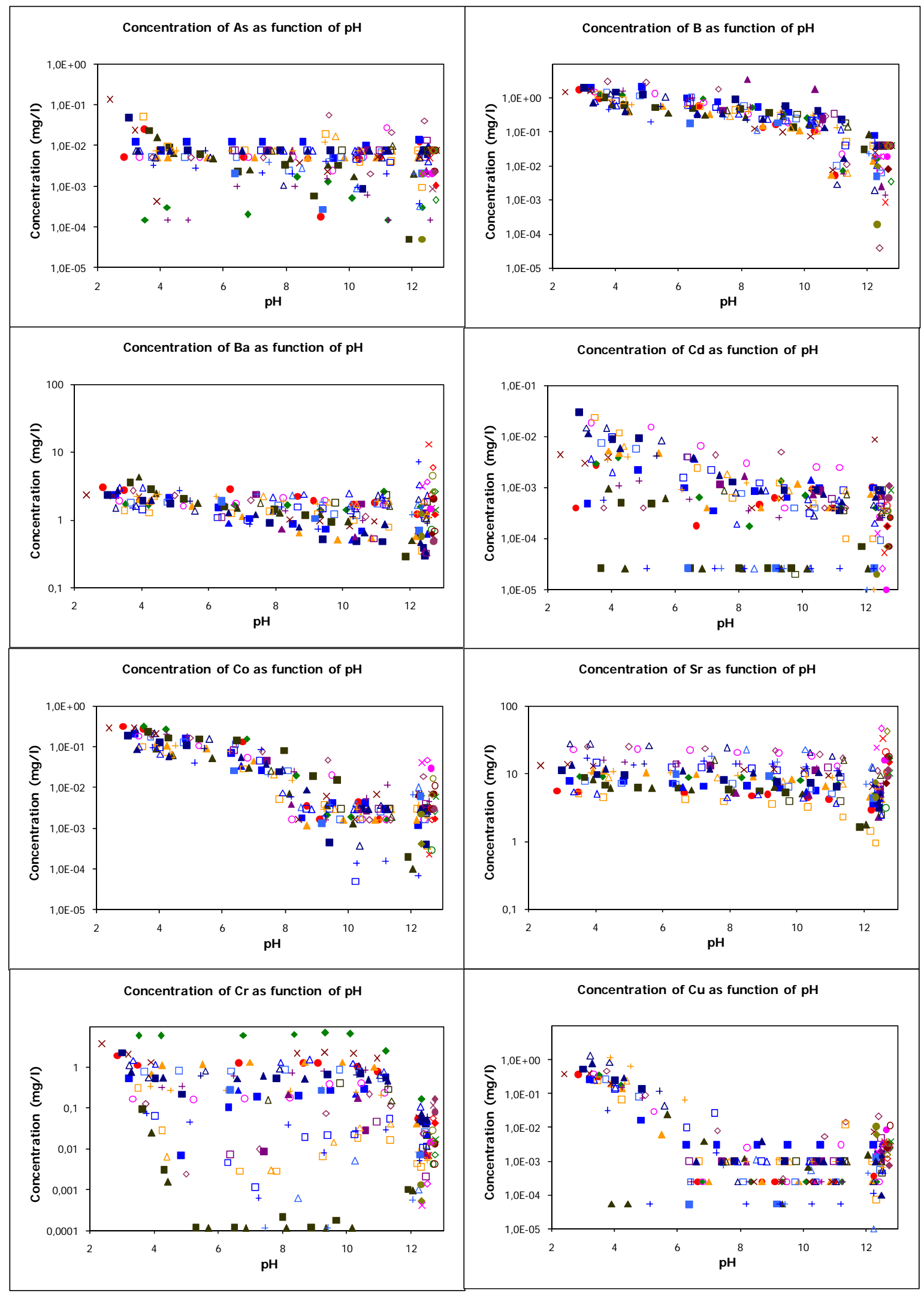

Figure A.1. $\quad \mathrm{pH}$ dependence test data cement mortars (As, B, Ba, Cd, Co, Sr, Cr and Cu). 


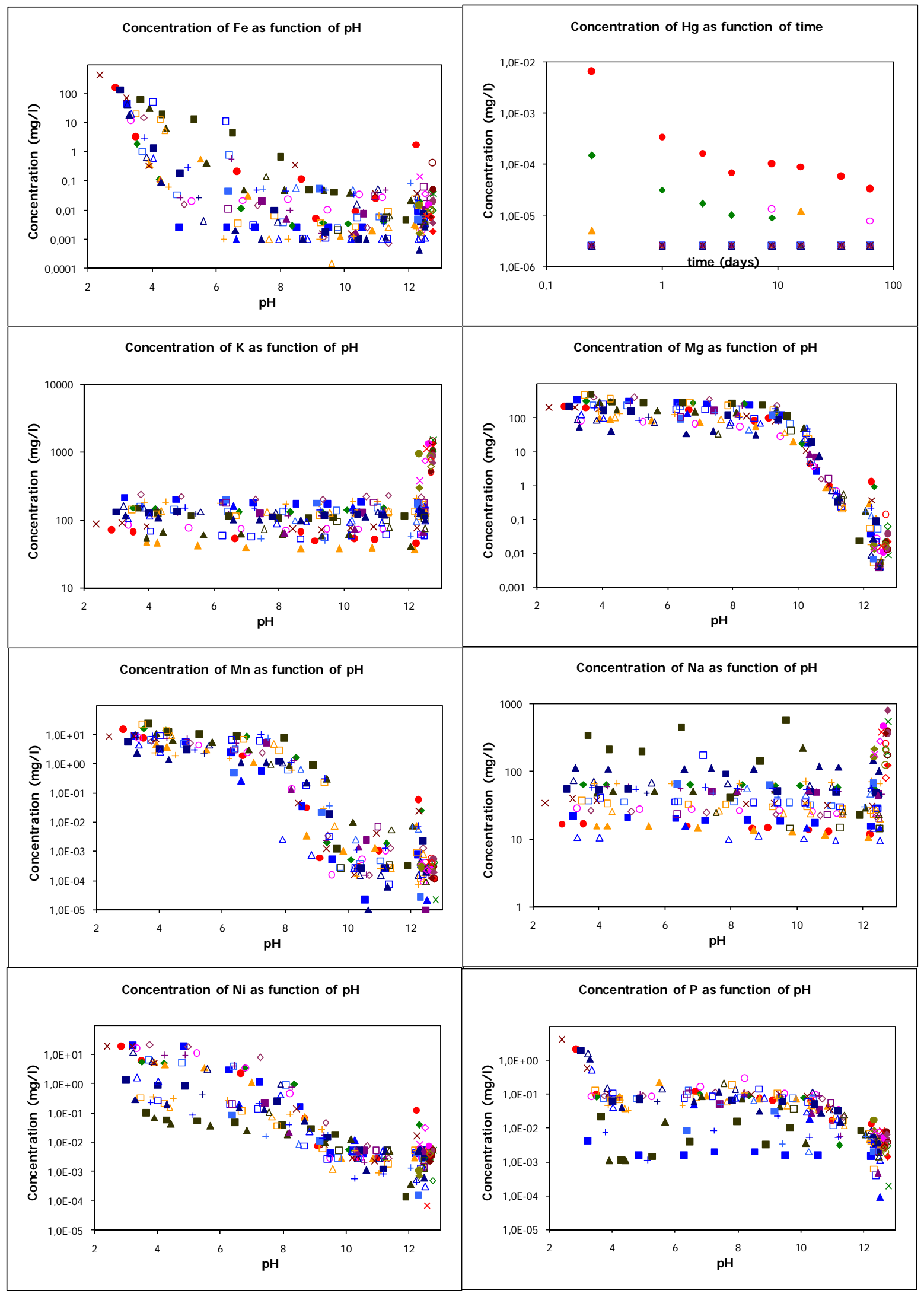

Figure A.2. $\mathrm{pH}$ dependence test data cement mortars ( $\mathrm{Fe}, \mathrm{Hg}, \mathrm{K}, \mathrm{Mg}, \mathrm{Mn}, \mathrm{Na}, \mathrm{P}, \mathrm{Ni})$. 


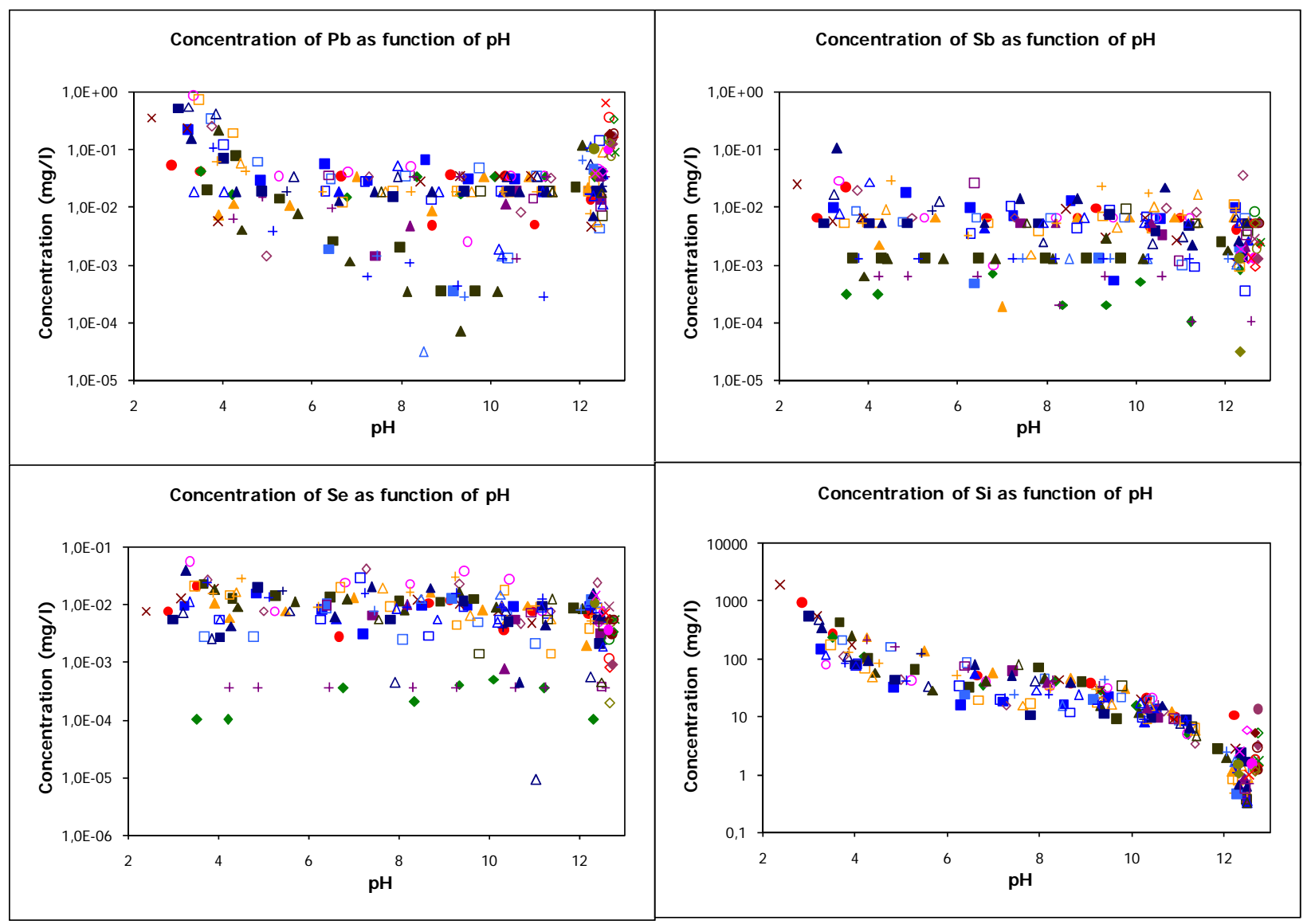

Figure A.3. pH dependence test data cement mortars (Se, Sb, $\mathrm{Pb}, \mathrm{Si}$ ). 


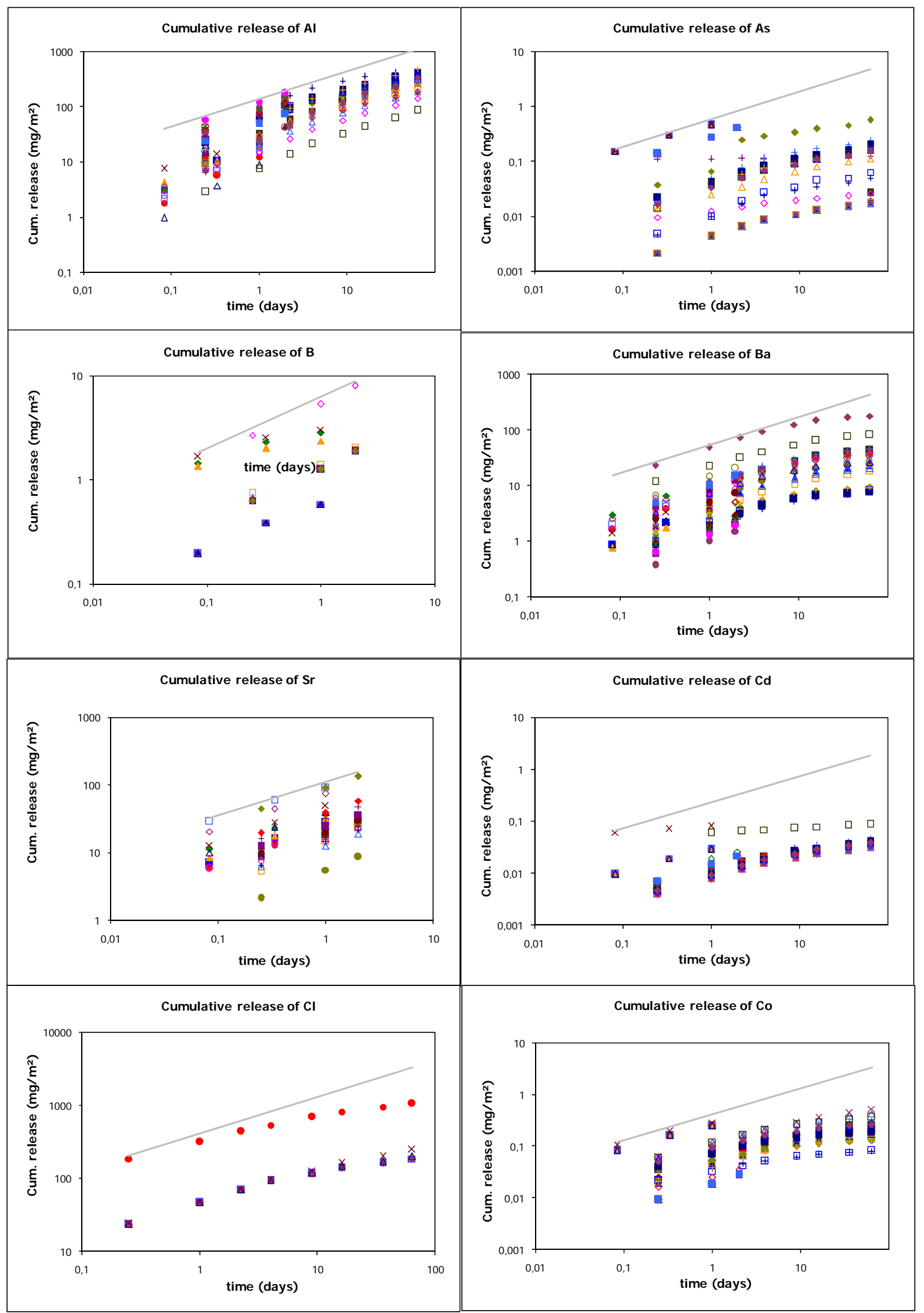

Figure A.4. Monolith leach test data cement mortars (Al, As, B, Ba, Sr, Cd, Cl, Co). 


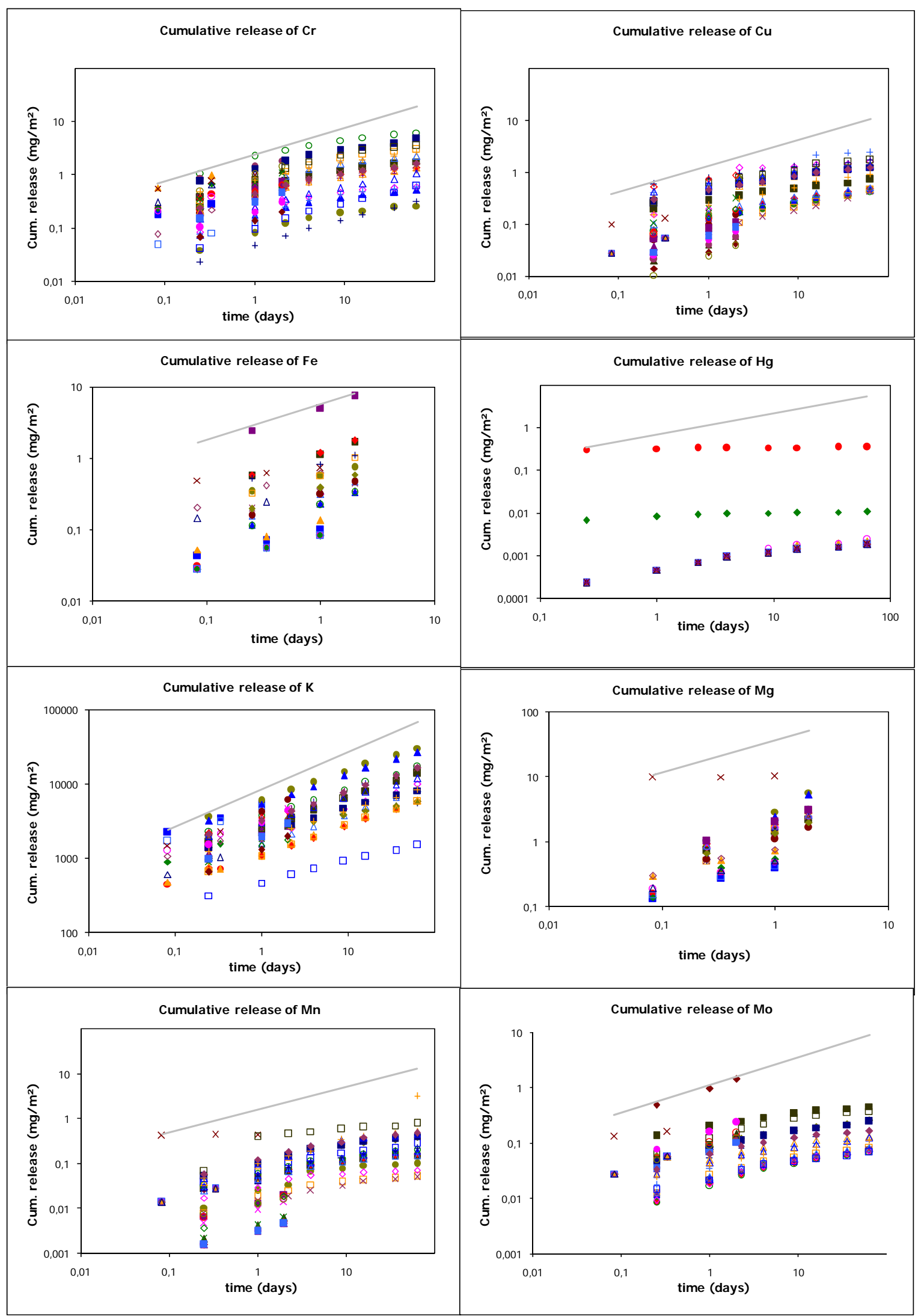

Figure A.4. Monolith leach test data cement mortars ( $\mathrm{Cr}, \mathrm{Cu}, \mathrm{Fe}, \mathrm{Hg}, \mathrm{K}, \mathrm{Mg}, \mathrm{Mn}, \mathrm{Mo})$. 


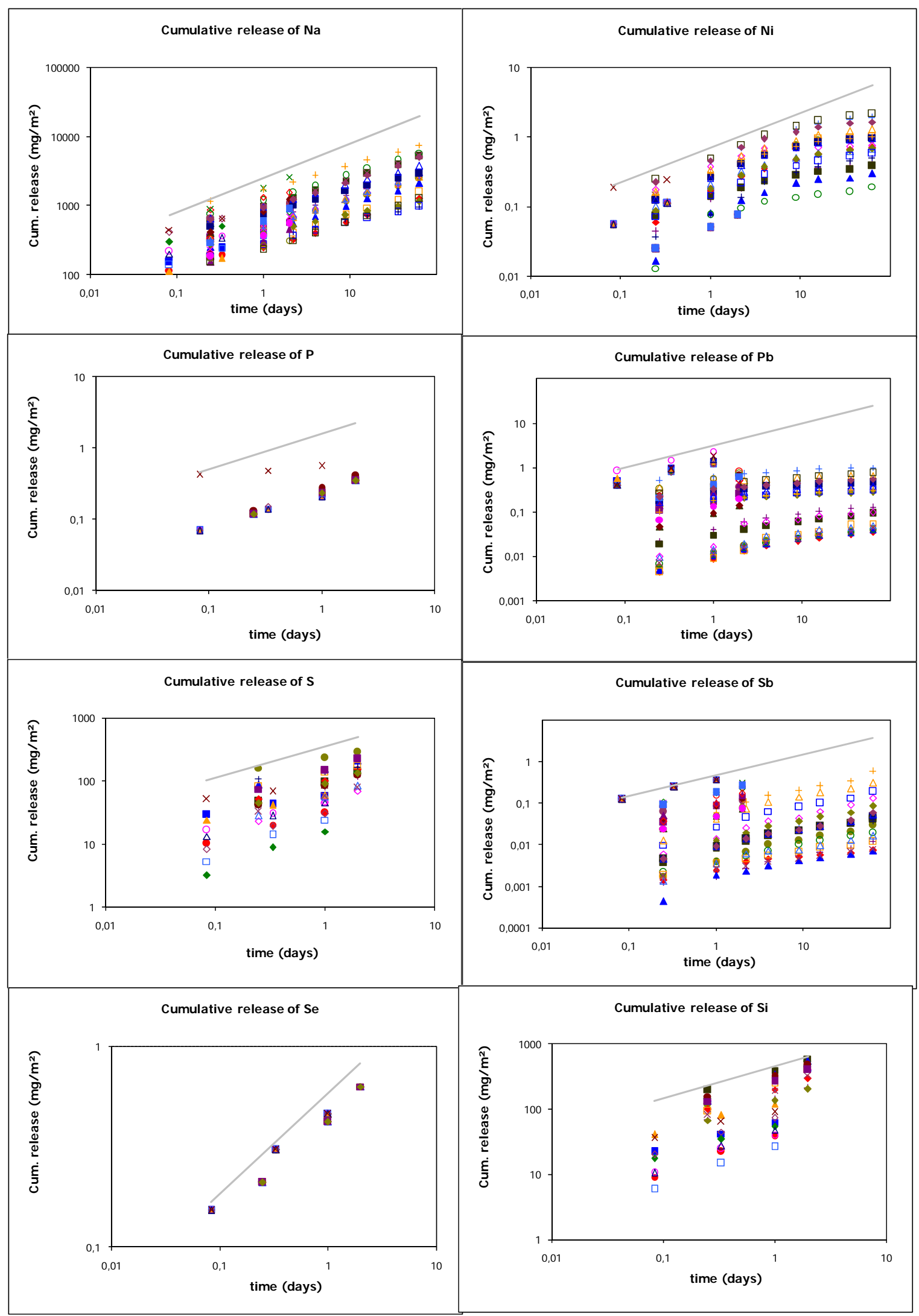

Figure A.4 Monolith leach test data cement mortars ( $\mathrm{Na}, \mathrm{Ni}, \mathrm{P}, \mathrm{Pb}, \mathrm{S}, \mathrm{Sb}, \mathrm{Se}, \mathrm{Si})$. 


\section{APPENDIX B \\ PARTITIONING OF SUBSTANCES OVER DIFFERENT CHEMICAL PHASES IN A BLENDED CEMENT MORTAR}


Prediction case Speciation session

Material

Solved fraction DOC

Sum of $\mathrm{pH}$ and pe

L/S

Clay

HFO

SHA

DOC/DHA data

Reactant concentrations

Reactant

$\mathrm{Ag}^{+}$

$\mathrm{Al}^{+3}$

$\mathrm{H}_{3} \mathrm{AsO}_{4}$

$\mathrm{H}_{3} \mathrm{BO}_{3}$

$\mathrm{Ba}^{+2}$

$\mathrm{Br}^{-}$

$\mathrm{Ca}^{+2}$

$\mathrm{Cd}^{+2}$

$\mathrm{Cl}^{-}$

$\mathrm{CrO}_{4}{ }^{-2}$

$\mathrm{Cu}^{+2}$

$\mathrm{F}^{-}$

$\mathrm{Fe}^{+3}$

$\mathrm{H}_{2} \mathrm{CO}_{3}$

$\mathrm{Hg}^{+2}$

$\mathrm{I}^{-}$

$\mathrm{K}^{+}$

$\mathrm{Li}^{+}$

$\mathrm{Mg}^{+2}$

$\mathrm{Mn}^{+2}$

$\mathrm{MoO}_{4}^{-2}$

$\mathrm{Na}^{+}$

$\mathrm{NH}_{4}^{+}$

$\mathrm{Ni}^{+2}$

$\mathrm{NO}_{3}^{-}$

$\mathrm{PO}_{4}{ }^{-3}$

$\mathrm{Pb}^{+2}$

$\mathrm{SO}_{4}{ }^{-2}$

$\mathrm{Sb}[\mathrm{OH}]_{6}^{-}$

$\mathrm{SeO}_{4}^{-2}$

$\mathrm{H}_{4} \mathrm{SiO}_{4}$

$\mathrm{Sr}^{+2}$

$\mathrm{Th}^{+4}$

$\mathrm{UO}_{2}^{+}$

$\mathrm{VO}_{2}^{+}$

$\mathrm{Zn}^{+2}$
Input specification

CEN VIA HOL 12 tank AA CBP Lothenbach

CEN VIA HOL 12 tank AA

HOL12 $(P, 1,1)$

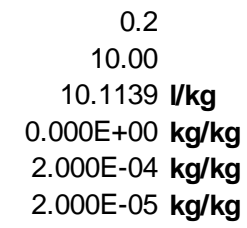

$$
\text { pH }
$$

1 to 14

mg/kg

not measured

$2.332 \mathrm{E}+03$

5.060E-01

$1.221 \mathrm{E}+01$

1.372E+01

not measured

4.698E+04

2.414E-01

$5.000 \mathrm{E}+01$

$3.055 \mathrm{E}+00$

$2.432 \mathrm{E}+00$

$5.000 \mathrm{E}+01$

$2.130 \mathrm{E}+02$

1.500E+04

not measured

not measured

1.407E+03

$6.934 \mathrm{E}+00$

$4.758 \mathrm{E}+03$

2.083E+02

2.939E-01

3.714E+02

not measured

3.452E+00

not measured

1.807E+00

7.106E+00

$2.000 \mathrm{E}+03$

6.537E-02

2.025E-01

$1.718 \mathrm{E}+03$

5.173E+01

not measured

not measured

1.143E+00

3.532E+01
Polynomial coeficients DOC

C0 $-7.699 \mathrm{E}+00$

C1 $-6.893 \mathrm{E}-16$

C2 $0.000 \mathrm{E}+00$

C3 $0.000 \mathrm{E}+00$

C4 $0.000 \mathrm{E}+00$

C5 $0.000 \mathrm{E}+00$

$\begin{array}{rrr}\text { [DOC] (kg/l) } & \text { DHA fraction } & \text { [DHA] }(\mathrm{kg} / \mathrm{l}) \\ 1.000 \mathrm{E}-07 & 0.20 & 2.000 \mathrm{E}-08\end{array}$

Selected Minerals

AA_2CaO_Al2O3_8H2O[s]

AA_2CaO_Al2O3_SiO2_8H2O[s]

AA_2CaO_Fe2O3_8H2O[s]

AA_2CaO_Fe2O3_SiO2_8H2O[s]

AA_3CaO_Al2O3_6H2O[s]

AA_3CaO_Al2O3_CaCO3_11H2O[s]

AA_3CaO_Al2O3_CaSO4_12H2O[s]

AA_3CaO_Fe2O3_6H2O[s]

AA_Al[OH]3[am]

AA_Anhydrite

AA_Brucite

AA_Calcite

AA_CaO_Al2O3_10H2O[s]

AA_Fe[OH]3[microcr]

AA_Gibbsite

AA_Gypsum

AA_Jennite

AA_Magnesite

AA_Portlandite

AA_Syngenite

AA_Tobermorite-I

AA_Tobermorite-II

Analbite

$\mathrm{Ca} 2 \mathrm{Cd}[\mathrm{PO} 4] 2$

$\mathrm{Cd}[\mathrm{OH}] 2[\mathrm{C}]$

$\mathrm{Cr}[\mathrm{OH}] 3[\mathrm{~A}]$

Fe_Vanadate

Magnesite

Manganite

$\mathrm{Ni}[\mathrm{OH}$ 2[s]

$\mathrm{Pb}[\mathrm{OH}] 2[\mathrm{C}]$

$\mathrm{Pb} 2 \mathrm{~V} 2 \mathrm{O} 7$

$\mathrm{Pb} 3[\mathrm{VO} 4] 2$

$\mathrm{PbCrO} 4$

$\mathrm{PbMoO} 4[\mathrm{c}]$

Rhodochrosite

Strontianite

Tenorite

Willemite 


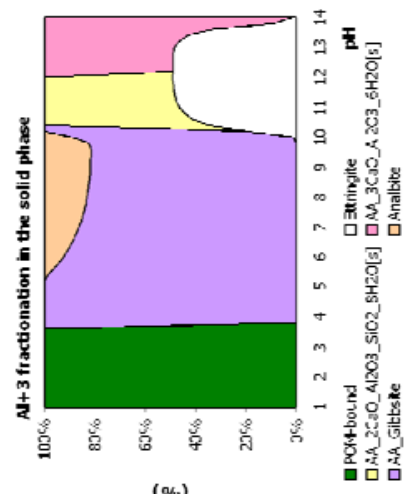

$(\%)$

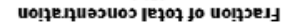

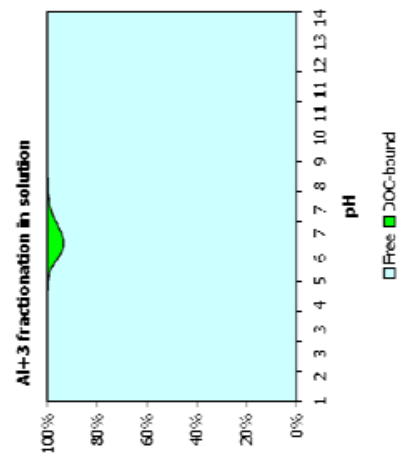

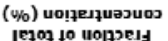
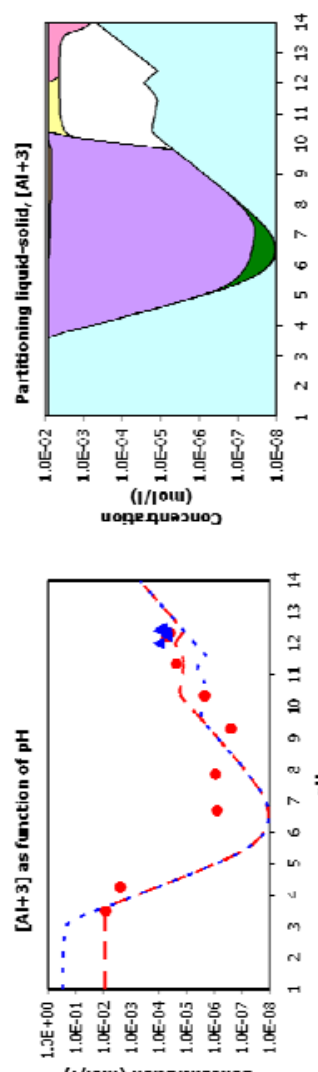

(1/10u1)

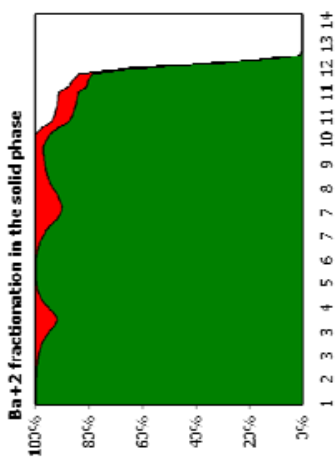

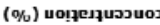
|루여 jo uo!̣pelt
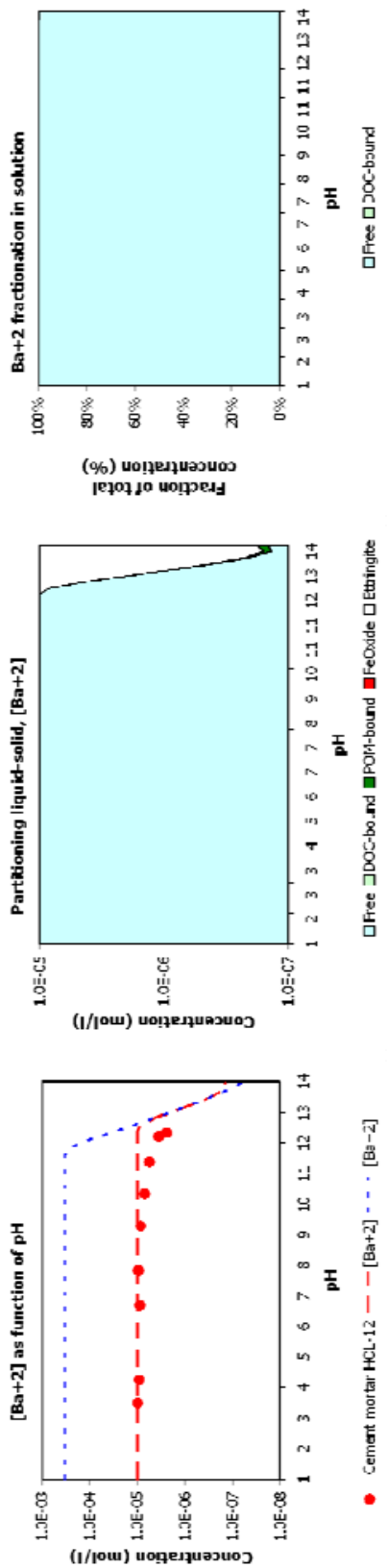
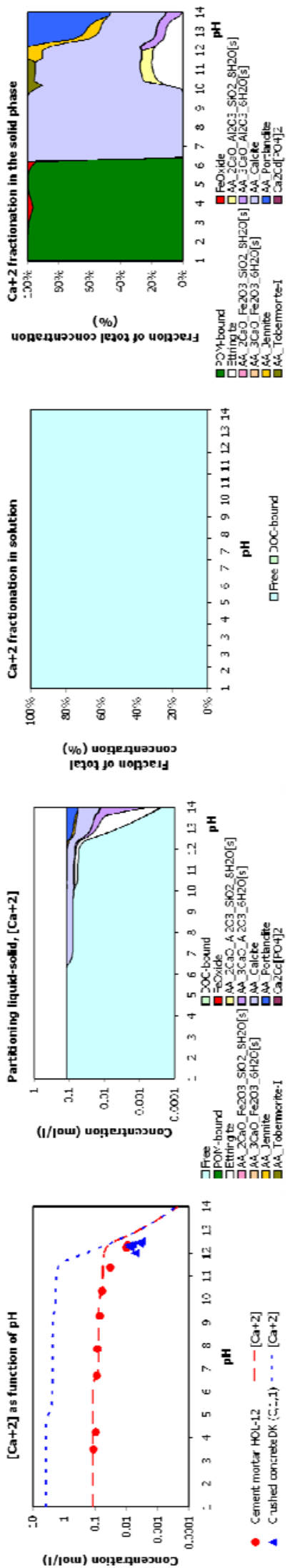

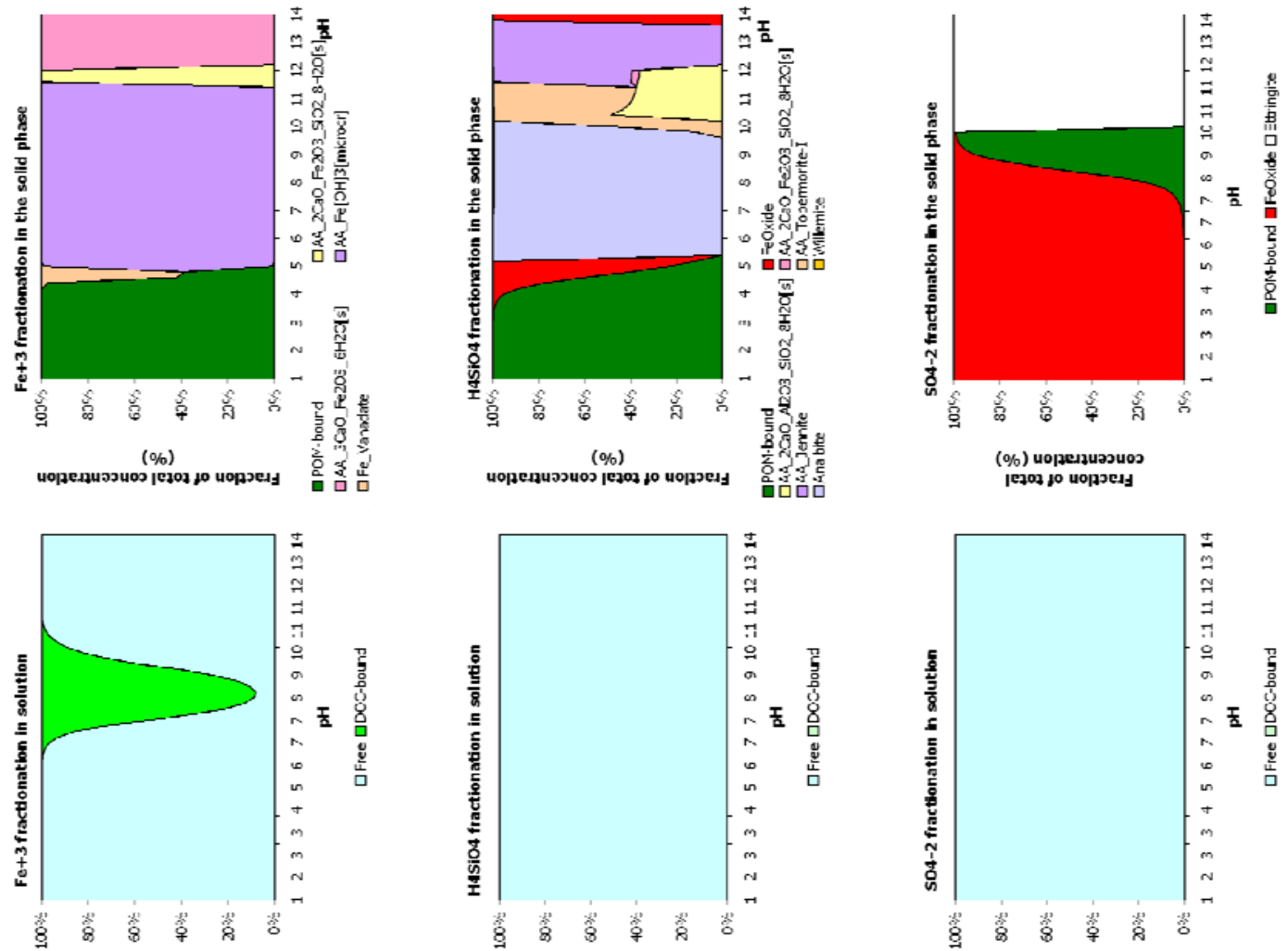

(\%) บo!zenuasuos

(\%) uongenuasuos

(\%) บo!penuasuos

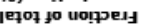
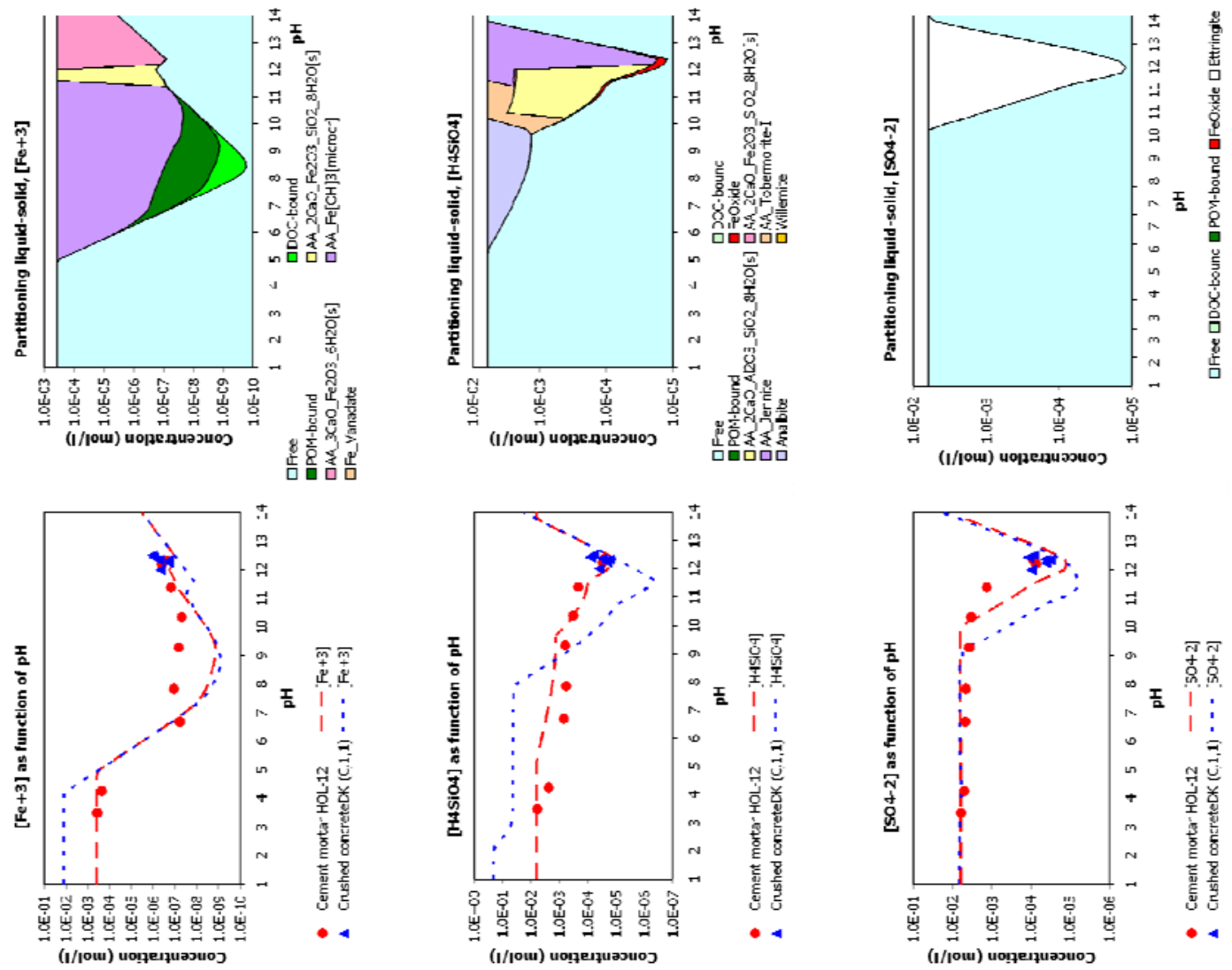


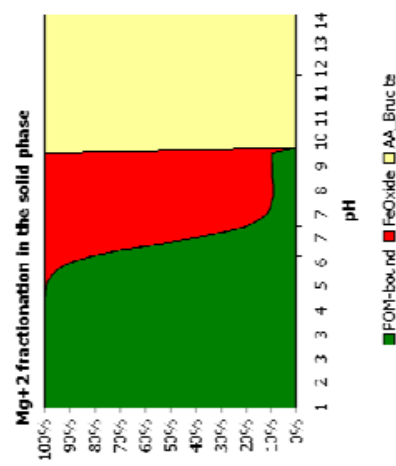

(\%) иоргезиวзиоз

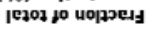

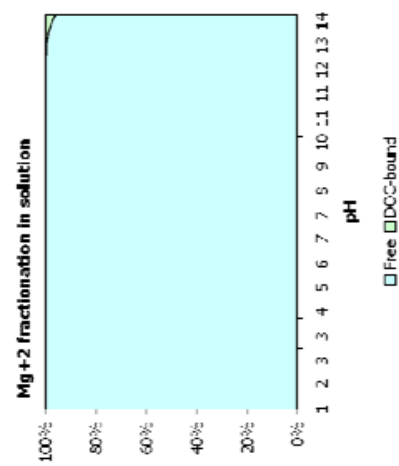

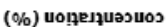
ןето7 to uo!prey
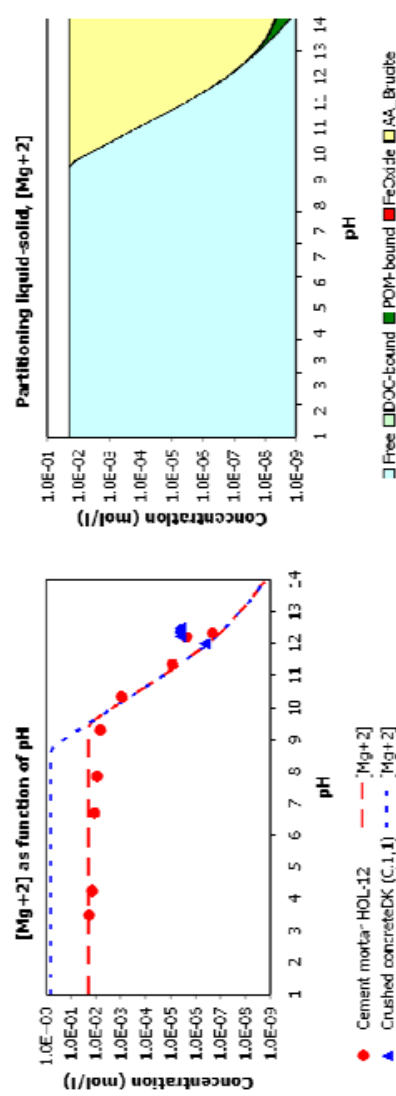

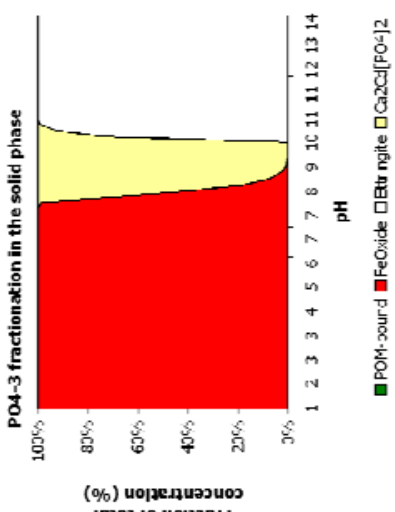

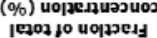

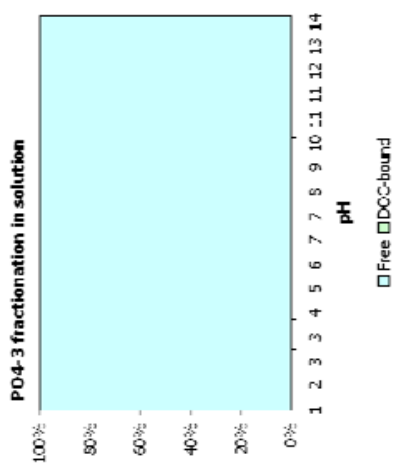

(\%) uonpenuasuos

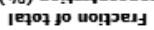
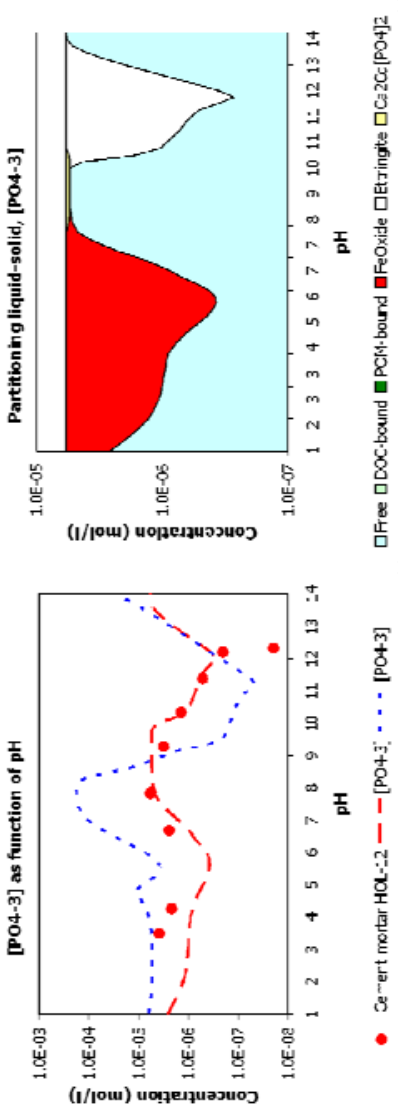

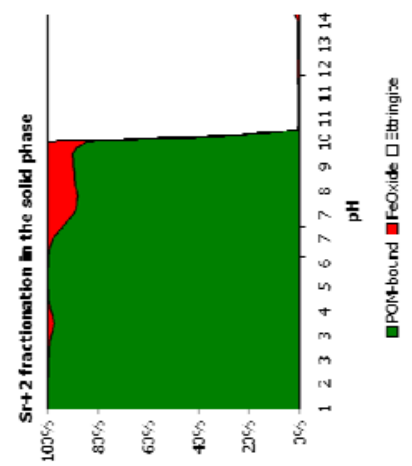

(\%) чордезиวзиоз

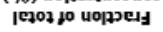

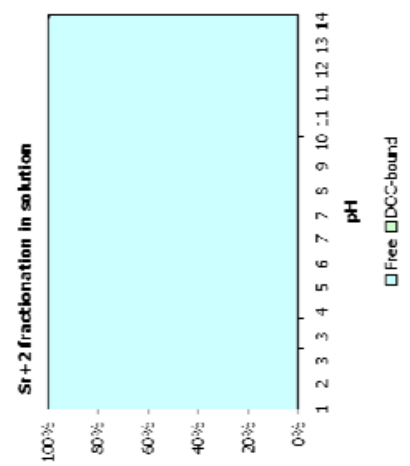

(\%) บo!penuasuos
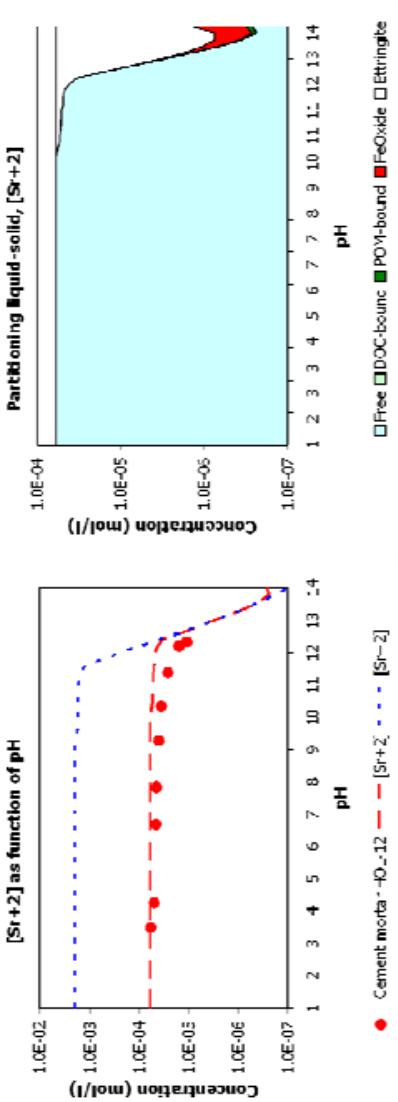


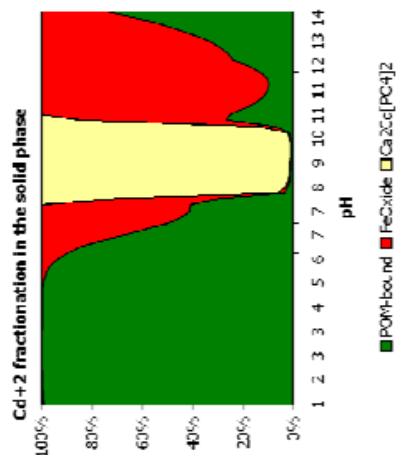

(\%) иорзезиวзиоз

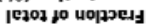

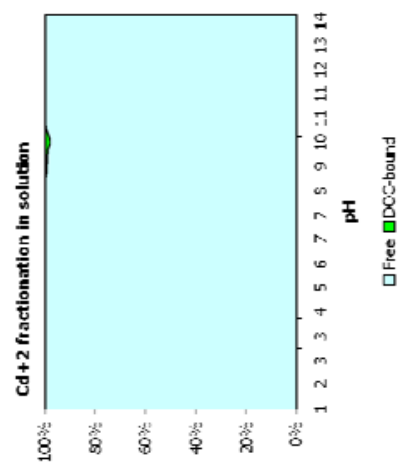

(\%) บo!zenuasuos

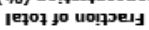
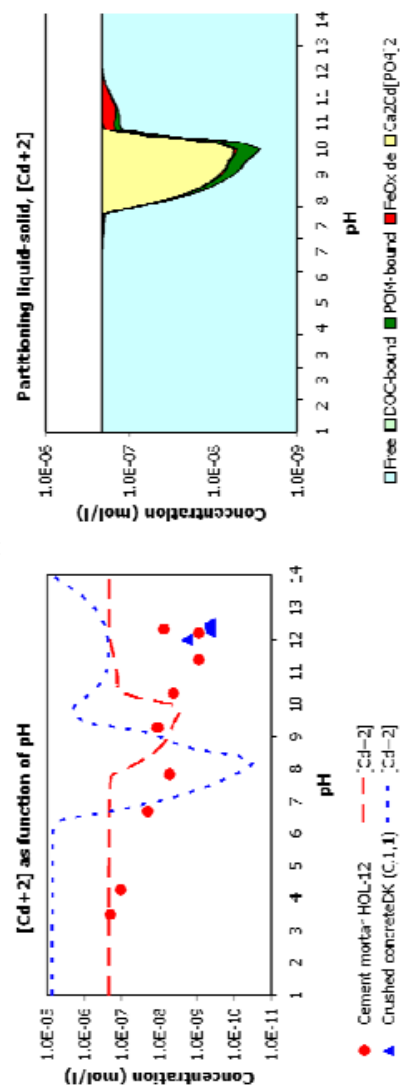
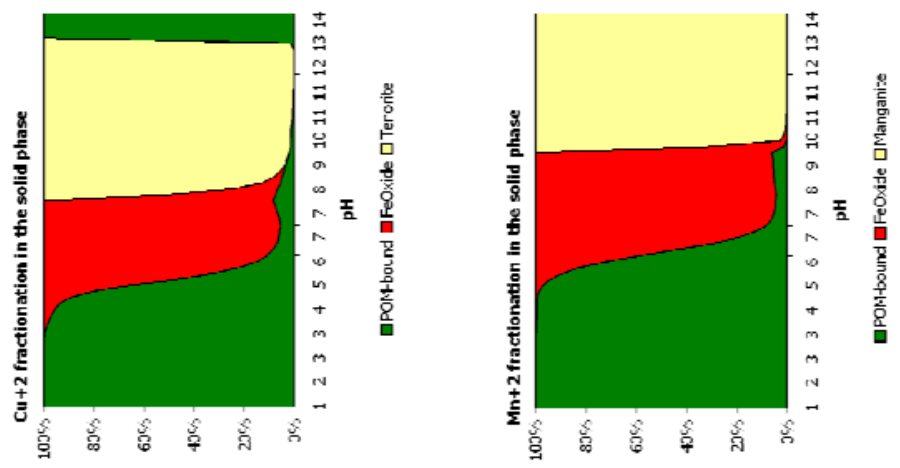

(\%) иорзедигวиоз

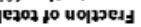

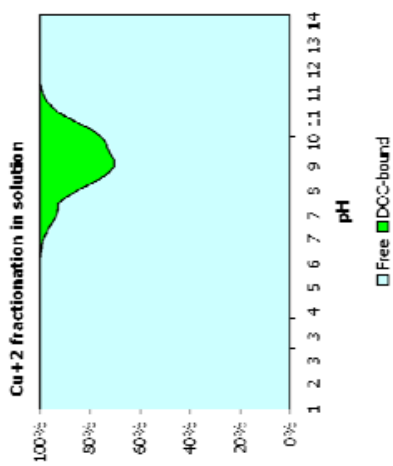

(\%) uo!jenuasuos (\%) vo!pe nuasuos
[eq07 10 uọjouts

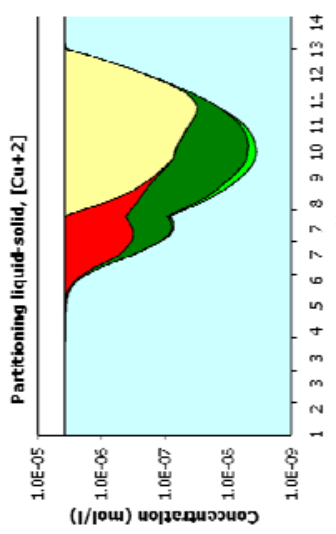

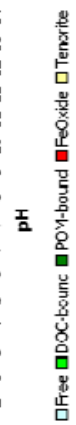

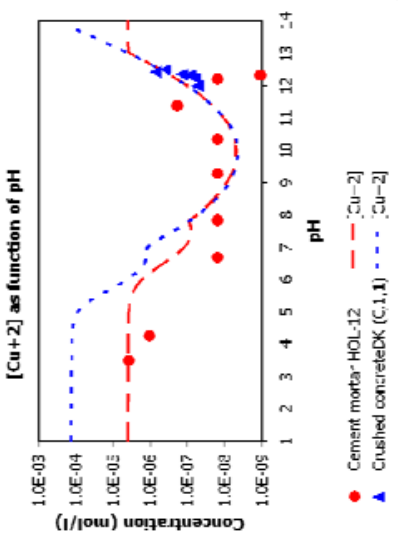

(\%) чорелзиวзиоз

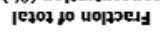

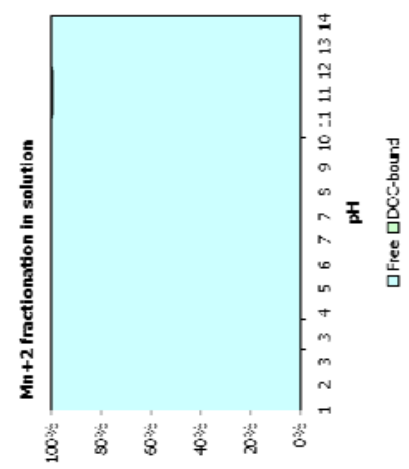

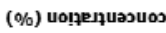
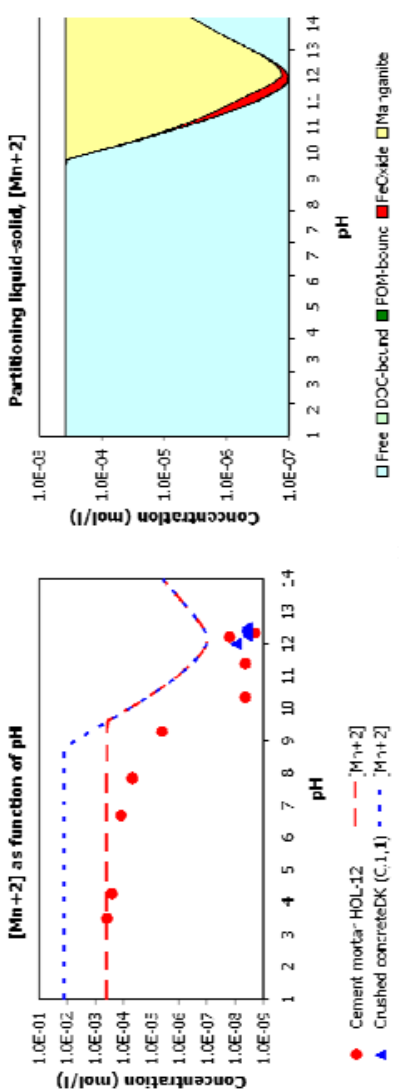

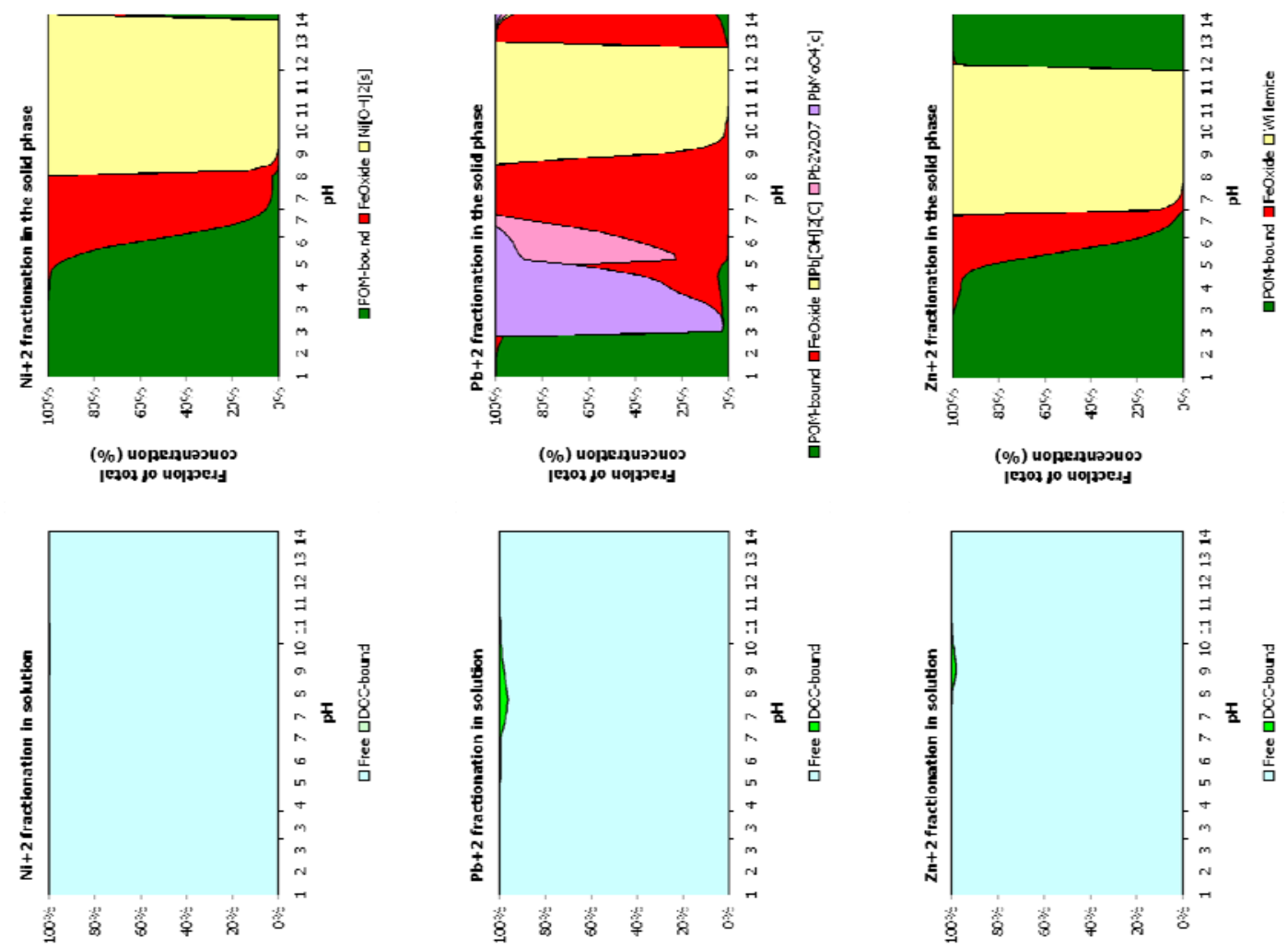

(\%) uo!̣eานuasuos

(\%) บo!zenuasuos

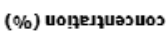
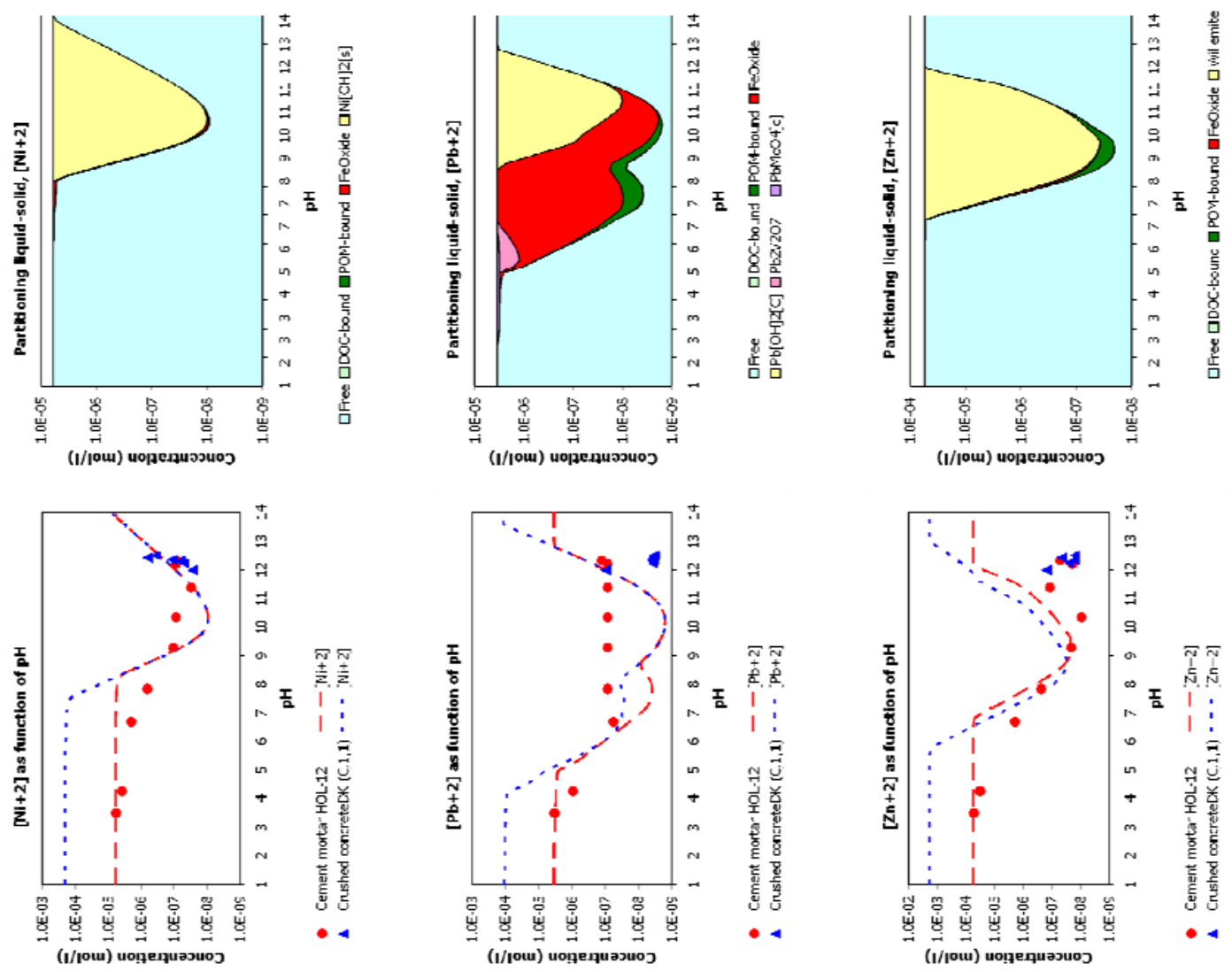


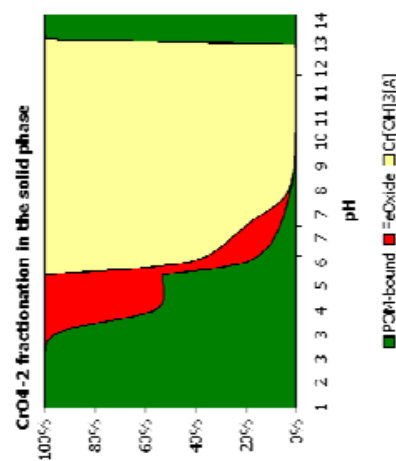

(\%) иорзезиәวиоз

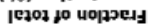

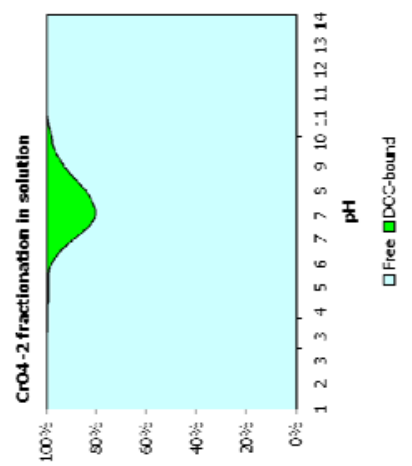

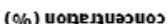

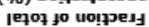
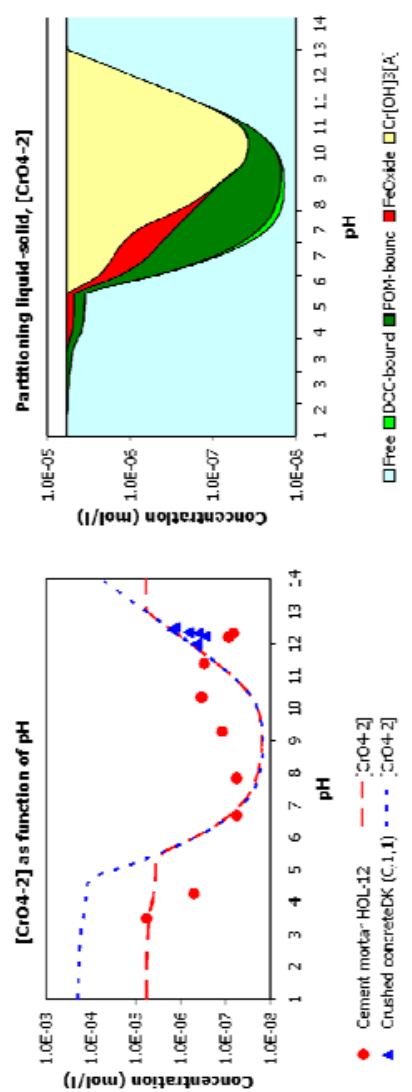
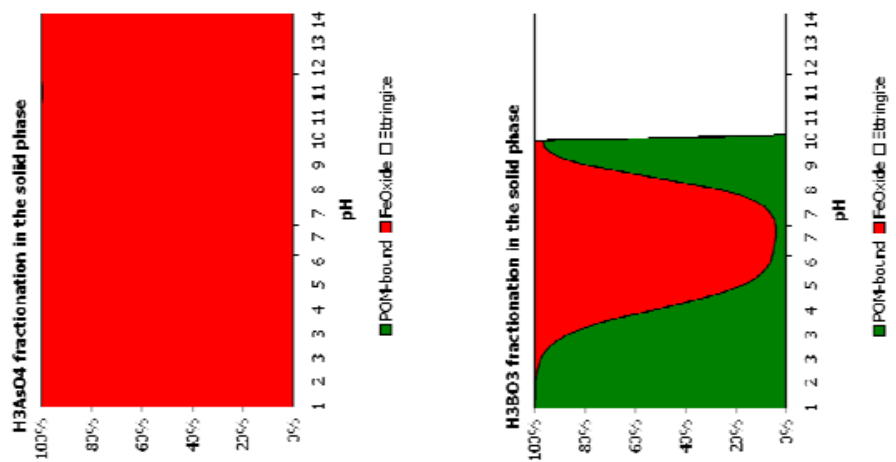

(\%) иорегзиวзиоз

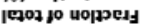

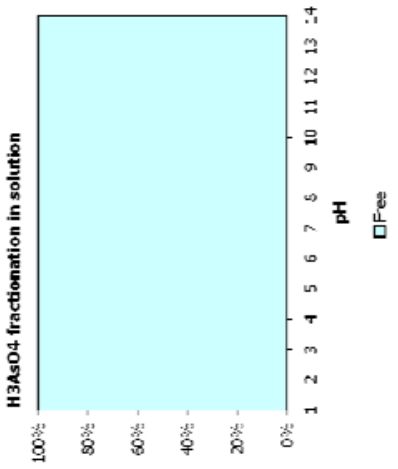

(\%) บo!genบของแอง

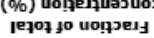
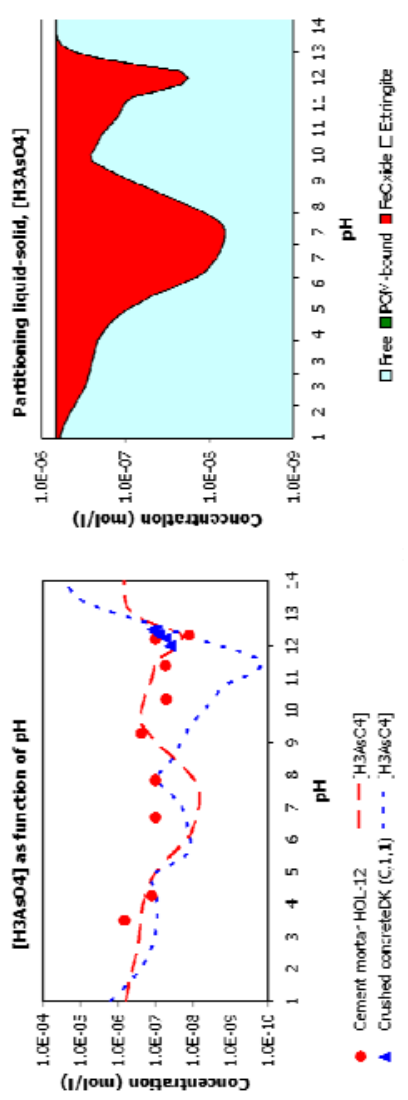

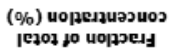

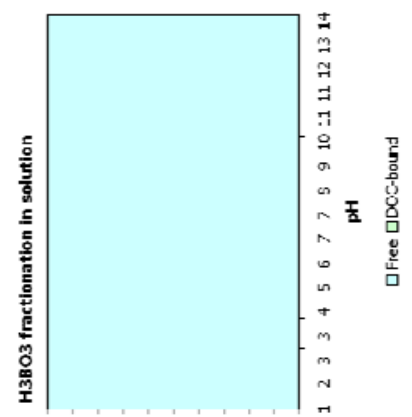

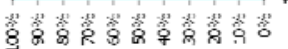

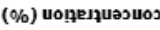
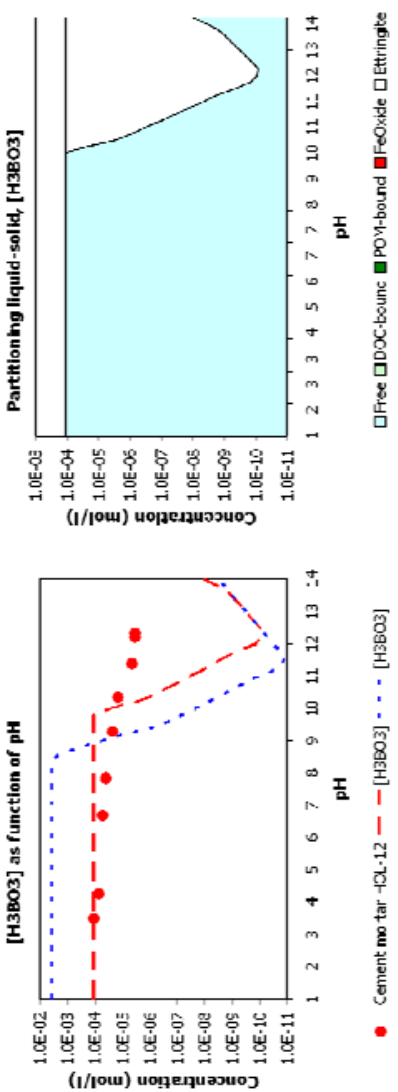

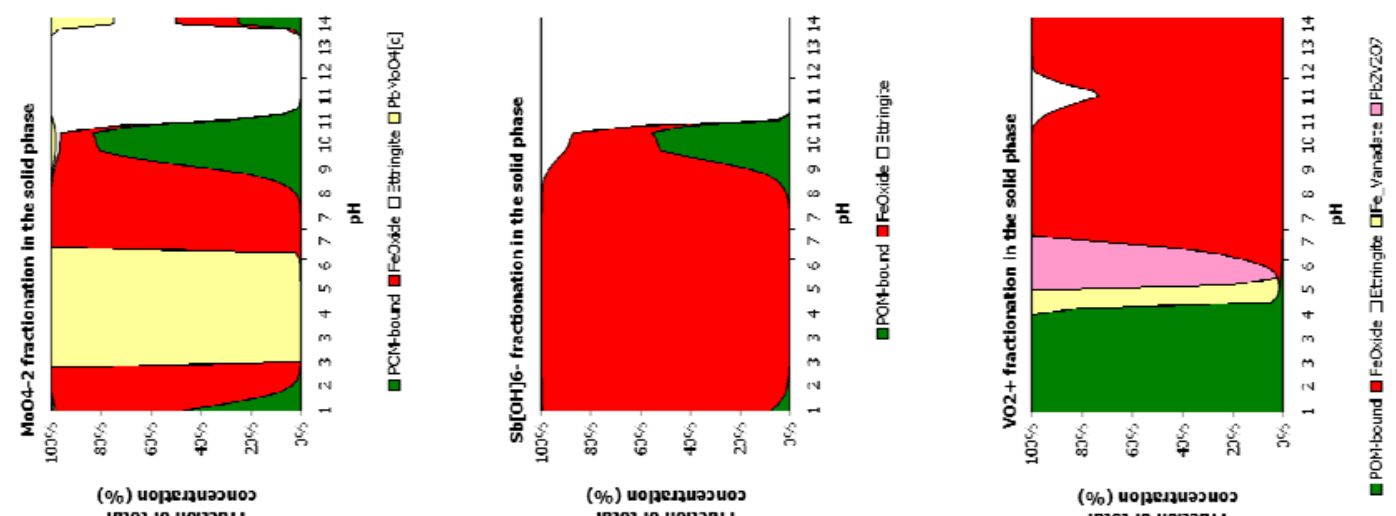

(\%) иорелиазио

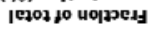

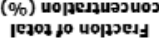
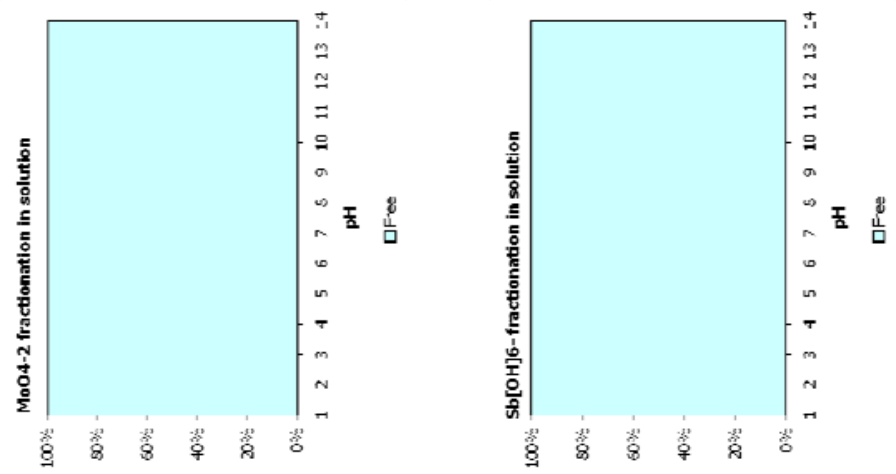

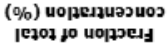

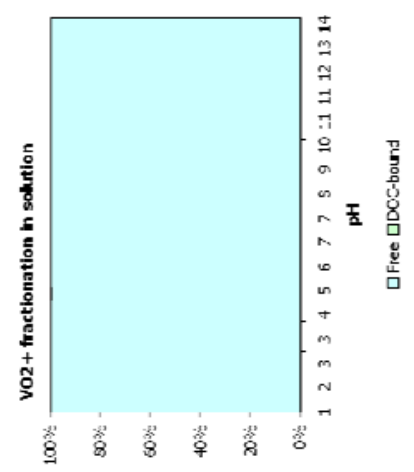

(\%) บоำ

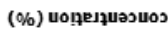

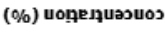

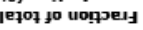
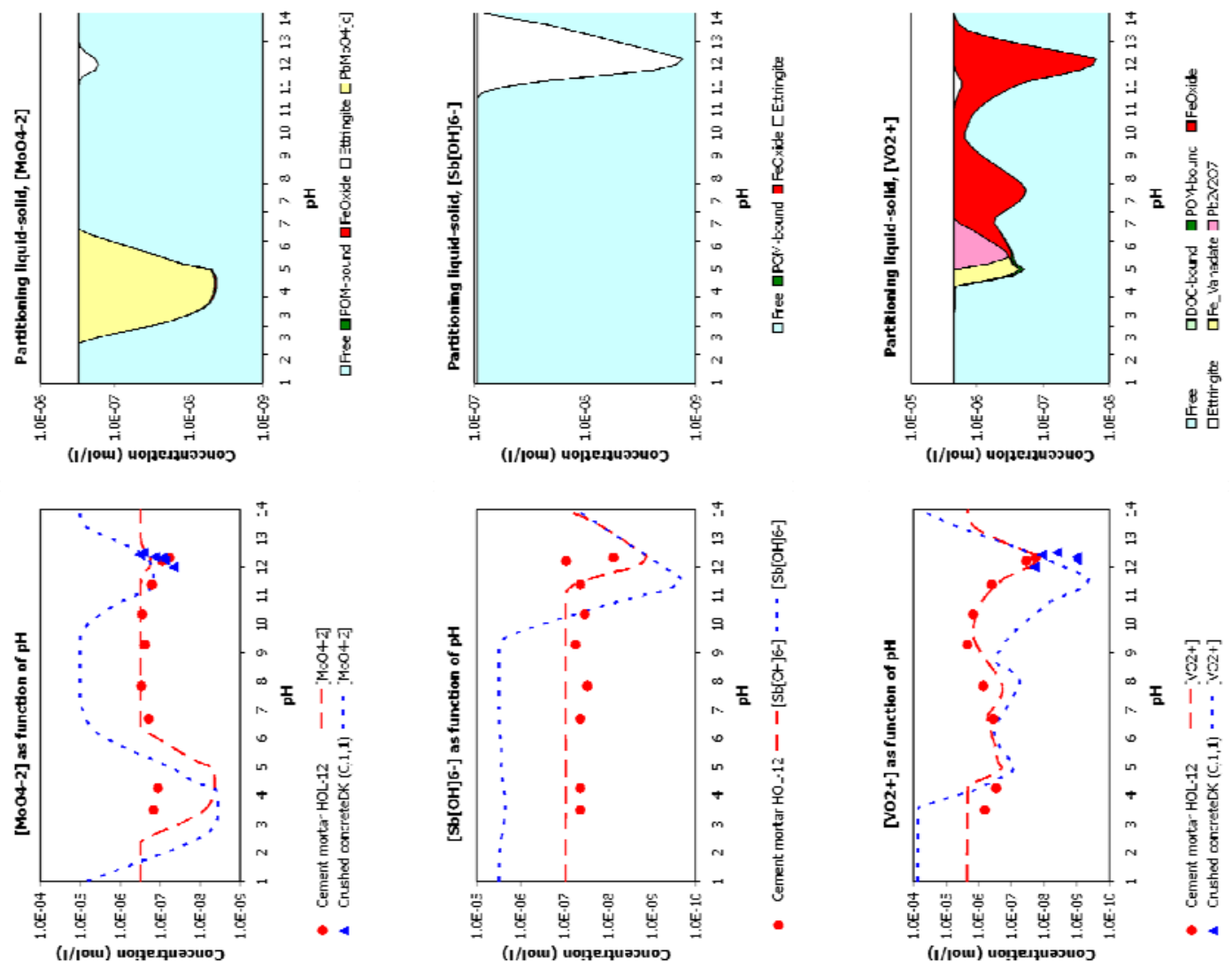


\section{APPENDIX C \\ DIFFERENT CEMENT MORTARS - SAME CHEMISTRY AND SORPTION PROPERTIES}


In the table below the basic input for all subsequent model runs is provided. Per mortar only the availability as derived from the $\mathrm{pH}$ dependence test was different and in case of reducing cements, the $\mathrm{pe}+\mathrm{pH}$ was adjusted.

Input specification

Prediction case CEN V/A HOL 12 tank AA CBP Lothenbach

Speciation session CEN VIA HOL 12 tank AA

Material $\quad \operatorname{HOL} 12(P, 1,1)$

Solved fraction DOC
Sum of $\mathrm{pH}$ and pe

L/S

Clay

HFO

SHA

0.2
10.00
$10.1139 \mathrm{l} / \mathbf{k g}$
$0.000 \mathrm{E}+00 \mathrm{~kg} / \mathbf{k g}$
$2.000 \mathrm{E}-04 \mathrm{~kg} / \mathbf{k g}$
$2.000 \mathrm{E}-05 \mathrm{~kg} / \mathbf{k g}$

$\begin{array}{lcr}\text { DOC/DHA data } & \text { pH } & \text { [DOC] (kg/l) } \\ & 1 \text { to } 14 & 1.000 \mathrm{E}-07\end{array}$

Reactant concentrations Reactant $\mathrm{mg} / \mathrm{kg}$

$\mathrm{Ag}^{+} \quad$ not measured

$\mathrm{Al}^{+3} \quad 2.332 \mathrm{E}+03$

$\mathrm{H}_{3} \mathrm{AsO}_{4} \quad$ 5.060E-01

$\mathrm{H}_{3} \mathrm{BO}_{3} \quad 1.221 \mathrm{E}+01$

$\mathrm{Ba}^{+2} \quad 1.372 \mathrm{E}+01$

$\mathrm{Br}^{-} \quad$ not measured

$\mathrm{Ca}^{+2} \quad 4.698 \mathrm{E}+04$

$\mathrm{Cd}^{+2} \quad 2.414 \mathrm{E}-01$

Cl $5.000 \mathrm{E}+01$

$\mathrm{CrO}_{4}^{-2} \quad 3.055 \mathrm{E}+00$

$\mathrm{Cu}^{+2} \quad 2.432 \mathrm{E}+00$

$\mathrm{F}^{-} \quad 5.000 \mathrm{E}+01$

$\mathrm{Fe}^{+3} \quad 2.130 \mathrm{E}+02$

$\mathrm{H}_{2} \mathrm{CO}_{3} \quad 1.500 \mathrm{E}+04$

$\mathrm{Hg}^{+2}$ not measured

$\mathrm{I}$ not measured

$\mathrm{K}^{+} \quad 1.407 \mathrm{E}+03$

$\mathrm{Li}^{+} \quad 6.934 \mathrm{E}+00$

$\mathrm{Mg}^{+2} \quad 4.758 \mathrm{E}+03$

$\mathrm{Mn}^{+2} \quad 2.083 \mathrm{E}+02$

$\mathrm{MoO}_{4}^{-2} \quad$ 2.939E-01

$\mathrm{Na}^{+} \quad 3.714 \mathrm{E}+02$

$\mathrm{NH}_{4}^{+} \quad$ not measured

$\mathrm{Ni}^{+2} \quad 3.452 \mathrm{E}+00$

$\mathrm{NO}_{3}{ }^{-} \quad$ not measured

$\mathrm{PO}_{4}^{-3} \quad 1.807 \mathrm{E}+00$

$\mathrm{Pb}^{+2} \quad 7.106 \mathrm{E}+00$

$\mathrm{SO}_{4}^{-2} \quad 2.000 \mathrm{E}+03$

$\mathrm{Sb}[\mathrm{OH}]_{6}^{-} \quad$ 6.537E-02

$\mathrm{SeO}_{4}{ }^{-2} \quad 2.025 \mathrm{E}-01$

$\mathrm{H}_{4} \mathrm{SiO}_{4} \quad 1.718 \mathrm{E}+03$

$\mathrm{Sr}^{+2} \quad 5.173 \mathrm{E}+01$

$\mathrm{Th}^{+4} \quad$ not measured

$\mathrm{UO}_{2}{ }^{+} \quad$ not measured

$\mathrm{VO}_{2}{ }^{+} \quad 1.143 \mathrm{E}+00$

$\mathrm{Zn}^{+2} \quad 3.532 \mathrm{E}+01$

Polynomial coeficients DOC

$\begin{array}{ll}\text { C0 } & -7.699 \mathrm{E}+00 \\ \text { C1 } & -6.893 \mathrm{E}-16 \\ \text { C2 } & 0.000 \mathrm{E}+00 \\ \text { C3 } & 0.000 \mathrm{E}+00 \\ \text { C4 } & 0.000 \mathrm{E}+00 \\ \text { C5 } & 0.000 \mathrm{E}+00\end{array}$

\section{DHA fraction [DHA] (kg/l)}

Selected Minerals 2.000E-08

AA_2CaO_Al2O3_8H2O[s]

AA_2CaO_Al2O3_SiO2_8H2O[s]

AA_2CaO_Fe2O3_8H2O[s]

AA_2CaO_Fe2O3_SiO2_8H2O[s]

AA_3CaO_Al2O3_6H2O[s]

AA_3CaO_Al2O3_CaCO3_11H2O[s]

AA_3CaO_Al2O3_CaSO4_12H2O[s]

AA_3CaO_Fe2O3_6H2O[s]

AA_Al[OH]3[am]

AA_Anhydrite

AA_Brucite

AA_Calcite

AA_CaO_Al2O3_10H2O[s]

AA_Fe[OH] $3[$ microcr]

AA_Gibbsite

AA_Gypsum

AA_Jennite

AA_Magnesite

AA_Portlandite

AA_Syngenite

AA_Tobermorite-I

AA_Tobermorite-II

Analbite

$\mathrm{Ca} 2 \mathrm{Cd}[\mathrm{PO} 4] 2$

$\mathrm{Cd}[\mathrm{OH}] 2[\mathrm{C}]$

$\mathrm{Cr}[\mathrm{OH}] 3[\mathrm{~A}]$

Fe_Vanadate

Magnesite

Manganite

$\mathrm{Ni}[\mathrm{OH}] 2[\mathrm{~s}]$

$\mathrm{Pb}[\mathrm{OH}] 2[\mathrm{C}]$

$\mathrm{Pb} 2 \mathrm{~V} 2 \mathrm{O} 7$

$\mathrm{Pb} 3[\mathrm{VO} 4] 2$

$\mathrm{PbCrO} 4$

$\mathrm{PbMoO} 4[\mathrm{c}]$

Rhodochrosite

Strontianite

Tenorite

Willemite 

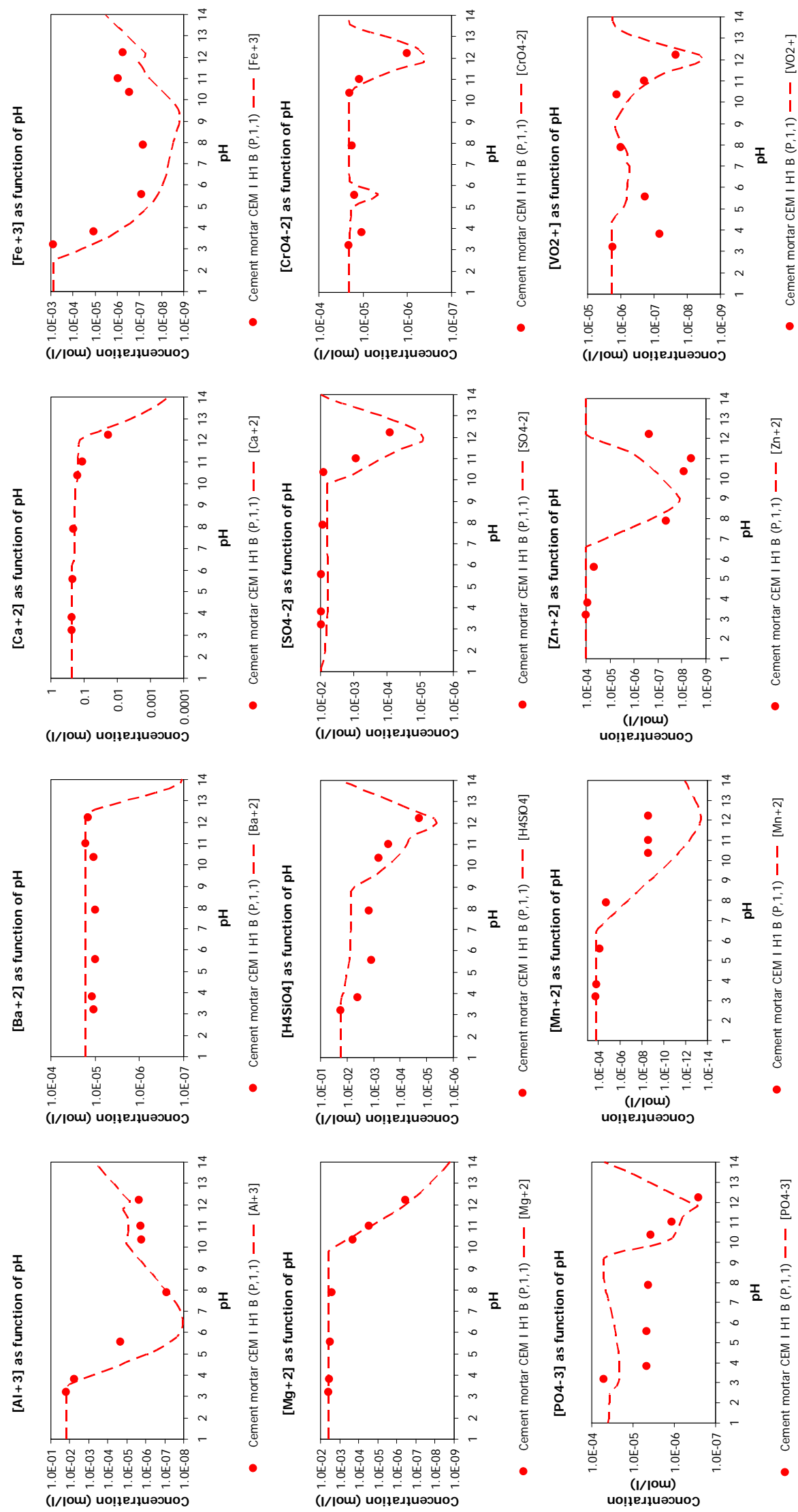

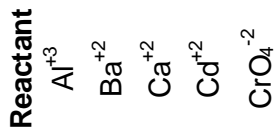



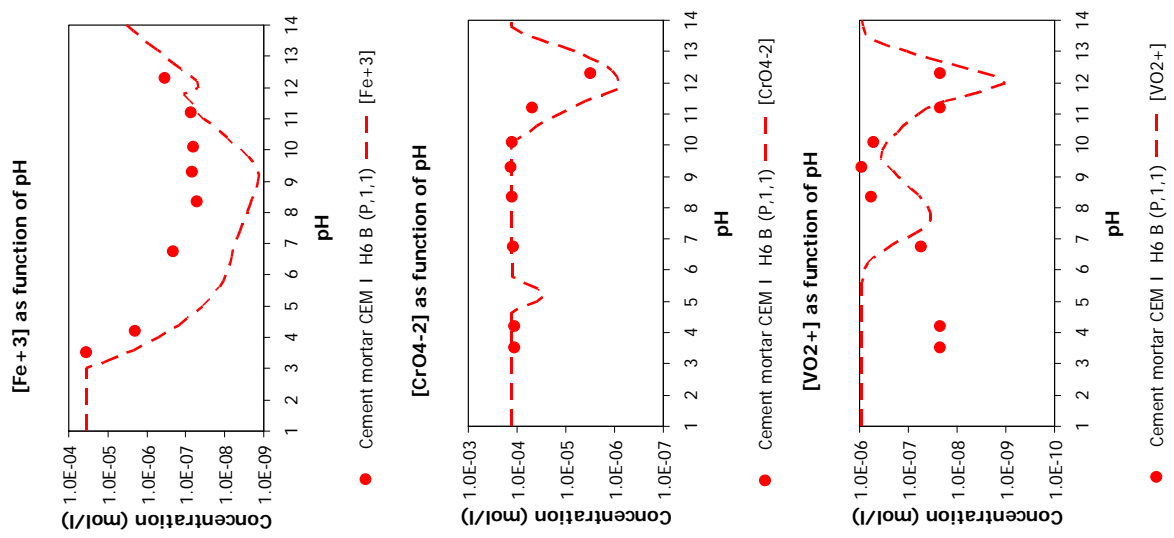

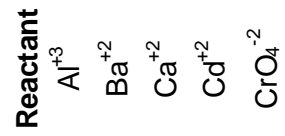
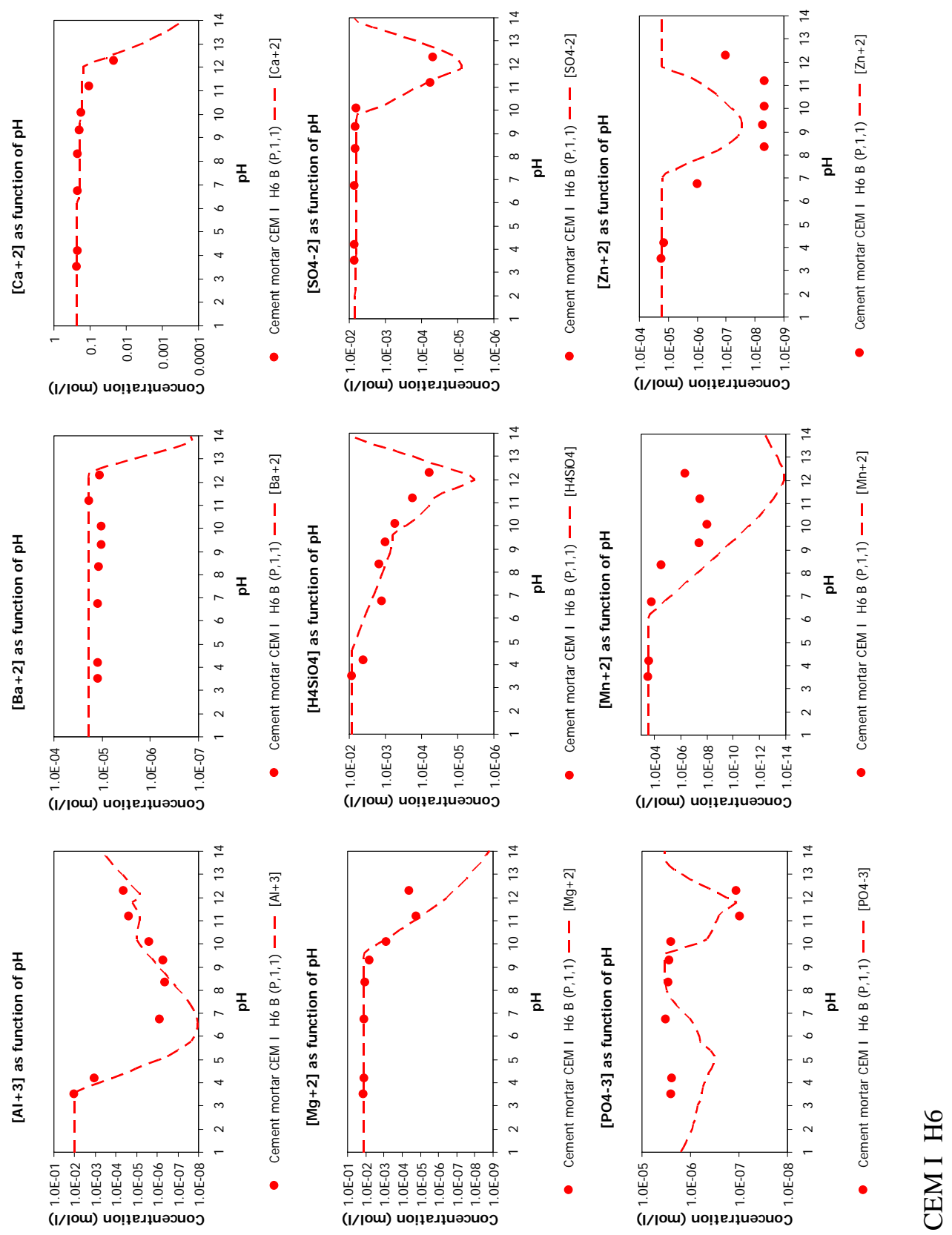


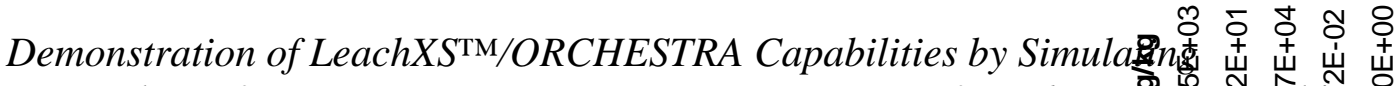
Constituent Release from a Cementitious Waste Form in a Reinforced Con
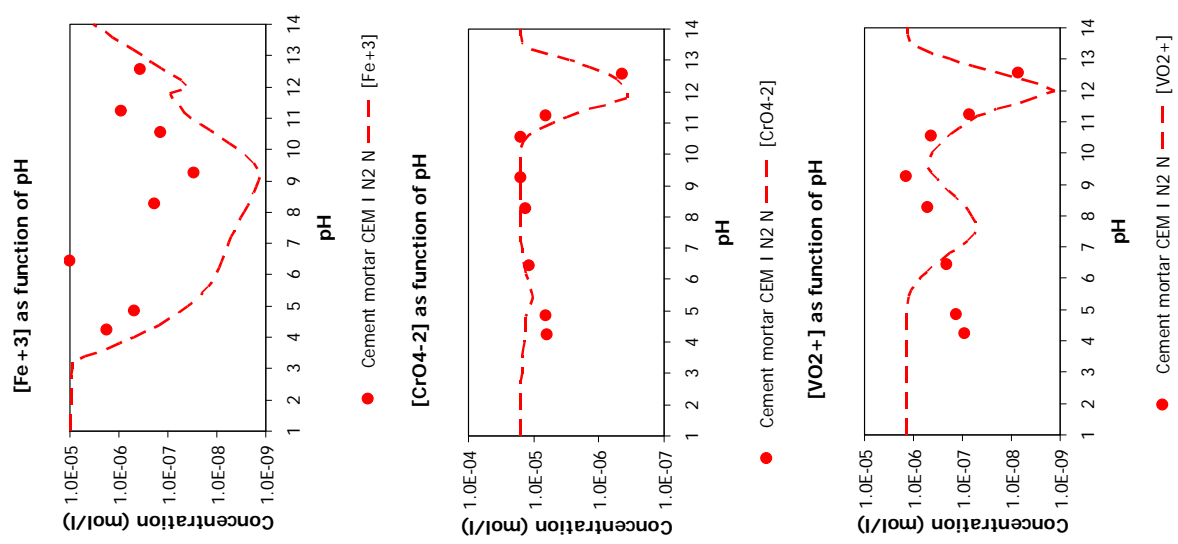

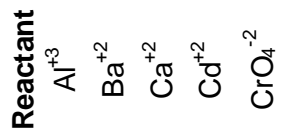
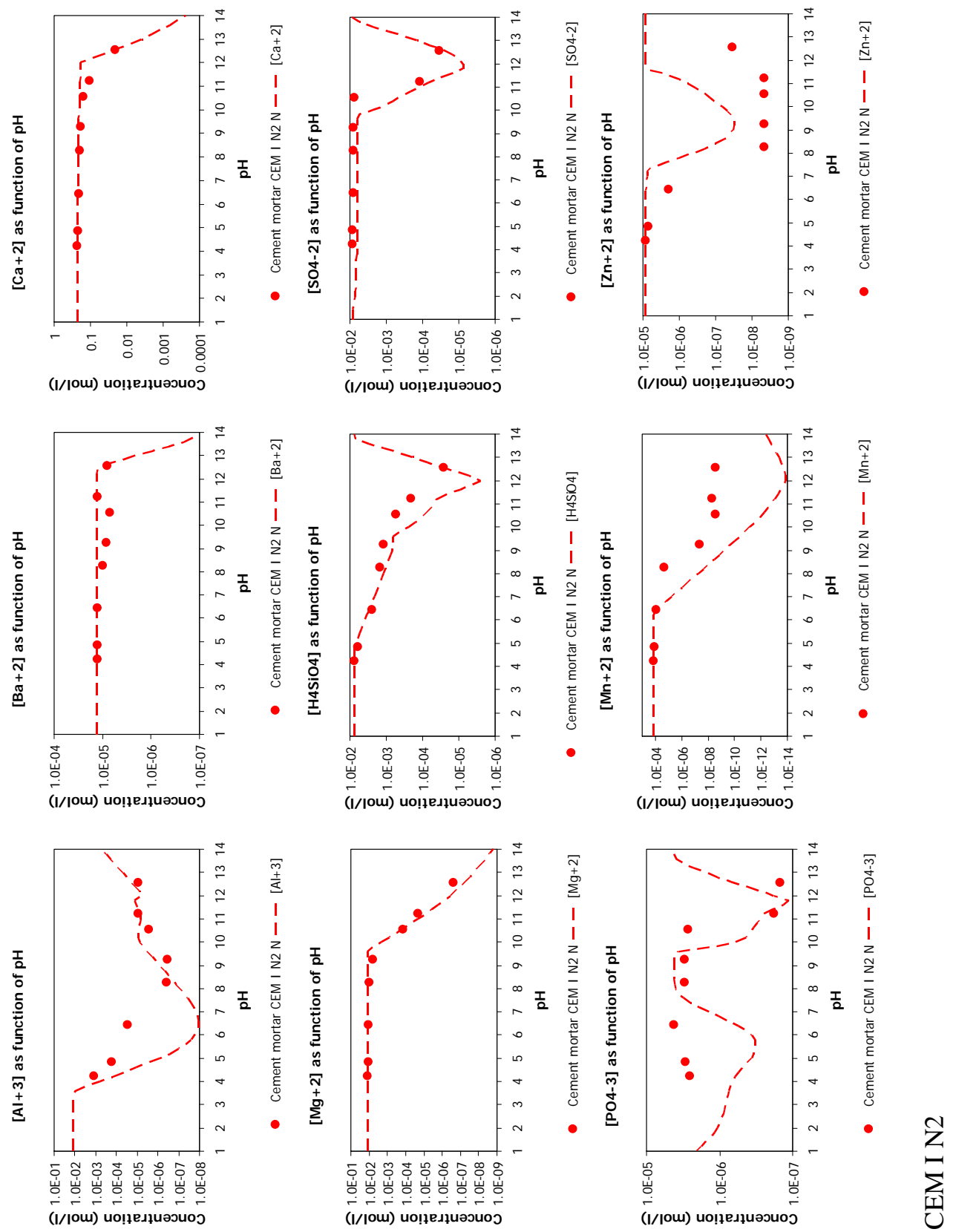
Demonstration of LeachXSTM/ORCHESTRA Capabilities by Simula Constituent Release from a Cementitious Waste Form in a Reinforced Con
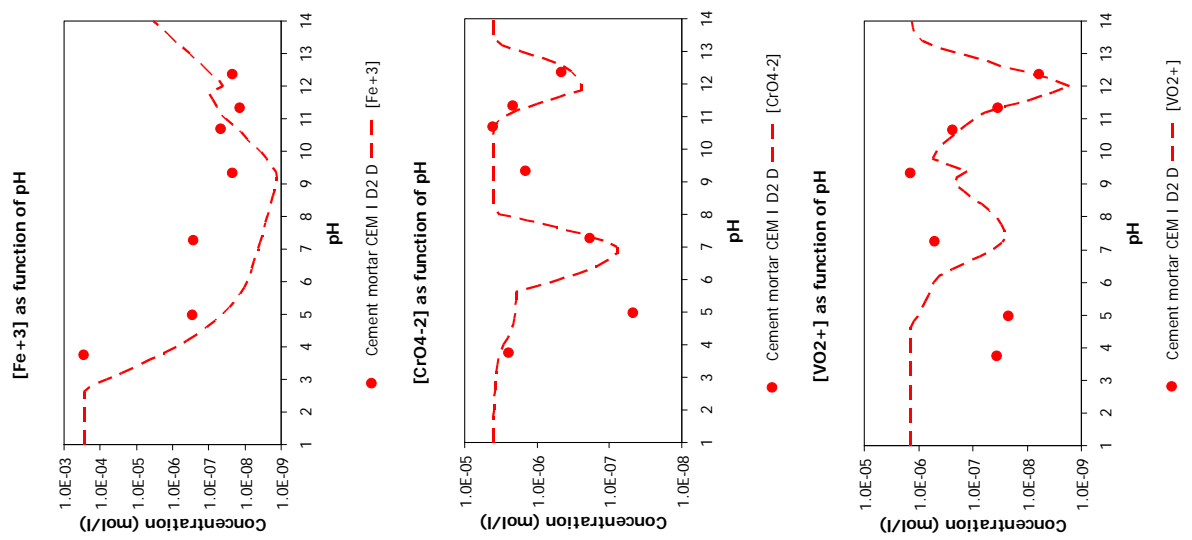

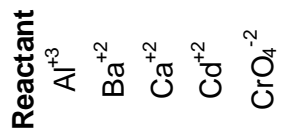
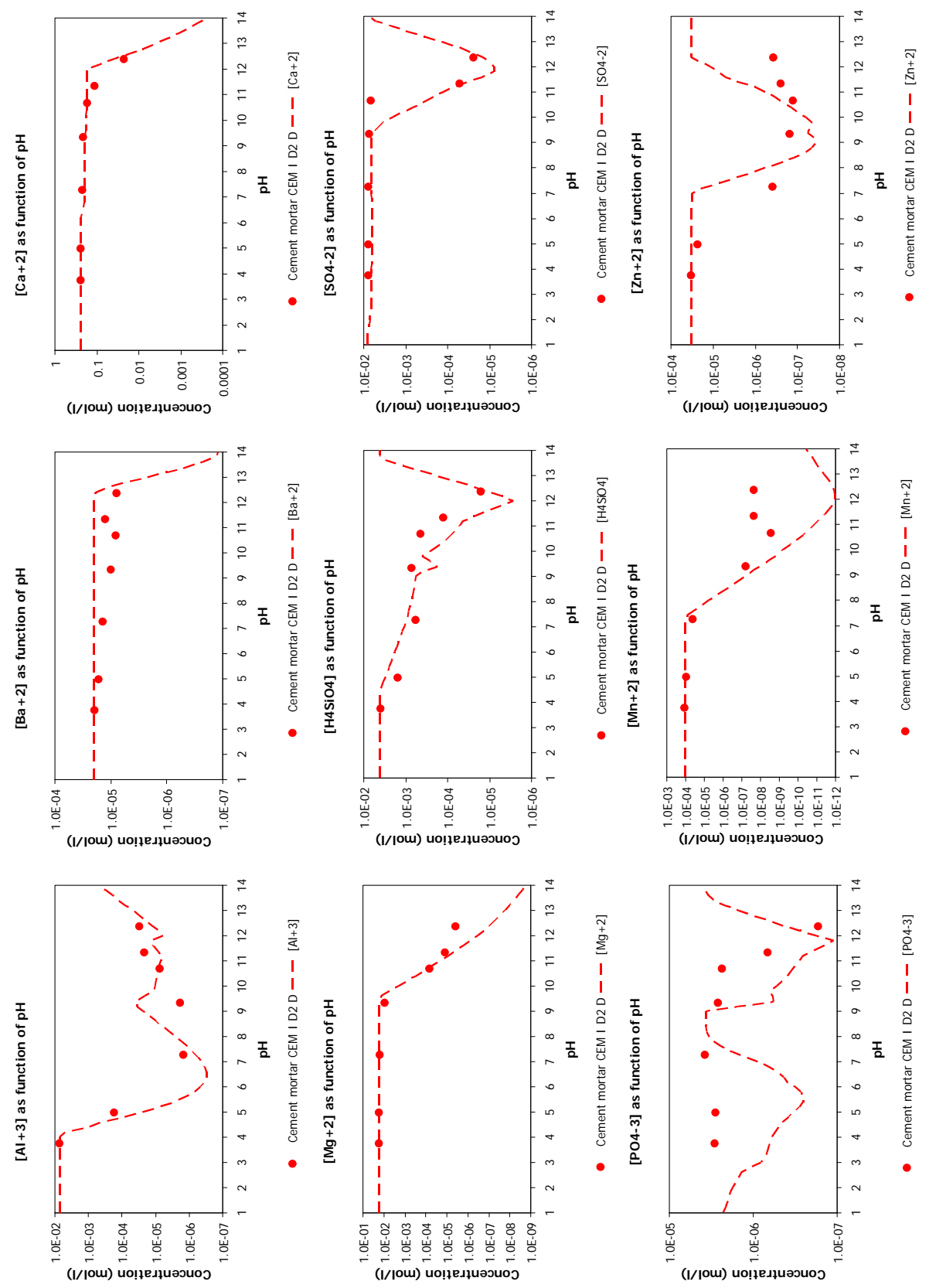

令 

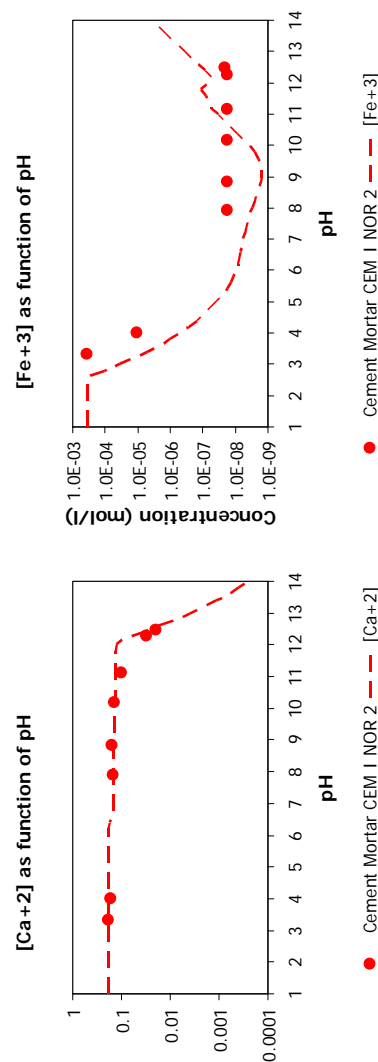

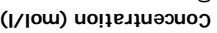
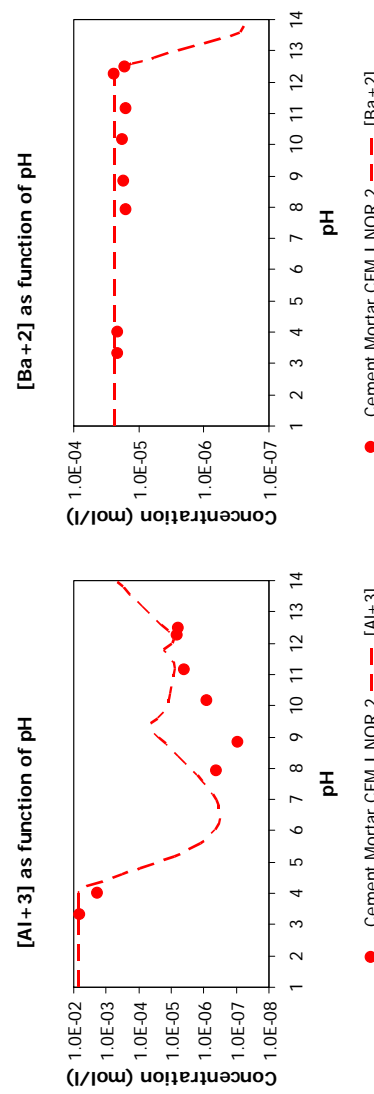
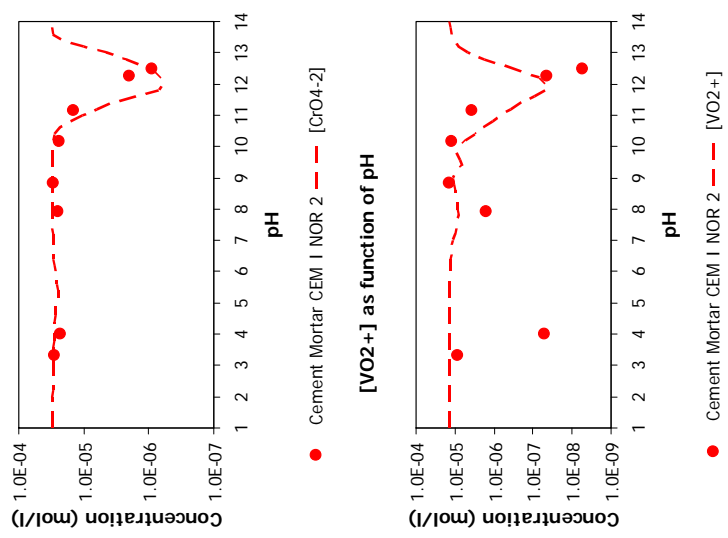

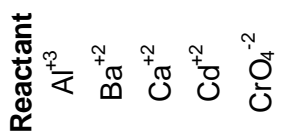
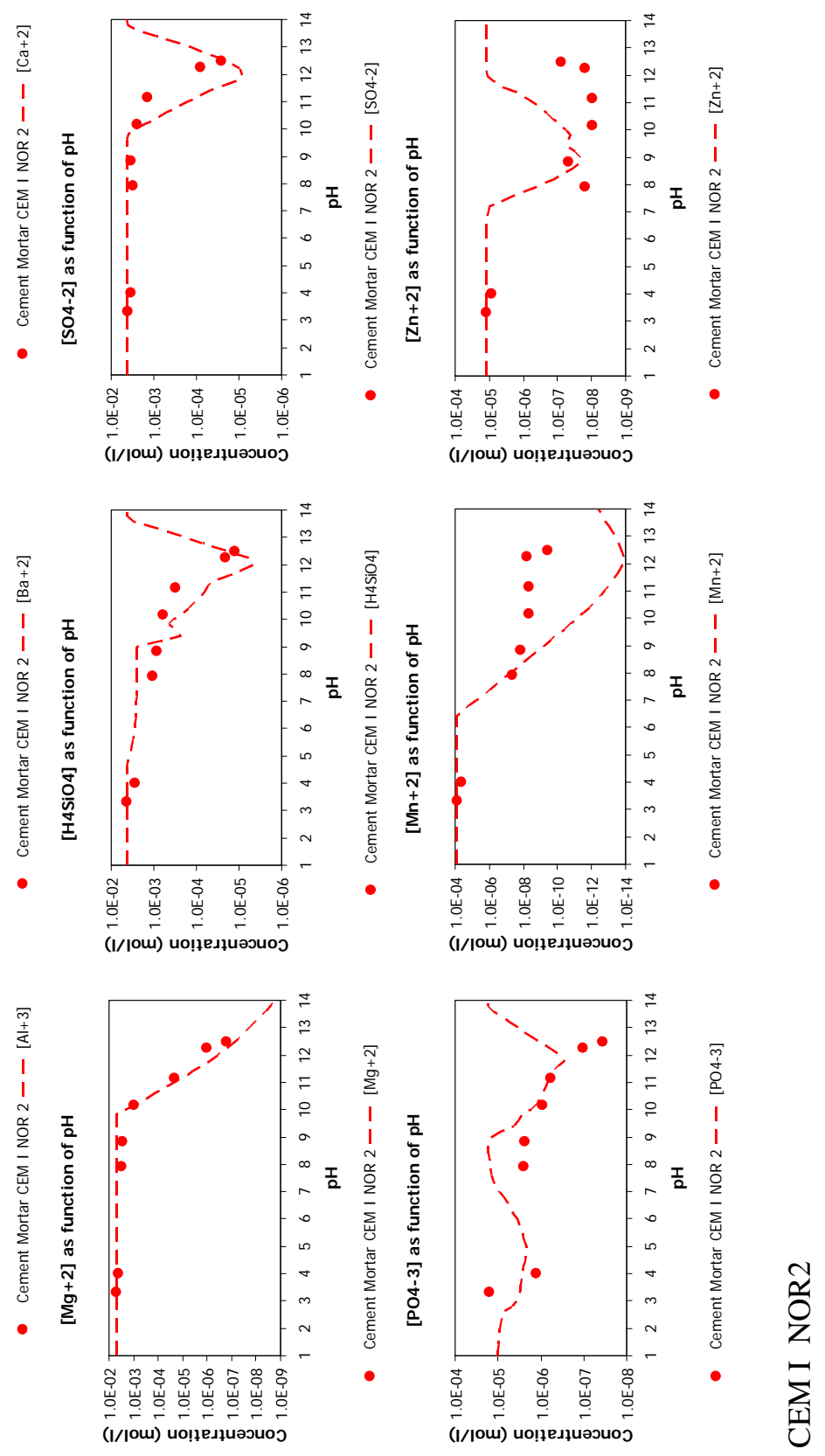

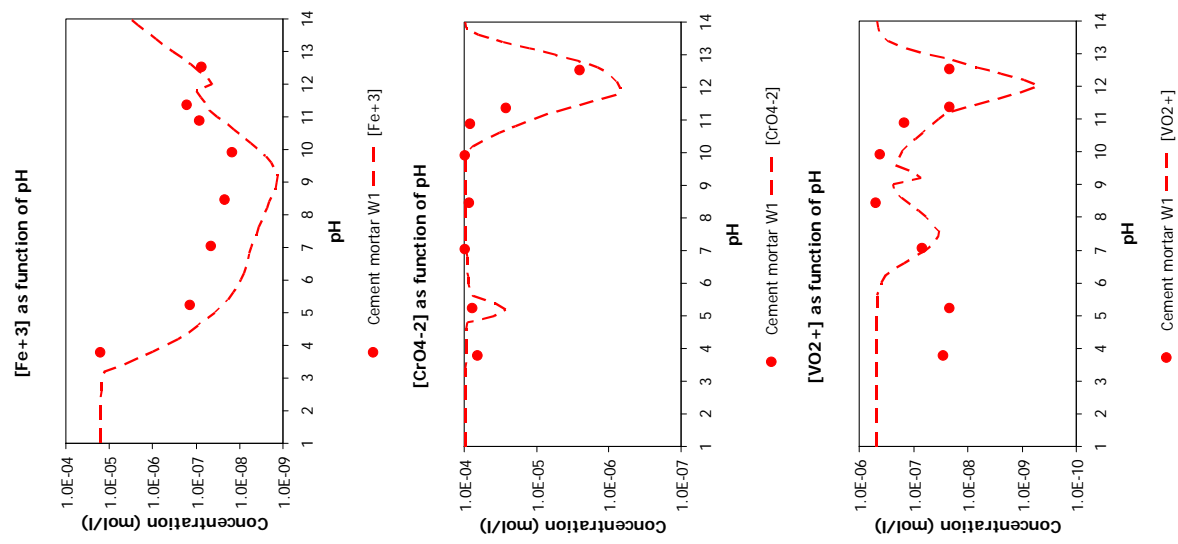

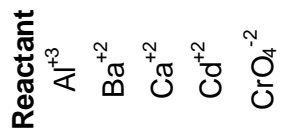
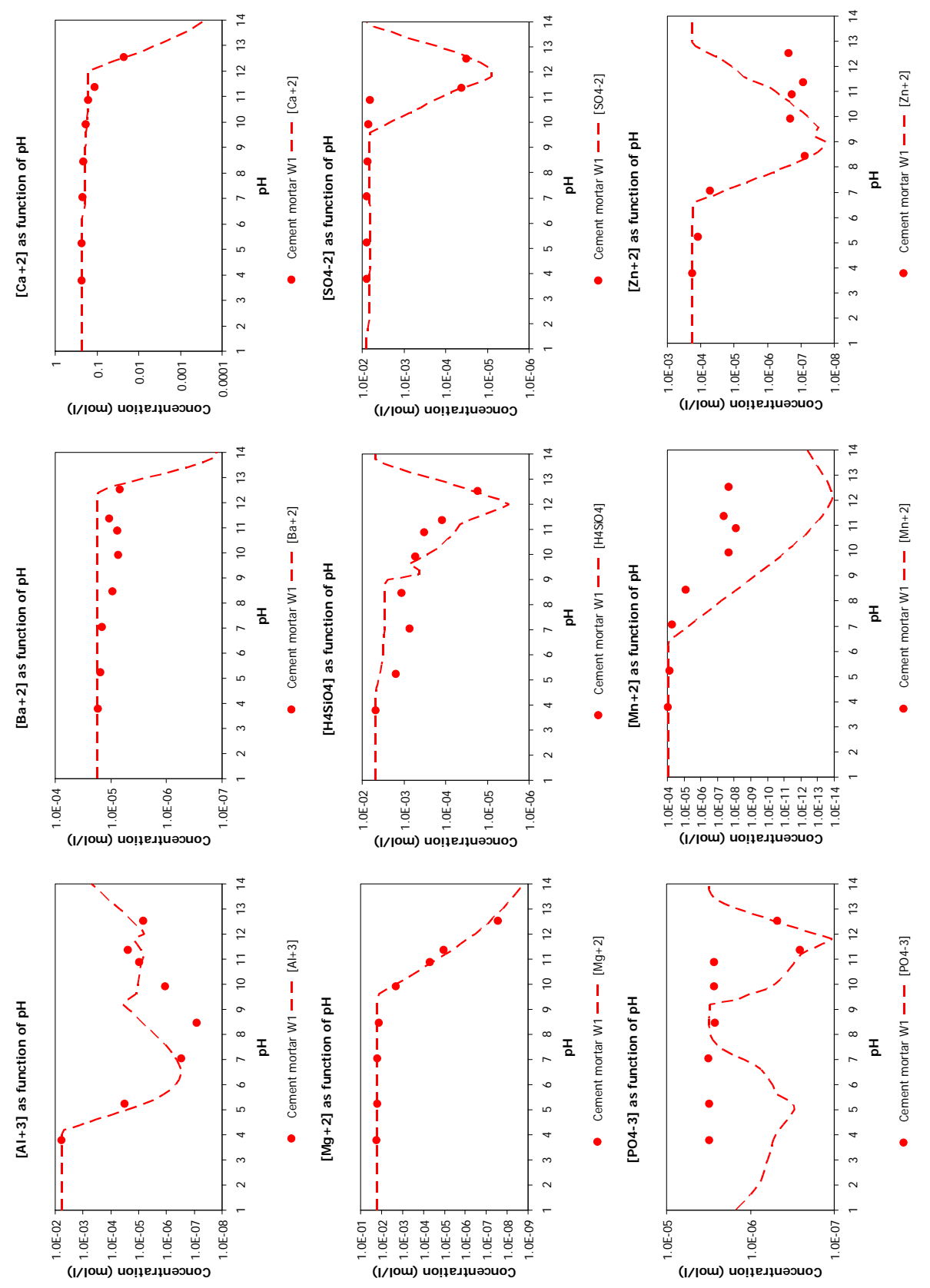

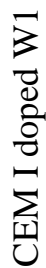


Demonstration of LeachXS TM/ORCHESTRA Capabilities by Simula Rु Constituent Release from a Cementitious Waste Form in a Reinforced Conê
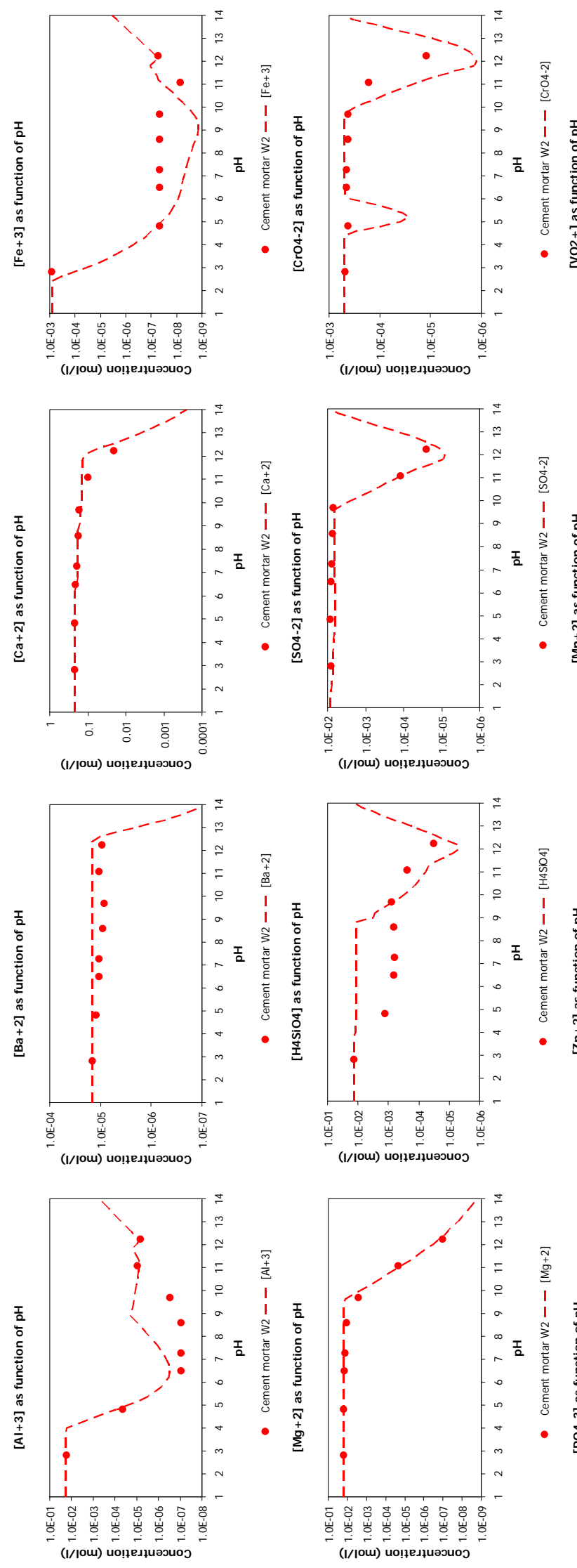

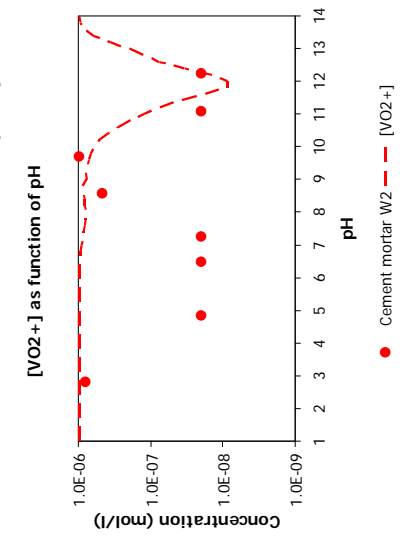

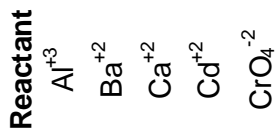

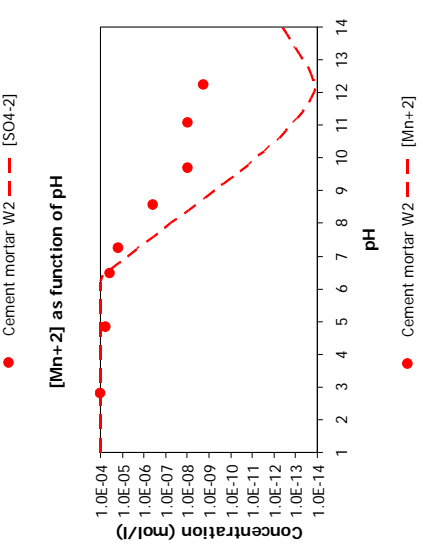

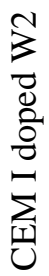



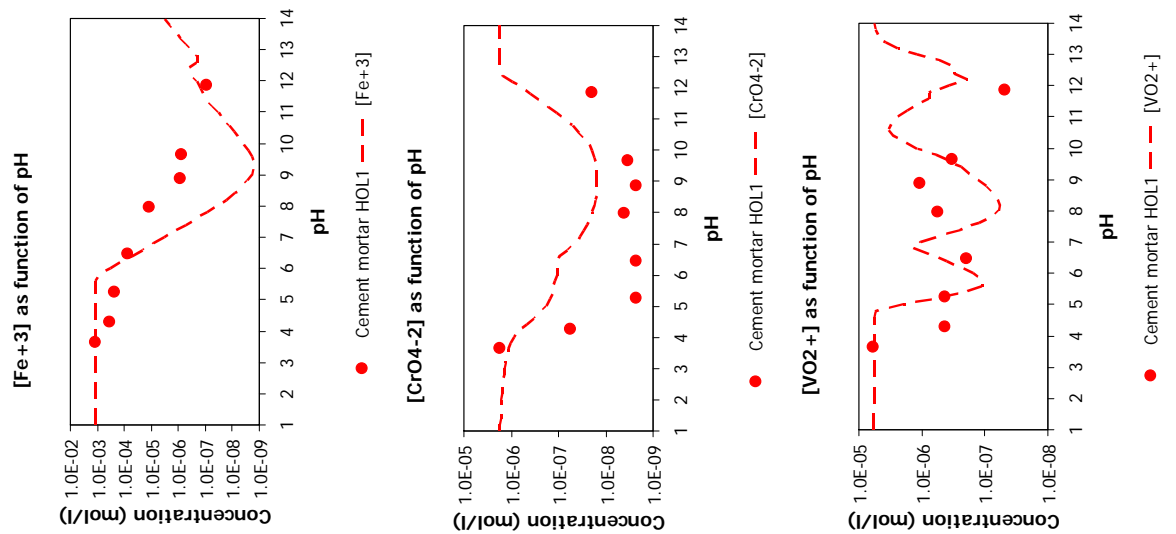

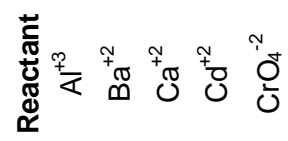
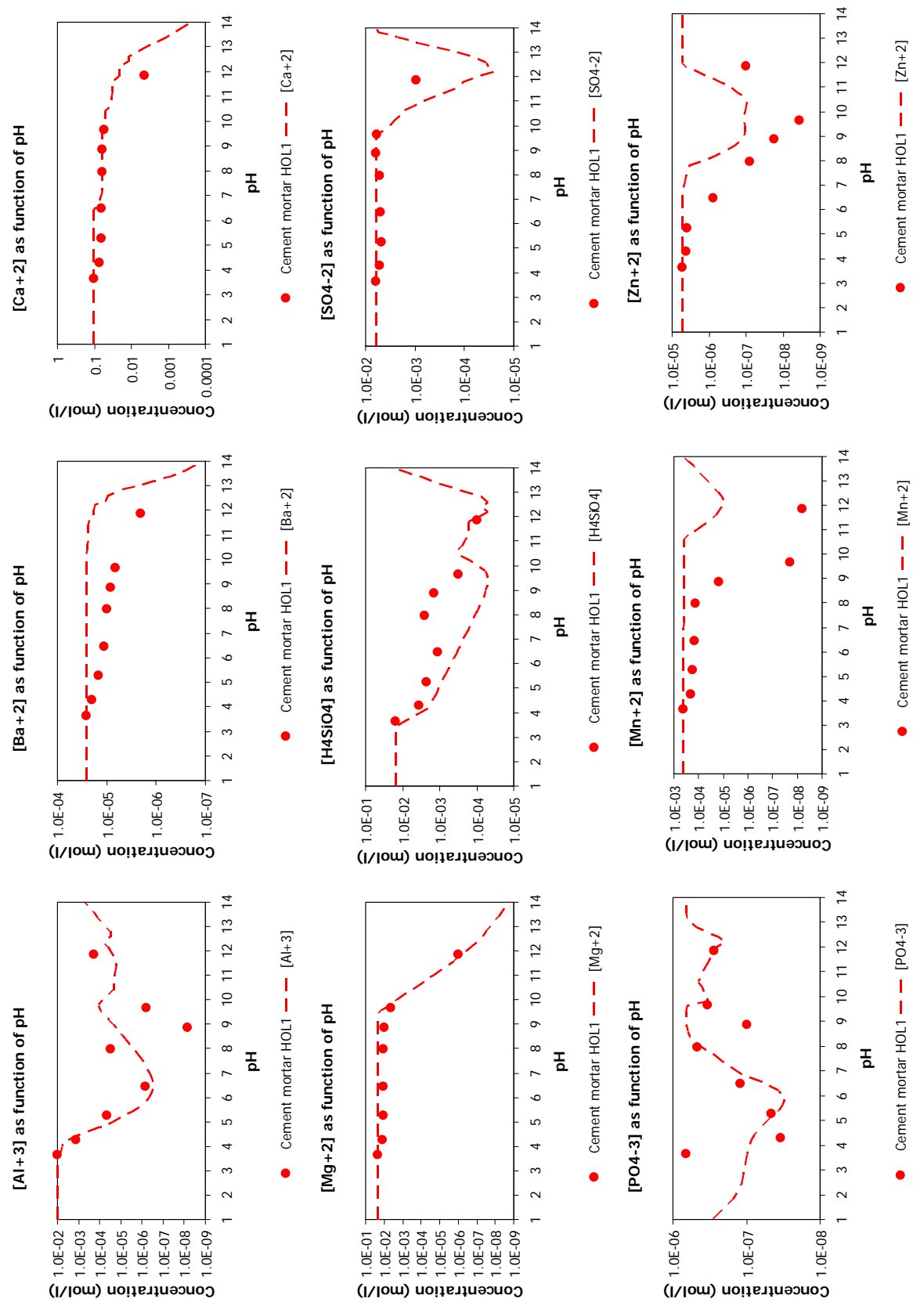

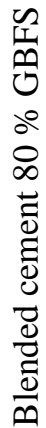



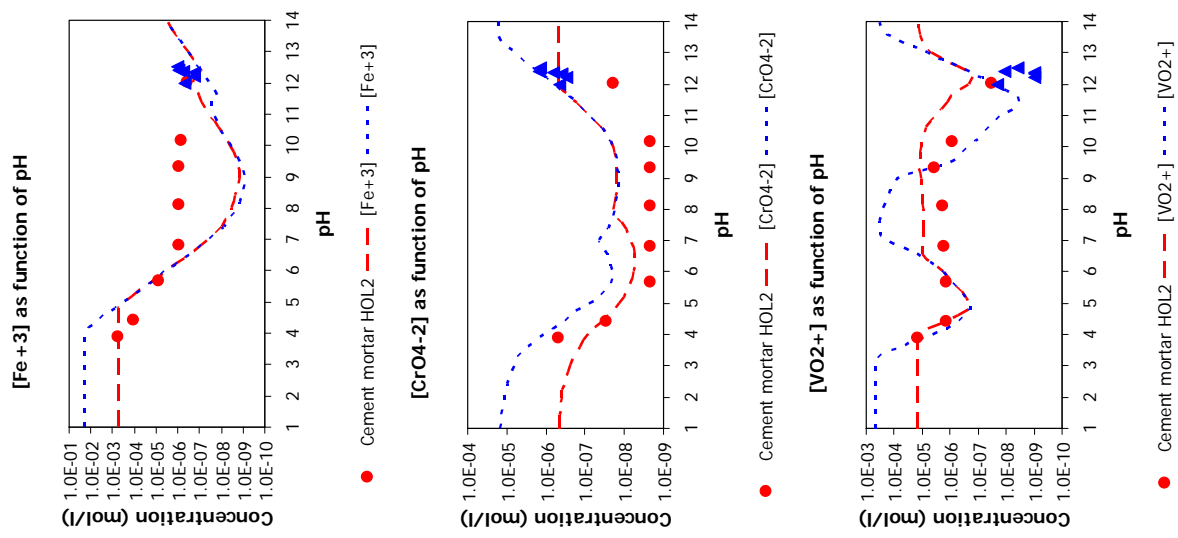

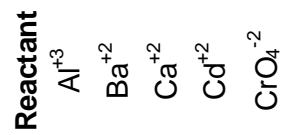
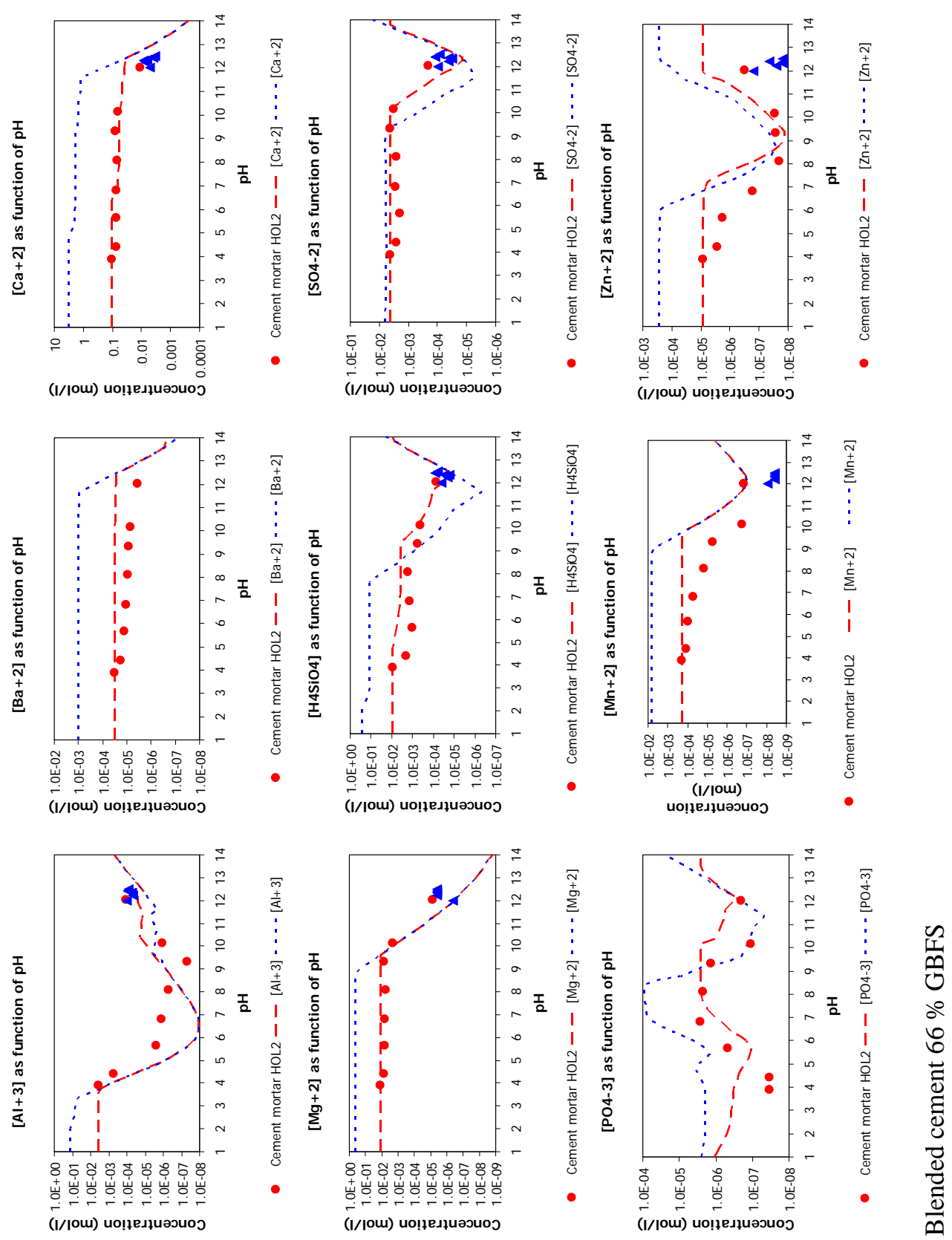
ఇึ

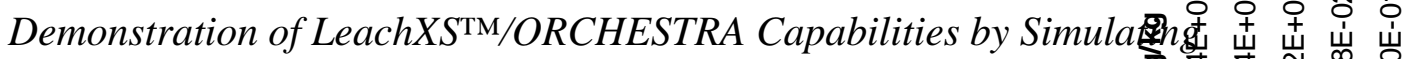
Constituent Release from a Cementitious Waste Form in a Reinforced Con
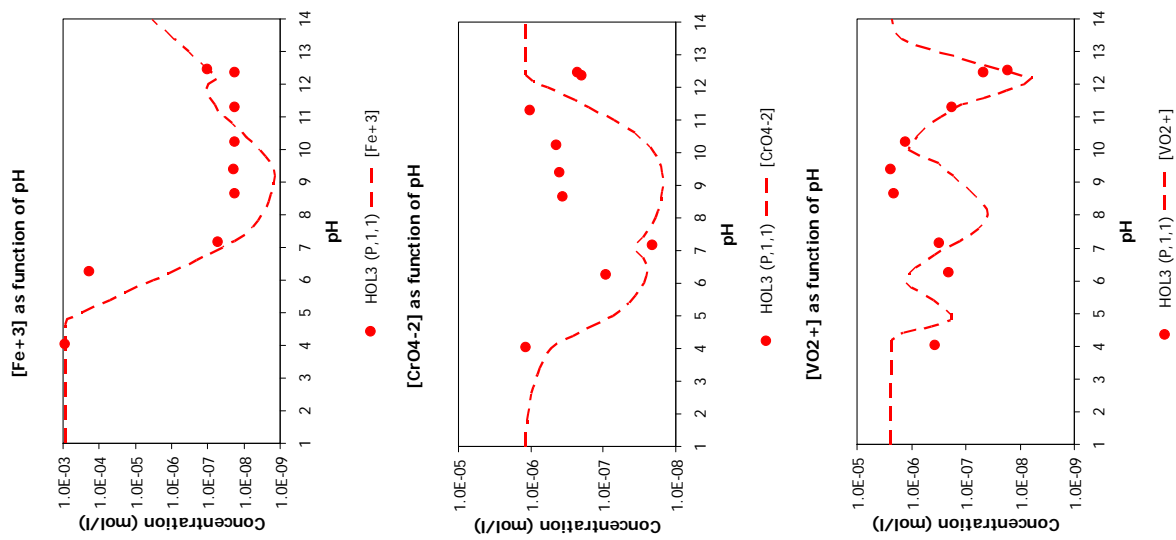

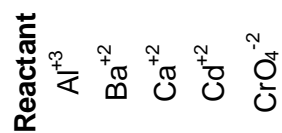
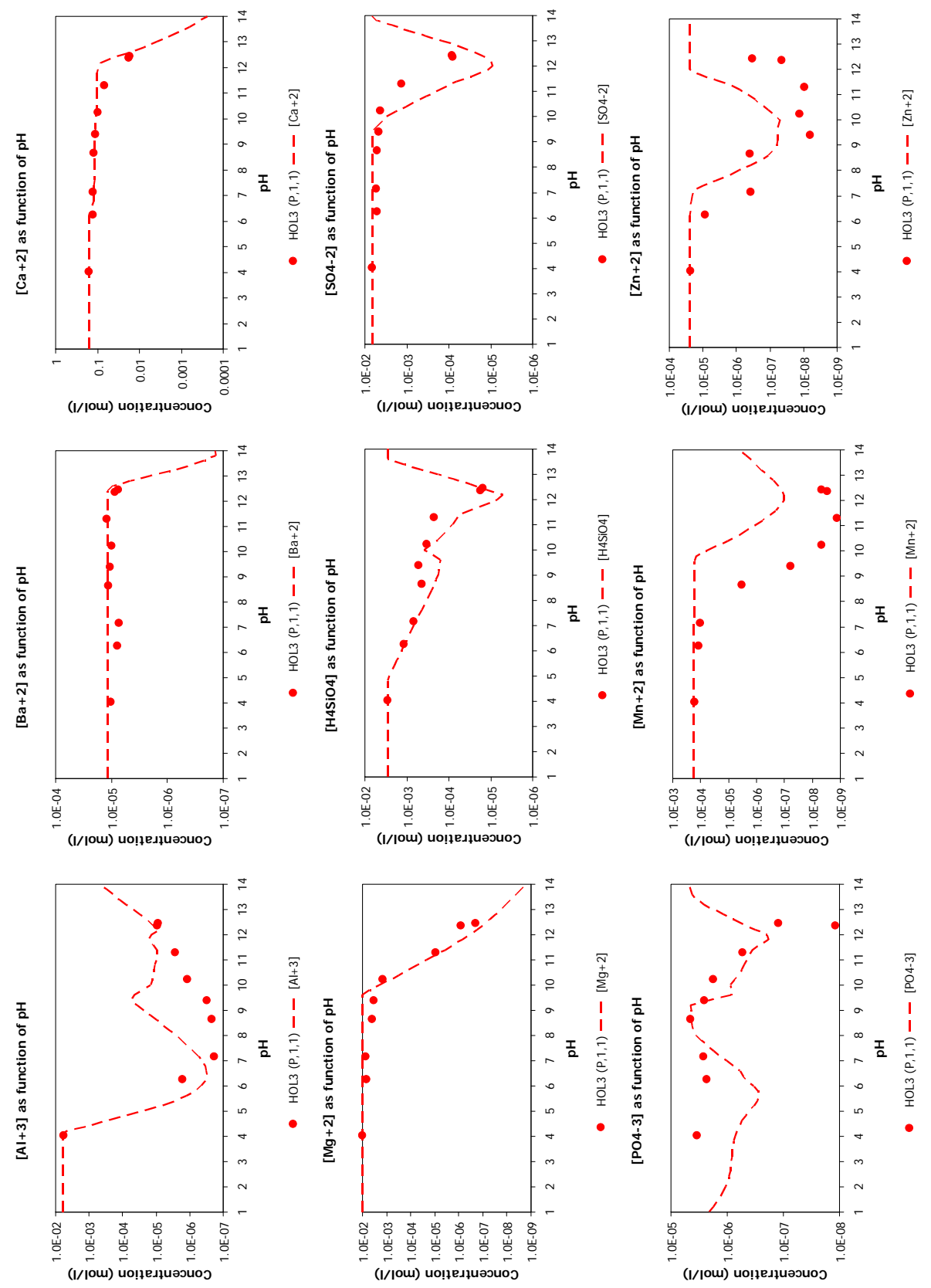

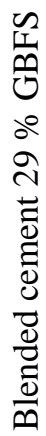



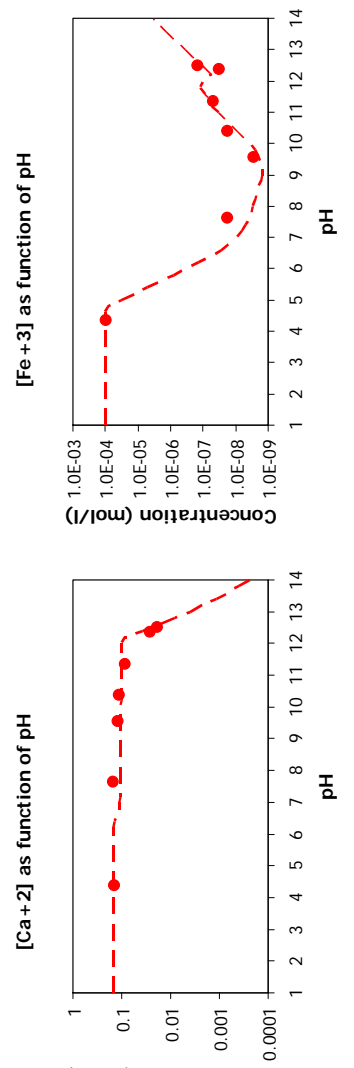

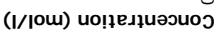
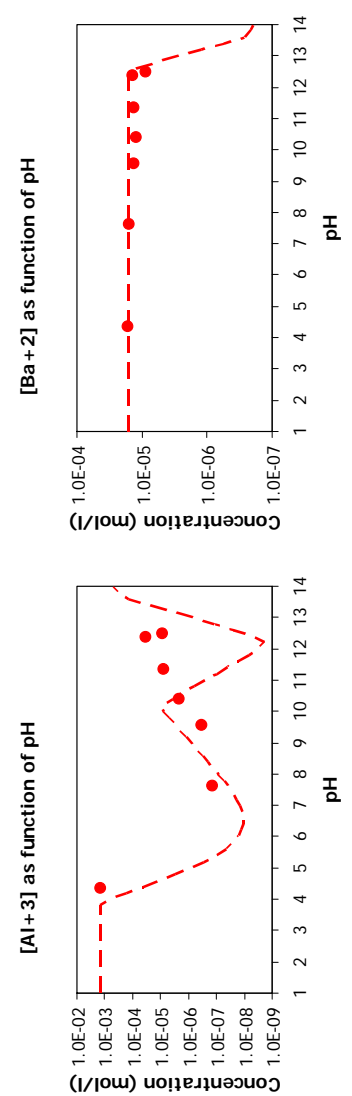
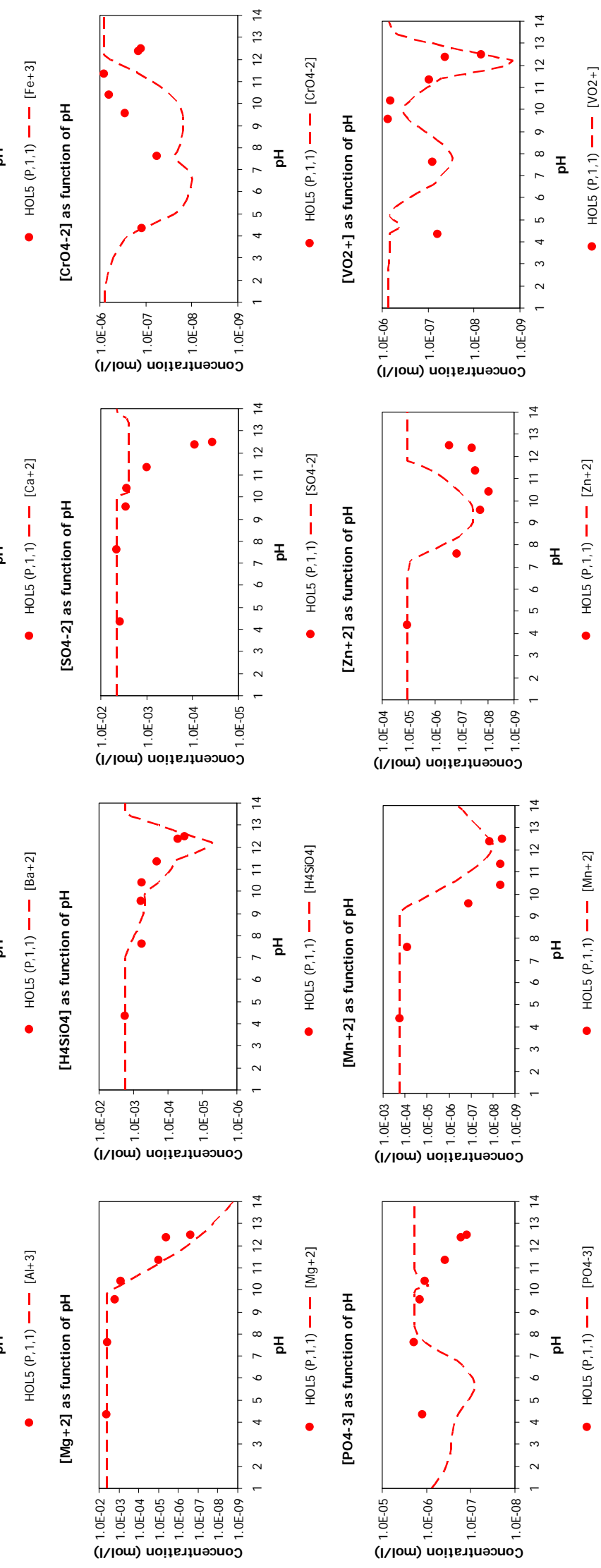

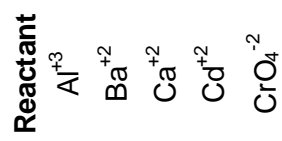



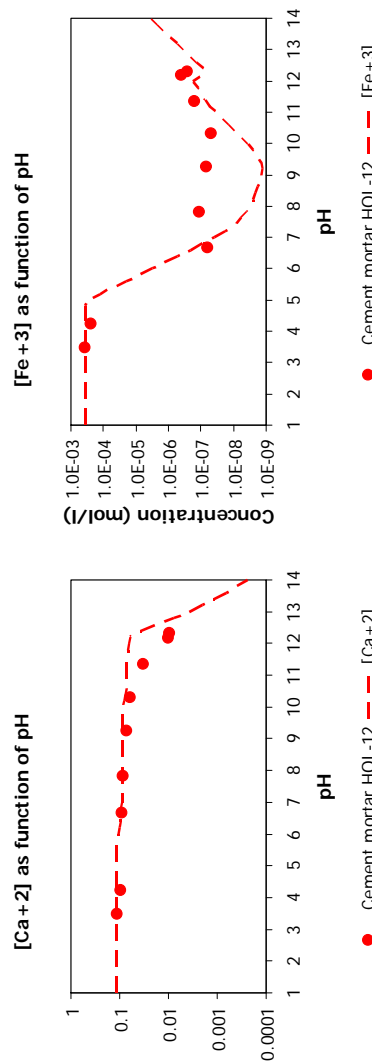

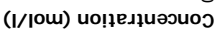

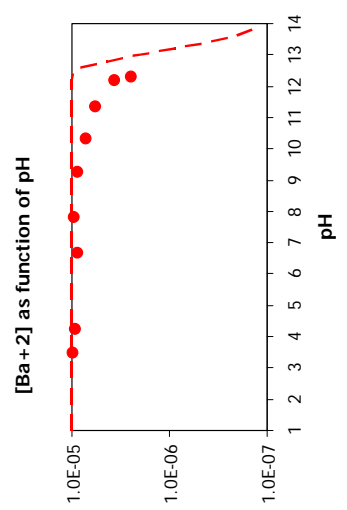

( / /ןou) uo!pexquәsuos

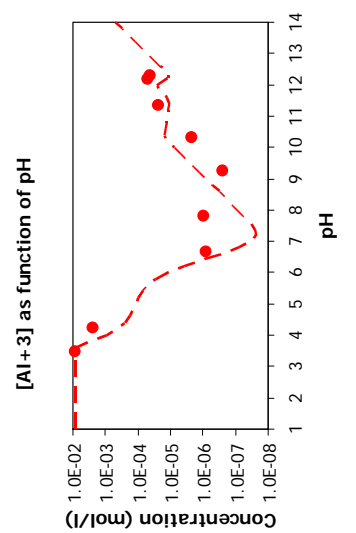

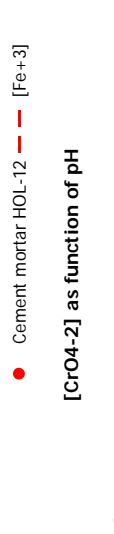
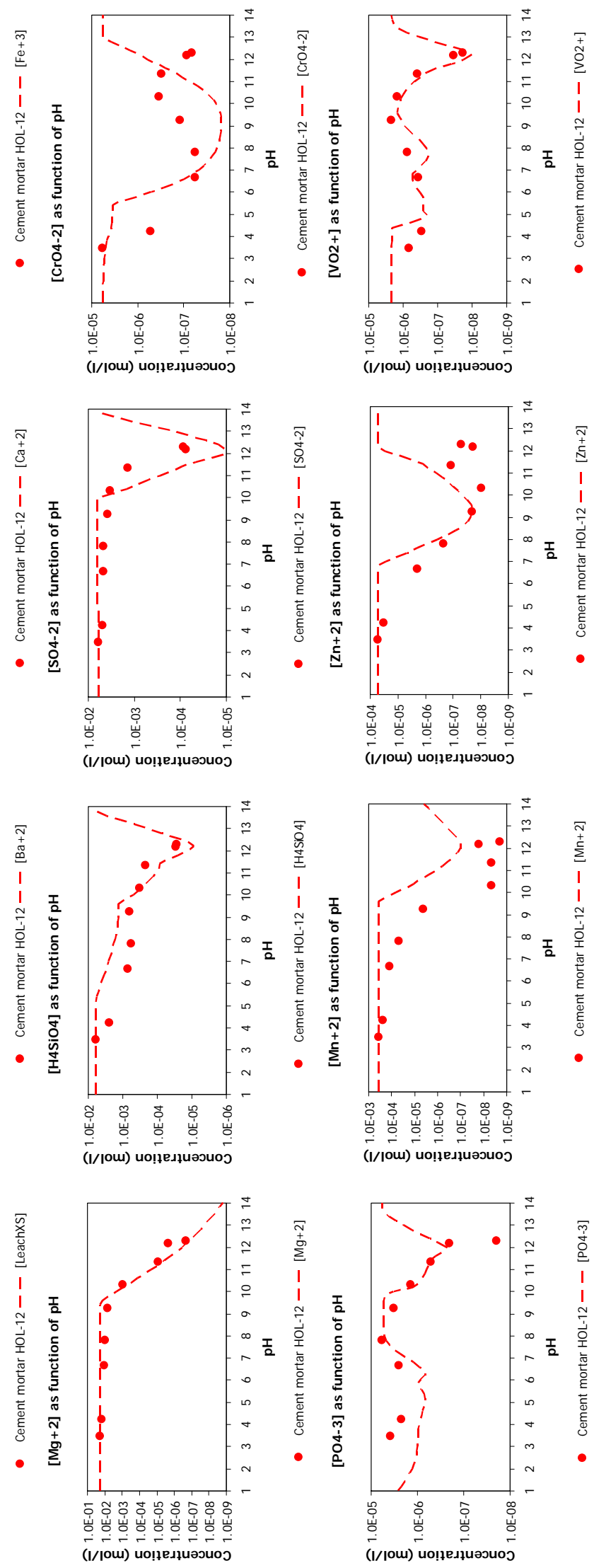

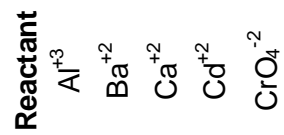

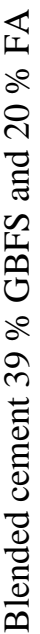



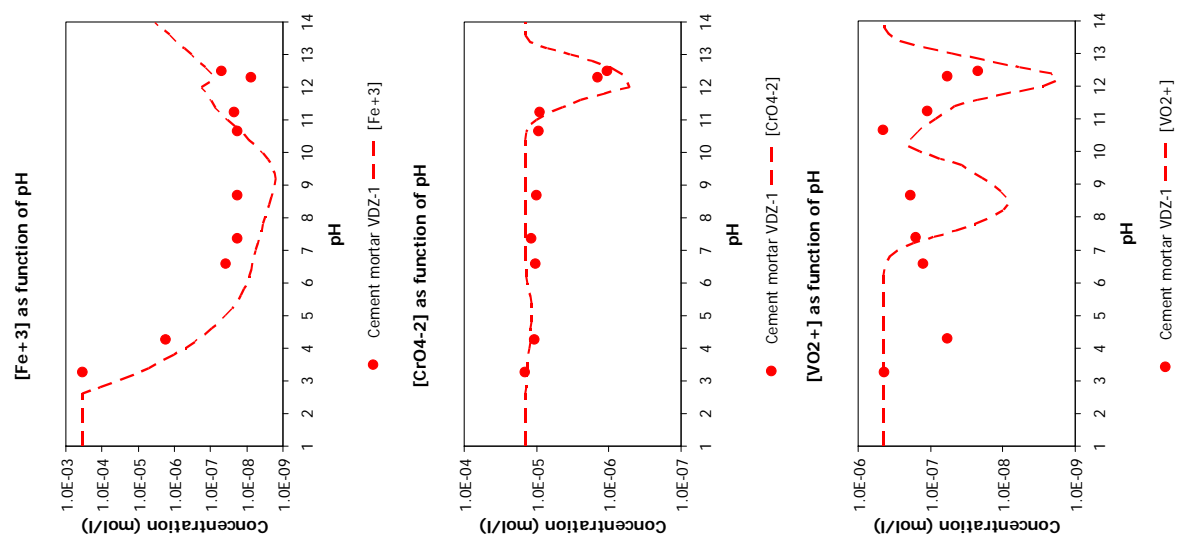

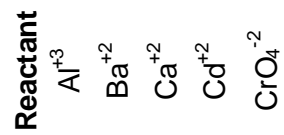
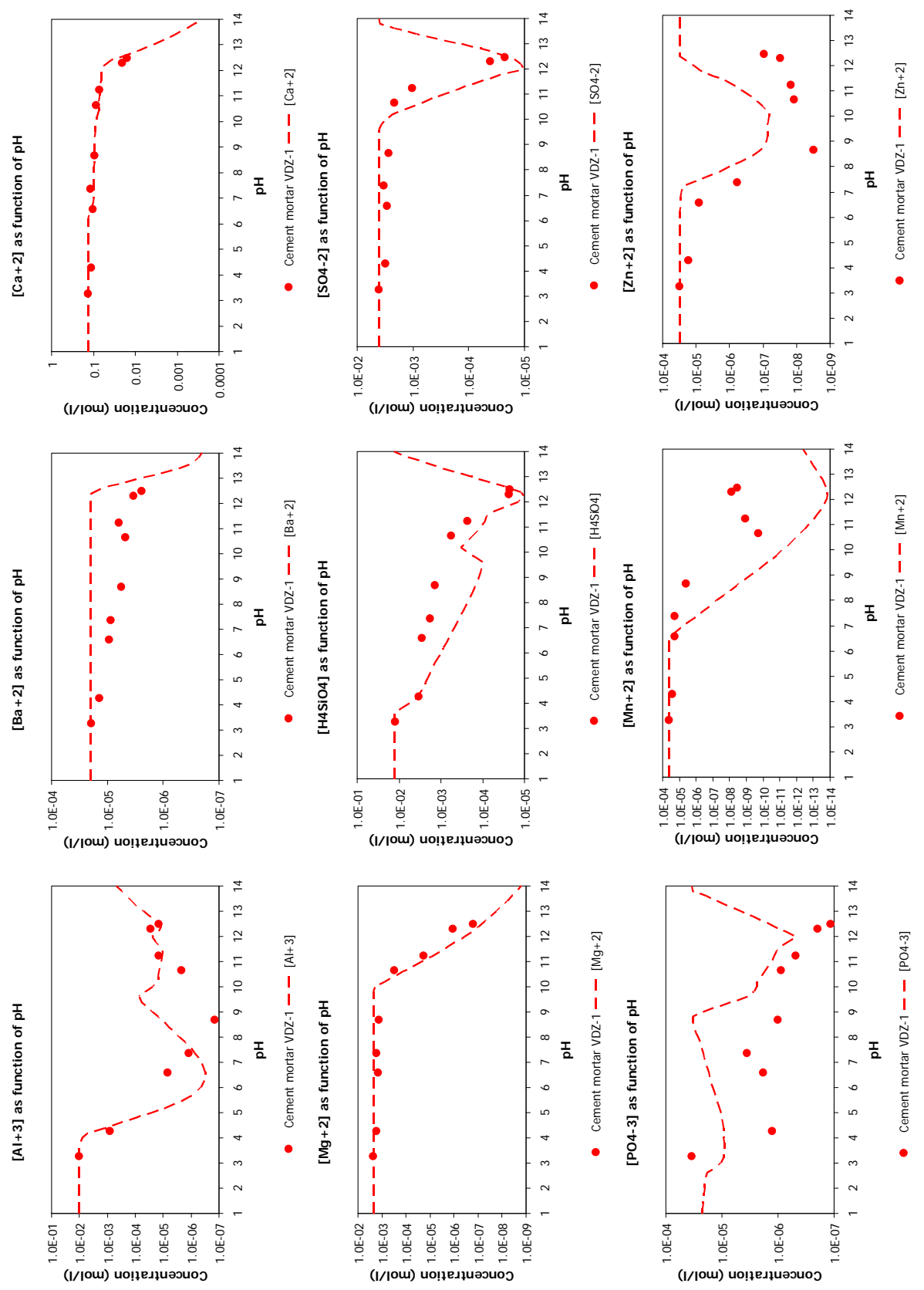

N 



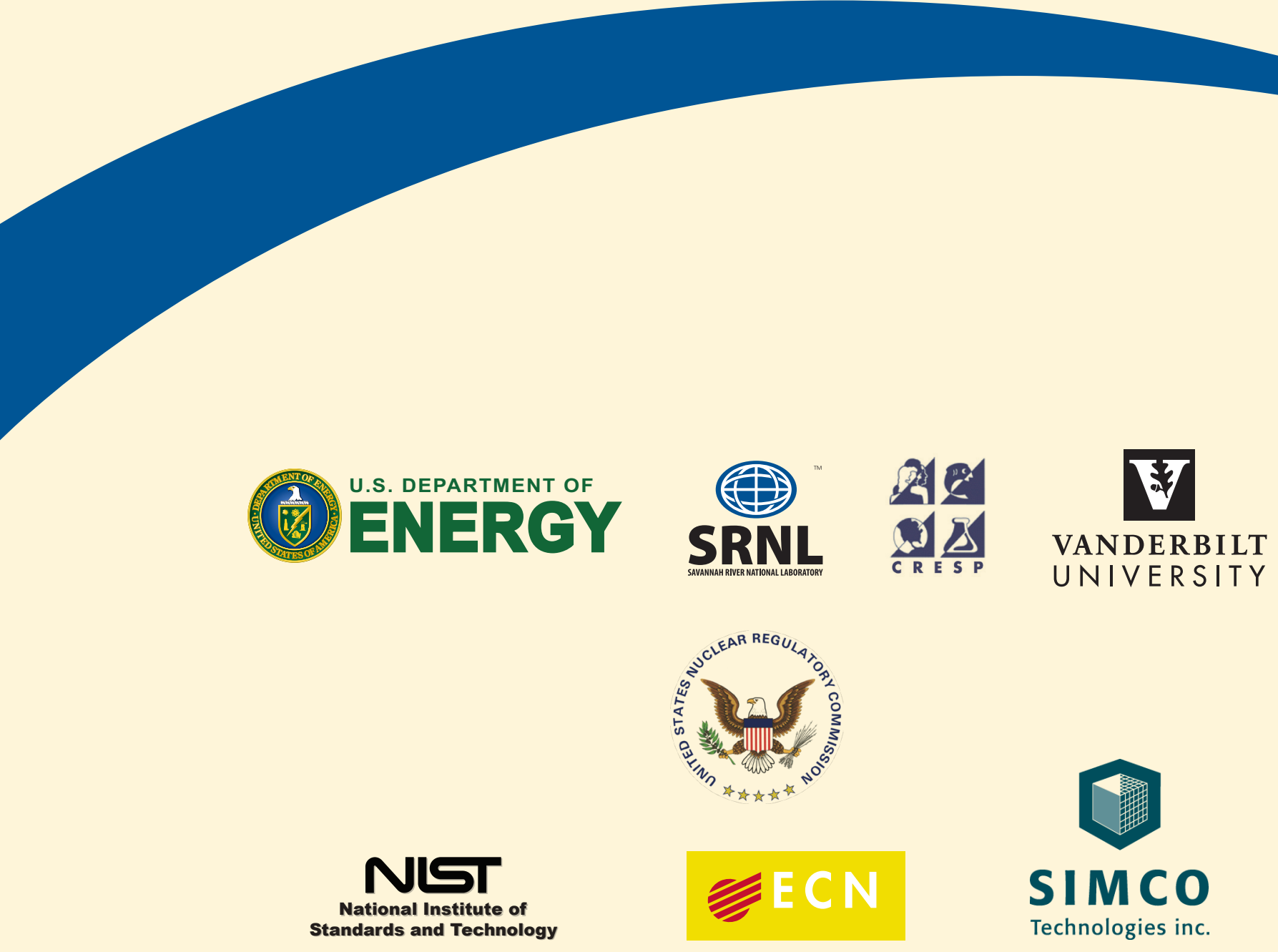

